\title{
Erster Beratungsgegenstand: \\ Staatszwecke im Verfassungsstaat - nach 40 Jahren Grundgesetz
}

1. Bericht von Prof. Dr. Christoph Link, Erlangen

Inhalt

I. Historische und methodische Probleme einer Staatszwecklehre .................... 10

1. Staatszwecke im ,modernen Staat"? .......... 10

2. Die Verdrängung der Staatszweckfrage in der neueren Staatsrechtslehre .................. 12

3. Staatszwecke als „Verfassungszwecke“? ........ 14

4. Autonome und heteronome Zwecksetzungen ...... 15

5. Staatszwecklehre und Volkssouveränität ........ 16

6. Staatszwecke - Staatsziele - Staatsaufgaben - Verfassungsdirektiven ................ 17

II. Die Gemeinwohlverantwortung des Verfassungsstaates . 19

1. Bonum commune und weltanschauliche Neutralität .. 20

2. Institutionelle Sicherungen der Gemeinwohlverpflichtung $\ldots \ldots \ldots \ldots \ldots \ldots \ldots \ldots \ldots \ldots \ldots \ldots \ldots \ldots \ldots \ldots \ldots \ldots, 22$

3. Bonum commune und Menschenbild ......... 23

4. Die Offenheit der Gemeinwohlkonkretisierung im demokratischen Prozeß ................. 25

III. Der Sicherheitszweck des Verfassungsstaates ....... 27

1. Die Verschränkung von Schutzpflicht und staatsbürgerlichem Rechtsgehorsam ............. 27

2. Das staatliche Gewaltmonopol ............. 28

3. Gewaltmonopol und Rechtsschutzgewährleistung ... 31

4. Die Akzeptanz der Rechtsordnung ........... 31

5. Ethische Neutralität des Verfassungsstaats? ...... 33

IV. Der Staatszweck Wohlfahrt .............. 34

1. Die Domestizierung des Wohlfahrtsstaats durch den Rechtsstaat.................... 34

2. Die Zukunftsdimension des Sozialstaats ....... 37 
3. Sozialstaatsprinzip und Wirtschaftsverfassung - das Problem der Staatsintervention ...................

V. Freiheitsgewährleistung als Staatszweck des Verfassungsstaats

1. Der Freiheitszweck als typusprägendes Element des demokratischen Verfassungsstaats ........... 42

2. Die Unterscheidung von Staat und Gesellschaft ... . 42

3. Das kontraktualistische Modell des status libertatis ... 43

4. Status negativus und "Freiheitsvorsorge“ ...... 43

5. „Verantwortung als Staatsprinzip“? .......... 45

VI. Staatszwecke und Verfassung $\ldots \ldots \ldots \ldots \ldots \ldots .47$

1. Staatszwecklehre und Allgemeine Staatslehre ... . . . 47

2. Staatszwecklehre und Staatsrechtslehre . . . . . . . . 47

3. Staatszwecklehre als Staatslegitimation . . . . . . . 49 
Vor der Staatsrechtslehrervereinigung über den Zweck des Staates zu sprechen bedeutet ähnliches wie vor Philosophen über den Sinn des Lebens. Die Komplexität des Gegenstands erfordert Reduktion und eine Auswahl, die notwendigerweise subjektiv ist. Insofern bitte ich um Milde angesichts der Nöte des Berichterstatters zu einem Thema, das zu einer tour d'horizon durch nahezu alle Bereiche des Staatsrechts und der Staatslehre einlädt. Es wird zusätzlich kompliziert durch seinen Untertitel. Auch hier kann nicht etwa eine Bilanz der staatsrechtlichen Entwicklung der vergangenen 40 Jahre gezogen werden. Herr Ress und ich sind übereingekommen, den Akzent auf die Staatszweckproblematik zu legen und sie nur exemplarisch anhand ausgewählter Einzelfragen zu verdeutlichen. Dabei haben wir uns die Aufgabe derart geteilt, daß ich mich sozusagen auf den allgemeinen Teil und die innerstaatlichen Aspekte des Themas konzentriere, während Herr Ress schwerpunktmäßig die dramatischeren Konsequenzen behandelt, die sich aus einer Auflösung des nationalstaatlichen Bezugsrahmens der überkommenen Staatszwecklehren ergeben. Grenzüberschreitungen sind dabei unvermeidlich.

Ich werde in einem ersten Teil die historischen und methodischen Probleme einer Staatszwecklehre zu skizzieren versuchen, in einem zweiten die Gemeinwohlverpflichtung der Staatsgewalt, die gleichsam als Klammer das folgende umschließt. In drei weiteren Abschnitten werde ich auf die zentralen Staatszwecke Frieden und Sicherheit, Wohlfahrt und Freiheit eingehen und zum Schluß die Frage nach der möglichen Relevanz einer Wiederbelebung der Staatszwecklehre stellen. Ich hoffe, damit jedenfalls einen möglichen Pfad durch den Problemdschungel zu schlagen. Daß es deren unendlich viele andere gibt, ist mir bewußt. 


\section{Historische und methodische Probleme einer Staatszwecklehre}

\section{Staatszwecke im "modernen Staat"?}

„Die Lehre vom Staatszweck“ ist „eine gar nicht aufzuwerfende Frage... Es sind das Fragen, welche einem früheren, naturrechtlich gestimmten Zeitalter wichtig und lösbar erscheinen mochten, die aber in der heutigen Staatsrechtswissenschaft kaum anders als durch Übergang zur Tagesordnung zu erledigen sind" .

In der Tat scheint das Thema "Staatszwecke im Verfassungsstaat" Unvereinbares zu verknüpfen. Die klassischen Staatszwecklehren ${ }^{2}$ hatten es unternommen, ein theologisch oder naturrechtlich begründetes Bild vom „richtigen“ Staat zu zeichnen. Hier erfolgte die Abgrenzung von Staatsgewalt und Bürgerfreiheit, hier wurden die Leitlinien einer bene moderata potestas ${ }^{3}$ gezogen und die Vision eines materiellen Rechtsstaats entwickelt, in dem herrscherliche und ständische Kompetenzen, Staatsnotwendigkeit und Eingriffsschranken, innere Souveränität und Gesetzesbindung unter dem Leitbild einer

1 G. Anschütz, Die Grundlagen des deutschen Staatsrechts, in: F.v. Holtzendorff/J.Kohler ( $\mathbf{H g}$.$) , Enzyklopädie der Rechtswissenschaft in systematischer$ Bearbeitung IV, 1914, S. 4 ff. (26).

2 Zur älteren Geschichte der Staatszwecklehre G. Jellinek, Allgemeine Staatslehre, 3. Aufl. 1914 (7. Neudr. 1960), S. 230 ff.; R. Schmidt, Allgemeine Staatslehre I, 1901, S. 145 ff.; O.v. Gierke, Das deutsche Genossenschaftsrecht IV, 1913 (Neudr. 1954), S. 404 ff.; E. Rosenthal, Der Wandel der Staatsaufgaben in der letzten Geschichtsperiode, 1913; H.v. Frisch, Die Aufgaben des Staates in geschichtlicher Entwicklung, in: G. Anschütz u. a. (Hg.), Handbuch d. Politik I, 3. Aufl., 1920, S. $86 \mathrm{ff}$; L. Waldecker, Die Theorien über den Umkreis der Staatstätigkeit, ebda. S. $73 \mathrm{ff}$.; A. Menzel, Zur Lehre vom Staatszweck, ZöR 7 (1928), S. $211 \mathrm{ff}$; H. Hug, Die Theorien vom Staatszweck, 1954; E. Mayer, Die Staatsziele im Wandel der Geschichte, in: Festg. R. Binder, 1930, S. 137 ff.; H. Nawiasky, Allgemeine Staatslehre IV, 1958; K. Hespe, Zur Entwicklung der Staatszwecklehre in der deutschen Staatsrechtswissenschaft des 19. Jahrhunderts, 1964, S.20 ff.; H.-U. Erichsen, Verfassungs- und verwaltungsrechtsgeschichtliche Grundlagen der Lehre vom fehlerhaften belastenden Verwaltungsakt und seiner Aufhebung im Prozeß, 1971, S.31 ff.; U.Scheuner, Die Staatszwecke und die Entwicklung der Verwaltung im deutschen Staat des 18. Jahrhunderts, in: Gedächtnisschr. f. H. Conrad, 1979, S. 467 ff.; H.P. Bull, Die Staatsaufgaben nach dem Grundgesetz, 2. Aufl. 1977, S. $17 \mathrm{ff}$;; Ch. Link, Herrschaftsordnung und bürgerliche Freiheit, 1979, S. 132 ff.; P. Preu, Polizeibegriff und Staatszwecklehre, 1983, S. $102 \mathrm{ff} ., 196 \mathrm{ff}$., 226 ff., $257 \mathrm{ff}$., $276 \mathrm{ff} . ; R$. Zippelius, Allgemeine Staatslehre, 10. Aufl. 1988, S. $104 \mathrm{ff}$;; ders., Geschichte der Staatsideen, 5. Aufl. 1985.

${ }^{3} \mathrm{~J} . \mathrm{H}$. Boehmer, Introductio in Jus publicum universale (1710), Ed.2, 1726, P. spec. I $\$ 21$ (p. 291). 
„justitia in omni regimine“4 zum Ausgleich gebracht werden sollten. Die Staatszwecklehre, zentraler Bestandteil des „allgemeinen Staatsrechts", des "Jus publicum universale" Verfassung der Respublica mit dem normativen Geltungsanspruch des Naturrechts. Insofern ist sie dem vorkonstitutionellen Status der politischen Ordnung verhaftet.

Jede Staatszwecklehre sieht sich deshalb heute einem empirischen und einem normativen Einwand ausgesetzt: Zum einen läuft sie danach Gefahr, durch die Hypostasierung „absoluter" Staatszwecke überzeitliche Allgemeingültigkeit für einen abstrakten Typus "Staat“ und seine Funktionen zu beanspruchen und dabei deren historische, politische, ökonomische und soziogeographische Variabilität zu übersehen. Ein realer Erkenntniswert komme allenfalls der Beschreibung derjenigen $\mathrm{Z}$ wecke zu, die sich ein bestimmtes Gemeinwesen in einer konkreten geschichtlichen Situation setzt, mithin der realen, „relativen "Staatszwecke". - Zum anderen: Haben nicht die Wertentscheidungen moderner Verfassungen, ihre Kompetenzordnung und ihre Konfliktregelungsmechanismen, namentlich das fein austarierte Verhältnis von Grundrechtsgewährleistungen und Schrankenregelung, die Funktion der älteren Staatszwecklehre übernommen, ihre Theoreme positiviert und in den Rang justiziablen Verfassungsrechts erhoben?' Ja müßte nicht jeder Wiederbelebungsversuch dem pouvoir constituant des demokratischen Verfassungsgebers zu nahe treten, seine Entscheidung durch die Behauptung überzeitlicher Staatszwecke relativieren und damit die rechtsstaatliche Verfassungsbindung durch subjektive Werturteile unterlaufen ${ }^{8}$ Die Feststellung von Staatszwekken hatte jedenfalls unter dem Regime des Naturrechts eine staatsbegrenzende Funktion. Wenn es die Aufgabe des modernen Staates ist, sich der jeweiligen „Lage" (im Sinne Herbert Krügers") anzupassen, so stellt sich die Frage nach der Vereinbarkeit einer solchen vorverfas-

+ U. Huber, De jure civitatis libri tres (1674), Ed.4, 1708, I. $1.1 \$ 15$ (p.3).

5 Link (s. Anm. 2), S. 45 ff. m. Nachw.; M. Stolleis, Geschichte des öffentlichen Rechts in Deutschland I, 1988, S. $291 \mathrm{ff}$.

${ }^{6}$ Jellinek (s. Anm. 2), S. 238; H. Krüger, Allgemeine Staatslehre, 2. Aufl. 1966, S.760; Th. Fleiner-Gerster, Kriterien für die Aufgabenverteilung von Staat und Gesellschaft, in: Bitburger Gespräche, 1984, S. $25 \mathrm{ff}$.

7 Zippelius, Staatslehre (s.Anm.2), S.50, 132 f.; K.Stern, Das Staatsrecht der Bundesrepublik Deutschland I, 2. Aufl. 1984, S. 82, 97.

${ }^{8}$ Dazu P. Häberle, Verfassungsrechtliche Staatsaufgabenlehre, AöR 111 (1986), S. 595 ff. (600 f.); Bull, Staatsaufgaben (s. Anm. 2), S. 31 f.

${ }^{9}$ (s. Anm. 6), S. VIf., 15 ff., 192 ff. u. ö. 
sungsrechtlichen Determinierung des Staatshandelns mit dem neuzeitlichen Staatsbegriff selbst; in der klassischen Terminologie gesprochen: mit der Souveränität des modernen Staates ${ }^{10}$.

\section{Die Verdrängung der Staatszweckfrage in der neweren Staatsrechtslebre}

Es erscheint deshalb durchaus folgerichtig, daß die Staatszwecklehre der deutschen Staatsrechtswissenschaft im 19. Jahrhundert verlorengegangen ist. Darüber darf die Renaissance dieses Lehrtopos in der ersten Jahrhunderthälfte nicht hinwegtäuschen. Unter dem Begriff der "Kulturzwecke" sollte der staatliche Anspruch auf bisher vornehmlich von der Kirche wahrgenommene Aufgaben begründet werden, während der „Machtzweck“ dem aufblühenden Nationalstaat Schubkraft verlieh. In Gestalt der „ökonomischen Zwecke“ endlich suchte man ein Korrektiv für liberales Laisser-faire und institutionalisierte damit zugleich in der Staatslehre das außenwirtschaftliche Schutzbedürfnis der Industrialisierungsepoche. Alle diese Interessen schienen mit der Reichsgründung im wesentlichen saturiert. Die Zwecke waren theoretisch zu einem so dichten Gewebe verflochten, daß sie einander zu einer staatlichen Allzuständigkeit ergänzten. Eine Staatszwecklehre, die ihren Gegenstand als „potentielle Totalität, verbunden mit aktueller Partialität"11 bestimmte, hob sich selber auf. Laband machte nicht zu Unrecht geltend, der Begriff des Zweckes sei nur in Verbindung mit einer konkreten Zielrichtung sinnvoll. Eine „Allseitigkeit der Zwecke" bedeute einen Widerspruch in sich" ${ }^{12}$.

Dabei ist es zunächst geblieben. Daß sich die Frage nach einer sich aus ihren Zielen legitimierenden Staatlichkeit ${ }^{13}$ indes nicht auf Dauer

10 Krüger, Staatslehre (s. Anm.6), S.761; H. Nawiasky, Allgemeine Staatslehre III, 1956, S. 51; W.v. Simson, Die Souveränität im rechtlichen Verständnis der Gegenwart, 1965, S. $70 \mathrm{ff}$., $90 \mathrm{ff}$., $168 \mathrm{ff} ., 210 \mathrm{f}$.; ders., Carl Schmitt und der Staat unserer Tage, AöR 114 (1989), S. 185 ff. (194-197).

${ }^{11}$ H. Rosin, Souveränität, Staat, Gemeinde, Selbstverwaltung, (Hirths) Annalen des Deutschen Reiches, 1883, S. 265 ff. (290); ebenso S. Brie, Theorie der Staatenverbindungen, 1887, S. 4, 100.

12 Das Staatsrecht des Deutschen Reiches I, 5. Aufl., 1911, S.67f. Fn. 2. Dies gelte nicht nur, weil ein derartiger Lehrtopos nichts mehr als Kriterium des Staatsbegriffs hergebe, sondern primär auch, weil „der Zweck eines Rechtsinstituts ... jenseits seines Begriffes“ liege (a. a. O. S. 67 f.).

13 Die prinzipielle Verbindung von Staatszweckproblem und Legitimierung des Staates betonen zu Recht Hespe (s. Anm. 2), S. 74; Zippelius, Staatslehre (s. Anm. 2), S. $110 \mathrm{ff}$. 
verdrängen ließ ${ }^{14}$, zeigten in Weimar die Werke von Smend und Heller. Smends Integration ${ }^{15}$ und Hellers ethisch gefüllte „Rechtssicherheitsorganisation " ${ }^{16}$ stellten je für sich Einheitsformeln und Legitimitätskriterien auf, in denen das Anliegen der älteren Staatszwecklehre in neuem Gewande wiederkehrte.

Gleichwohl stand die Weimarer Staatslehre noch in einer Kontinuität rechtsstaatlicher Tradition, die das Grundproblem der Staatsrechtfertigung in den metajuristischen Bereich verweisen konnte. Erst die Indienstnahme des Staates für mörderische Ziele durch die „Großtyrannen" unseres Jahrhunderts, die Auflösung der Rechtsstaatlichkeit im Säurebad der Ideologien, ließ die Frage nach dem Telos einer Staatlichkeit, die diesen Namen verdient, wieder virulent werden und weckte die Erinnerung an eine theoretische Kultur des Staatsdenkens. Die frühen Länderverfassungen geben davon ebenso Zeugnis ${ }^{17}$ wie die Beratungen des Parlamentarischen Rats ${ }^{18}$ und zentrale Aussagen des Grundgesetzes ${ }^{19}$.

It Vgl. dazu bereits H. Gerber, Freiheit und Bindung der Staatsgewalt, 1932, S. 10 f. u. ö.

15 Verfassung und Verfassungsrecht, 1928, jetzt in: Staatsrechtliche Abhandlungen und andere Aufsätze, 2. Aufl. 1968, S. $119 \mathrm{ff}$. (127f., $161 \mathrm{f.,} 165,193 \mathrm{f}$.); ders., Das Problem der Institutionen und der Staat, 1967, jetzt ebda. S. $500 \mathrm{ff}$. (503 ff.); ders., Staat, 1959, jetzt ebda. S. 517 ff. (521). - Dazu R. Bartlsperger, Die Integrationslehre Rudolf Smends als Grundlegung einer Staats- und Rechtstheorie, Diss. jur. Erlangen 1964, S. $90 \mathrm{ff}$.; P. Badura, Staat, Recht und Verfassung in der Integrationslehre, AöR 16 (1977), S. 305 ff. (309f., 317); J. Poeschel, Anthropologische Voraussetzungen der Staatstheorie Rudolf Smends, 1978, S. $208 \mathrm{ff} . ;$ A.v. Campenhausen, Rudolf Smend, in: F. Loos (Hg.), Rechtswissenschaft in Göttingen, 1987, S. $510 \mathrm{ff}$. (520 f.).

16 H. Heller, Staatslehre, 3. Aufl. 1963, S. 199 ff., 333. - Dazu I. Staff, Lehren vom Staat, 1981, S. $400 \mathrm{ff}$., $406 \mathrm{f}$.

17 Neben den Präambeln der meisten Landesverfassungen besonders deutlich in Art. 1 Abs. 2 und 3 Verf. Rheinland-Pfalz (1947): „Der Staat hat die Aufgabe, die persönliche Freiheit und Selbständigkeit des Menschen zu schützen, sowie das Wohlergehen des einzelnen und der innerstaatlichen Gemeinschaften durch die Verwirklichung des Gemeinwohls zu fördern. Die Rechte und Pflichten der öffentlichen Gewalt werden durch die naturrechtlich bestimmten Erfordernisse des Gemeinwohls begründet und begrenzt“. Ähnlich Art. 1 Verf. Baden-Württemberg; Art. 1 Verf. Saarland.

18 Dazu jetzt $H$. Bethge, Staatszwecke im Verfassungsstaat - 40 Jahre Grundgesetz, DVBl. 1989, S. 841 ff. (841).

19 Präambel, Art. 1, 20, 79 Abs. 3. 


\section{Staatszwecke als „Verfassungszwecke“?}

Gerade diese verfassungsrechtliche Positivierung war es aber, die das Problem der „Staatszwecke im Verfassungsstaat“ zunächst auf das Instrumentarium der Verfassungsexegese verwies. Der Verfassungspositivismus in den ersten Jahrzehnten der Bundesrepublik, der bald zugunsten eines „Bundesverfassungsgerichtspositivismus“ $\left(\right.$ Schlink) ${ }^{20}$ abdankte, verortete derartige Fragen namentlich in der Grundrechts- und Sozialstaatsdogmatik. Daß die konkrete Verfassungsordnung im Vordergrund des Interesses stand, nicht so sehr das von ihr Geordnete, der Staat des Grundgesetzes selbst ${ }^{21}$, läßt sich indes nicht nur mit jenem Verfassungspositivismus erklären. Die Bundesrepublik wurde zunächst und in den ersten beiden Jahrzehnten eher als ein Transitorium empfunden, als ahistorisches Produkt von Niederlage und Siegerzwietracht, belastet mit den Geburtsfehlern von Spaltung und Besatzungsregime. Wenn die Staatsräson der Bundesrepublik in ihrer eigenen Überwindung lag, so eignete sie sich wenig als Identifikationsobjekt gelebter Gemeinschaft. Ihr mangelte die irrationale Komponente des Staatsbewußtseins ${ }^{22}$; sie wurde akzeptiert, aber nicht geliebt. Andererseits erschienen die traditionellen Werte der Staatlichkeit durch das Vergangene diskreditiert. Die Perversion nationalen Staatsbewußtseins erhob nun die Distanz zu jeder geistigen, traditionellen oder nationalen Grundlegung des Gemeinschaftslebens in den Rang aufgeklärter Bürgertugend ${ }^{23}$. Der vielzitierte Verfassungspatriotismus ${ }^{24}$ bot in der Rechtsordnung eine scheinbar entpolitisierte Integrationsbasis, über der der durch sie konstituierte Staat als „wirkende Einheit des politischen Geschehens" ${ }^{\text {" } 25}$ aus dem Blick geriet.

Es mag auch ein Aspekt eines sich konsolidierenden Staatsbewußtseins sein, daß sich in neuerer Zeit die Stimmen mehren, die über die

20 Die Entthronung der Staatsrechtswissenschaft durch die Verfassungsgerichtsbarkeit, Der Staat 28 (1989), S. 161 ff. (163).

${ }_{21}$ U. Scheuner, Staatszielbestimmungen, jetzt in: Staatstheorie und Staatsrecht, Ges. Abhandlungen, 1978, S. 223 ff.; J. Isensee, Die Verfassung als Vaterland, Zur Staatsverdrängung der Deutschen, in: A.Mohler ( $\mathrm{Hg}$.), Wirklichkeit als Tabu, 1986, S. $11 \mathrm{ff}$.

${ }^{22}$ Dazu v. Simson, AöR 114 (1989), S. 185 ff. (206).

${ }^{23}$ In diese Richtung J.Habermas, Zum Begriff der politischen Beteiligung, jetzt in: ders., Kultur und Kritik, 1973, S. 9 ff. (40f.).

${ }_{24}$ D. Sternberger, Verfassungspatriotismus, in: 25 Jahre Akademie für Politische Bildung, Tutzing 1982, S. 76-87. - Dazu Isensee (s. Anm. 21), S. 33 Fn. 23.

25 Scheuner, Staatszielbestimmungen (s. Anm. 21), S. 223. 
dogmatische Beschäftigung mit den Staatszielbestimmungen des $G^{26}$ hinaus eine Staatszwecklehre als Desiderat reklamieren ${ }^{27}$. Die damit verfolgten Anliegen gehen freilich weit auseinander: Die Spannweite reicht von einer Begrenzung staatlicher Aktivitäten ${ }^{28}$ bis hin zu einer weitgehenden Indienstnahme der Gesellschafr zur Bewältigung ökologischer Krisen ${ }^{29}$.

\section{Autonome und heteronome Zwecksetzungen}

Dagegen herrscht weitgehende Einigkeit darüber, daß eine solche Staatszwecklehre nicht mehr an die älteren Zielbestimmungen anknüpfen könne, die in ihrer philosophischen Abstraktion an den konkreten Aufgaben des Verfassungsstaats der Gegenwart vorbeigin$\operatorname{gen}^{30}$. Dies ist sicher richtig für jene ältere Schicht des Staatsdenkens, die die politische Gestaltung in einen überzeitlichen ordo eingebettet sah, der ihr Telos bestimmte und "staatliche“ Herrschaft nur als Verwaltung einer vorgegebenen Aufgabe erscheinen ließ. In dem Maße aber, in dem die rationale Naturrechtslehre an die Stelle einer derart transzendenten Staatszweckbestimmung eine immanente setzte, stellte sich das grundlegende Problem einer weltlichen - und das heißt: politischen - Legitimation des Herrschaftsverbandes „Staat“. Ihre Entdeckung war die Zweckrationalität der societas civilis. Die Gesellschaftsvertragslehre hatte die konsensuale Begründung der Staatlichkeit nicht als historische oder realpsychologische ausge-

26 Zuletzt Th. Maunz, Staatsziele in der Verfassung von Bund und Ländern, BayVBl. 1989, S. $545 \mathrm{ff}$.

27 Häberle, AöR 111 (1986), S. 595 ff. (611); T. Fleiner-Gerster, Allgemeine Staatslehre, 1980, S. VII, 391; P. Saladin, Wachstumsbegrenzung als Staatsaufgabe, in: FS U. Scheuner, 1973, S. 541 ff. (557); ders., Verantwortung als Staatsprinzip, 1984, S. 13; H. H. v. Armim, Staatslehre der Bundesrepublik Deutschland, 1984, S. 471;E.W. Böckenförde, Die verfassungstheoretische Unterscheidung von Staat und Gesellschaft als Bedingung der individuellen Freiheit, Rhein.-Westf. Akad. der Wiss., Vortr. 183, 1973, S. 39 Fn. 96; ders., VVDStRL 30 (1971), S. 164 (Disk.-beitr.); W. Leisner, Öffentliches Amt und Berufsfreiheit, AöR 93 (1968), S. 161 ff. (187); ders., Der Triumph, 1985, S. 31-33. - Zur Notwendigkeit interdisziplinärer Arbeit s. neben Häberle (a. a. O.) auch K. Stern, Staatsziele und Staatsaufgaben in verfassungsrechtlicher Sicht, in: Bitburger Gespräche 1984, S. 5 ff. (15); G. F. Schuppert, Entzauberung des Staates oder "Bringing the state back in?", Der Staat 28 (1989), S. 91 ff. (91).

${ }_{28}$ v. Arnim, Staatslehre (s. Anm. 27), S. 471.

29 Namentlich Saladin, Verantwortung (s. Anm. 27), S. $123 \mathrm{ff}$.

${ }^{30} \mathrm{~J}$. Isensee, in: J. Isensee/ P. Kirchhof ( $\mathrm{Hg}$.), Handbuch des Staatsrechts der Bundesrepublik Deutschland (i. folg. HdbStR) III, 1988, $\$ 57$ Rdn. 32 ff., 116; Stern, Staatsziele (s. Anm. 27), S.6; Scheuner, Staatszielbestimmungen (s. Anm. 21), S. 343; ders., Staatszwecke (s. Anm. 2), S. 467 ff. (468). 
geben, sondern als hypothetische betrachtet ${ }^{31}$. Weniger kompliziert: der Staat muß so angesehen werden, als sei er eine zweckrationale Schöpfung seiner Bürger, als beruhe alle Herrschaft auf der prinzipiellen Zustimmung der Beherrschten. Mir scheint dies ein unverlierbarer Besitz jedes humanen Staatsdenkens zu sein, der im Verfassungsstaat nur seine demokratische Aktualisierung erfahren hat. Es schließt ein Verständnis des Staates als „sittlicher Zweck an sich“ ${ }^{32}$ ebenso aus wie jede Hypostasierung eines Kollektivs. Damit kann die Frage nach den Staatszwecken sinnvoll nur dort gestellt werden, wo eine solche Rückkopplung an die finale gesellschaftliche Steuerung der politischen Ordnung nicht aufgehoben ist, wo sich der Staat nicht als Selbstzweck verselbständigt ${ }^{33}$.

\section{Staatszwecklehre und Volkssowveränität}

Damit bleibt freilich das Problem der potentiellen Allzuständigkeit. Man hat den Staat geradezu im Gegensatz zum Zweckverband gesehen, weil ihm - ein König Midas - alles, was er anfaßt, zur Aufgabe wird ${ }^{34}$. In einer demokratischen Staatsordnung würde dies die prinzipielle Ungebundenheit und Unbindbarkeit der volonté générale bedeuten. Und in der Tat ist dies ein Herzstück der klassischen marxistischen Staatslehre. Demgegenüber legt im Verfassungsstaat die Verfassung dem Leviathan nicht nur nachträglich Fesseln an, sie begründet ihn als verfassungsmäßigen und erlaubt ein Reagieren auf die „Lagen“ ${ }^{35}$ nur im Rahmen der Verfassung und mit verfassungsmäßigen Mitteln ${ }^{36}$. Die allseitige Zwecksetzungskompetenz ist damit konstitutionell beschränkt. Das Grundgesetz, überwiegend abhold allem pädagogischen Pathos, gibt hier freilich nur wenige Leitlinien vor ${ }^{37}$.

${ }^{31}$ Link, Herrschaftsordnung (s. Anm. 2), S. 245 m. w. N.

32 Vgl. G.F. Hegel, Grundlinien der Philosophie des Rechts, hrsg. v. Hoffmeister, 4. Aufl. 1955, $\$ 258$ mit Anmerkung; aus neuerer Zeit Krüger, Staatslehre (s. Anm. 6), S. 192 m. w. N.

${ }_{33}$ H. Nawiasky, Allgemeine Staatslehre II/1, 1952, S. 199 f.; dagegen sieht $v$. Arnim, Staatslehre (s. Anm. 27), S. 175, schon im Begriff des Staatszwecks das Mißverständnis vom Staat als Selbstzweck angelegt.

${ }^{34}$ Krüger, Staatslehre (s. Anm. 6), S. 196, 759 ff.

${ }_{35}$ Krüger, Staatslehre (s. Anm. 6), S. 761.

${ }_{36}$ M. Kriele, Einführung in die Staatslehre, 4. Aufl. 1990, S. 111 ff.; Bull, Staatsaufgaben (s. Anm. 2), S. $33 \mathrm{f}$.

${ }^{37} \mathrm{Vgl}$. zum Folgenden Isensee, HdbStR III, $\$ 57$ Rdn. $121 \mathrm{ff} . ;$ R. Herzog, HdbStR III, \$58 Rdn. 28 ff.; Häberle, AöR 111 (1986), S. 595 ff. (605); vgl. auch W. Leisner, Öffentlichkeitsarbeit der Regierung im Rechtsstaat, 1966, S. 80, $82 \mathrm{ff.}$ 
Neben den Staatszielbestimmungen des sozialen Rechtsstaats, dem Wiedervereinigungsgebot, der Verfassungsentscheidung für die internationale Zusammenarbeit ${ }^{38}$ und dem Verbot des Angriffskrieges ist dies vor allem das Bekenntnis zur Menschenwürde als oberstem Konstitutionsprinzip. Daneben lassen sich aus der Zusammenschau einzelner Verfassungsbestimmungen Inhalt und Grenzen einzelner Staatszwecke entnehmen, so die Friedenssicherung nach innen und außen, kulturstaatliche Direktiven, das Neutralitätsgebot, Schutzpflichten für Individual- und Gemeinschaftsgüter. Darauf wird im einzelnen noch einzugehen sein.

\section{Staatszwecke - Staatsziele - Staatsanfgaben - Verfassungsdirektiven}

Es liegt auf der Hand, daß diese Aufgabenzuweisungen staatstheoretisch auf unterschiedlichen Ebenen liegen. Es bedarf daher zunächst einer terminologischen Klarstellung ${ }^{39}$. Wenn im folgenden von Staatszwecken ${ }^{40}$ die Rede ist, so ist damit die Frage nach legitimierenden und begrenzenden Konstanten der Staatstätigkeit gestellt. Dies freilich nicht im Sinne einer überzeitlichen und für alle Staaten geltenden spekulativen Teleologie ${ }^{41}$. Diesem Mißverständnis hat die ältere Staatslehre dort Vorschub geleistet, wo sie von den "prima principia“ in die Niederungen der "conclusiones" herabstieg und ganze Staatszweckkataloge entwarf ${ }^{42}$. Sie sind durchweg aus Verallgemeinerungen der historisch-konkreten politischen Umwelt gewonnen und stehen zu dieser in einem unlösbaren - kritischen oder affirmativen Zusammenhang. Dagegen scheinen mir ihre Grundanliegen Konstanten des neuzeitlichen Staatsdenkens zu bezeichnen, die zwar sicher

\footnotetext{
${ }^{38} \mathrm{~K}$. Vogel, Die Verfassungsentscheidung des Grundgesetzes für eine internationale Zusammenarbeit, 1964.

39 Dazu Bull, Staatsaufgaben (s. Anm.2), S. 29 m.w. N., 43 ff.; ders., Staatszwecke im Verfassungsstaat, NVwZ 1989, S. 801 ff. (802).

${ }^{40} \mathrm{Vgl}$. U. Matz, Der überforderte Staat, in: W. Hennis u. a. (Hg.), Regierbarkeit I, 1977, S. $82 \mathrm{ff}$. (82f.); G. Küchenhoff/E. Küchenhoff, Allgemeine Staatslehre, 8. Aufl. 1977, S. $99 \mathrm{ff}$.

+1 Dagegen zu Recht Isensee, HdbStR III, $\$ 57$ Rdn. 116.

12 Dies gilt vor allem dort, wo sie die bestehenden Hoheitsrechte durch eine naturrechtliche Staatszwecklehre zu unterfangen unternahm. - Dazu Link, Herrschaftsordnung (s.Anm.2), S.86; ders., Johann Stephan Pütter, in: M. Stolleis (Hg.), Staatsdenker im 17. und 18. Jahrhundert, 2. Aufl. 1987, S. 310 ff. (319ff.); Preu (s. Anm. 2), S. $102 \mathrm{ff}$.
} 
nicht Allgemeingültigkeit beanspruchen können ${ }^{43}$, die aber jedenfalls das Selbstverständnis des aus ihrer Wurzel erwachsenen freiheitlichen Verfassungsstaats prägen. Staatszwecke in diesem Sinne sind die Verpflichtung auf das Gemeinwohl, Friedenssicherung nach innen und außen, Wohlfahrt im weitesten Sinn und Gewährleistung individueller wie korporativer Freiheit. Diese „klassische Quadriga “44 der Staatszwecke legitimiert den konkreten Staat in dem Maße ihrer Verwirklichung ebenso wie den staatsbürgerlichen Rechtsgehorsam.

Solche abstrakten Zwecke bedürfen der Konkretisierung in Richtung auf Art und Mittel ihrer Realisierung. Ihr dienen Staatszielbestimmungen $\left(I p s e n^{45}\right)$. Staatsziele liegen auf einer „mittleren Ebene der Reflexion ${ }^{\text {"46 }}$. Sie beschreiben die tatsächlichen Funktionen eines bestimmten Staates und weisen seinem Handeln die Richtung ${ }^{47}$. Staatsziele können Konkretionen allgemeiner Staatszwecke sein - so das Sozialstaatsprinzip als spezifische (Teil-)Ausprägung des Wohlfahrtszwecks -, sie können aber auch die Staatstätigkeit programma-

${ }^{43} \mathrm{Da}$ auch die ältere Naturrechtslehre keineswegs von der Allgemeingültigkeit ihrer Theoreme ausgeht, zeigt die Lehre vom imperium herile, dem „Sklavenstaat“, in dem die Staatsgewalt nicht dem Gemeinwohl, sondern dem herrscherlichen Privatnutzen dient. Dieses Kontrastmodell wird nicht nur als kritisches Potential eingeführt, auf dessen düsterer Folie sich eine zivilisierte Gemeinschaftsordnung um so leuchtender abhebt, sondern dient etwa bei Grotius auch zur Begründung dafür, die (völkerrechtliche) Staassqualität nicht an moralische Bewertungskriterien zu binden. Dazu Link, Herrschaftsordnung (s. Anm. 2), S. 33, 41, 81, 115f., 132; ders., Hugo Grotius als Staatsdenker, 1983, S. 25 f. (jeweils m. Nachw.).

${ }_{44}$ Etwas abweichend Bethge, DVBl. 1989, S. 841 ff. (843) (Freiheit, Frieden, Sicherheit und demokratische Selbstbestimmung); H.Hofmann, Die Zukunft gestalten, in: Veröff. d. Walter-Raymond-Stiftung 27 (1989), S. 21 ff. (23) (Sicherheits-, Rechts-, Sozial- und Kulturzweck); Herzog, HdbStR III, \58 Rdn. 24 f. (Gefahrenabwehr nach außen, Sicherung des inneren Friedens, Gesellschaftsgestaltung und Sozialstaatlichkeit).

45 Über das Grundgesetz, 1950, S. 14; zum Begriff R. Herzog, in: Maunz/Dürig, GG, Art. 20 Abschn. I, Rdn. 8 f.; Stern, Staatsrecht I (s. Anm. 7), S. 121 f. m. w. N.; Scheuner, Staatszielbestimmungen (s. Anm. 21), S. $227 \mathrm{ff}$.

+6 Scheuner, Staatszielbestimmungen (s. Anm. 21), S. 240; ähnlich Stern, Staatsziele (s. Anm. 27), S. 18.

47 Weiter wird der Begriff gefaßt bei Isensee, HdbStR III, $₫ 57$ Rdn. 115: „Staatsziele sind die Belange des Gemeinwohls (öffentliche Interessen), die der Staat sich zu eigen macht und in deren Dienst er sich planmäßig stellt." Als Staatsziele erscheinen dann auch innere/äußere Sicherheit, Gewähr von Frieden, Freiheit und Wohlfahrt (Rdn. 117), die nach der hier verwendeten Terminologie als Staatszwecke bezeichnet werden. Wie hier im Ergebnis P. Badura, Staatsrecht, 1986, S. 194. 
tisch auf die Bewältigung besonderer „Lagen“ gerade dieses Gemeinwesens verpflichten (Wiedervereinigungsgebot). Demgegenüber werden unter Staatsaufgaben hier die Modalitäten zur Staatszielverwirklichung verstanden, d.h. das auf ein solches Ziel hin aufgegebene Handeln. Sie sind konkreter als die Staatsziele zu bestimmen und sind durch ihren imperativen Charakter gekennzeichnet. Fine weitere Konkretion bilden schließlich die Verfassungsdirektiven, die in unterschiedlicher Bestimmtheit inhaltliche Vorgaben zur Annäherung an Staatsziele machen. Trotz Lerches klassifikatorischer Vorarbeit ${ }^{48}$ ist insoweit freilich die Terminologie noch immer recht uneinheitlich.

Weniger die Staatszwecke, von denen hier zu reden ist, als vielmehr die Staatsziele haben teil an der verfassungsrechtlichen Relativierung, d. h. an der Positivierung durch eine rechtliche Rahmenordnung. Sie und die ihnen korrespondierenden Staatsaufgaben sind damit konstitutionell verfügbar geworden, erschließen sich aus dem komplexen Regelwerk moderner Verfassungen, das sie materiell ebenso begründet wie begrenzt und kompetentiell auf die verschiedenen Staatsorgane verteilt. Dieser mit dem 19. Jahrhundert in Deutschland einsetzende Prozeß hat die dahinterstehende Staatszwecklehre verkümmern lassen - und damit auch die Frage nach dem legitimierenden Sinn der Staatlichkeit. Gerade manche Entwicklungen und Tendenzen der vergangenen $40 \mathrm{Jahre}$ geben aber Anlaß, sie erneut zu stellen. Ich orientiere mich dabei an der genannten "klassischen Quadriga“ der Staatszwecke. Um im Bild zu bleiben - gelenkt, gezügelt und zu einem Gespann verbunden wird sie durch die Gemeinwohlbindung allen staatlichen Handelns. Von ihr soll darum zunächst die Rede sein.

\section{Die Gemeinwohlverantwortung des Verfassungsstaates}

Daß die politische Herrschaft dem Wohl der Beherrschten und nicht dem der Herrschenden verpflichtet ist, ist ein Grundsatz so alt wie die Reflexion über den Herrschaftsverband Staat selbst. Insofern ist das Gemeinwohl allgemeinster Staatszweck, zugleich Rechtfertigung und Grenze aller Staatsgewalt. Zunehmend wird die Gemeinwohlbindung des Souveräns zur nachdrücklich betonten Rechtspflicht. Die einhellige Befürwortung dieses Postulats in allen politischen Lagern zeigt, daß in der vorkritischen Staatslehre unter diesem Mantel eine

18 Das BVerfG und die Verfassungsdirektiven, AöR 90 (1965), S. $341 \mathrm{ff}$. (346 ff.). 
Fülle divergierender Vorstellungen Unterschlupf fand. Dabei ist es auch nach Kant geblieben. Trotzdem hat sich die Gemeinwohlbindung auch unter dem GG nicht zu einer Leerformel verflüchtigt ${ }^{49}$.

\section{Bonum commune und weltanschauliche Neutralität}

a) Sicherlich die folgenreichste Mutation des Gemeinwohlbegriffs ist seine Säkularisierung. Bis weit in das 17. Jahrhundert hinein galt die Sorge für das Seelenheil der Bürger als selbstverständliche, ja zentrale Staatsaufgabe. Die umfassende herrscherliche Gemeinwohlverantwortung wurzelt in diesem göttlichen Amtsauftrag und transzendiert als cura religionis alle regiminalen Aufgaben. Die salus publica ist eine salus publica christiana.

Die vielbeschriebene „Entstehung des modernen Staates als Vorgang der Säkularisation “50 schwächt diese theologische Imprägnierung zusehends ab. Die Beschränkung auf den irdischen Friedens- und Wohlfahrtszweck tritt als eigentliches Telos der staatlichen Gemeinschaft hervor. „Die Staaten sind nicht um der Religion willen gegründet", heißt es bei Pufendorf $^{51}$ und Locke ${ }^{52}$ - und das heißt: Gesellschaft und Staat bestehen allein um der Bewältigung diesseitiger Ordnungsaufgaben willen. Der moderne Staat stellt die religiöse Wahrheitsfrage nicht mehr. Die konfessionelle Neutralität des Staates $^{53}$ weitet sich zur religiösen und entläßt die Kirchen in die Freiheit ihres selbstbestimmten Wirkens.

49 So aber F. Ossenbübl, Welche normativen Anforderungen stellt der Verfassungsgrundsatz des demokratischen Rechtsstaates an die planende staatliche Tätigkeit..., Gutachten B zum 50.DJT, 1974, S.3138; auch K. Eichenberger, Der geforderte Staat, in: Regierbarkeit I (s. Anm. 40), S. 103 ff. (112): „lenkungsschwache Vagheit" des Gemeinwohlbegriffs; Saladin, Wachstumsbegrenzung (s. Anm. 27): Gemeinwohlformel „in der Gegenwart zur Tautologie verblaßt“ (S.555); wie hier H.H.v.Arnim, Gemeinwohl und Gruppeninteresse, 1977, S. 5 ff.; Isensee, HdbStR III, $\$ 57$ Rdn. 35-40, 112-114; Bull, NVwZ 1989, S. 801 ff. (805).

${ }_{50}$ E. Troeltsch, Das Wesen des modernen Geistes, jetzt in: Ges. Schriften IV, 1925, S. 297 ff. (302 ff.); Krüger, Staatslehre (s. Anm.6), S. 32 ff., E.-W. Böckenförde, Die Entstehung des Staates als Vorgang der Säkularisation, in: FS E. Forsthoff, 1967, S. $77 \mathrm{ff}$;; M. Heckel, Weltlichkeit und Säkularisierung, jetzt in: Ges. Schriften II, 1989, S. 912 ff. (931 f.); Link, Herrschaftsordnung (s. Anm. 2), S. 134 f.

${ }^{51}$ De jure naturae et gentium (1672), Ed.G. v. Mascov, 1759 (Neudr. 1967), VII. 2. $\$ 8$ (II p. 136).

52 A letter concerning Toleration (1689), Ed.J. Ebbinghaus, 1966, p.42, vgl. auch p. 12-14.

${ }_{53} \mathrm{Zu}$ ihren Anfängen M. Heckel, Deutschland im konfessionellen Zeitalter, 1983, S. $52 \mathrm{ff}$. 
b) Im modernen Verfassungsstaat westlicher Prägung ist die religiöse zur weltanschaulichen Neutralität erweiter ${ }^{54}$. Das BVerfG hat dies mit der Formel umschrieben, der Staat solle Heimstatt aller Bürger ohne Unterschied ihrer Religion und Weltanschauung ${ }^{55}$ sein. Dies schließt ebenso wie eine religiöse auch eine ideologische Determination des Gemeinwohls als bindende Zielvorgabe der Staatlichkeit aus. Dieser Grundsatz gewann seine fundamentale Bedeutung nicht nur auf der Folie der NS-Diktatur ${ }^{56}$, sondern grenzte die freiheitlichpluralistische Verfassungsordnung auch von der sich zunehmend ideologisch verfestigenden Herrschaftsform im anderen deutschen Staat ab. Indem sich der Staat des Grundgesetzes nicht in den Dienst einer Weltanschauung stellt, sich mit keiner, auch nicht mit der der jeweiligen Mehrheit identifiziert, ist für eine "wissenschaftliche“ Bestimmung des bonum commune ebensowenig Raum wie für deren institutionelle Absicherung in Gestalt einer durch angeblich historisches Gesetz zur Herrschaft berufenen, im Besitz der objektiven Wahrheit befindlichen Staatspartei ${ }^{-57}$. Zwar hindert der Neutralitätsgrundsatz Bürger und Parteien nicht, religiös oder weltanschaulich geprägte Gemeinwohlvorstellungen in das politische Kräftespiel einzubringen. Grund- und Minderheitsrechte ebenso wie institutionelle Vorkehrungen sollen aber der Ausbildung ideologischer Monopole vorbeugen. Der politisch Andersdenkende irrt nicht über das wahre bonum commune, so daß ihm gegenüber die Wahrheit der volonté générale im Recht wäre, die Durchsetzung einer Gemeinwohlkonzeption ruht nicht auf der materiellen Rationalität der Wahrheit, sondern auf der formellen Rationalität des Mehrheitsprinzips ${ }^{58}$. An dieser

5t Krüger, Staatslehre (s. Anm. 6), S.764f.; E.W. Böckenförde, Der Staat als sittlicher Staat, 1978, S. 31; K. Schlaich, Neutralität als verfassungsrechtliches Prinzip, 1972.

55 BVerfGE 19, 206 (216).

56 Dazu näher M. Stolleis, Gemeinwohlformeln im nationalsozialistischen Recht, 1974, S. 76 ff., 303 ff.; B. Rüthers, Entartetes Recht, 1988, S. $190 \mathrm{ff}$.

57 BVerfGE 5, 85 (224f.).

${ }^{58}$ H. Hofmann, Legitimität und Rechtsgeltung, 1977, S. 87 ff.; ders. / H. Dreier, Repräsentation, Mehrheitsprinzip und Minderheitenschutz, in: H.-P.Schneider/ W.Zeh (Hg.), Parlamentsrecht und Parlamentspraxis, 1989, S. $165 \mathrm{ff}$. (186 ff., v.a. 190). Grundsätzlich dazu H.Kelsen, Allgemeine Staatslehre, 1925, S. 368-371. Stärker als Richtigkeits- und Vernünftigkeitsgewähr wird die Mehrheitsentscheidung gesehen bei C. Offe, Politische Legitimation durch Mehrheitsbindung?, in: B. Guggenberger/C. Offe (Hg.), An den Grenzen der Mehrheitsdemokratie, 1984, S. 150 ff. (153); Krüger, Staatslehre (s. Anm. 6), S. 981 f., vgl. auch S. 284 f.; Kriele, Einführung (s. Anm. 36), S. 188. Dagegen mit Recht Ch.Gusy, Das Mehrheits- 
Prämisse scheiden sich freiheitliche von totalitären Herrschaftsformen $^{59}$. Daß eine solche dem deutschen Staatsdenken keineswegs immanente Konzeption $^{60}$ nach 1949 zunächst weitgehend das politische Bewußtsein prägte, lag sicherlich zum geringsten Teil an Reeducationsversuchen der Besatzungsmächte. Es wurde vielmehr durch eine allgemeine Ideologiemüdigkeit befördert, die das „Zeitalter der Ideologien" ${ }^{61}$ hierzulande als Geschichte erscheinen ließ. Erst eine gewisse Reideologisierung in den späten sechziger Jahren hat überkommene Denkmuster neu belebt. Angesichts der Menschheitsbedrohung durch moderne Waffentechnik und heraufzichende ökologische Gefahren kehrt die alte Konzilsfrage, ob der heilige Geist nicht auch bei der Minderheit sein könne, in neuem Gewande dort wieder, wo scheinbar allein richtige Wege zur Katastrophenabwehr abseits der demokratischen Willensbildung durchgesetzt werden sollen ${ }^{62}-$ legitimiert durch eine Heilsgewißheit, dergegenüber das als „Atomstaat“, „Überwachungsstaat“ und Staat des umweltzerstörenden Kapitals ausgegebene Gemeinwesen von vornherein als Hort des bonum commune in Frage steht. Solche weitverbreiteten Strömungen geben Anlaß zu der Sorge, daß der offene Prozeß der Gemeinwohlfindung erneut ideologisch überformt wird ${ }^{63}$.

\section{Institutionelle Sicherungen der Gemeinwoblverpflichtung}

Der Richtpunkt des Gemeinwohls, daß nämlich alle politische Herrschaft im Dienste der im Staatsverband lebenden Menschen zu stehen hat, wird institutionell nicht nur durch Verfahrensregeln, sondern insbesondere durch die mit dem öffentlichen Amt verbun-

prinzip im demokratischen Staat, AöR 106 (1981), S. 329 ff. (341); H. Dreier, Das Majoritätsprinzip im demokratischen Verfassungsstaat, in: Z.f. Parl.fragen 1986, S. 94 ff. (105); vgl. auch schon H. Kelsen, Vom Wesen und Wert der Demokratie, Neudr. d. 2. Auflage 1929, 1963, S. 99.

$59 \mathrm{Vgl}$. H. Buchheim, Totalitäre Herrschaft, 2. Aufl. 1962, S. $90 \mathrm{ff}$.

${ }^{60}$ Dazu etwa E.Fraenkel, Deutschland und die westlichen Demokratien, 2. Aufl. 1964, S. $32 \mathrm{ff}$.

61 Vgl. K. D. Bracher, Zeit der Ideologien, 1982, S. 18.

${ }_{62} \mathrm{Vgl}$. zu diesen modernen Infragestellungen des Mehrheitsprinzips den Sammelband Guggenberger/Offe (s. Anm.58), insbes. die Beiträge von I. Fetscher, U.K. Preuß, D. Rucht und Guggenberger/Offe.

${ }^{63} \mathrm{Chr}$. Graf v.Krockow, Politik und menschliche Natur, 1987, S. $162 \mathrm{ff}$;; $H$. Oberreuter, Abgesang auf einen Verfassungstyp?, jetzt in: ders. $(\mathrm{Hg}$.$) , Wahrheit$ statt Mehrheit?, 1986, S. $23 \mathrm{ff}$. (28 ff.). 
dene Pflichtenstellung gesichert ${ }^{64}$. Der moderne Staat hat das Verhältnis von beneficium und Amt umgekehrt. Nicht die Pfründe begründet die Amtspflichten, sondern erst deren Erfüllung ist Grund des Anspruchs auf amtsgemäße Besoldung ${ }^{65}$. Dies verbietet nicht nur die Entstehung einer Nomenklatura mit ihren Privilegienbündeln. Auch im demokratischen Verfassungsstaat erliegen namentlich die Parteien immer wieder der Versuchung, die Gemeinwohldestinatäre zu segmentieren, d. h. ihrer Klientel Sondervorteile zuzuwenden und insgesamt Partikularinteressen mit dem Gemeinwohl zu identifizieren ${ }^{66}$.

\section{Bonum commune und Menschenbild}

a) Wenn das bonum commune die politische Herrschaft in den Dienst der Menschen stellt, so verliert diese Formel ihren Blankettcharakter aber letztlich erst mit der Bestimmung des der jeweiligen Verfassungsordnung zugrundeliegenden Menschenbildes. Denn das Wohl der Beherrschten reklamiert auch die Diktatur für sich. Das Grundgesetz verpflichtet alle staatliche Gewalt auf Achtung und Schutz der Menschenwürde ${ }^{67}$. Es unterscheidet sich von totalitären Herrschaftsformen dadurch, daß es damit die Würde des jetzt lebenden Menschen meint, so wie er nun einmal ist, nicht erst eines zu erziehenden "neuen Menschen“. Das verpflichtet die staatliche Tätigkeit auf das Wohl der Gegenwart, die nicht nur als zwangsläufige Durchgangsstufe zu künftigen Paradiesen erscheint. Eine derart säkulare Eschatologie $e^{68}$ mit all ihrer gerade in diesen Tagen greifbaren

${ }^{64}$ Näher Isensee, HdbStR III, $\$ 57$ Rdn. 10, 64-68; ders., in: E. Benda /W. Maihofer/H.-J. Vogel (Hg.), Handbuch des Verfassungsrechts (i. folg. HdbVerfR) II, 1984, S. 1149 ff. (1152 ff.); H. Lecheler, HdbStR III, \$72 Rdn. 14 f., 82 ff.; W. Hennis, Amtsgedanke und Demokratiebegriff (1962), jetzt in: U. Matz (Hg.). Grundprobleme der Demokratie, 1973, S. $323 \mathrm{ff}$; krit. W. Leisner, Legitimation des Berufsbeamtentums, 1988, S. $70 \mathrm{ff}$.

${ }^{65}$ Isensee, HdbVerfR II, S. 1153; Krüger, Staatslehre (s. Anm. 6), S. 267 f.

${ }^{66}$ Dazu M. Stolleis, VVDStRL 44 (1986), S. 7 ff. (24); ders., Art. „Gemeinwohl“, in: Ev. Staatslexikon ${ }^{3}, 1987$, Sp. $1061 \mathrm{ff} .(1063)$; Lecheler, HdbStR III, $\$ 72$ Rdn. $107 \mathrm{ff} ;$ v. Arnim, Staatslehre (s. Anm. 27), S. $304 \mathrm{ff}$.

67 Für P. Häberle, Das Menschenbild des Verfassungsstaates, 1988, S.35, „anthropologische Prämisse" des Verfassungsstaates; ähnlich E. Denninger, Staatsrecht I, 1973, S. 19. Näher zur Grundlage des grundgesetzlichen Menschenbildes BVerfGE 4, 7 (16); Häberle (a. a.O.), S. 44 ff.; F. Kopp, Das Menschenbild im Recht und in der Rechtswissenschaft, in: FS K. Obermayer, 1986, S. $54 \mathrm{ff}$.

${ }^{68}$ Näher K. Löwith, Weltgeschichte und Heilsgeschehen, 2. Aufl. 1953, S. 38 ff.; H.D. Wendland, Christliche und kommunistische Hoffnung, in: MarxismusStudien III, 1954, S. $214 \mathrm{ff}$. 
Tragik ist dem freiheitlichen Verfassungsstaat fremd ${ }^{69}$. Dies bedeutet natürlich nicht, daß damit dessen generationsübergreifende Verantwortung geleugnet werden soll. Aber in seiner planerischen Gestaltung hat die Gegenwart einen Eigenwert, der nicht nur als notwendig unvollkommene Antizipation einer Heilserwartung erscheint.

b) Mit seiner realistischen Anthropologie $e^{70}$ hat der Verfassungsstaat westlicher Prägung eine tiefgreifende Entscheidung innerhalb zweier Traditionsströme des politischen Denkens getroffen. Seit jeher stehen sich in der Staatslehre die Leitideen eines eher pessimistischen und eines optimistischen Menschenbildes gegenüber ${ }^{71}$. Die optimistische $\mathrm{Va}-$ riante sah die ursprüngliche Freiheit, Gerechtigkeit und Sozialität des Menschen durch die herrschenden gesellschaftlichen Verhältnisse verformt und erhoffte sich demgemäß von deren Umgestaltung einen Bewußtseinswandel, der die Vernunft zu sich selbst befreit und eine gerechte Gemeinschaftsordnung ohne Zwangsmechanismen hervorbringt. Dieses totalitarismusanfällige Menschenbild ließ dort, wo die vorgeblich deformierenden Faktoren beseitigt waren, Opposition als falsches Bewußtsein, mithin als Pathologie erscheinen, deren $\mathrm{Z}_{\text {wangs- }}$ behandlung gerade das Gemeinwohl förderte. Diese uns aus der marxistischen Fortentwicklung Roussseaus vertrauten Leitgedanken ${ }^{72}$ haben auch in der Bundesrepublik zeitweise Einfluß gewonnen. Die „antiautoritäre“ Bewegung, die sich von einer repressionsfreien Selbstbestimmung ${ }^{73}$ und einer "Demokratisierung ${ }^{474}$ aller Lebensbereiche eine Veränderung der als ungerecht empfundenen Strukturen erhoffte, die Infragestellung der Institutionen des Gemeinschaftslebens, die Hoffnung, der "mündige Bürger" werde die Erbsünde abstreifen und sich stets sozialadäquat verhalten, hat Teile der den Vätern des Grundgesetzes noch selbstverständlichen Fundamente der Staatlichkeit unterspült.

69 Krit. zum Menschenbild des GG als „Staatsreligion der Bundesrepublik“ $H$. Ridder, Das Menschenbild des Grundgesetzes, in: Demokratie und Recht 7 (1979), S. 123 ff. $(123,129$ f.); vgl. auch Denninger, Staatsrecht (s. Anm. 67), S. 19, 25-27.

$70 \mathrm{~W}$. Geiger, Menschenrecht und Menschenbild in der Verfassung der Bundesrepublik Deutschland, jetzt in: FS H.J. Faller, 1984, S. 3 ff. (13).

${ }_{71}$ R. Zippelius, Die Bedeutung kulturspezifischer Leitideen für die Staats- und Rechtsgestaltung, Abh.d. Akad. d. Wiss. u. d. Lit. Mainz, 7/1987, S. 17 ff.; Häberle, Menschenbild (s. Anm. 67), S. 36 ff.

72 Zum sozialistischen Menschenbild neuestens V.Peter, Kritik der marxistischsozialistischen Rechts- und Staatsphilosophie, 1989, S. $137 \mathrm{ff}$.

73 Krit. dazu M. Kriele, HdbVerfR I, 1984, S. 129 ff. (158ff.).

74 Vgl. W. Mantl, Repräsentation und Identität, 1975, S.275-334 m. w. N. 
c) Demgegenüber sichert der demokratische Verfassungsstaat Würde und Freiheit des Menschen gerade durch seine anthropologische Skepsis. Daß der Verfassungsstaat mit der Unvollkommenheit des Menschen rechnet, zeigen die rechtsstaatlichen Sicherungen, namentlich der Gewaltenteilung ${ }^{75}$. Daß er diese Unvollkommenheit akzeptiert, erweist die Konzeption der grundrechtlichen Freiheit als Freiheit auch zu nichtgemeinwohlorientiertem Verhalten ${ }^{76}$. Die Grenzen der Skepsis markiert das BVerfG, wenn es mit seinem normativen Leitbild des sozial verantwortlichen Menschen 77 dessen Ansprechbarkeit auf seine soziale Pflichtenstellung voraussetzt und so das düstere Hobbessche Szenario vermeidet, in dem die Wölfe nur durch die absolute Macht des Souveräns zu zähmen sind ${ }^{78}$. Die unterschiedlichen beiden deutschen Verfassungssysteme nach 1949 haben deutlich gemacht, daß ein derartiges begrenzt skeptisches oder gemäßigt optimistisches ${ }^{79}$ Menschenbild Bedingung einer freiheitlichen Staatlichkeit ist.

\section{Die Offenheit der Gemeinwoblkonkretisierung im demokratischen Prozeß}

a) Innerhalb der so beschriebenen Leitgrundsätze ist die nähere Bestimmung des Gemeinwohls dem demokratischen Prozeß aufgegeben $^{80}$. Diese Offenheit der Gemeinwohlkonkretisierung bietet keine materielle Richtigkeitsgewähr ${ }^{81}$. Demokratische Willensbildung und Entscheidung sind nicht durch ein im ideologischen Gerinnungspro-

\footnotetext{
75 Zippelius, Bedeutung (s. Anm. 71), S. 20; Häberle, Menschenbild (s. Anm. 67).

76 J. Isensee, Die verdrängten Grundpflichten des Bürgers, DÖV 1982, S. $609 \mathrm{ff}$. (615).

77 BVerfGE 4, 7 (15f.); 12, 45 (51); 27, 344 (351); 30, 1 (20); 32, 373 (379); 65, 1 (44); dazu G. Dürig, in: Maunz/Dürig, GG, Art. 1 Rdn. 46 ff.; K. Hesse, Grundzüge des Verfassungsrechts der Bundesrepublik Deutschland, 16. Aufl. 1988, S. 47, Rdn. 116; E. Niebler, Die Rechtsprechung des BVerfG zum obersten Rechtswert der Menschenwürde, BayVBl. 1989, S. $737 \mathrm{ff}$.

${ }^{78}$ De cive (1642), cap. 1 Nr. $10 \mathrm{ff}$., dt. unter d. Titel „Vom Menschen, Vom Bürger", hrsg. v. G. Gawlik, 2. Aufl. 1959, S. 82 f.

${ }_{79}$ So Häberle, Menschenbild (s. Anm. 67), S. 40 f.; vgl. auch W. Leisner, Demokratie, 1979, S. $225 \mathrm{ff}$.

so Bericht der Sachverständigenkommission Staatszielbestimmungen/Gesetzgebungsaufträge, hrsg. von den Bundesministern des Inneren und der Justiz, 1983, Rdn. 69.

81 Vgl. Th. Ellwein, HdbVerfR II, S. 1029 ff. (1138).
} 
zeß fixiertes bonum commune ersetzbar. Der demokratische Konsens ist daher Bedingung einer freiheitlichen Gemeinwohlrealisierung. Wenn das Grundgesetz ihn zur Grundlage einer Teilnahme am Verfassungsleben macht, die wehrhafte Demokratie in Verfassungsrang erhebt $^{82}$, so liegt darin auch eine Entscheidung für die Harmonisierung von Freiheit und Gemeinwohl. Kompetentiell ist die Gemeinwohlverpflichtung Legislative und Exekutive gleichermaßen auferlegt.

b) Im vertikalen Staatsaufbau, aber auch im Verhältnis von staatlichen und gesellschaftlichen Institutionen ${ }^{83}$ ist immer wieder der Versuch unternommen worden, dem Grundgesetz feste Zuständigkeitsregelungen im Sinne des Subsidiaritätsprinzips zu entnehmen. Die Vernünftigkeit eines solchen Regulativs wird man schwerlich bestreiten können. Aber es teilt mit allen Prinzipien allenfalls eine gewisse Leitbildfunktion, die nicht normativ verabsolutierbar ist ${ }^{84}$. Dem steht schon die staatliche Souveränität entgegen, die eine überpositive Kompetenzzuweisung ausschließ $t^{85}$. Das Grundgesetz folgt zwar in vielem den Grundsätzen derartiger Subsidiarität, ohne sie aber durchgängig zu verwirklichen ${ }^{86}$. Man wird darin ein Gebot guter Politik zu sehen haben, in der Sprache der älteren Staatslehre: eine Klugheitsregel ${ }^{87}$, nicht aber ein Konstitutionsprinzip. Der Gemeinwohlbegriff erweist sich damit letztlich auch kompetentiell als offen.

82 Dazu E. Denninger/H.H. Klein., VVDStRL 37 (1979), S. 7 ff., 53 ff.; A. Sattler, Die rechtliche Bedeutung der Entscheidung für die streitbare Demokratie, 1982.

${ }^{83}$ Etwa H. Peters, Art. „Staat“, in: StLexGörrG ${ }^{6}$, VII, 1962, Sp. $520 \mathrm{ff} .(534 \mathrm{f}$.); P. Mikat, „Staat VIII“, in: StLexGörrG ${ }^{7}, \mathrm{~V}, 1989$, Sp. 157 ff. (161); vorsichtig A. Rauscher, Art. „Subsidiarität I“, ebda., Sp. $386 \mathrm{ff.}$

${ }_{84}$ J.Isensee, Subsidiaritätsprinzip und Verfassungsrecht, 1968, S. 313 u. ff.; ders., HdbStR III, $\$ 57$ Rdn. 79; ähnlich H.H. Rupp, HdbStR I, 1987, $\$ 28$ Rdn. 51 ff. m.w. N.; Fleiner-Gerster (s.Anm.6), S.27, 32; für ein „elastisch“ verstandenes Subsidiaritätsprinzip auch v. Arnim, Staatslehre (s. Anm. 27), S. $474 \mathrm{ff}$.

${ }^{85}$ So dezidiert Krüger, Staatslehre (s. Anm.6), S.775; krit. auch Eichenberger (s. Anm. 49), S. 113.

${ }_{86}$ R. Herzog, Subsidiaritätsprinzip und Staatsverfassung, Der Staat 2 (1963), S. $399 \mathrm{ff}$. (411 ff,); ders., Art. „Subsidiaritätsprinzip“, in: Ev. Staatslexikon ${ }^{3}, 1987$ Sp. 3563 ff. (3566 f.); weitergehend O. Kimminich, Die Subsidiarität in der Verfassungsordnung des freiheitlichen demokratischen Rechtsstaats, in: ders. ( $\mathrm{Hg}$.), Subsidiarität und Demokratie, 1981, S. 30 ff. (61).

87 Vgl. R. Herzog, Allgemeine Staatslehre, 1971, S. 151. 


\section{Der Sicherheitszweck des Verfassungsstaats}

\section{Die Verschränkung von Scbutzpflicht und staatsbürgerlichem Rechtsgehorsam}

Eine der ältesten Konkretionen des Gemeinwohls ist die Sicherheit der Bürger ${ }^{88}$. Auch dieser Begriff verliert im 17. Jahrhundert seinen theologischen Beziehungsreichtum. In säkularisierter Form wird die bürgerliche Sicherheit unter dem Schild der staatlichen Rechtsordnung in der naturrechtlichen Staatslehre zum zentralen Motiv des Sozialvertrags und damit zum Kern der Staatslegitimation. Subjectio trahit protectionem. Für Hobbes ist dies der einzige Zweck des Staates, aus dem sich alle anderen Aufgaben herleiten. Seine Erfüllung begründet und begrenzt den bürgerlichen Gehorsam ${ }^{89}$. Diese unauflösliche Verschränkung von staatlicher Schutzfunktion und Gehorsamsanspruch findet sich noch bei Laband ${ }^{90}$. Freilich wird das subjektiv-rechtliche Element, das die ältere Staatslehre ganz überwiegend festgehalten hatte, im Verlaufe des 19. Jahrhunderts zunehmend und in dem Maße auf eine objektive Schutzpflicht reduziert, wie sich das Staatsbild ins Transpersonale entrückt. Auch die Rechtsprechung des $B$ VerfG hat hieran nur wenig geändert ${ }^{91}$.

Schutzpflicht und Schutzanspruch für Leben, körperliche Unversehrtheit, individuelle Freiheit und Eigentum bilden den Kern einer jedenfalls der modernen Staatlichkeit unabdingbaren inneren Friedens- und Sicherheitsgewährleistung ${ }^{92}$. Sie verwirklicht sich in der Schaffung einer wirksamen, die Interessensphären im Verhältnis Bürger-Bürger und Bürger-Staat abgrenzenden Rechtsordnung, in deren Durchsetzungsmöglichkeit unter Reduktion der Privatgewalt auf den Ausnahmefall (Gewaltmonopol) sowie in der Bereitstellung der hierfür erforderlichen Institutionen ${ }^{93}$.

88 J. Isensee, Das Grundrecht auf Sicherheit, 1983, S. 3 ff.; G. Robbers, Sicherheit als Menschenrecht, 1987, S.27ff.; E. Klein, Grundrechtliche Schutzpflichten des Staates, NJW 1989, S. 1633 ff.; D. Murswiek, Die staatliche Verantwortung für die Risiken der Technik, 1985, S. 102 ff.; K. Eichenberger, Die Sorge für den inneren Frieden als primäre Staatsaufgabe, in: ders., Der Staat der Gegenwart, 1980, S. $73 \mathrm{ff}$.

89 Leviathan, 1651, III, chap. 29 (p. 174).

9o Staatsrecht I (s. Anm. 12), S. 156; vgl. dazu Robbers (s. Anm. 88), S. 114 f.

91 Vgl. BVerfGE 39, 1 (41 ff.); 46, 160 (164f.); 49, 89 (141f.); 53, 30 (57f.). S. auch BVerfGE 77, 170 (214).

${ }_{92}$ Chr. Starck, Frieden als Staatsziel, in: FS K. Carstens, 1984, Bd. 2, S. $867 \mathrm{ff}$. (868).

${ }_{93}$ Herzog, HdbStR III, $\$ 58$ Rdn. 26; vgl. auch F. Ermacora, Der Staat als Rechtsordnung, in: FS G. Winkler, 1989, S. 9 ff. 
In diesen ineinander verflochtenen Teilbereichen haben sich Defizite insbesondere in der Akzeptanz von Teilen der Rechtsordnung und des Gewaltmonopols gezeigt, die die staatliche Schutzpflicht für Frieden und Sicherheit jedenfalls partiell einem Erosionsprozeß aussetzen.

\section{Das staatliche Gewaltmonopol}

a) Das Gewaltmonopol ${ }^{94}$ ist untrennbar mit der Entstehung des neuzeitlichen Staates verbunden. Dabei ging es nicht - jedenfalls nicht primär - um die Zurückdrängung von „Privat" -gewalt. Eigentliches Ziel war das Verbot der Fehde als Rechtstitel "öffentlicher", wenngleich mit der Landeshoheit konkurrierender Gewaltausübung zwischen kleineren Herrschaftsverbänden ${ }^{95}$. Das mühsam durchgesetzte Gewaltmonopol war freilich zunächst im monarchischen Staat im absoluten Herrscher zentriert. Erst im 19. Jahrhundert wurde es demokratisch „eingefangen“, d.h. Legitimationsgrundlage des Gewaltmonopols sollte nicht mehr die Herrschersouveränität bilden, sondern die Herrschaft des Gesetzes. Erst die Unterwerfung unter Zwangsgesetze - so Kant - begründet „den Friedenszustand, in welchem Gesetze Kraft haben "96. Das Gewaltmonopol ist deshalb untrennbar mit der Geltung der Rechtsordnung verknüpft, es dient nicht dem Recht der Macht, sondern soll die Macht des Rechts sichern. Es legitimiert nur rechtlich begründete und begrenzte Gewalt. Im Verfassungsstaat bedeutet dies, daß Gewalt nur im Rahmen verfassungsmäßiger Gesetze, beschränkt durch die grundrechtlichen Gewährleistungen, geübt werden kann ${ }^{97}$ - und auch hier an die rechtsstaatlichen Grundsätze des Übermaßverbotes, des Vertrauensschutzes, der Garantien von objektivem Rechtsschutz und fairem Verfahren gebunden ist. Der Primat des Rechtes schließt die Zulässig-

${ }_{94}$ Dazu Isensee, HdbStR I, $₫ 13$ Rdn. 74 ff.; ders., Die Friedenspflicht des Bürgers und das Gewaltmonopol des Staates, in: FS K. Eichenberger, 1982, S. 23 ff.; D. Merten, Rechtsstaat und Gewaltmonopol, 1975.

95 Grundlegend O.Brunner, Land und Herrschaft, 6. Aufl. 1973, S. $1 \mathrm{ff}$; E. Kaufmann, Art. „Fehde“, in: HRG I, 1971, Sp. 1083 ff. (1084 f.); D. Willoweit, Die Verwaltung und Entwicklung der spätmittelalterlichen Landesherrschaft, in: K. Jeserich/H. Pohl/G.-Ch. v. Unruh (Hg.), Dt. Verwaltungsgeschichte I, 1983, S. $66 \mathrm{ff} .(71)$.

96 Zum ewigen Frieden (1795), in: Werke, hrsg. v. d. Kgl. Preuß. Akad. d. Wissensch., 1904 ff., VIII, S. 343 ff. (366); dazu H.J. Faller, Gewaltmonopol des Staates und Selbstschutzrecht des Bürgers, in: FS W. Geiger, 1989, S. 3 ff. (7).

97 R. Scholz, Rechtsfrieden im Rechtsstaat, NJW 1983, S. 705 ff. (707). 
keit gesellschaftlicher "Gegengewalt" aus ${ }^{98}$. Staatliche Zwangsgewalt ist gewiß nicht das einzige, nicht einmal das zentrale Steuerungsinstrument ${ }^{99}$, aber sie ist als ultima ratio zur Sicherung des inneren Friedens und zur Gewährleistung von Schutz und Sicherheit unverzichtbar.

b) Die Kritik an dieser Einsicht hat indes Konjunktur ${ }^{100}$. Nach einer Allensbach-Umfrage von $1986^{101}$ halten sich in der Gesamtbevölkerung Befürworter und Gegner in etwa die Waage ${ }^{102}$, während bei den unter 30jährigen bereits ein deutliches Übergewicht der Ablehnung erkennbar ist ${ }^{103}$. Hier zeigt sich, daß dieses Kernelement der staatlichen Schutz- und Friedenssicherungspflicht keineswegs mehr auf einer selbstverständlichen Akzeptanz ruht, wie sie in den ersten Jahrzehnten der Bundesrepublik vorausgesetzt werden konnte. Unter einer Camouflage des Gewaltbegriffs erscheint „ziviler Ungehorsam $^{\text {" } 104}$ als Bürgertugend und polizeiliches Vorgehen gegen Rechtsbrüche gerät so - je nach dem Gewicht ethischer Motivationen für „Widerstand“ - unversehens in den Mahlstrom von VerhältnismäBigkeitswertungen ${ }^{105}$.

98 Ähnlich G.Püttner, Der Rechtsstaat und seine offenen Probleme, DÖV 1989, S. 137 ff. (141).

${ }_{99}$ Herzog, Staatslehre (s. Anm. 87), S. 155 ff.; ders., Von der Akzeptanz des Rechts, Festg.z. 10jährigen Jubiläumd. Gesellsch.f. Rechtspolitik, 1984,S. 127ff.(128).

$100 \mathrm{Vgl}$. S. Eisel, Minimalkonsens und freiheitliche Demokratie, 1986, S. $186 \mathrm{ff}$.

101 Allensbacher Archiv, IfD-Umfrage 4077, August/September 1986.

102 Dafür: $45 \%$, dagegen $44 \%$, unentschieden $11 \%$.

${ }^{103}$ Dafür: $38 \%$, dagegen $48 \%$, unentschieden $14 \%$. Diese Ergebnisse werden freilich dadurch relativiert, daß nur etwa einem Drittel der Befragten der Begriff bekannt und von diesen wiederum sich nur ein Viertel über seine Bedeutung im klaren war.

$104 \mathrm{Vgl}$. hierzu aus der schon fast unüberschaubaren Literatur einerseits R. Dreier, Widerstandsrecht im Rechtsstaat, in: FS H. U. Scupin, 1983, S. $573 \mathrm{ff}$. sowie die Beiträge von dems. und H.Schüler-Springorum, in: P. Glotz (Hg.), Ziviler Ungehorsam im Rechtsstaat, 1983; andererseits W. Hassemer, Ziviler Ungehorsam - ein Rechtfertigungsgrund?, in: FS R. Wassermann, 1985, S. 325 ff.; U.Karpen, "Ziviler Ungehorsam" im demokratischen Rechtsstaat, JZ 1984, S. 240 ff.; Th. Lenckner, Strafrecht und ziviler Ungehorsam, JuS 1988, S. 349 ff.; Starck (s. Anm. 92), S.881 ff.; vgl. auch BVerfGE 73, 250 und BGH, JZ 1988, S. $772 \mathrm{ff}$.

105 Krit. Herzog, HdbStR III, $\$ 58$ Rdn. 39 ff.; Götz, HdbStR III, \$79 Rdn. 29 ff.; Isensee, HdbStR I, $\$ 13$ Rdn. 74 ff.; A. Randelzhofer, HdbStR I, $\$ 15$ Rdn. 8f.; Scbolz, NJW 1983, S. 705 ff. (709f.); W. Martens, Wandlungen im Recht der Gefahrenabwehr, DÖV 1982, S. $89 \mathrm{ff}$. (97f.); Bethge, DVBl. 1989, S.841 ff. (845 f.). 
c) Sicherheitsdefizite zeigen sich zunächst allgemein im steilen Anstieg der Straftaten ${ }^{106}$. Vor allem aber geht es um die zur Massenerscheinung gewordene politisch und wirtschaftlich motivierte Gewalt ${ }^{107}$. Der Rechtsbindung der staatsmonopolistischen Gewalt korrespondiert die Friedenspflicht der Bürger. Dies bedeutet natürlich nicht den Versuch einer Beschneidung grundrechtlich legitimierter Kritik. Im Gefolge des Brokdorf-Beschlusses des BVerfG ${ }^{108}$ ist indes die staatliche Reaktionsmöglichkeit im Vorfeld von absehbar gewalttätigen Demonstrationen nicht unerheblich beschränkt ${ }^{109}$.

d) Im präventiven Bereich ist auch bei schweren Gefährdungen der Rechtsgüter Leben, Gesundheit und Eigentum der Anspruch auf polizeiliches Einschreiten, als wesentliche Errungenschaft des grundrechtssichernden Rechtsstaates gefeiert ${ }^{110}$, deutlich relativiert. Im repressiven Bereich liegt die Wahrscheinlichkeit einer Verurteilung politisch motivierter Gewalttäter erheblich unter dem Risiko sonstiger Straftaten. Hier hat sich an dem skeptischen Befund Ipsens zum 25. Jahrestag des $G^{111}$ wenig geändert - und auch dieses wenige beruht nicht auf einer effektiveren Erfüllung der staatlichen Schutzpflichten, sondern eher auf einem zeitweisen Mangel an geeigneten Mobilisierungsobjekten für die latente Breitbandempörung. In der Unfähigkeit, seiner Friedens- und Schutzpflicht zu genügen, zeigen sich Krisensymptome des Rechtsstaats ${ }^{112}$. Zu Recht ist darauf hinge-

\footnotetext{
106 Vgl. die Nachw. bei Faller (s. Anm. 96), S. 3 f.

107 Hierzu anschaulich D. Merten, Rechtsstaatsdämmerung, in: FS R. Samper, 1982, S. $41 \mathrm{ff}$.

${ }^{108}$ BVerfGE 69, 315. - Dazu krit. V.Götz, Versammlungsfreiheit und Versammlungsrecht im Brokdorf-Beschluß des BVerfG, DVBl. 1985, S. 1347 ff. (1352); H.Schneider, Anmerkung zum Brokdorf-Beschluß, DÖV 1985, S.783ff.; M. Kloepfer, HdbStR VI, $\$ 143$ Rdn. $5 \mathrm{ff.}$

${ }_{109}$ Vgl. A. Dietel/M.Kniesel, Der Brokdorf-Beschluß des BVerfG und seine Bedeutung für die polizeiliche Praxis, Die Polizei 1985, S. 335 ff.; zur Schadensbilanz der „Demonstrationen“ um die Startbahn West (neben Toten und zahlreichen Schwerverletzten Sachschäden und Kosten in Höhe von nahezu 60 Mio. DM) K. Gemmer, Polizeiliche Erfahrungen zur Praxis des Demonstrationsstrafrechts, in: B. Rill / R. Scholz (Hg.), Der Rechtsstaat und seine Feinde, 1986, S. 97 ff. (98).

110 Martens, DÖV 1982, S. 89 ff. (97); vgl. auch V. Götz, Allgemeines Polizeiund Ordnungsrecht, 9. Aufl. 1988, Rdn. 274.

"1' H.P. Ipsen, Über das Grundgesetz - nach 25 Jahren, DÖV 1974, S. $289 \mathrm{ff}$. (292f.).

112 Dazu E.Schmidt-Aßmann, HdbStR I, $\$ 24$ Rdn. 97; K. A. Bettermann, Der totale Rechtsstaat, 1986.
} 
wiesen worden, $\mathrm{da} ß$ seine grundrechtliche Bindung nicht nur durch das Übermaßverbot, sondern auch durch ein „Untermaßverbot ${ }^{\text {" } 113}$ markiert wird.

\section{Gewaltmonopol und Rechtsschutzgewäbrleistung}

Der Schutzzweck des Staates schließt einen effektiven Rechtsschutz $e^{1 n^{14}}$. Die alte Konnexität von Gewaltmonopol und Gerichtsschutz hat das GG durch Art. 19 Abs. 4 systematisch abgeschlossen. Aber man wird das dem Friedenszweck immanente Versprechen des effektiven Rechtsschutzes kaum als erfüllt ansehen können, wenn sich die Verfahren über Jahre hinziehen ${ }^{115}$. Die deutsche Rechtsstaatsperfektion zeigt hier zunehmend ihren Januskopf ${ }^{116}$. Die hohe Zahl erfolgloser Verfassungsbeschwerden läßt erkennen, daß fachgerichtliche Entscheidungen ihre Funktion verlieren, den Rechtsfrieden auch gegenüber der unterlegenen Partei herzustellen. Ursache dafür ist, so scheint mir, nicht nur die intransigente Weigerung, Niederlagen zu akzeptieren, sondern sind letztlich diffuse Erwartungshaltungen, die den Staat als Garanten gegen Einbußen an materiellem oder immateriellem Wohlbefinden mißverstehen ${ }^{117}$.

\section{Die Akzeptanz der Rechtsordnung}

Das Gewaltmonopol bedarf, da es der Durchsetzung des Rechts dient, der überwiegenden Akzeptanz eben jenes im demokratischen Verfahren gesetzten Rechts durch die Bürger ${ }^{118}$. Der Schutz- und Friedenszweck des Staates hat deshalb, wenn er nicht zur Diktatur verkommen will, sein Widerlager im prinzipiellen freiwilligen Geset-

113 Götz, HdbStR III, $\$ 79$ Rdn. 30 f.

11+ BVerfGE 8, 326; 25, 365; 35, 72; 51, 185; 54, 41; 67, 58.

115 Dazu H. Sendler, 40 Jahre Rechtsstaat des Grundgesetzes: Mehr Schatten als Licht?, DÖV 1989, S. 482 ff. (489); ders., Der Rechtsstaat im Bewußtsein seiner Bürger, NJW 1989, S. 1761 ff. (1769).

116 K.A. Bettermann, Der Zustand des Rechtsstaates, Cappenberger Gespräche 21, 1986, S. $75 \mathrm{ff}$., empfiehlt zur Bekämpfung der Prozeßflut deshalb gar eine Einschränkung der Rechtsweggarantie des Art. 19 Abs. 4 GG.

117 O.R. Kissel, Justiz zwischen Anspruch und Wirklichkeit, DRiZ 1987, S. $301 \mathrm{ff}$. (311); P. Kirchhof, Nach vierzig Jahren: Gegenwartsfragen an das Grundgesetz, JZ 1989, S. 453 ff. (458).

118 R. Wassermann, Rechtsstaat ohne Rechtsbewußtsein?, 1988, S. 13 f.; H. Hill, Das Verhältnis des Bürgers zum Gesetz, DÖV 1988, S.666ff. (667); G. Ress, Die Autorität des Verfassungsrechts, in: T. Stein (Hg.), Die Autorität des Rechts, Koll. z. 65. Geburtstag v. K. Doehring, 1985, S. 5 ff. (16). 
zesgehorsam ${ }^{119}$ als Regelfall. Diese als Sekundärtugend bespöttelte Basis einer in Frieden bestehenden Rechtsgemeinschaft ist in den 40 Jahren des Grundgesetzes deutlich abgebröckelt. Man wird Erosionserscheinungen nicht allein in ideologischen Deformationen des Rechtsbewußtseins sehen können. Die Bereitschaft, das angeblich formale Recht um "höherer Werte" willen beiseitezuschieben, hat durch kalkulierte Rechtsbrüche von Roben- und Talarträgern moralisch die höheren Weihen empfangen. Aber die Bereitschaft, das demokratische Gesetz nur dort zu akzeptieren, wo es mit den eigenen Interessen konform geht, beschränkt sich keineswegs auf derartige Erscheinungen. Dies zeigen die Massendelikte des Alltags, etwa im Steuerrecht und im Straßenverkehr, die verharmlosende Bewertung von Ladendiebstählen - insgesamt die erschreckend niedrig gewordene Hemmschwelle dort, wo „es keinen Armen trifft", wo Geschädigte unpersönliche Kollektive oder die Gemeinschaft sind. Sicherlich wird man die Ursachen auch in der unübersichtlich gewordenen Welt $\mathrm{zu}$ suchen haben, der eine Unübersichtlichkeit der Rechtsordnung ${ }^{120}$ korrespondiert, deren Gebote mit zunehmender Komplexität unmittelbare Einsehbarkeit und ethische Nachvollziehbarkeit verlieren ${ }^{121}$. Das Steuerrecht bietet hierfür ein signifikantes Beispiel ${ }^{122}$.

Es ist aber doch vor allem der Rückgang eines in der Gesellschaft verwurzelten Wertbewußtseins, die Zersetzung eines als selbstverständlich empfundenen moralischen Verhaltenskodex ${ }^{123}$, dessen Übertretung - wie Christian Thomasius noch voraussetzen konnte - den Verlust der "tranquillitas animi“" nach sich zieht ${ }^{124}$. Dies mag der Preis einer sich zunehmend pluralisierenden Gesellschaft bei schwindender Integrationskraft wertsetzender Institutionen, etwa der Kirchen, sein. Aber es ist auch die vielfach anzutreffende gleichheitswidrige Prämierung des Rechtsbruchs, nicht nur durch die in vielen Bereichen

119 H. Röken, Gesetzesgehorsam statt Gesetzesakzeptanz, DÖV 1989, S. 54 ff.

120 Dazu E.Denninger, Der Präventionsstaat, KJ 1988, S. $1 \mathrm{ff}$. ( $6 \mathrm{ff}$.); Hill (s. Anm. 118), S. 667 f.; Sendler, NJW 1989, S. 1761 ff. (1762f.).

121 Herzog, Staatslehre (s. Anm. 87), S. 134 f.

${ }^{122}$ K. Tipke, Steuerrecht, 11. Aufl. 1987, S. 65 ff.; B. Knobbe-Keuk, Zum Verfall der Steuergesetzgebung, BB 1988, S. 1086 ff.; G. Wicbmann, Einkommensteuerrecht - einmal anders betrachtet, BB 1989, S. 361 ff.

${ }^{123}$ Dazu J. Isensee, Freiheit - Recht - Moral. Das Dilemma des Rechtsbewußtseins im deutschen Verfassungsstaat, in K. Weigelt (Hg.), Freiheit - Recht Moral, 1988, S. 14 ff. (17).

${ }_{124} \mathrm{Cbr}$. Thomasius, Fundamenta iuris naturae et gentium, Ed.4, 1718 (Neudr. $1963)$, S. $153 \$ X L, 175 \$ X X X V$. 
minimale Sanktionsgefahr, die den Rücksichtslosen belohnt, sondern auch die - aus was für achtbaren Gründen auch immer - nachträgliche Legalisierung. Die Amnestie bei Einführung der Quellensteuer ${ }^{125}$ ist hier nur ein Beispiel. Das mehrfach kritisierte „informelle Verwaltungshandeln “126 mag im Einzelfall vernünftige Ergebnisse zeigen, läßt aber auch im staatlichen Bereich eine Großzügigkeit im Umgang mit dem Recht erkennen, der das allgemeine Gesetz um der Einzelfallgerechtigkeit willen zur Disposition stellt ${ }^{127}$. Der Friedens- und Sicherheitszweck des Rechtsstaates zielt aber auch und gerade auf den Komplementärwert der Rechtssicherheit ${ }^{128}$.

\section{Ethische Neutralität des Verfassungsstaates?}

Aber es bedarf noch mehr als des Rufes nach der Sanktionseffektivität. Gesetzesakzeptanz ist ein vermittlungsfähiger und vermittlungsbedürftiger Wert eines friedlichen Zusammenlebens. Die weltanschauliche Neutralität des Staates gebietet keine ethische Farbenblindheit ${ }^{129}$. Die landesverfassungsrechtlichen Erziehungsziele zeigen hier weit geringere Skrupel als Teile der Staatsrechtslehre. Obermayer hat vor Jahrzehnten einmal den „ethischen Standard des Grundgesetzes“ als pädagogische Leit- und Grenzlinie des schulischen Erziehungsauftrags im demokratischen Staat bezeichnet ${ }^{130}$. Daran scheint mir richtig zu sein, daß die Verfassung ein Beziehungssystem von individueller Freiheit und Gemeinschaftsgebundenheit vorgibt, dessen ethische

${ }_{125}$ Krit. H.-W. Arndt, Gleichheit im Steuerrecht, NVwZ 1988, S. 787 ff. (793); K. Tipke, Die rechtliche Misere der Zinsbesteuerung, BB 1989, S. $157 \mathrm{ff}$.

126 Hierzu H. Bauer, Informelles Verwaltungshandeln im öffentlichen Wirtschaftsrecht, VerwArch 78 (1987), S. 241 ff.; D. Murswiek, Freiheit und Freiwilligkeit im Umweltrecht, JZ 1988, S. 985 ff.; Püttner, DÖV 1989, S. 137 ff. (140f.).

127 Vgl. zum Ganzen a. Sendler, NJW 1989, S. $1761 \mathrm{ff}$. (1762 ff.); J. Burmeister, Praktische Jurisprudenz und rechtsethischer Konsens in der Gesellschaft, in: Gedächtnisschr. f. W. K. Geck, 1989, S. 97 ff. (98ff.).

128 Zur Gefährdung der Rechtssicherheit durch das den Staat der Industriegesellschaft strukturell überfordernde Verlangen nach "Rechtsgütersicherheit" Denninger, KJ 1988, S. $1 \mathrm{ff}$.

129 Vgl. F. Bydlinksi, Fundamentale Rechtsgrundsätze - Zur rechtsethischen Verfassung der Sozietät, 1988, S. 95 f.; Burmeister (s. Anm. 127), S. 110 ff.; anders E.W. Böckenförde, Der Staat als sittlicher Staat, 1978, S. $24 \mathrm{f}$.

${ }_{130}$ K. Obermayer, Gemeinschaftsschule - Auftrag des GG, 1967, S. 23 f.; vgl. a. $P$. Haberle, Grundrechtsgeltung und Grundrechtsinterpretation im Verfassungsstaat, JZ 1989, S.913 ff. (915); zur Bedeutung für die Öffentlichkeitsarbeit von Staatsorganen s. a. BVerfGE 44, 125 (147 f.); skeptisch insofern Leisner, Öffentlichkeitsarbeit (s. Anm. 37), S. $79 \mathrm{ff}$. 
Grundlage zwar der religiösen oder weltanschaulichen Vertiefung bedarf, die aber auch als rational vermittelbare philosophia practica demokratischer Bürgerpflicht einen Eigenwert besitz $t^{131}$. Entgegen manchen Rahmenrichtlinien ist weniger eine Konflikts- als eine Friedenserziehung in diesem Sinne ein Postulat des friedenssichernden Rechtsstaats. Denn Rechtsfrieden und Rechtssicherheit sind nicht nur elementarer Staatszweck, die freiheitliche Demokratie lebt zugleich von ihrer Bewährung als Gemeinschaftsaufgabe.

\section{Der Staatszweck Wohlfahrt}

\section{Die Domestizierung des Woblfabrtsstaats durch den Rechtsstaat}

a) Georg Jellinek zieht die Grenze zwischen „expansiven“ und „limitierenden“ Staatszwecken dort, wo der Staat nicht nur als Instrument des Sicherheits-, Freiheits- und Rechtsschutzes angesehen wird, sondern primär als im Dienst der öffentlichen Wohlfahrt stehend. Hier werde „das Tätigkeitsgebiet des Staates ins Schrankenlose gewei-

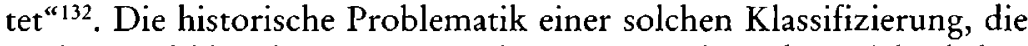
noch von altliberalen Kategorien bestimmt ist, kann hier nicht diskutiert werden ${ }^{133}$. Das Sozialstaatsprinzip des Grundgesetzes begrenzt den Schutz- und Sicherungszweck nicht auf Rechtssicherheit und Rechtsgüterschutz, sondern hat die Schutz- und Vorsorgepflicht des Staates für die Grundlagen menschenwürdigen Lebens zum Verfassungsauftrag erhoben ${ }^{134}$. Damit setzt es eine Tradition der Staatszweckbestimmung fort, die durch liberal-rechtsstaatliche Postulate des 19. Jahrhunderts keineswegs unterbrochen war ${ }^{135}$. In der älteren

131 Ähnlich Burmeister (s. Anm.127), S. $120 \mathrm{ff}$; O. Kimminich, Zur „EthikKonjunktur" im Umwelt- und Technikrecht, Jahrbuch des Umwelt- und Technikrechts, Bd. 5, 1988, S. 108 f., $121 \mathrm{f}$.

132 Jellinek (s. Anm. 2), S. $243 \mathrm{ff}$. einerseits und $246 \mathrm{ff}$. andererseits.

133 Dazu Link, Herrschaftsordnung (s. Anm. 2), S. $136 \mathrm{ff}$.

${ }_{134}$ Seit BVerfGE 1, 97 (105) st. Rspr. Dazu E. Forsthoff, VVDStRL 12 (1954), $8 \mathrm{ff}$. (42 f.), sowie H.F. Zacher, HdbStR I, $\$ 25$ Rdn. 25; R.-U. Scblenker, Rückschrittsverbot und Grundgesetz, 1986, S.93; R.Scholz, Sozialstaat zwischen Wachstums- und Rezessionsgesellschaft, 1981, S. 24; Chr. Starck, Gesetzgeber und Richter im Sozialstaat, DVBI. 1978, 937 ff. (938); K. Obermayer, Der Sozialstaat als Herausforderung der Menschlichkeit, RdA 1979, S. 1 ff. (15); B. Müller-Volbehr, Der soziale Rechtsstaat im System des Grundgesetzes, JZ 1984, S. $6 \mathrm{ff}$. (9).

${ }^{135}$ G. A. Ritter, Der Sozialstaat. Entstehung und Entwicklung im internationalen Vergleich, 1989, S. $46 \mathrm{ff}$. Zur - in moderner Terminologie - sozialstaatlichen Gesetzgebung etwa (aber keineswegs nur) in Preußen G. Landwebr, Staatszweck 
deutschen Staatslehre behauptet sich neben dem Schutz von Freiheit und Eigentum die wohlfahrtsstaatliche Komponente. Öffentliche und private Wohlfahrt werden als wechselseitig aufeinander bezogene Größen beschrieben. Die Glückseligkeit der Untertanen ist „Endzweck der Republic ${ }^{\text {"136 }}$. Es ist der Gedanke des Wohlfahrtsstaates, der vornehmlich in der deutschen Staatslehre ausgeformt wird, am deutlichsten in der patriarchalischen Sozialethik des lutherischen Fürstenstaats ${ }^{137}$. Die Idee der umfassenden Daseinsvorsorge als öffentliche Aufgabe scheint mir der eigentliche Beitrag des Luthertums zur modernen Staatsidee zu sein.

b) Letztlich wurzelt das seit $\mathrm{Kant}^{138}$ als Eudämonismus abgetane "Glückseligkeits"-ideal in der tieferen, immer wieder verschütteten Einsicht in die Vorläufigkeit politischer Ordnungen, die nicht dazu berufen sind, außerhalb ihrer selbst liegende - sittliche oder ideologische - Werte zu verwirklichen und so das Glück der Gegenwart der Schimäre künftiger Paradiese zu opfern. Es ist zugleich die Einsicht in die ökonomische Bedingtheit der Menschenwürde. Das Grundgesetz hat die latente Spannung zwischen liberté und égalité in der Formel vom sozialen Rechtsstaat ${ }^{139}$ zu vermitteln versucht. Es stellt damit die

und Staatstätigkeit in Preußen während der 1. Hälfte des 19. Jahrhunderts, in: FS K. Kroeschell, 1987, S. 249 ff. und allg. demnächst D. Klippel, Der Lohnarbeitsvertrag in Naturrecht und Rechtsphilosophie des 18. und 19. Jahrhunderts, in: FS A. Söllner, 1990.

${ }_{136}$ N.H. Gundling, Einleitung zur wahren Staatsklugheit, 1751, cap. $7 \$ 1$ (S. 234); weitere Nachw. bei Link, Herrschaftsordnung (s. Anm.2), S. 137 Fn. 19 ff.; zu Christian Wolffs bedeutendem Beitrag ders., Die Staatstheorie Christian Wolffs, in: W.Schneiders (Hg.), Christian Wolff 1679-1754, 1983, S. $171 \mathrm{ff}$. (173f.).

137 Etwa bei D. Reinkingk (1590-1664); zu ihm Link, in: M. Stolleis (Hg.), Staatsdenker im 17. und 18. Jahrhundert, 2. Aufl. 1987, S. 78 ff. und V. L. v. Seckendorff (1626-1692); dazu Stolleis, ebda. S. $148 \mathrm{ff}$.

${ }_{138}$ Vgl. vor allem Ueber den Gemeinspruch: Das mag in der Theorie richtig sein ..., in: Werke (s. Anm. 96) VIII, S. 275 ff. (302). Dazu, daß die kantische Frage nach der Verallgemeinerungsfähigkeit individueller Handlungen gerade aus moralphilosophischer Sicht Grenzen des Sozialstaates aufzuzeigen vermag, Chr. Starck, Ist der kategorische Imperativ ein Prinzip des Sozialstaats?, ZRP 1981, S. $97 \mathrm{ff}$. (101).

139 Das sozialstaatliche Aufgabenfeld wird über Art. 20 Abs. 1, 28 Abs. 1 GG durch zahlreiche weitere Verfassungsbestimmungen abgesteckt. Hierzu zählen insbesondere Art. 9 Abs. 3 i.V.m. Art. 74 Nr. 12 GG als institutionelle Garantie herkömmlicher Grundsätze des Arbeitsrechts, die Kompetenznormen der Art. 74 Nr.6, 7-16, Art. 91 a sowie die Übergangsregelungen der Art. 119, 120, 120 a (dazu K.J. Bieback, Sozialstaatsprinzip und Grundrechte, EuGRZ 1985, S.657 ff. [660] 
anspruchsvolle Aufgabe, die notwendige Statik des bürgerlichen Rechtsstaates und die Dynamik des Sozialstaats ${ }^{140}$ als dialektische Einheit zu begreifen, Sozialstaatlichkeit in die Formtypik des Rechtsstaats zu fassen und den Rechtsstaat auf die Herstellung sozialer Gerechtigkeit zu verpflichten. Dabei griffe es zu kurz, den Sozialstaat auf das Feld ökonomischer Vorsorge einzuengen. Soziale Gerechtigkeit realisiert sich auch in der Gleichheit von Bildungschancen, in der Sicherung der natürlichen Lebensgrundlagen und im Kulturstaatsauftrag ${ }^{141}$.

c) In diesem Rahmen kann es heute nicht nur um die "Herstellung erträglicher Lebensverhältnisse" gehen, wie es das BVerfG noch 1951 forderte ${ }^{142}$. Über diesen Minimalstandard ist die „Verpflichtung des Gesetzgebers zu sozialer Aktivität" längst hinausgewachsen. Es liegt gleichwohl im "Prozeßcharakter des Sozialstaats“ (Zacher) ${ }^{143}$ begründet, daß er nie an sein Ziel kommen kann, ohne doch auf ein solches zu verzichten. Trotzdem - oder gerade deshalb - produziert der Sozialstaat im Maße seiner Entfaltung Erwartungshaltungen, deren immer nur teilweise mögliche Einlösung Zufriedenheit, „Glückseligkeit" und damit Loyalitätsbindungen ${ }^{144}$ nur beschränkt zu fördern

sowie A. Bleckmann, Zum materiellrechtlichen Gehalt der Kompetenzbestimmungen des GG, DÖV 1983, S. 129 ff. [808f.]), weiterhin die „sozialen Grundrechte“ - etwa Art. 6 Abs. 5 - wie überhaupt die Grundrechte in ihrem objektiv-rechtlichen Gehalt (vgl. z. B. BVerfGE 75, 40 [65]).

${ }_{140}$ Hierzu vor allem Zacher, HdbStR I, $\$ 25 \mathrm{Rdn} .66$. Vgl. dens., Was können wir über das Sozialstaatsprinzip wissen?, in: FS H. P. Ipsen, 1977, S. 207 ff. (240 ff.) sowie F. Hufen, VVDStRL 47 (1988), 142 ff. (147) und Cb. Degenhart, Rechtsstaat - Sozialstaat. Anmerkungen zum aktuellen Problemstand, in: FS H.U. Scupin, 1983, S. 537 ff. (553).

${ }^{141}$ Zur Gleichheit der Bildungschancen vgl. BVerfGE 33, 303 (332). Zur Verbindung von Sozialstaatsprinzip und staatlichen Umweltschutzpflichten Stern, Staatsrecht I (s. Anm. 7), S. 908; Zacher, HdbStR I, $\$ 25$ Rdn. 69. Zum Kulturstaatsauftrag BVerfGE 36, 321 (331) sowie Stern, Staatsrecht III/1, 1988, S. 884 f.; E.-R. Huber, Zur Problematik des Kulturstaats, 1958; P. Häberle (Hg.), Kulturstaatlichkeit und Kulturverfassungsrecht, 1982; M. Heckel, Staat, Kirche, Kunst, 1968, S. $125 \mathrm{ff}$; W. Maihofer, HdbVerfR II, S. $953 \mathrm{ff}$.

${ }_{142}$ BVerfGE 1, 97 (105).

${ }_{143} \mathrm{ZgS} 134$ (1978), S. 15 ff. (16).

${ }_{144}$ Zur materiellen Legitimierung des Staates durch das Sozialstaatsprinzip neben der formellen durch das demokratische Prinzip Maibofer, HdbVerfR I, S. $173 \mathrm{ff}$. (193 ff.). Dazu, daß der Staat seine Legitimationsprobleme hier gleichsam selbst produziert, M.Spieker, Legitimationsprobleme des Sozialstaats, 1986, S. $15 \mathrm{f}$., $76 \mathrm{ff}$. sowie H. Krüger, Von der Staatspflege überhaupt, in: H. Quaritsch (Hg.), Die Selbstdarstellung des Staates, 1977, S.21 ff. (30). Vgl. auch dens., Staatslehre (s. Anm. 6), S. 804 . 
vermag. Da die Verteilungsmasse konjunkturabhängig bleibt, verschärft sich diese Problematik bei sinkendem Sozialprodukt. Die relativ undramatischen Wirtschaftskrisen der jüngeren Vergangenheit haben die Spannungslage von Rechts- und Sozialstaat in ein neues Licht gerückt. Das notwendig gewordene Zurückschneiden von Ansprüchen provozierte nicht nur eine politische Kampagne gegen "Sozialabbau“ ${ }^{145}$, sondern führte mit der These eines „sozialen Rückschrittsverbotes ${ }^{\text {"146 }}$ auch zu Bemühungen um eine konstitutionelle Absicherung von Besitzständen. Sie finden ihre Grenzen freilich in der unerbittlichen Dialektik von Sein und Sollen. Gleichwohl hat die politische Realität die Schwierigkeit erwiesen, verbandsmäßig verteidigte Besitzstände anzutasten. Der progressiven sozialstaatlichen Dynamik entspricht ein regressiver Immobilismus. Die im großen und ganzen glücklichen Wachstumsbedingungen der Bundesrepublik haben dem System bisher einen grundlegenden Belastungstest erspart. Sie haben selbst eine langanhaltende Massenarbeitslosigkeit so abzufedern erlaubt, daß der Umschlag der sozialen in die politische Krise vermieden werden konnte. Nach der Eingliederung der Flüchtlinge hat der Sozialstaat damit seine zweite große Bewährungsprobe bestanden.

\section{Die Zukunftsdimension des Sozialstaats}

a) Auch der Sozialstaat ist ein "System in der Zeit" ${ }^{147}$. Die ihm aufgegebenen Probleme stellen sich nicht nur in der Horizontale der Gegenwart, sondern zunehmend auch in jener Vertikale, die die Vergangenheit mit der Zukunft verbindet. Die Verpflichtung auf das "Eủ $\zeta \tilde{\eta} v "$ der hier und jetzt seinem Schutz anvertrauten Bürgerschaft bildet keinen Freibrief für eine Bedürfnisbefriedigung auf Kosten zukünftiger Generationen ${ }^{148}$. Ipsen hat die geschilderte Dynamik des

145 Vgl. hierzu J. Strasser, Grenzen des Sozialstaats?, 2. Aufl., 1983; H. Ehrenberg / A. Fuchs, Sozialstaat und Freiheit, 1980, S. 123 ff. und R. G. Heinze/B. Hombach /H. Scherf $(\mathrm{Hg}$.), Sozialstaat 2000, 1987.

${ }^{1+6}$ Hierzu vor allem Schlenker (s. Anm. 134), bes. S. 100. Krit. J. Isensee, Der Sozialstaat in der Wirtschaftskrise, in: FS J. Broermann, 1982, S. 365 ff. (369); Scholz, Sozialstaat (s. Anm.134), S.32; Degenhart, Rechtsstaat - Sozialstaat (s. Anm. 140), S. 537 ff. (541); vgl. auch D. Subr, Rechtsstaatlichkeit und Sozialstaatlichkeit, Der Staat 9 (1970), S.67 ff. (92).

${ }^{147}$ Hierzu allg. Krüger, Staatslehre (s. Anm.6), S. $125 \mathrm{ff}$. - Zu den verfassungsrechtlichen Schranken für Privatisierungen jetzt $H$. Lecheler, Grenzen für den Abbau von Staatsleistungen, 1989.

148 Hofmann (s. Anm. 44), S. 21 ff. (32). 
Sozialstaats auf den prägnanten Nenner der "Wachstumsvorsorge“ gebracht ${ }^{149}$. Zwar bedeutet Wachstum keineswegs notwendig steigenden Ressourcenverbrauch, im vielstimmigen Chor der Wachstumskritiker ist deshalb ein ideologischer cantus firmus unüberhörbar. Indes: Die jüngere Geschichte der Bundesrepublik hat gezeigt, daß Wachstum durch Staatsvorsorge nur beschränkt produzierbar ist und daß nicht nur konjunkturelle Wechselfälle den Sozialstaat gerade in seinem klassischen Kernbereich einer Alters- und Krankheitsvorsorge an seine Grenzen geführt haben. Namentlich die 1957 eingeführte Rentendynamik basierte auf der linearen Extrapolation wirtschaftlicher und demographischer Entwicklungen, deren Fehleinschätzung heute mit der brutalen Frage nach der „Finanzierbarkeit der Alten “ 150 die im Generationenvertrag angelegte Partnerschaftskrise von Ökonomie und Ethik sichtbar macht ${ }^{151}$.

b) Die Grenzen des Wachstums haben damit den Sozialstaat vor die immer schwieriger zu bewältigende Aufgabe einer gerechten intertemporalen Lastenverteilung gestellt. Die Droge der Staatsverschuldung hat Abhängigkeiten geschaffen, die allenfalls noch eine Rückführung der Neuverschuldung zulassen. Man muß nicht die "klassische tiefe Abneigung der Ökonomen gegen die Staatsverschuldung " teilen ${ }^{152}$ und dem Satz des amerikanischen Nationalökonomen Buchanan mehr als eine Pointe abgewinnen, daß „der Wohlfahrtsstaat sein eigenes Ableben mit dem ersten Dollar" garantiert, "den er sich als Schuld auferlegt" ${ }^{\prime 53}$, um in einem ständig wachsenden Schuldensockel trotz inflationärer Relativierung eine generationenübergreifende Umverteilung zu sehen ${ }^{154}$. Die Grenzen der Staatsverschuldung

149 Zuerst in VVDStRL 34 (1966), 222 (Disk.beitr.). - Ebenso Badura (s. Anm. 47), S.199. Krit. Starck, DVBl. 1978, $937 \mathrm{ff.}$ (939f.); N.Achterberg, VVDStRL 38 (1980), S. 55 ff. (85); Bieback, EuGRZ 1985, 657 ff. (661). Im Hinblick auf die Verankerung dieses Auftrags gerade im Sozialstaatsprinzip zu Recht skeptisch Scholz, Sozialstaat (s. Anm. 134), S. 9 f.

150 H. Diessenbacher, Sind die Alten noch finanzierbar?, FAZ v. 18. 8. 1989, S.6.

$151 \mathrm{Vgl}$. Gutachten der Kommission des Verbandes Deutscher Rentenversicherungsträger "Zur Entwicklung der gesetzlichen Rentenversicherung " vom Juni 1987, S. 59 ff., 65 f. Das Rentenreformgesetz 1992 (BGBI. I, 1989, S. $2261 \mathrm{ff}$.) hat freilich grundlegende Reformvorschläge nicht aufgegriffen.

152 J.M. Buchanan, Demos und Wohlfahrtsstaat, in: P. Koslowski u. a. (Hg.), Chancen und Grenzen des Sozialstaats, 1983, S. 117 ff. (118).

153 Buchanan, ebda.

154 Zum "crowding-out-Effekt" der Staatsverschuldung M. Neumann, Theoretische Volkswirtschaftslehre I, 3. Aufl. 1988, S. 189 ff.; G. Fels, Die Konsequenzen der Staatsverschuldung, in: H.Siebert $(\mathrm{Hg}$.), Perspektiven der deutschen Wirt- 
sind vom BVerfG zwar gesehen, aber nicht verfassungsrechtlich präzisiert worden. Es hat dem Gesetzgeber einen weiten Einschätzungsund Beurteilungsspielraum zugebilligt, ihm zwar eine Darlegungslast auferlegt, aber die Justiziabilität auf eine Plausibilitätskontrolle dieser Darlegungen zurückgenommen ${ }^{155}$. Das normative Konzept einer justitia distributiva intertemporalis bleibt unbefriedigend.

c) Ähnliche Probleme stellen sich im Umweltschutz ${ }^{156}$. Die Diskussion um die Verankerung als Staatszielbestimmung im GG kann hier nicht nachgezeichnet werden ${ }^{157}$. Es steht indes zu befürchten, daß damit nur die Fronten im Glaubenskrieg um den Vorrang dirigistischer oder marktwirtschaftlicher Strategien verfassungsdogmatisch befestigt würden, ohne daß dem ein meßbarer Effektivitätsgewinn entspräche.

\section{Sozialstaatsprinzip und Wirtschaftsverfassung - das Problem der Staatsintervention}

a) Die Janusköpfigkeit des Wohlfahrtszwecks beschreibt ein Kernproblem der Staatslehre seit dem ausgehenden 18. Jahrhundert. Seinen realgeschichtlichen Hintergrund hatte es im gewaltsamen Beglükkungsoptimismus des Spätabsolutismus, der dann im Terror des Wohlfahrtsausschusses eine schaurige totalitärdemokratische Metamorphose erlebte. Der Verfassungsstaat des Grundgesetzes hat deshalb den zum Sozialstaat entschärften Wohlfahrtsstaat im grundrechtsgebundenen Rechtsstaat domestiziert. Damit ist er allein mit einem System freiheitlicher Ordnung kompatibel. Die freiheitssi-

schaftspolitik, S. 85 ff. (90). Allgemein zum Problem der intergenerativen Gerechtigkeit H.H. v.Arnim, Grundprobleme der Staatsverschuldung, BayVBl. 1981, $514 \mathrm{ff}$; ders. / D. Weinberg, Staatsverschuldung in der Bundesrepublik Deutschland, 1986, S. $35 \mathrm{ff}$.; P. Henseler, Verfassungsrechtliche Aspekte zukunftsbelastender Parlamentsentscheidungen, AöR 108 (1983), S. 488 ff.; G. Püttner, Staatsverschuldung als Rechtsproblem, 1980.

155 BVerfGE 79, 311 (346). Dies letztlich aufgrund der mangelnden Operationalität des Begriffs "gesamtwirtschaftliches Gleichgewicht". Dazu jetzt W.Heun, Staatshaushalt und Staatsleitung, 1989, S. $142 \mathrm{ff}$.

156 D. Rauschning u. E. Hoppe, VVDStRL 38 (1980), S. 167 ff., $211 \mathrm{ff}$; D. Murswiek, Umweltschutz - Staatszielbestimmung oder Grundsatznorm, ZRP 1988, S. 14 ff. (17).

157 Zum Diskussionsstand vgl. die Dokumentation zur Anhörung vor dem Rechtsausschuß des Bundestages: Verankerung des Umweltschutzes im Grundgesetz (Zur Sache 88/2), hrsg. v. Deutschen Bundestag, Referat Öffentlichkeitsarbeit, 1988. 
chernde Funktion der Trennung von Staat und Gesellschaft hat hier ihren eigentlichen Probierstein, indem sie einem wohlfahrtsstaatlichen Politikverständnis Schranken setzt, das tendenziell „eine Art von Gesamtverantwortung für die Gesellschaft zu okkupieren "158 trachtet. Dabei geht es nicht nur um Grenzen gegenüber einem „emanzipativen "Sozialstaatsverständnis ${ }^{159}$. Subtiler stellen sich die Probleme bei der sozialstaatlich intendierten Staatsintervention in gesellschaftliche Prozesse.

b) Die Interdependenz der Freiheitlichkeit von politischem und ökonomischem System - von der Freiburger Schule der Ordoliberalen bis Hayek immer wieder betont ${ }^{160}$ - ist uns in den Ereignissen der vergangenen Monate handgreiflich vor Augen geführt worden. Die vom BVerfG zwar apodiktisch behauptete, durch den Hinweis auf Grundrechte aber faktisch relativierte These von der wirtschaftspolitischen Neutralität des GG erscheint als eine vereinfachende Reduk$\operatorname{tion}^{161}$. Sicherlich läßt die Verfassung eine Bandbreite an Regulierungsintensität $z u$. Es erscheint aber in einem auf das „Prinzip Wettbewerb“ (Krüger) gegründeten politischen System nur um den Preis grundrechtlicher Freiheit möglich, die invisible hand des individuellen ökonomischen Interessenausgleichs durch die visible hand des Staates

${ }^{158}$ N. Lubmann, Politische Theorie im Wohlfahrtsstaat, 1981, S. 121.

159 Bezeichnung von Spieker, ZfP 1974, S.331. In diesem Sinne aber bereits W. Abendroth, VVDStRL 12 (1954), S. 85 ff. (Disk.beitr.); ders., Zum Begriff des demokratischen und sozialen Rechtsstaates im Grundgesetz der Bundesrepublik Deutschland, 1954, jetzt in: E. Forsthoff ( $\mathrm{Hg}$.), Rechtsstaatlichkeit und Sozialstaatlichkeit, 1968, S. 114 ff. Ähnlich $H$. Ridder, Die soziale Ordnung des Grundgesetzes, 1975; H.H. Hartwich, Sozialstaatspostulat und gesellschaftlicher Status quo, 3. Aufl. 1978; ders., Die Entwicklung des deutschen Sozialstaats zwischen bürokratischer Instrumentalisierung und demokratischer Zukunftsvorsorge, in: A. Randelzhofer/S. Süß (Hg.), Konsens und Konflikt, 1986, S. 105 ff.

${ }_{160} \mathrm{Vgl}$. F.A. v. Hayek, Der Weg zur Knechtschaft, 1946, bes. S. 98. Für die Ordoliberalen F. Böhm, Die Bedeutung der Wirtschaftsordnung für die politische Verfassung (1946), jetzt in: U.Scheuner (Hg.), Die staatliche Einwirkung auf die Wirtschaft, 1971, S. 85-109, bes. S. 96; A. Müller-Armack, Die zweite Phase der Sozialen Marktwirtschaft (1960), jetzt in: ders., Wirtschaftsordnung und Wirtschaftspolitik, 1966, S.267 ff., bes. S.288; neuerdings Hofmann (s. Anm.44), S. $21 \mathrm{ff}$. (27); vgl. auch Leisner, Demokratie (s. Anm. 79), S. $164 \mathrm{ff}$.

$161 \mathrm{Vgl}$. die grundlegenden Entscheidungen BVerfGE 4, 7; 50, 290. Wenn das BVerfG gelegentlich von „einer grundsätzlich marktwirtschaftlich geordneten Wirtschaft" spricht (BVerfGE 30, 292 [311]; ähnliche Formulierungen in BVerfGE 12,281 [293]; 18, 315 [327]; 32, 311 [317]), handelt es sich weniger um „verwirrende Zwischentöne" (so Bäumler, DÖV 1979, S. 335 ff. [328]) als um deskriptive Aussagen. 
zu ersetzen. Staats und Staatsrechtslehre vermögen hier ebensowenig wie die Nationalökonomie präzise Grenzen zu ziehen. Ein Alternativprogramm wie das des bayerischen Verfassungsentwurfs von 1946: „Die Volkswirtschaft wird nach einem einheitlichen Plan durch die Staatsregierung geleitet" ${ }^{\prime 162}$, wäre indes schwerlich in Kongruenz mit einer grundrechtlichen Wertordnung zu bringen.

c) Das von dem Kathedersozialisten Adolph Wagner aufgestellte Gesetz wachsender Staatsaufgaben ${ }^{163}$ begegnet deshalb nicht nur normativer Skepsis. Auch faktisch ist es durch die Entwicklung allenfalls partiell bestätigt worden: Die Staatsquote hat sich - nach anfänglichem steilen Anstieg - bei etwas unter $50 \%$ eingependelt - freilich auf hohem Niveau ${ }^{164}$. Die Deregulierungsdebatte zeigt in einigen Bereichen praktische Folgen. Wenngleich die Bundesregierung davon ausgeht, daß derzeit nur rund die Hälfte der Wirtschaft in unverfälschtem Wettbewerb steht ${ }^{165}$, sind hier doch vom gemeinsamen Markt deregulierende Impulse zu erwarten. Insgesamt ist die sozialstaatliche Aufgabenerfüllung untrennbar mit dem Wirtschaftlichkeitsgebot verknüpft, dem $v$. Arnim zu Recht verfassungsnormative Qualität zuschreibt ${ }^{166}$. Es erzwingt eine Kosten-Nutzen-Analyse nicht nur unter ökonomischen, sondern auch unter Zweckverwirklichungskriterien. Diese finale Konditionierung der Staatstätigkeit ist Ausdruck der Rationalität des modernen Staates. Der Planungs- und Steuerungsoptimismus der 60er Jahre ist angesichts der beschränkten Interventionserfolge ${ }^{167}$ (etwa im Bereich des Arbeitsmarktes) und der SchwieS. 10.

${ }_{162}$ Art. 113 Abs. 1; Sten. Ber. d. Verf.Aussch. d. bay. verf.geb. Landesvers. I,

${ }_{163}$ Grundlegung der politischen Oekonomie, 3. Aufl., 1. Theil 1892, S. 893 ff. Allg. zur Genese des Interventionsstaats jetzt M. Stolleis, Die Entstehung des Interventionsstaats und das öffentliche Recht, ZNR 11 (1989), S. $129 \mathrm{ff}$.

164 Sie lag 1970 noch bei $39,1 \%$ und erreichte 1982 einen Höchststand von $49,8 \%$. Seither bewegt sie sich zwischen 46 und $47 \%$, vgl. Zahlen zur wirtsch. Entwicklung der Bundesrepublik Deutschland 1989, hrsg. vom Institut d. deutschen Wirtschaft. Krit. zum Maßstab der Staatsquote Chr. Watrin, Staatsaufgaben - die ökonomische Sicht, in: Bitburger Gespräche 1984, S. 41 ff. (45).

${ }_{165}$ K. König, Kritik öffentlicher Aufgaben, 1989, S. 44.

166 H.H. v.Amim, Wirtschaftlichkeit als Rechtsprinzip, 1988, bes. S. $67 \mathrm{ff}$;; s. auch schon dens., VVDStRL 39 (1981), $286 \mathrm{ff}$. (316 ff.).

167 Zur nationalökonomisctren Problematik A.Gutowski, Nach der Enttäuschung: Der Staat auf dem Rückzug, in: R. Vaubel/H.D. Barbier (Hg.), Handbuch der Marktwirtschaft, 1986, S. 284 ff. (285); N. Kloten, Das Stabilisierungsproblem, Konzeption und wirtschaftspolitische Praxis, Jahrestagung d. Vereins $f$. Sozialpolitik 1988, Ref. 3, bes. S. 25. 
rigkeit, die Auswirkungen von punktuellen Eingriffen in hochkomplexe Systeme abzuschätzen ${ }^{168}$, eher einer heilsamen Skepsis gewichen. Mit Lubmann wird man die realistische Chance derartiger Steuerungseingriffe auf Möglichkeiten einer rechtzeitig korrigierenden Intervention zu reduzieren haben, „die gleichwohl nicht beanspruchen kann, das Gesamtgeschehen planmäßig zu kontrollieren und sich auch nicht als Fortschritt zu rechtfertigen " versucht ${ }^{169}$. Eine solche Akzeptanz der Grenzen des Wohlfahrtsstaats vermag nicht nur seine Freiheitlichkeit, sondern auch seinen Bestand zu sichern.

\section{Freiheitsgewährleistung als Staatszweck des Verfassungsstaats}

\section{Der Freibeitszweck als typusprägendes Element des demokratischen Verfassungsstaats}

Die Trias Gemeinwohl, Wohlfahrt, Schutz- und Friedensfunktion bildet - in unterschiedlicher Gewichtung - die Legitimationsbasis des modernen Staates. Differenzierungskriterium zwischen dessen autoritärer und verfassungsstaatlicher Ausprägung - und typusprägend für die letztere - ist allein das Maß der teleologischen Ausrichtung auf die Gewährleistung staatsbürgerlicher, individueller und kollektiver Freiheit. Dabei tritt der Freiheitszweck nicht nur additiv zu den anderen Staatszwecken hinzu, sondern er bestimmt zugleich Grund, Art und Grenzen von deren Realisierung. Davon war bereits mehrfach die Rede.

\section{Die Unterscheidung von Staat und Gesellschaft}

Der Staatszweck Freiheitssicherung setzt voraus, daß das politische System sich nur als Teilsystem des Sozialen versteht, daß es nicht eine potentielle Regelungskompetenz für alle Bereiche personaler Lebensgestaltung beansprucht. Freiheitsgewährleistung im Sinne des Verfassungsstaats westlicher Prägung beruht m. a.W. auf der Unterscheidung von Staat und Gesellschaft und damit auf der Anerkennung eines staatsfreien autonomen Bereichs selbstverantwortlicher Lebensgestaltung ${ }^{170}$. Das GG hat dies in Art. 1 Abs. 2 durch das Bekenntnis zu den

168 Dazu jetzt D. Dörner, Die Logik des Mißlingens, 1989.

169 Lubmann (s. Anm. 158), S. 145.

170 Böckenförde, Verfassungstheoretische Unterscheidung (s. Anm.27), S. 32f.; Herzog, Staatslehre (s. Anm. 87), S. 146; H.H. Klein, Die Grundrechte im demokratischen Staat, 1974, S.47; krit. K. Hesse, Bemerkungen zur heutigen Problema- 
unverletzlichen und unveräußerlichen Menschenrechten als Grundlage der Sozialgemeinschaft zum Ausdruck gebracht.

\section{Das kontraktualistische Modell des status libertatis}

Freiheitsgewährleistung in diesem Sinne verlangt also zunächst die Möglichkeit eines legitimen Rechtsstandpunkts außerhalb des Leviathans und im Gegenüber zu ihm. Hobbes und Roussean hatten dies folgenreich für die Zukunft - auf unterschiedliche Weise durch die Zusammenziehung von Gesellschafts- und Herrschaftsvertrag zu einem Rechtsakt ausgeschlossen, in dem der Bürger seine Rechtsstellung im Augenblick ihrer Entstehung zugleich an den Souverän oder die volonté générale überträgt. Dagegen ermöglichte die bei Grotius, Pufendorf und Locke ausgeformte zweistufige Vertragsgestaltung eine Unterscheidung von unveräußerlicher und abtretbarer, in die libertas civilis zu transformierender Freiheit und legte so die Fundamente einer systematischen Begründung von gegen den Staat bestehenden, seinen Wirkungskreis begrenzenden Rechten ${ }^{171}$. Das Grundgesetz hat die Konsequenzen dieses kontraktualistischen Modells durch die primäre Ausgestaltung der Grundrechte als Abwehrrechte übernommen. Dies schließt eine Verengung auf ein funktionaldemokratisches Verständnis aus, wonach der Kern der Grundrechtsgewährleistung im Ermöglichen eines „freien Prozesses demokratischer Staatshervorbringung " besteht ${ }^{172}$.

\section{Status negativus und "Freiheitsvorsorge"}

a) Bereits die Frage nach dem Staatszweck Freiheitsverwirklichung impliziert indes eine über die Anerkennung subjektiver Abwehrrechte hinausgehende Grundrechtsvorsorge des Verfassungsstaats. Grundrechte als Abwehrrechte markieren ja nur Grenzen, nicht Zwecke des Staates ${ }^{173}$. Auf der Basis von Ansätzen der Weimarer Staatsrechts-

tik und Tragweite der Unterscheidung von Staat und Gesellschaft, DÖV 1975, S. 437 ff. (439f.); P. Saladin, VVDStRL 35 (1977), S. 7 ff. (35f.); ders., Verantwortung (s. Anm. 27), S.157. Noch anders H.Ebmke, "Staat" und "Gesellschaft" als verfassungstheoretisches Problem, in: FS R. Smend, 1962, S. 23 ff. (45).

171 Dazu jetzt R. Saage, Vertragsdenken und Utopie, 1989, S. 62 f.

${ }_{172}$ Ebenso E.W. Böckenförde, Grundrechtstheorie und Grundrechtsinterpretation, NJW 1974, S. 1529 ff. (1534f.); L.H. Michel, Staatszwecke, Staatsziele und Grundrechtsinterpretation, 1986, S. $259 \mathrm{ff}$.

173 Murswiek (s. Anm. 88), S. 105. 
lehre ${ }^{174}$ ist nach 1949 auf mehreren Wegen versucht worden, Grundrechte über diesen „Primäreffekt ${ }^{\text {"175 }}$ hinaus als objektivrechtliche Normen, als "Gemeinwohlaufgaben der res publica" ${ }^{176}$ zu begreifen. Gemeinsam ist allen darauf gerichteten Konzeptionen, daß sie die Grundrechte als objektiv-rechtliche Normierung einer staatlichen Freiheitsvorsorge verstehen ${ }^{177}$. Sie berühren sich mit einer älteren deutschen Verfassungstradition, die die Grundrechtskataloge nicht auf subjektive Freiheitsgewährleistungen reduzierte, sondern diesen die Garantie bestimmter institutionell verfestigter Rahmenbedingungen zur Seite stellte ${ }^{178}$. Man wird sich vor jeder Vereinseitigung derartiger Grundrechtstheorien hüten müssen, indes besteht ein breiter Konsens darüber, daß sie nur unterschiedliche Interpretationstopoi für die Effektuierung der Grundrechte im Hinblick auf wechselnde Gefahrenlagen bilden, daß sie einander nicht ausschließen,

174 Smend, Verfassung (s. Anm. 15), S. $161 \mathrm{ff}$; ders., VVDStRL 4 (1928), S. 44 ff.; G. Leibholz, Begründet der... Grundsatz der Gleichheit... durchsetzbares subjektives Recht (1931), jetzt in: ders., Die Gleichheit vor dem Gesetz, 2. Aufl. 1959, S. $216 \mathrm{ff}$. (230); dazu Stern, Staatsrecht III/1 (s. Anm. 141), S. $491 \mathrm{ff}$.

175 R.Herzog, Grundrechte und Gesellschaftspolitik, in: FS E.Hirsch, 1968, S. $72 \mathrm{ff}$.

176 P. Häberle, VVDStRL 30 (1972), S. 104; ders., AöR 111 (1986), S. 602 f.; ders., Praktische Grundrechtseffektivität, Die Verwaltung 22 (1989), S. 409 ff.

177 BVerfGE 7, 198 (204f.); 33, 301 (330ff.); 35, 79 (114) und die in Anm. 91 genannten Entscheidungen. S. dazu H.D. Jarass, Grundrechte als Wertentscheidungen bzw. objektivrechtliche Prinzipien in der Rechtsprechung des Bundesverfassungsgerichts, AöR 110 (1985), S. $363 \mathrm{ff}$; aus der abundanten Literatur neben Häberle H.H. Rupp, Vom Wandel der Grundrechte, AöR 101 (1976), S. $161 \mathrm{ff}$; Isensee, HdbStR III, $\$ 57$ Rdn. 148; Hesse, HdbVerfR I, S. 95; A.Bleckmann, Staatsrecht II - Die Grundrechte, 3. Aufl. 1989, S.259ff. Überblick über die Entwicklung der objektiven Grundrechtsfunktionen in Literatur und Rechtsprechung bei Stern, Staatsrecht III/1 (s. Anm. 141), S. 894 ff.; neuere Versuche zu einer „Rekonstruktion der klassischen Grundrechtsfunktion“ einer „Freiheit durch Eingriffsabwehr", die auch bisher als objektive Grundrechtsgehalte verstandene Schutzwirkungen einschließt, bei Schlink, EuGRZ 1984, S. 457 ff.; G. Lübbe-Wolff, Die Grundrechte als Eingriffsabwehrrechte, 1988; s.a. Robbers (s. Anm. 88), S. 186 ff.; Murswiek (s. Anm. 88), S. 91 ff., 106 ff.; J. Schwabe, Probleme der Grundrechtsdogmatik, 1977, S. 213 ff.; dens., Die sogenannte „Drittwirkung“ der Grundrechte, 1971 , S. 16 f., $154 \mathrm{ff}$.

${ }_{178} U$. Scheuner, Die institutionellen Garantien des Grundgesetzes (1953), in: ders., Staatstheorie und Staatsrecht (s. Anm.21), S.665 ff. (668f., $672 \mathrm{f}$.); ders., VVDStRL 22 (1965), S. 33 ff.; s. bereits C.Schmitt, Verfassungslehre (1928), 3. Aufl. 1957, S. $170 \mathrm{ff}$; vgl. zu dieser Tradition Stern, Staatsrecht III/1 (s. Anm. 141), S. $756 \mathrm{ff}$. 
sondern ergänzen ${ }^{179}$. In ihrer ordnungspolitischen ${ }^{180}$ Dimension vermögen sie zwar zur Erkenntnis verfassungsgeschützter Werte und Ziele zu verhelfen, nicht aber verfassungstranszendente Wertsysteme zu begründen - ebenso wie die Grundrechte selbst kein geschlossenes System bilden, sondern geronnene Erfahrung typischer historischer Gefährdungslagen ${ }^{181}$. Deshalb wird man objektiv-rechtliche Funktionen der Grundrechte jeweils grundrechtsspezifisch zu bestimmen haben. Dies gilt nicht nur, gilt aber in besonderem Maße für die Ermittlung leistungsrechtlicher Gehalte. Das BVerfG hat hier zu Recht vorgeschobene Frontlinien zurückgenommen ${ }^{182}$.

b) Der alte Graben zwischen Grundrechten und Organisationsrecht, der im klassischen Verständnis nur durch die Institutionen der Rechtsstaatlichkeit überbrückt wurde, ist im Staatszweck Freiheitssicherung weitgehend eingeebnet. Dies geschah freilich um den Preis einer weit vorgetriebenen richterlichen Kognition einerseits und andererseits einer Relativierung der Grundrechte als unmittelbar vom Bürger einzufordernder Gewährleistungen. Die immer wieder erhobene Forderung nach Aufnahme erweiterter sozialer Grundrechte in das GG hätte diesen Prozeß von einzelnen Facetten der Grundrechtswirkungen auf ganze Gewährleistungsbereiche selbst ausgedehnt ${ }^{183}$. $\mathrm{Zu}$ Recht ist dem - jedenfalls auf Bundesebene ${ }^{184}$ etwa bei einem Umweltgrundrecht - widerstanden worden. Der Staatszweck Freiheitsgewährleistung lebt von seinen Effektivitätsgarantien, die sich im Maße einer programmatischen Verflüchtigung zersetzen und unerfüllbare Erwartungen wecken müßten.

\section{5. „Verantwortung als Staatsprinzip“?}

Staatsbürgerliche Freiheit ist nicht nur "Freiheit zu“, sie bleibt aber eingebunden in den sozialen Bezugsrahmen. Die Kantsche Bestim-

179 F. Ossenbübl, Die Interpretation der Grundrechte in der Rechtsprechung des BVerfG, NJW 1976, S.2100 ff. (2105); Rupp, AöR 101 (1976), S. $161 \mathrm{ff}$; ähnlich auch R.Alexy, Theorie der Grundrechte, 1986, S.28ff.; W.Brugger, Elemente verfassungsliberaler Grundrechtstheorie, JZ 1987, S. 633 ff.; krit. Böckenförde, NJW 1974, $1529 \mathrm{ff}$. (1536).

180 Michel (s. Anm. 172), S. 220.

181 U. Scheuner, VVDStRL 22 (1965), S. 42 ff.

$182 \mathrm{Vgl}$. BVerfGE 75, 40 (61 ff.) gegenüber BVerfGE 33, 303 (330); dazu s. Ch. Link, Staatliche Subventionierung konfessioneller Privatschulen, in: FS W. Geiger, 1989, S. $604 \mathrm{ff}$.

183 Vgl. auch Bethge, DVBI. 1989, S. 841 ff. (847f.).

184 Vgl. aber Art. 141 BV. 
mung des objektiven Rechts als „Inbegriff der Bedingungen, unter denen die Willkür des einen mit der Willkür des anderen nach einem allgemeinen Gesetz der Freiheit zusammen bestehen kann" 185 , ist auch dem freiheitssichernden Verfassungsstaat aufgegeben. Die globalen Bedrohungen menschlicher Existenz durch die Zerstörung der natürlichen Lebensgrundlagen haben zu Versuchen geführt, Freiheit unter dem Primat der Verantwortung als Staatsprinzip neu zu definieren und die grundrechtlichen Gewährleistungen auf ein gefährdungsneutrales Niveau zu reduzieren ${ }^{186}$. Eine solche Konzeption, die grundrechtliche Freiheit entsprechend einer alten deutschen Tradition ${ }^{187} \mathrm{im}$ wesentlichen auf die Freiheit des Glaubens, des Denkens und der Feder beschränkt ${ }^{188}$, muß sich indes auf ihre Prämisse befragen lassen, ob nämlich ein die Handlungs- und Wirtschaftsfreiheit absorbierender Staat wirklich eher die Gewähr bietet, die zur Bekämpfung dieser Gefahren nötigen Ressourcen zu produzieren und die hierfür erforderlichen Innovationspotentiale freizusetzen. Die Erfahrung mit real existierenden autoritären Staatstypen erweist eher das Gegenteil. Die Chance des freiheitlichen Staates, die ihm zur Verfügung stehenden Lenkungsinstrumente zu einer wirksamen Problemlösung einzusetzen, scheint mir ungleich größer zu sein, als selbst die einer aufgeklärten Diktatur, von der sich etwa Rudolf Babro Rettung erhofft ${ }^{189}$.

Der in den Grundrechten positivierte Freiheitsgewährleistungszweck legt den Verfassungsstaat zwar nicht auf ein konkretes politisches Modell fest, aber er schließt doch bestimmte Staats- und Gesellschaftsbilder aus und verpflichtet das staatliche Handeln unwiderruflich auf das Leitmotiv der Freiheit, in dem - wie die Erfahrung zeigt - nicht unberechtigten Vertrauen, daß eine freiheitliche Ordnung am ehesten in der Lage ist, flexibel und kreativ auf Krisen und Bedrohungen zu reagieren.

185 Metaphysische Anfangsgründe der Rechtslehre (= Metaphysik der Sitten I, 1797), Einleitung in die Rechtslehre, in: Werke (s. Anm. 96), VI, S. 230.

186 Saladin, Verantwortung (s. Anm.27), S. 82 ff.; ders., Wachstumsbegrenzung (s. Anm. 27), S. $550 \mathrm{ff}$.

187 Vgl. Link, Herrschaftsordnung (s. Anm. 2), S. 145.

188 Saladin, Verantwortung (s.Anm.27), S. 160; ders., Wachstumsbegrenzung (s. Anm. 27), S. 559.

${ }_{189}$ Logik der Rettung, 1987, S. 478 f., 491 ff. u. passim; vgl. auch R. L. Heilbroner, Die Zukunft der Menschheit, 1976, S. 78 f., $100 \mathrm{f}$. 


\section{Staatszwecke und Verfassung}

\section{Staatszwecklebre und Allgemeine Staatslebre}

Jede Staatszwecklehre sieht sich notwendig mit der Frage nach ihrer konkreten Relevanz konfrontiert. Sie stellt sich zunächst auf der staatstheoretischen Ebene - und das heißt im Bereich der Allgemeinen Staatslehre als deskriptiver, allenfalls appellativer, nicht aber normativer Disziplin ${ }^{190}$. Nach der hier vertretenen Auffassung bilden die behandelten Staatszwecke unaufgebbare Kernfunktionen des modernen Verfassungsstaats. Sie sind insofern typusprägend für eine durch gemeinsame Merkmale bestimmte Gestaltungsform der politischen Ordnung. Andererseits bezeichnen sie keinen numerus clausus der Staatsaufgaben. Sie lassen die "General- und Blankovollmacht" (Krüger $)^{191}$ unberührt, kraft derer sich der Staat zur Bewältigung konkreter Aufgaben weitere, historisch variable Ziele zu setzen vermag. Insofern vermag eine Staatszwecklehre nur klarzustellen, daß sich die Verfolgung solcher Ziele in den Rahmen jener Kernfunktionen einzufügen hat, daß sich ihre Realisierungsmodalitäten nicht dazu in Widerspruch setzen können, wenn sie nicht typusverändernd wirken wollen.

\section{Staatszwecklebre und Staatsrechtslehre}

Schwieriger zu beantworten ist die Frage nach den staatsrechtlichen Konsequenzen einer solchen Aussage. Ich teile insoweit nicht die Ansicht von Häberle, daß der Verfassungsstaat keine Anleihen beim Staat der Allgemeinen Staatslehre zu machen habe ${ }^{192}$. Das Grundgesetz legt den von ihm konstituierten Staat auf eben jenen Typus des freiheitlichen, friedenssichernden, schutzgewährenden, der sozialen Solidarität und letztlich einem nicht ideologisch vorgeprägten Gemeinwohl verpflichteten Gemeinwesens fest, formt ihn aber in spezifischer Weise aus und realisiert so den Idealtypus in einer bestimmten historischen und geopolitischen Situation. Verfassungsinterpretation hat ihr Substrat in dieser normativen Konkretisierung, und nur dies ist wohl mit dem genannten Diktum gemeint. Die typusprägenden Kernfunktionen der Verfassungsstaatlichkeit haben durchweg, wenn auch in sehr verschiedener Gestalt, ihre Verankerung im positiven Verfassungsrecht gefunden. Insofern geht es nicht

190 Vgl. nur Zippelius, Staatslehre (s. Anm. 2), S. 1 ff. m. w. N.

191 Staatslehre (s. Anm. 6), S. 760 f.; ihm folgend Herzog, Staatslehre (s. Anm. 87),

S. 148; Isensee, HdbStR III, $\$ 57$ Rdn. 156.

192 AöR 111 (1986), S. 595 ff. (600). 
darum, metakonstitutionelle Postulate in Verfassungsrang zu erheben. Eine Staatszwecklehre vermag nicht mehr, aber auch nicht weniger zu leisten, als auf der mittleren Reflexionsebene der Staatsziele Konstanten von Variablen zu unterscheiden, etwa im Geltungszeitraum des GG das Wiedervereinigungsgebot als durch den Freiheitsgewährleistungszweck begrenzt zu erkennen. Elementare Staatszwecke bezeichnen Prioritätsstufen (Saladin) ${ }^{193}$, Primäraufgaben (Stern) $)^{194}$, faktische und geistige Notwendigkeiten (Eichenberger) ${ }^{195}$. Als solche binden sie im Maße ihrer verfassungsrechtlichen Positivierung den Gesetzgeber ${ }^{196}$ und können als Abwägungs- und Auslegungshilfe Wirkungen auch im exekutivischen und judiziellen Bereich entfalten ${ }^{197}$. In ihrer konstitutionellen Ausformung sind sie mehr als nur ein „Theorieangebot" (Häberle) ${ }^{198}$, sondern teilen mit den Staatszielbestimmungen die Funktion als Richtungsvorgabe der Staatstätigkeit. Konkurrenzprobleme sind wie bei anderen Verfassungswerten im Wege optimierenden Ausgleichs zu lösen.

Auch hier gilt, daß die konstitutionell positivierten Staatszwecke der souveränen Aufgabenkompetenz-Kompetenz des Staates, d. h. der demokratischen Gestaltungsfreiheit, nur dort Schranken setzen, wo verfassungsrechtlich festgeschriebene Kernfunktionen der Staatlichkeit beeinträchtigt werden. In ihrer Ausgestaltung unterliegen sie dem demokratischen Proze $\beta^{199}$. Nur so kann sichergestellt werden, daß Staatszwecke nicht zum Trojanischen Pferd einer Gruppenmoral wer$\operatorname{den}^{200}$.

193 Verantwortung (s. Anm. 27), S. 119, v. a. 153 ff.; vgl. auch dens., Verfassungsreform und Verfassungsverständnis, AöR 104 (1979), S. 345 ff. (384 ff.).

194 Bitburger Gespräche 1984, S. 16. Krit. Häberle, AöR 111 (1986), S. 600 f.

195 Staat (s. Anm. 49), S. 103.

196 Stern, Staatsrecht I (s. Anm.7), S. 85, 122 m.w. N.; II, 1980, S.609; Th. Maunz / R. Zippelius, Deutsches Staatsrecht, 27. Aufl. 1988, S. 39 f.; Bericht der Sachverständigenkommission (s. Anm. 80), Rdn. 35 u. ö.

197 Bericht der Sachverständigenkommission (s. Anm. 80), Rdn. 7, 40, vgl. auch Rdn. 162f.; Maunz/Zippelius, Staatsrecht (s. Anm. 196), S. 97 f., vgl. auch S. 144; Lerche, AöR 90 (1965), S. 341 ff. (363).

198 AöR 111 (1986), S. 605.

199 Scheuner, Staatszielbestimmungen (s. Anm.21), S. 236 f.; Badura (s. Anm. 47), S. 194.

200 Ähnlich $M$. Heckel zum verwandten Problem der Grundpflichten, VVDStRL 41 (1983), S. 113 (Disk.beitr.). 


\section{Staatszwecklebre als Staatslegitimation}

Staatszwecke haben damit teil an der Programmfixierung durch die Verfassung. Ihr besonderer Rang liegt in der Legitimationsfunktion einer Herrschaftsordnung, als die sich auch der demokratische Verfassungsstaat darstellt. Die Dialektik von Zweckerfüllung und Gehorsamsanspruch erscheint mir als der eigentliche Grund dafür, daß sich die Staatszweckfrage entgegen Anschütz' Einspruch nicht von der Tagesordnung der Staatsrechtslehre absetzen läßt. 
Leitsätze des Berichterstatters über:

\section{Staatszwecke im Verfassungsstaat \\ - nach 40 Jahren Grundgesetz}

I.

1. Staatszwecklehren seben sich prinzipiell einem empirischen und einem normativen Einwand ausgesetzt. Sie laufen danach Gefabr, Allgemeingültigkeit für "den" Staat und seine Funktionen zu beanspruchen und dabei deren historische, politische, ökonomische und geographische Variabilität zu überseben. Ein realer Erkenntniswert komme allenfalls der Systematisierung derjenigen Zwecke $z u$, die sich ein bestimmtes Gemeinwesen in einer konkreten bistorischen Situation aktuell setzt, mithin den "relativen" Staatszwecken. Ins Normative gewendet bedeutet dies, daß Leitlinien des Staatshandelns nicht aus metajuristischen, überzeitlich-philosophisch begründeten Teleologien hergeleitet werden können, sondern allein aus den normativen Vorgaben, die sich die souveräne Staatsgewalt selbst gibt. Im Verfassungsstaat ist hierfür der demokratische pouvoir constituant berufen.

2. Die älteren Staatszwecklehren hatten unter diesem Lebrtopos eine materielle Verfassung entworfen, die im Rabmen des "Jus publicum universale" - kritisch oder affirmativ - eine naturrecbtliche Verbindlichkeit beanspruchte. Demgegenüber gründete der aufkommende Positivismus Staatszwecke auf die souveräne Gestaltungsmacht des Staates und verband sie zugleich zum Anspruch potentieller Totalität. Eine "Allseitigkeit der Zwecke" erschien als Widerspruch in sich (Laband). Dabei ist es auch trotz vereinzelter Neuansätze in Weimar geblieben. Dem lag die selbstverständliche Voraussetzung des wohlgeordneten Rechtsstaats zugrunde, der von seiner Abgrenzungskompetenz zwischen staatlicher und gesellschaftlicher Sphäre keinen prinzipiell freibeitsfeindlichen Gebrauch macht. Erst die Erfahrungen mit den totalitären Weltanschauungsdiktaturen haben die im Staatszweckproblem enthaltene Legitimationsfrage politischer Herrschaft neu gestellt. 
3. Die in solchen Erfabrungen wurzelnde Diskreditierung traditioneller Staatlichkeit bat in der Bundesrepublik lange nachgewirkt. Sie begünstigte einen Verfassungspositivismus, der in der Rechtsordnung eine scheinbar entpolitisierte Integrationsbasis fand. Dariiber geriet der durch sie konstituierte Staat als "wirkende Einheit des politischen Geschehens" weithin aus dem Blick. Dementsprechend sind auch die früber im Zusammenhang der Staatszwecke behandelten Materien in die Verfassungsinterpretation, namentlich in die Grundrechts- und Staatszieldogmatik abgewandert.

4. Die neuerdings vielfach als Desiderat reklamierte Wiederbelebung der Staatszwecklehre impliziert es, Ordnung und von ihr Geordnetes, Verfassung und Staat, in ihrer dialektischen Beziebung zu sehen. Das Grundgesetz setzt ein Staatsbild voraus, in dem allein die Frage nach Staatszwecken sinnvoll gestellt werden kann: Der Staat ist nicht Selbstzweck, sondern steht im Dienste seiner Bürger. Der Verfassungsstaat knüpft insofern an die Traditionen der kontraktualistischen Staatslehre an.

5. Terminologisch benennen "Staatszwecke" die legitimierenden und limitierenden Konstanten des modernen Staates allgemein und des demokratischen Verfassungsstaats im besonderen, d.h. die typusprägenden Kernfunktionen: Gemeinwoblbindung, Friedenssicherung nach innen und außen, Schutzpflicht, Woblfabrt (im weitesten Sinn) unter Gewährleistung individueller wie korporativer Freibeit. Sie konkretisieren sich auf einer mittleren Reflexionsebene in den Statszielen, obne diese auf einen numerus clausus festzulegen. Demgegenüber bezeichnen Staatsaufgaben die Modalitäten der Staatszielverwirklichung. Eine weitere Kategorie bilden die Verfassungsaufträge, die in unterschiedlicher Bestimmtheit inhaltliche Vorgaben zur Annäberung an Staatsziele enthalten. Staatszwecke, Staatsziele, Staatsaufgaben und Verfassungsaufträge determinieren das Staatshandeln mitbin auf unterschiedlichen Konkretisierungsstufen.

\section{II.}

6. Allgemeinstes Telos der Staatlichkeit und Richtpunkt aller anderen Staatszwecke ist das Gemeinwobl. Die Säkularisierung des Gemeinwoblbegriffs konstituiert den modernen freibeitlichen Staat als religiös und weltanschaulich neutrales Gemeinwesen, als Friedensordnung zunächst über den streitenden Konfessionen, dann über den kontroversen Ideologien. Sie schließt das Wabrheitsmonopol einer Staatspartei ebenso aus wie die Erbebung weltanschaulicher Mebrbeitspositionen zur volonté générale. 
7. Der Gemeinwoblbezug der Staatstätigkeit findet seine Sicherung in der Neutralität rechtsstaatlicher Institutionen, vor allem aber in der Pflichtenstellung des öffentlichen Amtes. Gefabren droben ihm von Versuchen, Institution und Amt zur Beute von Parteien und anderen Gruppen zu machen, Partikularinteressen mit dem Gemeinwobl zu identifizieren.

8. Die Verdiesseitigung des Gemeinwoblbegriffs orientiert sich an einem Menschenbild, das den Menschen in seiner realen Befindlichkeit ernst nimmt. Sie schließt eine Staatsform aus, die zu ibrem Funktionieren erst den "neuen Menschen" benötigt. Bezugspunkt aller staatlichen Tätigkeit ist deshalb das Wohl der konkreten Bürgergemeinschaft. Dem widersprechen säkulare Eschatologien, in denen der Gegenwart ein Eigenwert nur als Durchgangsstufe zu künftigen Paradiesen zukommt. Das Gemeinwobl bildet deshalb - unbeschadet der auch dem Verfassungsstaat aufgegebenen Zukunftsverantwortung - eine in der Realität der Gegenwart zu verwirklichende Aufgabe, nicht einen transitorischen Wert im Kontext irdischer Heilserwartungen.

9. Im Rabmen dieser Determinanten ist die Gemeinwoblverwirklichung kompetentiell dem demokratischen Prozeß aufgegeben. Bindungen können sich nicht aus einem metakonstitutionellen Subsidiaritätsprinzip ergeben. Rationalität und Freibeitlichkeit der Subsidiarität begrïnden aber eine Leitbildfunktion, die sich imperativ im Einzelfall indes nur kraft konkreter Verfassungsdirektiven durchzusetzen vermag.

III.

10. Schutzpflicht des Staates und Schutzanspruch des Bürgers für die Rechtsgüter Leben, körperliche Unversehrtheit, Freibeit und Eigentum bilden den Kern der mit der modernen Staatlichkeit unabdingbar verbundenen Friedens- und Sicherbeitsgewäbrleistung. Traditionell bildet ibre Erfüllung die Legitimationsgrundlage des staatlichen Anspruchs auf Loyalität und Rechtsgehorsam. Seine Verwirklichung findet der Friedens- und Sicherbeitszweck in der Schaffung einer interessenabgrenzenden Rechtsordnung, in deren Durchsetzung unter Beschränkung der Privatgewalt auf den Ausnabmefall (Gewaltmonopol) und in der Vorbaltung der bierfür erforderlichen Institutionen.

11. Das verfassungsstaatliche Gewaltmonopol legitimiert sich aus seiner strikten Rechtsbindung. In der Anerkennung gesellschaftlicher „Gegengewalt" leben ältere ständestaatliche Denkmuster wieder auf, aus deren Überwindung der moderne Staat hervorgegangen ist. 
Gleichwohl sind Akzeptanzdefizite des Gewaltmonopols deutlich gewachsen. Ihnen korrespondieren wachsende Sicherbeitsdefizite, die auch auf der richterlichen Überdehnung der Anforderungen an eine wirksame staatliche Reaktion im präventiven und repressiven Bereich beruhen. Die Berufung auf "zivilen Ungehorsam" hat kalkulierten Gesetzesbruch in den Rang einer Bürgertugend erboben. Die quantitative Überforderung des Rechtsstaats durch massenbafte Inanspruchnabme der Gerichte und dadurch bedingte überlange Verfabrensdauer gefäbrdet darüber binaus einen effektiven Recbtsschutz.

12. Faktische Geltungssicherbeit der Rechtsordnung wird indes nicht primär durch Sanktionen, sondern durch überwiegende Gesetzesakzeptanz begründet. Sie ist - nicht zuletzt gefördert durch staatlichen leichtbändigen Umgang mit dem demokratischen Gesetz - in weiten Bereichen des alltäglichen Gemeinschaftslebens im Schwinden begriffen. Gefordert erscheint deshalb auf der Basis des Art. 7 Abs. 1 GG eher eine Friedens- als eine Konfliktserziebung, die Vermittlung von Voraussetzungen und Überlebensbedingungen des demokratischen Rechtsstaats als Gemeinschaftsaufgabe.

\section{IV.}

13. Das Sozialstaatsprinzip bat die alte Schutz- und Vorsorgepflicht des Staates für die Grundlagen menschenwürdigen Lebens zum Staatsziel erboben. Das "Glückseligkeits"-Postulat berubte auf der Einsicht in die Vorläufigkeit politischer Ordnungen und verpflichtete den Staat auf zeitliche Woblfabrt der konkreten Untertanengemeinschaft. Auch dem gemäßigten Liberalismus des 19. Jabrbunderts ging es nicht um eine Eliminierung, sondern um eine rechtsstaatliche Einbindung des Woblfabrtszwecks. In dieser Tradition stellt das Grundgesetz die Aufgabe, die Statik des bürgerlichen Rechtsstaats mit der sozialstaatlichen Dynamik in Einklang zu bringen. Das hierin notwendigerweise beschlossene Konfliktpotential kann nicht durch die Begründung eines Rangverhältnisses zwischen beiden Gewäbrleistungen entschärft werden.

14. Der sozialstaatliche Entwicklungsprozeß, der begrifflich sein Ziel nie erreichen kann, hat Loyalitätsbindungen nur in beschränktem Umfang $z u$ verstärken vermocht. Steigende Erwartungshaltungen gerieten spätestens bei Wachstumsstagnation in Konflikt mit der ökonomischen Realität. Versuche, Besitzstände über ein soziales Rückschrittsverbot konstitutionell $z u$ verfestigen, baben zwar nur geringe 
Resonanz gefunden. Indes zeigt die Schwierigkeit, verbandsmäßig verteidigte Positionen anzutasten, da $\beta$ der progressiven sozialstaatlichen Dynamik ein regressiver Immobilismus korrespondiert. Gleichwobl bat der Sozialstaat durch die soziale Abfederung der Massenarbeitslosigkeit deren Umschlagen in eine politische Krise vermieden und damit - nach der Eingliederung der Vertriebenen - seine zweite Bewährungsprobe bestanden.

15. In neuerer Zeit ist mehr als bisher ins Bewußtsein getreten, daß auch der Sozialstaat als "System in der Zeit" existiert. Die Probleme der intertemporalen Verteilungsgerechtigkeit haben sich vor allem in den Bereichen der Staatsverschuldung, der Rentenfinanzierung und des Umweltschutzes gestellt. Schlüssige Lösungskonzepte zeigen sich bisher nur in Ansätzen. Die Zukunftsdimension des Sozialstaats bildet die ernsteste Herausforderung der Woblfabrtsstaatlichkeit.

16. Der historischen Gefabr des Woblfabrtsstaates, einem obrigkeitlich-bürokratischen Beglückungsoptimismus, ist das Grundgesetz durch die rechtsstaatliche und grundrechtliche Domestizierung begegnet. Das verfassungsstaatliche Sozialstaatsprinzip ist deshalb allein mit einer freiheitlichen Ordnung kompatibel. Dies zieht einem wohlfahrtsstaatlich intendierten Politikverständnis Grenzen, das tendenziell eine Gesamtverantwortung für die Gesellschaft okkupiert. Die Interdependenz von Freibeitlichkeit des politischen und des ökonomischen Systems relativiert die These von der wirtschaftspolitischen Neutralität des Grundgesetzes. Damit sind der sozialstaatlich motivierten Wirtschaftsintervention durch Übermaßverbot und Wirtschaftlichkeitsprinzip auch dort Scbranken gezogen, wo das grundrechtliche Schutzsystem versagt. Die beschränkten Interventionserfolge (etwa im Bereich des Arbeitsmarktes) zeigen zudem die Schwierigkeit, die Auswirkungen punktueller Eingriffe in hocbkomplexe Systeme zuverlässig abzuschätzen.

V.

17. Freibeitsgewäbrleistung als Staatszweck prägt den Typus des demokratischen Verfassungsstaats. Sie tritt nicht nur additiv zu den anderen Staatszwecken hinzu, sondern bestimmt Grund, Modalität und Grenzen von deren Realisierung. Sie setzt einen legitimen Rechtsstandpunkt außerhalb des Leviathan voraus und damit die Unterscheidung von Staat und Gesellschaft. Die primäre Abwebrfunktion der Grundrecbte bildet daber das Fundament einer freibeitlichen Staatsgestaltung. 
18. Eine „ordnungspolitische" Funktion der Grundrechte kann diesen Primäreffekt nur ergänzen, nicht aber verdrängen. Sie knüpft an besondere deutsche Verfassungstraditionen an. Gleichwobl vermag sie nicht, verfassungstranszendente Wertsysteme zu begründen. Vielmebr sind derartige objektive und institutionelle Gehalte grundrechtsspezifisch zu ermitteln. Dies gilt in besonderem Maße für die leistungsrechtliche Dimension der Grundrechte.

19. Die Begrenzung grundrechtlicher Freiheit durch ibren sozialen Bezugsrabmen legitimiert nicht ibre Unterordnung unter die „Verantwortung als Staatsprinzip". Auch angesichts globaler Bedrobungen ist es dem freibeitssichernden Verfassungsstaat verwehrt, die libertas civilis im wesentlichen auf die Freibeit des Glaubens, des Denkens und der Feder zu beschränken. Dies bedeutet nicht, verfassungsrechtliche Schutzwälle um den Egoismus zu zieben. Vielmebr erscheint eine freibeitlich verfaßte Sozialgemeinschaft am ehesten in der Lage, die zur Gefahrenminimierung benötigten Ressourcen zu produzieren und das erforderliche Innovationspotential freizusetzen.

\section{$V I$.}

20. Die Frage nach der Relevanz einer Staatszwecklebre stellt sich zunächst auf der staatstbeoretischen Ebene. Hier vermag sie den Typus des freibeitlichen Verfassungsstaats von anderen Formen politischer Ordnung abzugrenzen und ihm schärfere Konturen zu geben. Sie läßt die demokratische Souveränität unberührt, kraft deren sich ein Staat weitere, historisch variable Ziele setzt. Sie kann insoweit nur deskriptive Aussagen über die Kongruenz derartiger Zielsetzungen und ibrer Realisierungsmodalitäten mit den typusprägenden Kernfunktionen machen.

21. Normative Verbindlicbkeit kommt Staatszwecken nur nach Maßgabe ibrer verfassungsrechtlichen Positivierung zu. In diesem Rahmen vermögen sie Prioritätsstufen zu kennzeichnen und bieten Abrägungs- und Auslegungshilfen. Insoweit teilen sie mit den Staatszielbestimmungen die Funktion der Richtungsvorgabe, aber auch die Konkretisierungsbedürftigkeit im demokratischen Prozeß. Ihre besondere Bedeutung liegt indes in der Legitimationsfunktion für den Herrschafts- und Rechtsgehorsamsanspruch des freiheitlichen Verfassungsstaats. 


\section{Staatszwecke im Verfassungsstaat \\ - nach 40 Jahren Grundgesetz}

2. Bericht von Prof. Dr. Dr. Georg Ress, Saarbrücken

Inhalt

I. Vorbemerkung: das Gründungsverstand

I. Vorbemerkung: das Gründungsverständnis $\ldots \ldots \ldots \quad 57$

II. Staatsbegriffe und Staatszwecke $\ldots \ldots \ldots \ldots \ldots \ldots 61$

III. Staatszwecke im Verfassungsstaat $\ldots \ldots \ldots \ldots \ldots \ldots 67$

IV. Internationalisierung und Europäisierung von Staatszwecken ....................... 79

V. Der Staatszweck „Sicherheit“ ............. 83

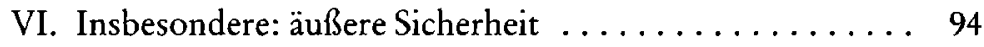

VII. Zum Staatszweck „Freiheit" . . . . . . . . . . . . 98

VIII. Sozialstaatsziel . . . . . . . . . . . . . . . . 101

IX. Integrationszweck . . . . . . . . . . . . . . 107

X. Konkretisierung und Konkurrenz . . . . . . . . . . 108 


\section{Vorbemerkung: das Gründungsverständnis}

1. Der Staatszweck ${ }^{1}$ der Bundesrepublik Deutschland wird maßgeblich durch ihr Gründungsverständnis ${ }^{2}$ bestimmt: nach den Erfahrungen der nationalsozialistischen Diktatur ${ }^{3}$ eine freiheirliche, rechtsstaatliche und demokratische Ordnung zu errichten, in deren Mitte der Mensch mit seiner Würde und seinen Rechten steht. Der ethische Grund, auf dem sich der pouvoir constituant gestellt sieht, wird mit dem Eingangssatz der Präambel des Grundgesetzes von der Verantwortung vor Gott und den Menschen appellativ angesprochen ${ }^{4}$. Auch 40 Jahre nach Erlaß des Grundgesetzes ist die Übergangszeit, die erst nach Vollendung der Einheit und Freiheit Deutschlands in freier Selbstbestimmung ihren Abschluß findet, nicht beendet ${ }^{5}$, ebensowenig wie das mit dem im GG selbst nicht aufgenommenen Begriff „Wiedervereinigung“ nur unvollkommen skizzierte Staatsziel ${ }^{6}$ er-

${ }^{1}$ Dem "Staatszweck" als eigener Kategorie des Staatsverständnisses ist seit dem 19. Jahrhundert und den zusammenfassenden Arbeiten von Hespe (Hespe, Klaus: Zur Entwicklung der Staatszwecklehre in der deutschen Staatsrechtswissenschaft des 19. Jahrhunderts, 1964) und Hug (Hug, Hans: Die Theorien vom Staatszweck, Diss. Zürich 1954) kaum Aufmerksamkeit gewidmet worden. Die Diskussion wurde erst durch K. Stern (Stern, Klaus: Das Staatsrecht der Bundesrepublik Deutschland, Bd.III/1, 1988, S.100ff.), Ch.Link (Link, Christian: Herrschaftsordnung und bürgerliche Freiheit, 1979, S. $144 \mathrm{ff}$.), L. Michel (Michel, Lutz H.: Staatszwecke, Staatsziele und Grundrechtsinterpretation unter besonderer Berücksichtigung der Positivierung des Umweltschutzes im Grundgesetz, 1986), $K$. Waechter (Waechter, Kay: Polizeigebühren und Staatszwecke, 1988) und die Begleitaufsätze zur Tagung (Bethge, Herbert: Staatszwecke im Verfassungsstaat 40 Jahre Grundgesetz -, DVBI. 1989, S. 841 ff.; Brugger, Winfried: Staatszwecke im Verfassungsstaat, NJW 1989, S. $2425 \mathrm{ff}$; Bull, Hans Peter: Staatszwecke im Verfassungsstaat, NVwZ 1989, S. $801 \mathrm{ff}$.) aufgegriffen.

2 Bethge, Herbert, a. a.O. (Anm.1), S.841.

${ }^{3}$ Grawert, Rolf: Die nationalsozialistische Herrschaft, in: Isensee, Josef/ Kirchhof, Paul (Hg.): Handbuch des Staatsrechts, Bd. I, 1987, $\$ 4$ Rdn. $15 \mathrm{ff}$.

+ Der in diesem Satz verborgene Zielcharakter wird mit Recht von Starck, Christian, in: v. Mangoldt / Klein/Starck, GG, Präambel, Rdn. 26 betont.

${ }^{5}$ Art. 146 GG kann für diesen Abschluß nicht als einzige Möglichkeit angesehen werden. Denn es ist auch ein Beitritt nach Art. 23 GG möglich; vgl. Klein, Eckart: An der Schwelle zur Wiedervereinigung Deutschlands, NJW 1990, S. $1065 \mathrm{ff}$;; Rauschning, Dietrich: Deutschlands aktuelle Verfassungslage, DVBl. 105 (1990), S. 393 ff. (399ff.).

- Der Staatszielcharakter ist eindeutig: vgl. Klein, Eckart: Die Staatsräson der Bundesrepublik Deutschland, in: Staat und Völkerrechtsordnung. Festschrift für Karl Doehring, 1989, S. 459 ff. (472); Klein, Hans H.: „... die Einheit und Freiheit Deutschlands zu vollenden " - Geltung und Bestand des Wiedervereinigungsgebo- 
reicht ist. Der Staat, dessen Zwecke es zu betrachten gilt, ist das unter dem Namen Bundesrepublik Deutschland auf einem territorialen Teilbereich neu verfaßte, aber fortbestehende Staatswesen, das nach wie vor mit den anderen Teilen Deutschlands, die sich in einem fortgeschrittenen Sezessionsproze ${ }^{7}$ befinden und die wie die DDR ebenfalls Staatlichkeit erlangt haben, nicht nur in völkerrechtlichen, sondern auch noch in staatsrechtlichen Bindungen steht ${ }^{8}$. Die Staatlichkeit ist noch immer überlagert von Vier-Mächte-Rechten und -Verantwortlichkeiten und deren inhaltlichen Zwecken ${ }^{9}$. Durch Art. 7 des Deutschlandvertrages ist die besatzungsrechtliche Zwecksetzung vertraglich eingebunden in die Ziele einer frei vereinbarten friedensvertraglichen Regelung mit endgültiger Grenzregelung und „ein wiedervereinigtes Deutschland, das eine freiheitlich-demokratische Verfassung ähnlich wie die Bundesrepublik Deutschland besitzt und das in die Europäische Gemeinschaft integriert ist“. Die Qualität eines fundamentalen Staatszielprogramms für die Bundesrepublik Deutsch-

tes, in: Verantwortlichkeit und Freiheit. Festschrift für Willi Geiger, 1989, S. $132 \mathrm{ff}$. (133, 142); Murswiek, Dietrich: Das Staatsziel der Einheit Deutschlands - nach 40 Jahren Grundgesetz, Reihe Themen der Carl Friedrich von Siemens Stiftung, 1989; Rauschning, Dietrich: Wiedervereinigungsgebot - Willensbildungsfunktion und Kontrollfunktion, in: Staat und Völkerrechtsordnung. Festschrift für Karl Doehring, 1989, S. 779 ff. (797); Ress, Georg: Grundlagen und Entwicklung der innerdeutschen Beziehungen, in: Isensee, Josef/Kirchhof, Paul ( $\mathrm{Hg}$.$) : Handbuch des$ Staatsrechts, Bd. I, 1987, \$11 Rdn. $55 \mathrm{f}$.

7 So bezüglich der DDR auch der Teso-Beschluß des BVerfG (E 77, 137 [151]); zum Fortbestand vgl. Ress, a.a.O. (Anm.6), Rdn. 47 f.; ders.: Die Rechtslage Deutschlands nach dem Grundlagenvertrag vom 21. Dezember 1972, 1978, S. 199 ff.; zum Teso-Beschluß vgl. z. B. Rauschning, a.a.O. (Anm.6); Tomuschat, Christian: Staatsvolk ohne Staat? in: Staat und Völkerrechtsordnung. Festschrift für Karl Doehring, 1989, S. 985 ff.; von Mangoldt, Hans: Praktische Fragen zur Einheit der deutschen Staatsangehörigkeit nach dem Teso-Beschluß des Bundesverfassungsgerichts, Politik und Kultur 16 (1989) H.3, S. 36 ff.

8 Von einer Gemengelage geht nunmehr offenkundig auch Bernhardt aus (vgl. Bernbardt, Rudolf: Die deutsche Teilung und der Status Gesamtdeutschlands, in: Isensee, Josef / Kirchhof, Paul [Hg.]: Handbuch des Staatsrechts, Bd. I, 1987, $\$ 8$, Rdn. 24, 32 ff. m. w. N.).

9 Diese Zwecke gehen auf die "supreme authority“ in der Berliner Erklärung vom 5. Juni 1945 zurück. Sie sind später auf die ungenaue Formel „Friedensvertrag, Wiedervereinigung, Berlin und Deutschland als Ganzes" reduziert worden; vgl. dazu die Formulierung in Art. 2 des Deutschland-Vertrages; noch ungenauer die Vier-Mächte-Erklärung in der UNO (siehe dazu Zündorf, Benno: Die Ostverträge, 1979, S. 287 ff.). Zum Zusammenhang mit den Feindstaatenklauseln (Art. 53 u. 107 UN-Charta; siehe Ress, Georg: Art. 107 UN-Charta, Rdn. 3 ff., in: Simma, Bruno (Hg.): Charta der Vereinten Nationen. Kommentar, 1990. 
land, das in seiner rechtlichen Qualifikation über rein völkerrechtliche Vertragsbestimmungen hinausreicht, ergibt sich aus zwei Erwägungen. Die Beschränkung der internationalen Handlungsfähigkeit ${ }^{10}$ der Bundesrepublik Deutschland in bezug auf bestimmte äußere Aspekte der Wiedervereinigung und die friedensvertragliche Regelung (oder ein entsprechendes "Substrat") - von Berlin ganz abgesehen - ist für sie rechtlich nur durch die gleichzeitige Einbindung nach Art. 7 des Deutschlandsvertrages 40 Jahre nach Inkrafttreten des Grundgesetzes hinnehmbar. Die Bundesrepublik hat den Fortbestand der vorbehaltenen Rechtspositionen hingenommen und sich für die Dauer des Vertrages des Arguments begeben, daß die Ausübung derartiger besatzungsrechtlicher Rechtspositionen 40 Jahre nach Inkrafttreten des Grundgesetzes völkerrechtlich nicht mehr haltbar sei" ${ }^{11}$. So gesehen ist Art. 7 eine notwendige rechtliche Folgerung aus der in der Präambel enthaltenen Verpflichtung, auf das Ende der Übergangszeit hinzuwirken ${ }^{12}$. Der Gründungszweck ist sowohl auf die völkerrechtliche Selbstbestimmung als auch auf die staatliche Einheitsvollendung ausgerichtet. Dabei begrenzt die völkerrechtliche Selbstbestimmung, wenn sie stattfindet, die staatliche Einheitsvollendung, mit anderen Worten, eine Wiedervereinigung gegen den frei geäußerten Willen der Deutschen in der DDR wäre nicht zulässig ${ }^{13}$. Eine Bindung der verfaßten Gewalten an den historischen Willen des pouvoir constitu-

10 Dazu Ress, a.a. O. (Anm.6), Rdn. 8.

$"$ Zum sui-generis-Charakter des Besatzungsregimes vgl. Ress, Rechtslage, a. a. O. (Anm. 7), S.27ff.

${ }_{12}$ Das mit dem Begriff Wiedervereinigungsgebot nur unvollkommen skizzierte Staatsziel ist weder faktisch noch rechtlich obsolet geworden (so aber Rottmann, Joachim: Über das Obsolet-Werden von Verfassungsnormen, in: Festschrift für Wolfgang Zeidler, Bd.2, 1987, S. $1097 \mathrm{ff}$. (1106f.); dagegen zu Recht Klein, Hans H., a.a.O. (Anm.6), S. 134 ff.). Faktisch deshalb nicht, weil die Umstände, die die Wiedervereinigung, oder anders gesagt: die Selbstbestimmung der Deutschen ohne alliierte Intergerenz objektiv unmöglich machen würden, angesichts der Unberechenbarkeit der historischen Entwicklung nicht nachweisbar sind; rechtlich deshalb nicht, weil es von den Normadressaten in zahlreichen Schritten zur Aufrechterhaltung des Trägers des Selbstbestimmungsrechts der deutschen Nation verfolgt wurde.

${ }_{13}$ Vgl. Doebring, Karl: Das Selbstbestimmungsrecht der Völker als Grundsatz des Völkerrechts (Bericht der Deutschen Gesellschaft für Völkerrecht, H.14), 1974 , S. $40 \mathrm{ff}$. Ob man davon sprechen kann, daß der provisorische Zweck die Legitimität des Grundgesetzes begrenzt (so Murswiek, Dietrich: Die verfassungsgebende Gewalt nach dem Grundgesetz für die Bundesrepublik Deutschland, 1978, S. 76), ist zweifelhaft, weil die Legitimität des Grundgesetzes sich auf nicht mehr als dieses Grundgesetz bezieht. 
ant, den sie nicht nachträglich ändern dürfen, kommt im Begriff des Deutschen Volkes nach Art. 20 Abs. 2 GG zum Ausdruck ${ }^{14}$, der eine Separierung der Staatsangehörigkeiten und die Aufgabe der einen deutschen Staatsangehörigkeit nicht zuläßt, solange von einer endgültigen Dismembration des Deutschen Reiches (oder einer endgültigen Sezession der DDR) nicht gesprochen werden kann. Alliierte Staatszwecksetzung im Rahmen fortbestehender besatzungsrechtlicher Befugnisse ist so wenigstens teilweise vertraglich eingebunden und mit der Präambel auch verfassungsrechtlich verknüpft. Die Zwecke des dem Grundgesetz zugrundeliegenden Staates weisen aufgrund dieser Zusammenhänge über das Gründungsstatut hinaus ${ }^{15}$. Bezeichnenderweise hat das Grundgesetz von der besatzungsrechtlichen Lage 1949 überhaupt keine Kenntnis genommen.

Nicht minder deutlich tritt für die Bundesrepublik die in der Präambel enthaltene Aufforderung, als gleichberechtigtes Glied in einem vereinten Europa dem Frieden der Welt zu dienen, als mit der Gründung angelegtes Staatsziel parallel hinzu ${ }^{16}$. Daneben lassen sich Staatszielbestimmungen wie das gesamtwirtschaftliche Gleichgewicht für die Wirtschaftsordnung ${ }^{17}$, das Ziel eines Sozialstaats ${ }^{18}$ und außenpolitische Staatsziele ${ }^{19}$ erkennen. Von den drei klassischen Staatszwecken ${ }^{20}$

14 Vgl. Ress, a.a. O. (Anm. 6), Rdn. 102.

15 In diesem Sinne auch Bethge (ders., a. a. O. [Anm. 1], S. 843).

16 Zum Verhältnis zum Wiedervereinigungsgebot siehe Bücking, H.H.: Wiedervereinigung Deutschlands und die Einigung Westeuropas - im Widerspruch?, in: Hacker, Jens / Mampel, Siegfried (Hg.): Europäische Integration und deutsche Frage, 1989, S. 65 ff.; Doehring, Karl: Die Wiedervereinigung Deutschlands und die europäische Integration als Inhalte der Präambel des Grundgesetzes, DVBI. 94 (1979). S. $633 \mathrm{ff}$.

17 Zu Art. 109 Abs. 2 GG vgl. BVerfG NJW 1989, 2457 (2458 ff.); Stern, Klaus: Das Staatsrecht der Bundesrepublik Deutschland, Bd. II, 1980, S. 1078 ff.; über den inneren Zusammenhang dieser Zielbestimmung mit der Sozialstaatsklausel vgl. Ipsen, Hans Peter: Gebundene Sozialstaatlichkeit, in: Festschrift für Konrad Zweigert, 1981, S. 747 ff. (755).

18 Vgl. dazu BVerfGE 22, 180 (204); Badura, Peter: Der Sozialstaat, DÖV 1989, S. $491 \mathrm{ff}$.

${ }_{19} \mathrm{Zu}$ erwähnen sind das Verbot des Angriffskrieges und die Aufgabe der Friedenssicherung als Ausformungen der Friedenspflicht (Präambel S. 1, Art. 1 Abs. 2, Art. 24 Abs. 2, Art. 26 Abs. 1 GG). Gleiches gilt für die Staatszielbestimmung der Kulturstaatlichkeit (BVerfGE 35, 79 [114]; 36, 321 [331]); vgl. hierzu z. B. Badura, Peter: Staatsrecht, 1986, S. 202.

${ }^{20} \mathrm{Vgl}$. hierzu Isensee, Josef: Das Grundrecht auf Sicherheit, 1983, S. 17; Starck, a. a. O. (Anm. 4), Rdn. 22 f.; Stern, Klaus: Staatsziele und Staatsaufgaben in verfassungsrechtlicher Sicht, in: Bitburger Gespräche. Jahrbuch 1984, S. 5 ff. (6). 
der Sicherheit, der Freiheit und der sozialen Wohlfahrt finden nur die beiden letzteren in den Grundrechten und im Sozialstaatsziel ausdrückliche Regelung. Der Staatszweck der Gewährleistung des inneren Friedens - samt Gewaltmonopol - läßt sich aus einzelnen Normen des Grundgesetzes in einer Gesamtschau ermitteln ${ }^{21}$.

Demgegenüber verfügen andere moderne Verfassungen wie die Spaniens und Portugals über Verfassungskataloge, in denen Zwecke, Ziele und Aufgaben umschrieben werden, die der moderne demokratische Verfassungsstaat sich stellt oder deren Besorgung von ihm erwartet wird. Eine rechtsvergleichende Betrachtung der Verfassungen der Mitgliedstaaten des Europarats zeigt, daß hier eine allgemein bemerkenswerte Tendenz $\mathrm{z}^{22}$ zu einer normativen Anreicherung der Verfassung um inhaltliche Ziele und Aufgaben sichtbar wird ${ }^{23}$.

\section{Staatsbegriffe und Staatszwecke}

2. Staatszwecke gehören zum Staat. Sie sind keine Gesellschaftszwecke und - jedenfalls auf den ersten Blick und in sprachlicher Sonderung - auch keine Verfassungszwecke. Das Thema zielt auf

${ }_{21}$ Vgl. die Kompetenzvorschriften über Strafrecht, Strafvollzug (Art. 74 Nr. 1), über Kriminalpolizei und Verfassungsschutz (Art. $73 \mathrm{Nr} .10$ ) sowie Art. 8 Abs. 1 GG, der gewährleistet, sich „friedlich“ und ohne Waffen zu versammeln; siehe dazu Götz, Volkmar: Innere Sicherheit, in: Isensee, Josef / Kirchhof, Paul (Hg.): Handbuch des Staatsrechts, Bd. III, 1988, $\$ 79$, Rdn. 3 ff.; Starck, a. a.O. (Anm. 4), Rdn. 22.

22 Diese Tendenz ist bisher in der Bundesrepublik nach der Arbeit der Sachverständigenkommission Staatszielbestimmungen/Gesetzgebungsaufträge (Der Bundesminister des Innern/Der Bundesminister der Justiz [Hg.]: Staatszielbestimmungen - Gesetzgebungsaufträge. Bericht der Sachverständigenkommission, 1983) nicht aufgegriffen worden.

${ }_{23}$ Dazu gehören neben den hergebrachten (vgl. z. B. Häberle, Peter: „Wirtschaft" als Thema neuerer verfassungsstaatlicher Verfassungen, Jura 1987, S. $577 \mathrm{ff}$.) insbesondere solche, die sich neuen Herausforderungen zuwenden, wie Naturschutz, Erhaltung natürlicher Ressourcen, sogar "der Lebensqualität des Volkes“ und natürlich Schutz und Förderung der Kultur. Ob dem Typus des demokratischen Verfassungsstaates, wie er in der Präambel der Europäischen Menschenrechtskonvention anhand materieller Kriterien qualifiziert wird - Zacher hat ihn treffend durch seine Offenheit gegenüber der Abgeschlossenheit und inhaltlichen Determiniertheit der sozialistischen Staaten umschrieben (VVDStRL 36 [1978], S. $134 \mathrm{f}$.) -, mit derartigen inhaltlichen Zielbestimmungen und sogar Gesetzesaufträgen ein Dienst erwiesen worden ist, wird sich erst nach Jahren - und nicht anhand eines bloßen Textvergleichs - beantworten lassen. 
den Staat in - oder hinter - der Verfassung. Die Staatszwecke des modernen Staates als für dessen Entstehen konstitutive Faktoren können auch im heutigen Verfassungsstaat begrenzenden, Gewährleistungspflichten auslösenden, ermächtigenden und Legitimation verleihenden Charakter haben ${ }^{24}$. Der Staat hat Sicherheit zu gewährleisten, Freiheit zu achten und ein Mindestmaß an sozialer Wohlfahrt anzustreben.

Staatszwecke, Staatsziele und Staatsaufgaben stehen in Zusammenhang, sind aber zu unterscheiden. Der Staatszweck fragt nach der Finalität des Staates, nach seinem "Wozu“ und dem einzelner staatlicher Funktionen, aber auch nach dem Umfang und damit nach der Begrenzung des Staates. Von den sonstigen in der Verfassung enthaltenen Staatszielen unterscheiden sich diese Staatszwecke durch ihre Herkunft als typische Normalausstattung des modernen Staates. Das Staatsziel kann einen einzelnen Aspekt aus den Staatszwecken besonders hervorheben oder eingrenzen oder eine der Verfassung eigentümliche Direktive hinzufügen, wie z. B. das Wiedervereinigungsgebot. Die Staatsaufgabe, wenn sie sich relativ konkret z. B. in dem Gesetzgebungsauftrag nach Art. 7 Abs. 5 GG zeigt (Gleichstellung der unehelichen Kinder), kann ein Mittel sein, um einem abstrakteren Staatsziel (Sozialstaatlichkeit/Gleichheit) näherzukommen ${ }^{25}$.

${ }^{24}$ Hinter diesen Alternativen stehen unterschiedliche Kategorien. Die Ermächtigung geht davon aus, daß dem Staat von vornherein nur beschränkte Aufgaben zur Verfügung stehen; wo sich solche nicht feststellen lassen, herrscht Freiheit (vgl. eine solche Betrachtung bei Stern, Klaus, a.a.O. [Anm.20], S. 7 f., 16ff.). Die Begrenzungstheorie sieht Staatszwecke als Grenzen des omnipotenten Staates, dem auf diese Weise bestimmte Aufgaben/Funktionen beschnitten werden, der im übrigen aber kompetent bleibt (vgl. Böckenförde, Ernst-Wolfgang: Die verfassungstheoretische Unterscheidung von Staat und Gesellschaft als Bedingung der individuellen Freiheit, 1973, S.17f.). Zur Gewährleistungsfunktion siehe Murswiek, Dietrich: Die staatliche Verantwortung für die Risiken der Technik, 1985, S. $102 \mathrm{ff}$.). Zur Legitimationsfunktion vgl. Isensee, Josef: Gemeinwohl und Staatsaufgaben im Verfassungsstaat, in: ders./Kirchhof, Paul (Hg.): Handbuch des Staatsrechts, Bd. III, 1988, $\$ 57$ Rdn. 116; vgl. auch Scheuner, Ulrich: Staatszielbestimmungen, in: Festschrift für Ernst Forsthoff, 2. Aufl. 1974, S. 340 ff.; Böckenförde, Ernst-Wolfgang: Der Staat als sittlicher Staat, 1978, S. 19: „Diese Zwecke stellen keine Zutat dar, die auch entfallen könnte, sie machen das geistige Prinzip des Staates aus, begründen seine Vernünftigkeit und seinen Charakter als allgemeines Wesen."

${ }^{25}$ Vgl. zur Terminologie z. B. Isensee, Josef, a. a.O. (Anm. 24) Rdn. $115 \mathrm{ff}$; Stern, a. a. O. (Anm.20), S.18, 20. Die Abgrenzung ist weniger gelungen bei Bull, Hans Peter: Die Staatsaufgaben nach dem Grundgesetz, 2. Aufl. 1977, S. $43 \mathrm{ff}$. m.w. N. 
3. Staatszwecke sind ihrem Ideengehalt nach eine Frucht der vernunftrechtlichen Staatstheorie. Einen einheitlichen Vorstellungsgehalt der Staatszwecke, die historisch gesehen die vielfältigsten Rechtfertigungsgründe und rationalen Begrenzungen des Staates abgeben, gibt es ebensowenig wie nur einen einzigen Begriff des Staates oder des Zwecks ${ }^{26}$. Immer aber steht vor der Entscheidung über die Art des Staates die über das Wesen des Menschen ${ }^{27}$. Soll er zu einer bestimmten Vollendung der Tugend, der Gerechtigkeit, zu einer neuen geistigen Existenz durch den Staat gelangen ${ }^{28}$ Oder geht es um das Machbare, die mehr oder weniger stabile Ordnung der Egoismen und Antagonismen?29 Die daran anknüpfenden Staatskonzeptionen werden je nachdem, für wie gut oder böse der Mensch aus theologischer Einsicht oder empirischer Beobachtung gehalten wird, mehr oder weniger Herrschaft für erforderlich halten ${ }^{30}$. Die vernunftrechtliche Staatsrechtslehre seit Hobbes ${ }^{31}$ und Locke ${ }^{32}$ hat diese empirischinduktiven Annäherungen in vielfältigen Variationen entfaltet und normativ-deduktiv überhöht. Die Staatszwecke waren keine beliebigen Spekulationen, sondern notwendige Entstehungselemente des modernen Staates ${ }^{33}$. In ihrem vernunftrechtlichen Gehalt sollten sie für den Bürger vornehmlich Sicherheit (inneren und äußeren Frieden)

26 Der Staatszweck kann abstrakt staatstheoretisch, aber auch teleologischnormativ oder aber - wie in der marxistischen Staatstheorie im Rahmen einer angeblich naturwissenschaftlich eschatologischen Zukunftsvision - teleologischkausal gedeutet werden (zur Unterscheidung vgl. Eisler, Rudolf: Der Zweck, 1914, S. 66).

27 Vgl. Herzog, Roman: Allgemeine Staatslehre, 1971, S. 108.

${ }^{28}$ So in den Jellinekschen Kategorien die ethische Theorie der Staatsrechtfertigung, wie sie zuerst Plato entwickelte; vgl. Jellinek, Georg: Allgemeine Staatslehre, 1922, S. $218 \mathrm{f}$.

${ }^{29}$ So in den Jellinekschen Kategorien die sogenannte Vertragstheorie der Staatsrechtfertigung, vgl. a. a. O., S. $201 \mathrm{ff}$.

30 Vgl. Haberle, Peter: Das Menschenbild im Verfassungsstaat, 1988, S. $36 \mathrm{ff}$; Kirchbof, Paul: Mittel staatlichen Handelns, in: Isensee, Josef/Kirchhof, Paul (Hg.).: Handbuch des Staatsrechts, Bd. III, 1988, $\$ 59$, Rdn. 5.

${ }_{31}$ Vgl. insbesondere „De Cive“ (1647) und "Leviathan or the Matter, Forme and Power of a Commonwealth Ecclesiasticall and Civil" (1651) sowie z. B. Warrender, H.: The Political Philosophy of Hobbes, 1957; Goldsmith, M. M.: Hobbes' Science of Politics, 1966.

32 Vgl. "Two Treatises of Government" (1690) sowie z.B. Euchner, Walter: Naturrecht und Politik bei John Locke, 1969; Gough,J. W.: John Locke's Political Philosophy, 2. Aufl. 1950.

33 So hat Gottfried Wilhelm Leibniz - der genius loci des Tagungsortes Hannover - den Akt der Staatsgründung wie Thomasius, Pufendorf und Hobbes 
und Freiheit verbürgen sowie je nach Ausprägung Kultur und soziale Wohlfahrt ermöglichen ${ }^{34}$. Der Staat wird nicht als Naturereignis, nicht als eine $z$ wangsläufige oder vorübergehende $Z$ wischenstufe im Prozeß der technischen Realisation, sondern als eine rationale Zweckschöpfung betrachtet, womit auch der Vorgang der Staatsgründung und -bewahrung individualitätsbezogen gedeutet wird ${ }^{35}$. Der rationalistischen Staatszweckbetrachtung liegt die Anerkennung und Achtung des Individuums als vernunftgesteuertes, selbstverantwortliches Wesen zugrunde. Diese Konzeption des begrenzten Staates begünstigte im 19. Jahrhundert die Entwicklung der bürgerlichen Gesellschaft $^{36}$. Mit der Vorstellung des Staates als Selbstzweck im 19. Jh. tritt nicht nur die instrumentale Staatsauffassung in den Hintergrund ${ }^{37}$,

nicht auf irgendeinen Sozialinstinkt zurückgeführt, sondern läßt den Staat seine Entstehung dem vernunftgesteuerten, also rationalen Konsens seiner Gründer verdanken (vgl. Schiedermair, Hartmut: Das Phänomen der Macht und die Idee des Rechts bei Gottfried Wilhelm Leibniz, 1970, S. $11 \mathrm{ff}$; $116 \mathrm{ff}$.).

${ }^{34}$ Der moderne Staat konstituiert sich als Friedens-, Entscheidungs- und Machteinheit zusammen mit diesen vernunftrechtlichen Vorstellungen über die Staatszwecke, welche die einheitliche Staatsgewalt (die innere Souveränität) gleichzeitig binden und begrenzen sollen (vgl. Böckenförde, Ernst-Wolfgang: Der Staat als sittlicher Staat, 1978, S. 12 ff.). Sie geben Umfang und Reichweite des Staatlichen an, jenseits dessen dem einzelnen eine spezifische Staatsfreiheit verbleibt. In ihrem limitativ-finalen Charakter sollen sie gleichzeitig die sich herausbildende einheitliche Herrschaft über den Menschen rechtfertigen. Wenn Haverkate aus der Aufnahme des Sozialstaatsprinzips in die Verfassung auf die Aufhebung der Zwecklimitierung i.S. der Beschränkung möglicher legitimer Zwecke des Staatshandelns schließt (vgl. Haverkate, Görg: Rechtsfragen des Leistungsstaates, 1983, S. 59, 116), dann vermengt er nicht bloß Staatszweck-bezogene und Zweck-Mittelbezogene Betrachtungen, sondern übersieht auch die Beschränkung, die der Wohlfahrtszweck durch die übrigen Staatszwecke im Konfliktfall erfährt.

${ }^{35}$ Deutlich Böckenförde, Ernst-Wolfgang, a.a.O. (Anm. 34), S. $19 \mathrm{ff}$. (21) mit der an Hegel (G. W. F. Hegel: Grundlinien der Philosophie des Rechts [Ausgabe Glockner], Stuttgart 1952, $\$ 260$ mit Zusatz S. 338) anknüpfenden Bemerkung, daß das Wesen des Staates darin liege, daß „das Allgemeine von den Individuen nicht getrennt, sondern verbunden ist mit der vollen Freiheit und Besonderheit der Individuen"; zur technischen Realisation und der zwangsläufigen Umbildung des Staates vgl. allgemein Stollberg-Rilinger, Barbara: Der Staat als Maschine, 1986, S. $101 \mathrm{ff}$.

${ }^{36} \mathrm{Vgl}$. Böckenförde, Ernst-Wolfgang: Die verfassungstheoretische Unterscheidung von Staat und Gesellschaft als Bedingung der individuellen Freiheit, 1973, S. $17 \mathrm{f}$; Isensee, Josef: Staat und Verfassung, in: ders./Kirchhof, Paul (Hg.): Handbuch des Staatsrechts, Bd. 1, 1987, \$13, Rdn. 50 f.; Rupp, Hans Heinrich: Die Unterscheidung von Staat und Gesellschaft, in: a. a. O., $\$ 28, R d n .3$.

37 Scharfer Kritiker der instrumentalen Staatsauffassung ist Herbert Krüger (Allgemeine Staatslehre, 2. Aufl. 1966, S. 196). 
sondern es geht die Anknüpfung an den rationalen Vorgang der Staatsbildung und Staatsrechtfertigung verloren. Die Staatszweckbetrachtung erschöpft sich in der Klassifikation von Staatsaufgaben als notwendige und akzidentielle ${ }^{38}$. Für den Positivismus kann das Recht beliebigen Inhalt und daher auch der Staat beliebige Zwecke haben ${ }^{39}$. Für Kelsen ${ }^{40}$ fällt die Frage, welche Zwecke mit dem sozialtechnischen Mittel ,Staat ${ }^{`}$ verfolgt werden sollen, als politisch außerhalb des Bereichs der allgemeinen Staatslehre. Sie postuliert nicht, daß der Staat keinen Zweck habe, sondern nur, daß sie nach seinem Zweck nicht mehr frage. Der Staat erscheint als konkrete staatliche $Z_{\text {wangsord- }}$ nung, als ein in sich geschlossenes logisch-autarkes System, das keiner weiteren Begründung oder Rechtfertigung durch ein außerhalb der Ordnung liegendes Moment bedürftig ist. Dabei wird nicht nur der Zweck im Recht übersehen, sondern auch, daß der moderne Verfassungsstaat auf den Voraussetzungen der Staatlichkeit beruht, welche die Verfassung aufnehmen und gestalten, aber ihrerseits - von hier nicht interessierenden Ausnahmen abgesehen - nicht schaffen $k^{k a n n} n^{41}$. Für die völkerrechtliche Betrachtung der Staaten als Völkerrechtssubjekte ist es selbstverständlich, daß Verfassungen kommen und gehen, die Staaten aber in ihrer Staatlichkeit fortbestehen ${ }^{42}$.

\footnotetext{
${ }^{38} \mathrm{Vgl}$. Hespe, a. a. O. (Anm. 1), S.26; Jellinek, a. a. O. (Anm. 28), S. $249 \mathrm{ff}$.

39 Nachweise und Kritik zu dieser Position bei Böckenförde, Ernst-Wolfgang: Gesetz und gesetzgebende Gewalt, 2. Aufl. 1981, S. $211 \mathrm{ff}$.

to Vgl. Kelsen, Hans: Allgemeine Staatslehre, 1925, S. 39. Bei Kelsen führt der Verzicht auf diese Frage im Rekursus zur hypothetischen Grundnorm, die keinen Staatszweck und keine Staatsrechtfertigung vermittelt. Hinter der Grundnorm, die kein Bestandteil des geltenden Rechts ist, kann aber ein „zweckbestimmtes, sollensgerichtetes effektives Wollen (stehen), das dem höchsten rechtlichen Sollen der Verfassung Geltung verleiht" (Winkler, Günther: Rechtstheorie und Rechtserkenntnis, 1990, S. 107). „Wer den Schleier hebt und sein Auge nicht schließt“ - so sagte Kelsen auf der Staatsrechtslehrertagung 1926 - „dem starrt das Gorgonenhaupt der Macht entgegen" (VVDStRL 3 [1927], S. 55).

${ }^{+1}$ Vgl. Isensee, Josef/Kirchbof, Paul: Vorwort, in: dies. (Hg.): Handbuch des Staatsrechts, Bd. I, 1987, S. VII; Isensee, Josef, a. a. O. (Anm. 36), Rdn. 24, 40. Auch Kelsen räumt in seiner "Reinen Rechtslehre“ (2. Aufl., S. 289f.) ein, daß allein das Bestehen einer Rechtsordnung für einen Staat noch nicht konstitutiv ist, vielmehr Voraussetzung für dessen Existenz die von der traditionellen Staatslehre geforderten drei Elemente Staatsvolk, Staatsgebiet und Staatsgewalt sind; vgl. dazu Ermacora, Felix: Staat als Rechtsordnung, in: Beiträge zum Verfassungs- und Wirtschaftsrecht. Festschrift für Günther Winkler, 1989, S. 3 ff. (8f.).

\$2 Im modernen westeuropäischen Verfassungsstaat treffen die beiden geistigen Entstehungslinien des modernen Staates - zum einen die vernunftrechtliche Lehre vom Gesellschafts- und Herrschaftsvertrag und zum anderen die englischen, liber-
} 
4. Zur Antwort auf das mit der Frage nach den Staatszwecken verbundene Legitimationsproblem bietet das Grundgesetz durch das Bekenntnis zu unverletzlichen und unveräußerlichen Menschenrechten „als Grundlage jeder menschlichen Gemeinschaft" (Art. 1 Abs. 2 GG) und durch die Anerkennung der Freiheit und Selbstentfaltung des einzelnen eine Antwort ${ }^{43}$. Mit dieser der Verfassung vorausliegenden Idee der Freiheit des Menschen ist auch die mit dem - wie Kant sagt - „natürlichen Rechte der Menschen zusammenstimmende Konstitution (verbunden), daß nämlich die dem Gesetz Gehorchenden auch zugleich, vereinigt, gesetzgebend tätig sein sollen " ${ }^{* 44}$. Menschenund freiheitsrechtliche und demokratische Legitimation fügen sich zusammen. Auch zur Rechtfertigung des modernen demokratischen Staates bietet sich der Rückgriff auf die mit der Idee der Freiheit des Menschen verbundene freiwillige Unterwerfung unter die selbstgewählte Herrschaft unter Verzicht auf Privatgewalt $a^{45}$. Der Staat

ties' und die nordamerikanische vorstaatliche Menschenrechtskonzeption, auf der aufbauend die Lehre vom just government bzw. government as trust entwickelt wurde - zusammen (vgl. dazu Brugger, Winfried: Grundrechte und Verfassungsgerichtsbarkeit in den Vereinigten Staaten von Amerika, 1987, S.408ff. und Steinberger, Helmut: Konzeption und Grenzen freiheitlicher Demokratie, 1974, $42 \mathrm{ff}$., $62 \mathrm{ff}$.). Auf der einen Seite steht die in der Verfassung verankerte rechtsstaatliche, durch das demokratisch zustande gekommene Gesetz begrenzte, durch Gewaltenteilung gebändigte Herrschaft, die durch das staatliche Gewaltmonopol inneren und äußeren Frieden sichert, auf der anderen Seite der durch die Staatszwecke in spezifischer Weise als vorstaatlich belassene Wirkungsbereich des Menschen und Bürgers, der durch die Anerkennung der Menschen- und Grundrechte strukturiert wird. Die Subjektivierung erreicht mit diesen gegen den Staat gerichteten Rechten ihren vorläufigen Abschluß, die Staatszweckbetrachtung tritt in ihrer Funktion der Sicherung eines vorstaatlichen Freiheitsraums zurück, die Staatszwecke werden in den Menschen- und Grundrechten „aufgehoben“ - ein Vorgang, der die Frage provoziert, ob damit eine Staatszweckbetrachtung überflüssig wird.

${ }^{43}$ Vgl. Böckenförde, Ernst-Wolfgang, a. a. O. (Anm. 43), S. 19 f.; Maibofer, Werner: Die Legitimation des Staates aus der Funktion des Rechts, ARSP Beiheft 15, 1981, S. $15 \mathrm{ff}$. (21); zur daneben bestehenden demokratischen Legitimation vgl. Scheuner, Ulrich: Die Legitimationsgrundlage des modernen Staates, ibidem, S. $1 \mathrm{ff}$.

${ }^{44}$ Kant, Immanuel: Streit der Fakultäten, A 155, 156, in: Werke (hrsg. v. W.Weischedel), 1966, Bd.6, S.364; vgl. auch Steinberger, Helmut, a.a.O. (Anm. 42), S. 256 Fn. 1047.

${ }_{45}$ Dieser vertragstheoretische Ansatz darf nicht mit einem realen Vertrag verwechselt werden; der Ansatz verweist vielmehr auf die konsensuale Basis der Staatsgewalt, und dem Konsensgedanken korrespondiert die „apriorische Idee der Freiheit (im Sinne der Selbstbestimmung des Einzelnen)"; Steinberger, Helmut, a. a. O. (Anm. 42), S. 262 Fn. 1060. 
schuldet im Verfassungsstaat dafür Sicherung des äußeren und inneren Friedens, Gewährleistung der Menschenwürde und der Grundfreiheiten. Zwischen dem Rechtsgehorsam und dem staatlichen Schutz besteht ein unauflöslicher Zusammenhang ${ }^{46}$. Der Satz „subiectio trahit protectionem " gehört seit dem berühmten Calvin-Case ${ }^{47}$ aus dem Jahr 1608 nicht nur zum ungeschriebenen Bestandteil des britischen Verfassungsrechts, sondern zum Grundbestand des modernen Staates. Er hat in zahlreichen Staaten zur Begründung von Ansprüchen (subjektiven Rechten) gegen den Staat gedient. Doebring ${ }^{48}$ hält dieses Grundverbältnis aufgrund rechtsvergleichender Untersuchungen für ein principe général des nations civilisées. Dieses Prinzip ist nicht nur ein Satz der Staatstheorie, sondern des der Verfassung vorausliegenden, aber von ihr aufgegriffenen und in bezug genommenen Staatsrechts und dabei Strukturelement des modernen Staates ${ }^{49}$.

\section{Staatszwecke im Verfassungsstaat}

5. Dem demokratischen Verfassungsstaat westeuropäischer Prägung, wie er der Europäischen Menschenrechtskonvention und den Mitgliedsvoraussetzungen der EG zugrundeliegt, eignen alle notwendigen Elemente des modernen Staates. Der Schutz der Menschenwürde, des inneren und äußeren Friedens sowie der Selbstschutz des Staates sind notwendige, aber für den modernen Staat nicht mehr hinreichende Staatszwecke. Für den Typus des modernen demokratischen Staates ist außerdem charakteristisch, daß er die Grund- und Menschenrechte sowie ein Mindestmaß an sozialer Sicherheit und an geistig-sittlicher Integration seiner Bürger gewährleisten soll. Er

t6 Isensee, Josef, a.a.O. (Anm.20), S. 18 ff.; Murswiek, Dietrich, a. a.O. (Anm. 24), S. 102 ff. m. w. N.

${ }^{7}$ Calvin's Case, 7 Co Rep. 1 a (5a); vgl. hierzu z. B. Holdsworth, Sir William: A History of English Law, Vo. IX, 3. Aufl. Reprint 1966, S. 81 ff.; Halsbury's Laws of England, 4. Aufl. Vo.8, 1974, S. 569, Rdn.861 Fn. 1.

+8 Doebring, Karl: Die Pflicht des Staates zur Gewährung diplomatischen Schutzes, 1959, S. 89.

+9 Vgl. Murswiek, Dietrich, a. a. O. (Anm. 24), S. 103; Isensee, Josef, a. a. O. (Anm.24), Rdn. $41 \mathrm{f}$; in den frühen amerikanischen Verfassungen tritt es uns noch ganz unvermittelt entgegen: vgl. die Formulierung in Art. III der Verfassung von New Hampshire v. 31.10.1783: "When men enter into a state of society, they surrender up some of their natural rights to that society, in order to insure the protection of others; and without such an equivalent, the surrender is void." 
beruht zwar wie alle Staaten auf geistigen Voraussetzungen, die er selbst insgesamt nicht schaffen kann ${ }^{50}$. Er darf aber in seinen Institutionen jenen Geist und jenes gemeinsame Erbe an geistigen Gütern pflegen, von deren Aufrechterhaltung die Präambel der Menschenrechtskonvention ausgeht ${ }^{51}$.

6. Im demokratischen Verfassungsstaat spricht eine Vermutung dafür, daß die Verfassung das Staatsbild abschließend fixiert hat und eine Erweiterung der verfassungsrechtlichen Legalität daher nur durch Rückgriff auf zweifelsfreie Elemente moderner Staatlichkeit möglich ist $^{52}$. Die formale Verfassung kennt in den Begriffen des demokratischen und sozialen Rechtsstaats und der Menschen- und Grundrechte aber genügend über sie selbst hinausführende Bezugnahmen auf materiale Werte ${ }^{53}$. Das BVerfG läßt in seinem Rekurs auf „die Sicherheit des Staates als verfaßter Friedens- und Ordnungsmacht und die von ihm zu gewährleistende Sicherheit... (als) ... Verfassungswerte, ... (von denen) ... die Institution Staat die eigentliche und letzte Rechtfertigung herleitet ${ }^{* 54}$, das beschriebene Grundverhältnis aufleuchten, auch wenn es die eigentliche Zwischenstufe, die von der Staatsrechtfertigung über die Staatszwecke zu den Verfassungszwecken führt, überspringt. In dem dargelegten Grundverhältnis hat der Staatszweck "Sicherheit" in all seinen modernen Ausfächerungen seine Wurzel. Ansonsten ist Vorsicht bei Bezugnahmen über den Verfassungstext auf den dahinterliegenden Staat geboten, da politische Selbstverständlichkeiten an den Randzonen alles andere als selbstverständlich zu sein pflegen. Deshalb kann verfassungsabhängige Staatsraison nicht zum Gegenspieler des Rechts werden ${ }^{55}$.

so Vgl. Böckenförde, Ernst-Wolfgang: Die Entstehung des Staates als Vorgang der Säkularisation, in: ders.: Staat, Gesellschaft, Freiheit, 1976, S. 42 ff. (60f.).

51 Zum Problem siehe Burmeister, Joachim: Praktische Jurisprudenz und rechtsethischer Konsens in der Gesellschaft, in: Verfassungsrecht und Völkerrecht. Gedächtnisschrift für Wilhelm Karl Geck, 1989, S. 97 ff. (110 ff.).

52 Mit leicht anderer Nuancierung Isensee, Josef, a. a. O. (Anm. 36), Rdn. 174.

53 Von Arnim spricht von der "mitschwingenden Ideenwelı", die das Grundgesetz geprägt hat (von Arnim, Hans Herbert: Staatslehre der Bundesrepublik Deutschland, 1984, S.11); vgl. ferner Benda, Ernst: Der soziale Rechtsstaat, in: ders. et al. (Hg.): Handbuch des Verfassungsrechts, 1983, S. 477 ff. (478ff.); Stern, Klaus, a. a. O. (Anm. 1), S. 221.

54 BVerfGE 46, 24 (56 f.); ebenso BVerwGE 49, 202 (209).

55 Vgl. Klein, Eckart, a.a.O. (Anm.6), S.477. Viel spricht dafür, daß den staatlichen Organen ausdrückliche und ausreichende Möglichkeiten an die Hand gegeben werden, einen funktionsfähigen Staat aufrechtzuerhalten und ihrer Frei- 
7. Über das Bild des modernen Staates hinausgehende Anhaltspunkte für positive und negative Staatszwecke lassen sich aus dem Völkerrecht gewinnen. Der noch im 19. Jh. klassische Staatszweck der Machterweiterung ${ }^{56}$ ist den Staaten heute durch das völkergewohnheitsrechtlich geltende Gewalt- und Interventionsverbot verwehrt ein Verbot, dessen Einhaltung nur unter Wahrung auch des innerstaatlichen Gewaltverbots möglich ist ${ }^{57}$. Die häufig anzutreffende Feststellung, daß der verfassungsneutrale Staatsbegriff des Völkerrechts sich in dem Selbstzweck (Erhaltungsfunktion) erschöpfe und das Völkerrecht die Frage, wozu Staaten gegründet worden sind und wie sie ihre Herrschaftsstruktur ordnen, nicht stelle, greift zu kurz. Das Völkerrecht gebietet dem Staat zwar nicht die Selbsterhaltung, wohl aber die Gewährleistung eines fremden- und menschenrechtlichen Mindeststandards - auch unabhängig von den beiden UNPakten ${ }^{58}$. Dazu gehört auch die Anerkennung der Personalität (Subjektstellung) und der Gleichheit jedes Menschen ${ }^{59}$. Diese fortschreitenden rechtlichen Verengungen der domaine réservé setzen einen funktionsfähigen Staat voraus. Die Strukturelemente des modernen Staates mit dem Sicherheitszweck sind daher Voraussetzungen für den völkerrechtlichen Staatsbegriff, zu dem positive Staatszwecke mit der Idee einer Verfassung der Völkerrechtsgemeinschaft ${ }^{60}$, dem interna-

heitsschutzfunktion gerecht $\mathrm{zu}$ werden. Nur in einem menschenbedrohenden Extremfall erscheint es zulässig, in einer Notstandslage auf ein mit dem Bild des modernen Staates einhergehendes Notrecht, das in die Verfassung nicht ausdrücklich aufgenommen wurde, zu schließen. Die Regelung in Art. 15 EMRK über die Einschränkbarkeit im Notstandsfall gibt dafür einen für solche Situationen notwendigen Mindestgehalt. „Wer in solcher Situation handelt, steht jedenfalls unter dem Risiko des Verfassungsbruchs"; Klein, Eckart, ibidem.

56 Noch 1922 hatte Georg Jellinek „ein solches offensives Vorgehen nicht überall als dem Staatszweck widersprechend" bezeichnet (vgl. Jellinek, Georg, a. a. O. [Anm.28], S.255).

57 Vgl. Heintzen, Markus: Das staatliche Gewaltmonopol als Strukturelement des Völkerrechts, Der Staat 1986, S. $17 \mathrm{ff}$.

${ }^{58}$ Internationaler Pakt über bürgerliche und politische Rechte v. 19.12.1966, BGBl. 1973 II S. 1534; Internationaler Pakt über wirtschaftliche, soziale und kulturelle Rechte v. 19.12.1966, BGBl. 1973 II S.1570; zur völkergewohnheitsrechtlichen Verankerung der Mindeststandards vgl. Verdross, Alfred/Simma, Bruno: Universelles Völkerrecht. Theorie und Praxis, 3. Aufl. 1984, $\$ 1209$, 1212 f., 1235.

59 Vgl. Doebring, Karl: Die allgemeinen Regeln des völkerrechtlichen Fremdenrechts und das deutsche Verfassungsrecht, 1963, S. $9 \mathrm{ff}$., $70 \mathrm{ff}$.; Schindler, Dietrich: Gleichberechtigung von Individuen als Problem des Völkerrechts, 1957, S. $28 \mathrm{ff}$.

60 Verdross, Alfred: Die Quellen des universellen Völkerrechts, 1973, S. $20 \mathrm{ff}$.; Mosler, Hermann: The International Society as a Legal Community, 1980, S. $15 \mathrm{ff}$. 
tionalen ordre public und mit den Beitrittsvoraussetzungen für die Vereinten Nationen, namentlich dem friedliebenden Charakter, hinzutreten ${ }^{61}$.

8. Die Staatszwecke des modernen Staates können auch im Verfassungsstaat den Charakter von Staatsbegrenzungen, Gewährleistungspflichten und Staatszielen haben. Ausgehend von der Verfassung stellt sich die Grundfrage, welche zusätzlichen Erkenntnisse aus einer Staatszweckbetrachtung gewonnen werden können. Drei Bereiche die Gemeinwohlermittlung, die Staatsaufgabenlehre und die Grundrechtstheorie - zeigen ihre Verbindung zu Staatszwecken.

9. Das BVerfG geht in ständiger Rechtsprechung davon aus, daß das Grundgesetz - u. a. um der Würde und Freiheit des Menschen willen - nicht eine "virtuell umfassende Staatsgewalt verfaßt (hat), sondern den Zweck des Staates materialiter auf die Wahrung des Gemeinwohls beschränkt, in dessen Mitte Freiheit und soziale Gerechtigkeit stehen"62. Die Ablehnung der virtuellen Allkompetenz ist zumindest mißverständlich ${ }^{63} . \mathrm{Ob}$ der genannte Staatszweck des Gemeinwohls ${ }^{64}$ sich lediglich aus der Summe der Partikularinteressen prozedural mit all den rechtsstaatlichen Sicherungen des demokratisch-parlamentarischen Staatswesens bildet ${ }^{65}$ oder zusätzlich an allge-

${ }^{61} \mathrm{Vgl}$. Jaenicke, Günther: Zur Frage des internationalen ordre public, Berichte der Deutschen Gesellschaft für Völkerrecht, Heft 7, 1967, S. 77 ff.; Frowein, Jochen Abr.: Das Staatengemeinschaftsinteresse - Probleme bei Formulierung und Durchsetzung, in: Staat und Völkerrechtsordnung. Festschrift für Karl Doehring, 1989, S. $219 \mathrm{ff}$.

62 BVerfGE 42, 312, (332).

${ }^{63}$ Sicherlich besteht - auch im Zeichen der Sozialstaatlichkeit - keine tatsächliche Allkompetenz (so aber Krüger, Herbert, a. a. O. [Anm. 37], S. 760, 830 f.), von der sie jedoch zu unterscheiden ist (vgl. Haverkate, a. a. O. [Anm. 34], S. 44 f.). Für eine virtuelle Allkompetenz z. B. Isensee, Josef, a. a.O. (Anm.24), Rdn. $158 \mathrm{ff}$; Kirchbof, Paul, a.a.O. (Anm.30), Rdn.2f.; kritisch: Eichenberger, Kurt: Der geforderte Staat: Zur Problematik der Staatsaufgaben, in: Hennis, Wilhelm (Hg.): Regierbarkeit. Studie zu ihrer Problematisierung, 1977, S. 103 ff. (104 ff.).

${ }_{64} \mathrm{Zu}$ den Auswirkungen der unterschiedlichen Gemeinwohlkonzeptionen auf die Staatszwecklehre siehe Bleckmann, Albert: Die Entwicklung der Allgemeininteressen aus den Grundrechten der Verfassung. Zur Staatszwecklehre des Grundgesetzes, 1990.

${ }^{65}$ Häberle, Peter: Öffentliches Interesse als juristisches Problem, 1970, S. 54 ff.; Stettner, Rupert: Grundfragen einer Kompetenzlehre, 1983, S. 202 ff. Dabei ist die von Häberle und Stettner vertretene aposteriorische Gemeinwohlkonzeption, die gesellschaftliche Interessenheterogenität fordert, wiederum von einer apriorischen Gemeinwohlidee, die gesellschaftliche Interessenhomogenität voraussetzt, zu unterscheiden (vgl. Vorländer, Hans: Verfassung und Konsens, 1981, S. $223 \mathrm{ff}$., $335 \mathrm{ff}$.). 
meinen Grundwerten wie der menschlichen Würde, Freiheit und sozialen Gerechtigkeit ausgerichtet ist, hat für den modernen Staat westeuropäischer Prägung in der Präambel der Europäischen Menschenrechtskonvention eine Antwort zugunsten einer materialen Zielvorstellung erhalten ${ }^{66}$. Da Gerechtigkeit jedoch nicht positiv, sondern allenfalls punktuell und im Wege negativer Evidenz feststellbar bleiben wird, ist das Substrat dieser Zweckvorstellung außerordentlich vage. Die instrumentale Hinwendung zur Freiheit und Selbstbestimmung des einzelnen bietet demgegenüber einen Ansatz zur Zurückdrängung rein kollektivistischer Gemeinwohlvorstellungen. Diese Ausrichtung an der Würde und Freiheit des Menschen führt zu einer nach der Gewichtigkeit gestuften Rechtfertigungslast für jedes öffentliche Interesse, das zur Einschränkung individueller Freiheit herangezogen wird ${ }^{67}$.

10. In eine vergleichbare Richtung weist die Staatszweckbetrachtung für eine Staatsaufgabenlehre ${ }^{68}$. Den Staatszwecken als Staatsbegrenzungen liegt ursprünglich die Unterscheidung zwischen Staat und Gesellschaft voraus. Diese Unterscheidung läßt sich auch unter dem Grundgesetz als Funktionentrennung und „Bedingung der individuellen Freiheit" aufrechterhalten. Der Staat hat gegenüber der freien Gesellschaft als zweiter „Wirkeinheit“ eine Garantenfunktion für den freien gesellschaftlichen Ablauf ${ }^{69}$.

66 Bleckmann, Albert: Vom subjektiven zum objektiven Rechtsstaatsprinzip, JöR 36 (1987), S. 1 ff. (19f.); Isensee, Josef, a. a. O. (Anm. 56), Rdn. 44 f.; von Arnim, Hans Herbert: Staatslehre der Bundesrepublik Deutschland, 1984, S. $124 \mathrm{ff}$.

67 Vgl. Bleckmann, Albert: Staatsrecht II - Die Grundrechte, 3. Aufl. 1989, S. $368 \mathrm{ff}$; Grabitz, Eberhard: Freiheit und Verfassungsrecht, 1976, S. $84 \mathrm{ff}$.

6s Vgl. hierzu Bull, Hans Peter: Die Staatsaufgaben nach dem Grundgesetz, 2. Aufl. 1977, insbes. S. 17 ff., 43 ff.; Del Vecchio, Giorgio: Über die Aufgaben und Zwecke des Staates, AöR 88 (1963), S. 249 ff.; Häberle, Peter: Verfassungsstaatliche Staatsaufgabenlehre, AöR 111 (1986), S. 595 ff.; zur Staatsaufgabenlehre aus der Sicht der politischen Ökonomie vgl. Hesse, Günter: Staatsaufgaben. Zur Theorie der Legitimation und Identifikation staatlicher Aufgaben, 1979.

69 Böckenförde, Ernst-Wolfgang, a.a.O. (Anm. 34), S.12ff. Es ist nicht von ungefähr, daß Böckenförde in diesem Zusammenhang von den „grundlegenden Staatszwecken und der ursprünglichen Verteilung der Zuständigkeiten zwischen Staat und Gesellschaft" spricht, die den Staat dazu verpflichtet, der gesellschaftlichen Ungleichheit entgegenzuwirken und sie durch sozialen Ausgleich und soziale Leistungen zu relativieren, um dadurch individuelle Freiheit und rechtliche Gleichheit für alle real zu erhalten (ders., Die Bedeutung der Unterscheidung von Staat und Gesellschaft im demokratischen Sozialstaat der Gegenwart, in: ders.: Staat, Gesellschaft, Freiheit, 1976, S. 185 ff. [205]). 
Die Staatszwecke in ihrer klassischen Staatsbegrenzungsfunktion könnten sich unter dem Grundgesetz in der Lehre vom Verfassungsvorbehalt wiederfinden, wonach die Organe des Staates nur handeln dürfen, wenn und soweit die Verfassung zu diesem Handeln ermächtigt. Solche Handlungsermächtigungen werden nicht nur im Sozialstaatsziel, das eine umfassende Gestaltung der Wirtschafts- und Finanzverfassung nach den Vorstellungen des Gesetzgebers erlaubt ${ }^{70}$, sondern auch in der objektiv-rechtlichen Seite der Grundrechte gesehen $^{71}$. Der Staat ist nicht notwendig verpflichtet, aber doch ermächtigt, die Voraussetzungen für eine generelle Ausübung der Grundrechte zu schaffen. Eine solche Sicht, die den Staat und insbesondere den Gesetzgeber über die Kompetenzbestimmungen hinaus auf die Verwirklichung von Staatszwecken und Staatszielen zurückdrängt, läßt sich aus der Verfassung nicht zwingend entnehmen ${ }^{72}$. Der Verfassung nach besteht im Prinzip eine Allkompetenz, die der demokratische Gesetzgeber im Rahmen der entweder dem Bund oder den Ländern insgesamt zustehenden Befugnis ausfüllen darf. Eine andere Auffassung würde auch zu eigentümlichen Verzerrungen führen, weil die Sozialstaatsklausel dann zwingend zu einer umfassenden Generalermächtigung zur Gestaltung der Wirtschafts- und Sozialverfassung wird und - wie mit Recht gesagt worden ist ${ }^{73}$ - „alle Staatszwecke sich durch die Grundrechte legitimieren" lassen.

Gleichwohl kann auf einer zweiten Ebene der Reflexion die Staatszweckbetrachtung für die Unterscheidung zwischen ausschließlichen und konkurrierenden, obligatorischen und fakultativen Staatsaufgaben von Bedeutung sein. Welche Aufgaben - neben den konkreten

70 Das Sozialstaatsziel als Verfassungsnorm über Staatsaufgaben führt in die Nähe der politischen Gestaltungsfreiheit des Gesetzgebers, denn die Staatsaufgaben sind unbestimmt, unbestimmbar und an veränderlichen Gegebenheiten und Einflüssen orientiert (vgl. Badura, a.a. O. [Anm. 18], S. 494).

${ }^{1} \mathrm{Vgl}$. Scheuner, Ulrich: Die Funktion der Grundrechte im Sozialstaat. Die Grundrechte als Richtlinie und Rahmen der Staatstätigkeit, DÖV 1971, S. 505 ff.; Stern, Klaus, a. a. O. (Anm. 17), S. $890 \mathrm{ff}$.

72 Dies folgt aus dem Fehlen klarer und systematischer Aussagen im Grundgesetz über Aufgaben und Zwecke des vom Grundgesetz verfaßten Staates (vgl. Herzog, Roman: Ziele, Vorbehalte und Grenzen der Staatstätigkeit, in: Isensee, Josef/Kirchhof, Paul [Hg.]: Handbuch des Staatsrechts, Bd.III, 1988, $\ 58$, Rdn. 28). Eine solche Sicht würde zudem der Wirkung von Staatszwecken, die direktiv, nicht determinativ ist (vgl. Brugger, Winfried, a. a. O. [Anm. 1], S. 2431), widersprechen.

${ }^{73}$ Bleckmann, Albert, a. a. O. (Anm.67), S. 269. 
im Grundgesetz enthaltenen Gesetzgebungsaufträgen ${ }^{74}$ - im modernen Staat als notwendig angesehen werden, läßt sich im Sinne eines auch innerstaatlich bedeutsamen Indizes aus der völkerrechtlichen Unterscheidung zwischen acta iure imperii und acta iure gestionis ablesen, einer Unterscheidung, die auch dann aussagekräftig ist, wenn nach der lex fori auf die Tätigkeit Privatrecht anzuwenden ist ${ }^{75}$. Der gesamte kommerzielle Sektor fällt aus dem staatlichen Kernbereich heraus. Hier liegen dem modernen Staat völkerrechtliche Leitbilder voraus, die innerstaatlich $z$ war nicht $z$ wingend sind, aber doch eine Indizwirkung dafür haben, was dem Staat zugerechnet wird und worauf er sich zur Inanspruchnahme staatlicher Immunität berufen darf. Einen zusätzlichen Anhaltspunkt bietet die Rechtsprechung zur EMRK bei der Frage, was in einer demokratischen Gesellschaft notwendig ist. Im James-Fall ${ }^{76}$ findet sich insofern der bemerkenswerte Satz:

„Die Beseitigung sozialer Ungerechtigkeiten ist eine der Funktionen des demokratischen Gesetzgebers. Insbesondere stellt die Wohnungspolitik für die Bevölkerung ein erstrangiges soziales Bedürfnis dar, dessen Regelung nicht völlig dem Spiel der freien Marktkräfte überlassen werden darf.“

Als weiterer völkerrechtlicher Anknüpfungspunkt nicht für ausschließliche, wohl aber für obligatorische Staatsaufgaben kann die völkerrechtliche Verantwortlichkeit herangezogen werden, also jene Fälle, in denen dem Staat eine Garantenstellung auch für das Handeln Privater zugerechnet wird" . Darüber hinaus darf der Staat, auch wenn er im Prinzip über eine Allkompetenz verfügt, nur jene Aufgaben wahrnehmen, für die ein öffentliches Interesse besteht ${ }^{78}$. So darf er als Steuerstaat nicht rein erwerbswirtschaftliche Unternehmenstätigkeit - über den beim Erlaß des Grundgesetzes vorgefundenen Grundbe-

${ }^{7+} \mathrm{Zu}$ erwähnen sind hier die Aufträge zur Gleichstellung der ehelichen mit den nichtehelichen Kindern (Art. 6 Abs. 5 GG) und zur Neugliederung des Bundesgebietes (Art. $29 \mathrm{GG}$ ). Vgl. Scheuner, Ulrich: Staatszielbestimmungen, in: Festschrift für Ernst Forsthoff, 1972, S. 325 ff. (333 ff.).

75 Vgl. hierzu Ress, Georg: Entwicklungstendenzen der Immunität ausländischer Staaten, ZaöRV 40 (1980), S. $217 \mathrm{ff}$.

${ }^{76}$ Europäischer Gerichtshof für Menschenrechte (EGMR), Urt. v. 21.2.1986, Nr. 3/1984/75/119, James u.a./ Vereinigtes Königreich, EuGRZ 1988, 341 (344).

77 Vgl. Murswiek, Dietrich: Die Pflicht des Staates zum Schutz vor Eingriffen Dritter nach der Europäischen Menschenrechtskonvention, in: Konrad, HansJoachim: Grundrechtsschutz und Verwaltungsverfahren. Internationaler Menschenrechtsschutz, 1985, S. $213 \mathrm{ff}$; Verdross/Simma, a. a. O. (Anm. 58), $\$ 1270 \mathrm{ff}$., $1281 \mathrm{ff}$.

$78 \mathrm{Vgl}$. Isensee, Josef: Subsidiaritätsprinzip und Verfassungsrecht, 1968, S. $208 \mathrm{f}$. 
stand hinaus - entfalten ${ }^{79}$. Ein Rückgriff auf eine vorverfassungsrechtliche Staatszweckkonzeption bringt über die in den Grundrechten enthaltenen Regelungsbegrenzungen hinaus keine zusätzliche Erkenntnis, aber Bestätigung. Auch aus einem Vorverständnis von Staatszwekken, das im Wege der Rechtsvergleichung ermittelt wird, lassen sich nur grobe Schlüsse auf eine Art gemeineuropäischer Aufgabenlehre des modernen Verfassungsstaates ziehen. Die Idee eines limited government als gemeineuropäischer Rechtssatz tritt in der Rechtsprechung des Straßburger Gerichtshofs - trotz des den Mitgliedstaaten eingeräumten Beurteilungsspielraums (marge d'appréciation) ${ }^{80}$ - deutlich bei der Frage des Gesundheitsschutzes, der Verstaatlichung, der Eingriffe in die Privatsphäre durch Abhörmaßnahmen usw. hervor ${ }^{81}$.

Gleichwohl wird die Frage, wieviel an innerer und sozialer Sicherheit gewährleistet werden muß, in den westeuropäischen Staaten trotz Rechtsharmonisierung in Teilgebieten immer noch höchst unterschiedlich beantwortet. Die Ausrichtung an der menschlichen Freiheit spricht für einen Rückgriff auf das Subsidiaritätsprinzip, welches in Art. $130 \mathrm{r}$ EWGV durch die EEA für den Umweltbereich eine partielle, wenn auch unvollkommene Aufnahme gefunden hat ${ }^{82}$.

79 Vogel, Klaus: Der Finanz- und Steuerstaat, in: Isensee, Josef / Kirchhof, Paul (Hg.): Handbuch des Staatsrechts, Bd.I, 1987, \$27 Rdn. 52 f.; Isensee, ibidem, S. $288 \mathrm{f}$; Ress, Georg: Regierungskontrolle von öffentlichen (staatlichen und halbstaatlichen) Industrieunternehmen, in: Liber Amicorum B.C.H. Aubin, 1979, S. $129 \mathrm{ff}$. (133f., 138f.); Grupp, Klaus: Wirtschaftliche Betätigung der öffentlichen Hand unter dem Grundgesetz, ZHR 140 (1976), 367 (392); a. A. Klein, Hans H.: Die Teilnahme des Staates am wirtschaftlichen Wettbewerb, 1968, S. $179 \mathrm{f}$.

${ }_{80}$ Vgl. EGMR, Fall Handyside, Urt. v. 7.12.1976, EuGRZ 1977, 38 (42); Fall Sunday Times, Urt. v. 26.4. 1979, EuGRZ 1979, 386 (388f.); Fall James, a. a. O. (Anm. 68), S. 344.

${ }^{81} \mathrm{Vgl}$. Merrills, J. G.: The development of international law by the European Court of Human Rights, 1988, S. $146 \mathrm{ff}$.

82 Zum Subsidiaritätsprinzip vgl. Everling, Ulrich: Gestaltungsbedarf des Europäischen Rechts, EuR 1987, 214 (220); Isensee, Josef: Subsidiaritätsprinzip und Verfassungsrecht, 1968; ders., a. a. O. (Anm. 24), Rdn. 79, 165 ff.; kritisch z. B. Schmidt-Jortzig, Edzard/Schink, Alexander: Subsidiaritätsprinzip und Kommunalordnung, 1982, S. 7 ff.; Herzog, Roman: Subsidiaritätsprinzip und Staatsverfassung, Der Staat 2 (1963), S. 339 ff. Sowohl dem externen Subsidiaritätsprinzip im Verhältnis zwischen Staat und Individuum bzw. Gesellschaft mit dem Regelungsmechanismus der Selbststeuerung als auch dem internen Subsidiaritätsprinzip innerhalb der verfaßten Staatlichkeit mit dem Regelungsmechanismus der Selbstverwaltung kommt staatsentlastende Funktion zu (vgl. Schuppert, Gunnar Folke: Selbstverwaltung, Selbststeuerung, Selbstorganisation - zur Begrifflichkeit einer Wiederbelebung des Subsidiaritätsprinzips, AöR 114 (1989), S. 127 ff. (139 ff., 143 ff.). 
Für eine funktionale Scheidung von Staat und Gesellschaft und eine daran anknüpfende Staatsaufgabenlehre geben die Staatszwecke demnach nicht mehr Aufschluß, als sich ohnedies aus den Handlungsermächtigungen des Grundgesetzes, insbesondere der objektiv-rechtlichen Seite der Grundrechte, ergibt. Hinter der notwendigen Rechtfertigung des Aufgreifens einer Aufgabe durch öffentliches Interesse steht jedoch eine am Menschen- und Staatsbild orientierte Staatszweckbetrachtung. Die rein ökonomische Theorie, die seit Hayek und Milton Friedman z. B. das Interesse an der öffentlichen Wahrnehmung des Postwesens, der Information und der Bildung und sogar des Währungswesens in Zweifel gezogen hat, ist nur am Wert möglichst effizienter und kostengünstiger, aber nicht allseitiger und sozialer Güterversorgung ausgerichtet. Das spezifische Optimierungsproblem, welches sich für die Staatszweckbetrachtung aus dem zugrundeliegenden Menschen- und Staatsbild ergibt, vermag die "reine“ ökonomische Theorie nicht zu lösen. Der homo oeconomicus ist nicht der Mensch im Grundgesetz.

11. Bei der Grundrechtsinterpretation zeigt sich die Verlagerung der objektiven Zwecksetzung des Staates. Je mehr die Freiheit in den Grundrechten und nicht in einer inhaltlichen Zweckbindung der Staatsgewalt und damit deren Begrenzung auf bestimmte Aufgaben gesehen wird, um so intensiver verlagert sich das Problem der Zweckbindung der Staatsgewalt in die Grundrechtsinterpretation, namentlich in die Schranken der Grundrechte ${ }^{83}$. Der gesamte Abgrenzungsstreit über das „bürgerliche Zuteilungssystem“ tritt in der Frage auf, welche nach Dringlichkeit gestuften Gemeinwohlzwecke der Staat zur Einschränkung von Grundrechten legitimerweise verfolgen darf. Diese Frage beherrscht spätestens seit dem Apothekenurteil ${ }^{84}$ über das

${ }_{83}$ Vgl. Stern, Klaus, a.a.O. (Anm. 17), S. 104. An einem konkreten Zweck (Gesundheitsschutz) zeigt dies Seewald, Ottfried: Zum Verfassungsrecht auf Gesundheit, 1981, S. 83 ff.; 139 ff. Dabei zeigt sich ein methodisches Problem. Wenn die konkreten Zwecke, die der Staat zu verfolgen hat und die ihn „begrenzen“, d. h. inhaltlich binden, nunmehr aus den Grundrechten entnommen werden, werden davon separierte eigene Staatszwecke überflüssig oder überdeckt; denn dann sind die Grenzen aus den Grundrechten die "Staatszwecke“, und das Verfahren wäre ein fragwürdiger Austausch der einen Kategorie gegen die andere, wobei sich die Frage stellt, was die Grundrechte dabei gewinnen, anders gewendet, ob die "Aufladung“ der Grundrechte durch die Dimension der Staatszwecke diese nicht überlastet, so daß eine Wiederherstellung der Staatszwecke als eigene separate Erscheinung die Grundrechte von der Legitimationsfunktion entlasten könnte.

s+ BVerfGE 7, 377 (399 ff.). 
Verhältnismäßigkeitsprinzip die Judikatur des Verfassungsgerichts. Vergleichbar werden die Staatszwecke in der Europäischen Menschenrechtskonvention bei der Frage relevant, welche Einschränkungen zum Schutz bestimmter Rechtsgüter in einer demokratischen Gesellschaft "notwendig“ sind ${ }^{85}$. Dabei kann die Staatszweckbetrachtung die bei der Grundrechtsinterpretation bestehende Unsicherheit schon deshalb nicht beheben, weil auch der Staatszweckbetrachtung die Anknüpfung an ein notwendigerweise vages Menschen- und Staatsbild zugrundeliegt. Die Probleme zeigen sich bei der Frage, ob der Staat auch den Zweck hat, die Voraussetzungen des Gebrauchs der Freiheitsrechte zu ermöglichen oder gar zu sichern (wie in der DDR $)^{86}$

Die Rückbesinnung auf die Staatszwecke des modernen Staates kann zwar nicht zu einer Rückverlagerung und juristischen Entlastung der Interpretation der Grundrechte von den Problemen der "richtigen" Grundrechtstheorie führen ${ }^{87}$, wohl aber zu einer Orientierungsentlastung, indem deutlich wird, daß der rechtliche Sitz der Probleme nicht vordergründig bei der Interpretation der Grundrechtsschranken liegt, sondern grundsätzlicher in den Grenzen der Staatsgewalt und damit in dem funktionalen Verständnis von Staat und Gesellschaft - als zwei auch in der EMRK als getrennt definier-

${ }^{85}$ Zum Streit um diese Voraussetzung siehe EGMR, Sunday Times-Fall, EuGRZ 1979, 386 (388); EGMR, Fall Handyside, EuGRZ 1977, 38 (40 ff.); vgl. dazu van Dijk, P./van Hoof, G.J.H.: Theory and Practice of the European Convention on Human Rights, 1984, S. 314 ff.; Ermacora, Felix: Richtungsweisendes Handyside-Urteil?, EuGRZ 1977, 363 f.; Fawcett, J. E. S.: The Application of the European Convention on Human Rights, 1987, S. 270 ff.; Hailbronner, Kay: Die Einschränkung von Grundrechten in einer demokratischen Gesellschaft, in: Völkerrecht als Rechtsordnung - Internationale Gerichtsbarkeit - Menschenrechte. Festschrift für Hermann Mosler, 1983, S. 359 ff. (362ff.).

${ }^{86}$ Eine solche Sicherungspflicht besteht in der DDR zumindest theoretisch; vgl. Brunner, Georg: Das Staatsrecht der Deutschen Demokratischen Republik, in: Isensee, Josef / Kirchhof, Paul (Hg.): Handbuch des Staatsrechts, Bd. I, 1987, \$10, Rdn. 81; Roggemann, Herwig: Die DDR-Verfassungen, 4. Aufl. 1989, S. 47 f., 261 ff.; kritisch zu solchen Entwicklungen Ress, Georg: Demonstration und Freiheit - Bemerkungen zur Einleitung, in: Demonstration und Straßenverkehr, 1970, S. IXff. (XXVIf.).

${ }^{87}$ Von einer solchen Entlastung scheint Häberle (vgl. ders., a. a. O. [Anm. 68], S. 608) auszugehen, wenn er von einer Staatsaufgabenlehre inhaltich und prozessual erwartet, daß "die Grundrechte bzw. die Grundrechtsdogmatik und ,Grundrechtspolitik' von manchen Funktionen entlastet werden, die sie wegen des Fehlens einer verfassungsrechtlichen Staatsaufgabenlehre im Rahmen des GG seit Jahrzehnten mit übernommen hat". 
ten Wirkeinheiten - verankert ist. Die Orientierungswirkung darf andererseits nicht überschätzt werden. Denn bei der Konkretisierung der Zweckbindung läßt die EMRK den Mitgliedstaaten eine weite marge d'appréciation (Beurteilungsspielraum) ${ }^{88}$. Sie gibt Auskünfte darüber, welche Maßnahmen zulässig, weniger aber darüber, welche Maßnahmen geboten sind. Die Überprüfung auf die innere Verfassungstreue ist demnach sowohl nach europäischem Gemeinschaftsrecht als auch nach der Europäischen Menschenrechtskonvention zulässig ${ }^{89}$, was aber nicht bedeutet, daß alle europäischen Staaten so verfahren müßten. Die schon genannte Entscheidung des Straßburger Gerichtshofs im James-Fall macht deutlich, daß die Konvention von der Unterscheidung zwischen Staat und Gesellschaft als einer Konstitutionsform des modernen Staates ausgeht ${ }^{90}$ und daß ein recht allgemeines Verständnis des Zwecks sozialer Gerechtigkeit die Abgrenzung zu den Grundrechten, insbesondere die Bedeutung des Eigentums für das Individuum, steuert ${ }^{\text {91. }}$. Der gemeineuropäische Standard,

${ }_{88} \mathrm{Vgl}$. oben, Anm. 80 sowie Ganshof van der Meersch, Walter J.: Le caractère "autonome“ des termes et la "marge d'appréciation“ des gouvernements dans l'interprétation de la Convention européenne des Droits de l'Homme, in: Protecting Human Rights: The European Dimension. Studies in honour of Gérard J. Wiarda, 1988, S. 201 ff.; Hailbronner, Kay, a. a. O. (Anm. 85), S. 381 ff.; Merrills, J.G., a.a.O. (Anm. 81), S.136ff.; Nedjati, Zaim M.: Human Rights under the European Convention, 1978, S. 183 ff.; Waldock, Sir Humphrey: Die Wirksamkeit der Europäischen Menschenrechtskonvention, EuGRZ 1979,. S. 599 ff. (600 ff.); Weidmann, Klaus W.: Der Europäische Gerichtshof für Menschenrechte auf dem Weg zu einem europäischen Verfassungsgerichtshof, 1985, S.245 ff.

${ }_{89}$ Vgl. EGMR Urt. Nr. 4/1984/76/120 v. 28.8.1986 im Fall Glasenapp gegen Bundesrepublik Deutschland, EuGRZ 1986, 497 (503 ff.); Urt. Nr. 5/1984/77/121 v. 28. 8. 1986 im Fall Kosiek gegen Bundesrepublik Deutschland, EuGRZ 1986, 509 (514ff.); Doebring, Karl: Abwehr verfassungsfeindlicher Bestrebungen im öffentlichen Dienst aus der Sicht der Rechtsvergleichung und des internationalen Rechts, in: Der freiheitliche Rechtsstaat und seine Gegner - Mittel und Grenzen der Abwehr, 1979, S. $107 \mathrm{ff}$. (118f., $120 \mathrm{f}$.); ders.: Gesamtbericht, in: Verfassungstreue im öffentlichen Dienst europäischer Staaten, 1980, S. 11 ff. (37 ff., 40 f.).

${ }^{9}$ Die Trennung wird dergestalt aufgegriffen, daß in der EMRK der Begriff Gesellschaft (societé, society) als der Bezugspunkt für die Zulässigkeit von staatlichen Regelungen gewählt wird. Zur staatstheoretischen und verfassungsrechtlichen Bedeutung siehe Böckenförde, Ernst Wolfgang, a. a.O. (Anm. 36), S. 10 ff.; ders.: Die Bedeutung der Unterscheidung von Staat und Gesellschaft im demokratischen Sozialstaat der Gegenwart, in: Rechtsfragen der Gegenwart. Festschrift für Wolfgang Hefermehl, 1972, S. $11 \mathrm{ff}$.

${ }_{91}$ Zum Eigentumsschutz in der Rechtsprechung des EGMR vgl. neben dem genannten James-Fall (Anm.68) den Fall Lithgow u.a./Vereinigtes Königreich, EuGRZ 1988, S. 350 ff. sowie den Fall Sporrong u. Lönnroth/Schweden, EuGRZ 
der als fortlaufende Konkretisierung der Zwecke des modernen westeuropäischen Staatstypus angesehen werden kann, bietet für die grundsätzliche Zweckbindung des Staates nur wenige über das deutsche Verfassungsverständnis hinausgehende Anhaltspunkte.

12. Die Möglichkeit, den Staat mit seinen Zwecken in der Verfassung normativ zu verdeutlichen, läßt sich auch durch eine aus der Zusammenschau einzelner Grundrechtsbestimmungen in Verbindung mit verfassungsrechtlichen Grundentscheidungen gewonnenen $\mathrm{Ge}-$ samtschau gewinnen. Derartige Grundentscheidungen, wie sie z.B. für den Steuerstaat oder für ein Kulturstaatsziel vertreten werden ${ }^{92}$, hat das BVerfG früher noch deutlicher gepflegt, als es ausführte, daß sich ,aus dem Gesamtinhalt der Verfassung gewisse verfassungsrechtliche Grundsätze und Grundentscheidungen ergeben, denen die einzelnen Verfassungsbestimmungen untergeordnet sind" und daß ,jede Verfassungsbestimmung... so ausgelegt werden (müsse), daß sie mit jenen elementaren Verfassungsgrundsätzen und Grundentscheidungen des Verfassungsgesetzgebers vereinbar ist ${ }^{\text {c } 93}$. Dieser Feststellung liegt die richtige Erwägung zugrunde, daß eine einzelne Verfassungsbestimmung nicht isoliert betrachtet und allein aus sich heraus ausgelegt werden kann. Sie steht in einem Sinnzusammenhang mit den übrigen Vorschriften der Verfassung, die eine innere Einheit darstellen. So hat das BVerfG ${ }^{94}$ z. B. den Verfassungsgrundsatz der militärischen Landesverteidigung aus Art. 12 a, 73 Nr. 1, 87 a und 115 GG als mögliche immanente Grundrechtsschranke aus Kompetenzvorschriften, Ermächtigungsnormen und Organisationsregeln abgeleitet. Die Verbindung zwischen Grundentscheidungen und Staatszwecken wird deutlich. Gehört die Sicherung des äußeren Friedens zu den Staatszwecken des modernen Staates, dann ist sie auch als ungeschriebenes

1983, S. 523 ff.; zur Rechtsprechung des EuGH zum Eigentumsschutz vgl. EuGH Rs. 44/79, Liselotte Hauer/Land Rheinland Pfalz, Slg. 1979, 3727 (3745 ff.); Rs. 41/79, Testa, Slg. 1980, 1979 (1998f.); Rs. 59/83, Biovilac/EWG, Slg. 1984, 4057 (4079); Rs. 116/82, Kommission/Deutschland, Slg. 1986, 2519 (2545).

${ }_{92}$ Vgl. z. B. Häberle, Peter: Vom Kulturstaat zum Kulturverfassungsrecht, in: ders. (Hg.): Kulturstaatlichkeit und Kulturverfassungsrecht, 1982, S. 1 ff. (37f.); Isensee, Josef: Steuerstaat als Staatsform, in: Hamburg - Deutschland - Europa. Festschrift für Hans Peter Ipsen, 1977, S. 409 ff. (420 f.).

93 BVerfGE 1, 14 (32f.).

94 BVerfGE 69, 1 (21); ähnlich bereits BVerfGE 28, 243 (261 f.); 32, 40 (46); 48, 127 (159); Kritik im Sondervotum von Böckenförde und Mahrenholz, BVerfGE 69, 57 (59ff.) sowie bezüglich der Begründung auch bei Isensee, Josef, a.a.O. (Anm. 56), Rdn. 126. 
Element in der Verfassungsordnung präsent ${ }^{95}$. Damit wird jedoch eine staatszweckoptimierende Umdeutung von Verfassungsnormen, die grammatikalisch und systematisch eine bestimmte Aussage, wie in Art. 12 a Abs. 2, enthalten, nicht zulässig. Nur wenn die Interpretation der Verfassungsbestimmung selbst mehrere Möglichkeiten offenläßt, ist zur Lösung des Auslegungsproblemes der Rückgriff auf den Staatszweck des modernen Staates möglich ${ }^{96}$.

\section{Internationalisierung und Europäisierung von Staatszwecken}

13. Der moderne Staat nimmt viele seiner Zwecke nicht mehr selbst, zumindest nicht autonom wahr. Die Neubelebung der Diskussion über die Staatszwecke beruht auf der fortschreitenden Internationalisierung und Europäisierung der Verwaltung. Die Internationalisierung - schon im 19.Jh. auf dem Gebiet des Eisenbahn- und Postverkehrs, derzeit in zahlreichen internationalen Organisationen - ist die Antwort auf das Defizit des modernen Territorialstaates zur Bewältigung der Daseinsvorsorge mittels der nationalen Verwaltung. Neben die nationale Zweckverfolgung tritt auf typischen Gebieten der Leistungsverwaltung daher die internationale. Gleiches gilt in neuerer

95 Daraus kann zwar nicht geschlossen werden, daß eine Landesverteidigung auch ohne ausdrückliche verfassungsrechtliche Regelung vom Gesetzgeber aufgegriffen und organisiert werden könnte. Es gehört aber zu dem Grundverhältnis, daß der einzelne auch Schutz vor Angriffen von außen beanspruchen kann. Dieser Sicht steht nicht entgegen, daß das Völkerrecht eine Landesverteidigung nicht zwingend gebietet („Aus dem Begriff des Staates, nämlich der Staatsgewalt oder der Souveränität, die vom Grundgesetz als selbstverständliche Voraussetzung der Staatlichkeit akzeptiert wurde, läßt sich keine grundsätzliche Verpflichtung zur Aufstellung von Streitkräften herleiten, sondern allenfalls ein Recht dazu." [Kirchhof, Ferdinand: Bundeswehr, in Isensee, Josef/Kirchhof, Paul [Hg.]: Handbuch des Staatsrechts, Bd. III, 1988, $\$ 78$ Rdn. 8]). Die Gewährleistung des äußeren Friedens gehört zu den Wesensmerkmalen des modernen Staates. Eine Entscheidung zugunsten der Landesverteidigung kann daher als Ausdruck der den modernen Staat prägenden Zielsetzung angesehen werden, so daß gegen die Auslegung als verfassungsrechtliche Grundentscheidung vor diesem Hintergrund im Prinzip nichts einzuwenden ist.

96 Zur daher berechtigten Kritik am Urteil des BVerfG zum Kriegsdienstverweigerungs-Neuordnungsgesetz (BVerfG NJW 1985, 1519) vgl. z. B. Becker, HansJoachim: Das Recht der Kriegsdienstverweigerung im Lichte des Urteils des Bundesverfassungsgerichts vom 24. April 1985, RiA 1986, S. 30 ff. (35); Eckertz, Rainer: Verfassungsgerichtliche Determinanten des KriegsdienstverweigerungsNeuordnungsgesetzes, JuS 1985, S. 683 ff. (684 ff.). 
Zeit mehr und mehr auch für Aufgaben der Gefahrenabwehr, wie die Bekämpfung des internationalen Terrorismus, des Drogenhandels oder der grenzüberschreitenden Umweltbelastung. Die Staatszwecke verändern durch die Auslagerung einzelner Sachbereiche zur Zweckverfolgung auf internationale Organisationen nicht nur ihre sachlich-räumliche Reichweite, sondern erfahren durch die Akte unter fremder Zweckverfolgung eine Ergänzung durch multilaterale Gemeinwohlvorstellungen. Dieser Wandel wirkt auf das Staatsbild, namentlich auf das Verhältnis des Bürgers zur Verwaltung zurück. Durch die Internationalisierung und Vergemeinschaftung verliert der Staat nicht nur rechtlich an Verwaltungsautonomie, sondern u.U. auch für den Bürger an identifikationsfähiger Substanz $z^{97}$.

97 Delbrück, Jost: Internationale und nationale Verwaltung - Inhaltliche und institutionelle Aspekte -, in: Jeserich, Kurt G.A./Pohl, Hans/von Unruh, Georg Christoph (Hg.): Deutsche Verwaltungsgeschichte, Bd. 5: Die Bundesrepublik Deutschland, 1987, S. 386 ff. (390). Bei internationalen Organisationen ist die Zweckbindung im Rahmen der Satzung und die daran anknüpfende objektive Auslegung (ähnlich einer innerstaatlichen Verfassung) eine seit der Entscheidung des Ständigen Internationalen Gerichtshofs zur Donau-Kommission (Publications de la Cour Permanente de Justice Internationale, Série No. 14, Recueil des Avis consultatifs. Compétence de la Commission Européenne du Danube, S.1 ff. [22ff.]) feststehende Rechtslage. Entsprechend der Theorie sind internationale Organisationen zwar in ihrer Rechtsfähigkeit funktional begrenzt, wobei die Möglichkeit des ultra-vires-Handelns die in den Zwecksetzungen fixierte Abgrenzung und damit den staatlichen (Freiheits-) Bereich verdeutlicht. Die Theorie stößt aber auf besondere methodische Probleme, weil eine gleichzeitige Weiterentwicklung des Gründungsvertrages der Internationalen Organisation durch organ- und mitgliedstaatliche Praxis nicht ausgeschlossen ist (Nachweise in: Bieber, Roland/Ress, Georg (Hg.): Die Dynamik des Europäischen Gemeinschaftsrechts, 1987, S.17ff.; $69 \mathrm{ff}$.; $92 \mathrm{ff}$; $101 \mathrm{ff}$.). Bei den Europäischen Gemeinschaften hätte man argumentieren können, daß in der Zwecksetzung und Umschreibung der Aufgaben in Art. 2 und 3 EWGV ausreichende funktionale Begrenzungen vorliegen. Diese sind indessen so weit formuliert, daß sie vor dem Hintergrund der lückenschließenden Kompetenzregel des Art. 235 EWGV einer Auslagerung der Zweckverfolgung wenige substantiell faßbare Schranken zu setzen vermögen (vgl. Everling, Ulrich: Zur föderalen Struktur der Europäischen Gemeinschaft, in: Staat und Völkerrechtsordnung. Festschrift für Karl Doehring, 1989, S.179ff. [184f.]). Noch nie ist vom EuGH ein auf Art. 235 EWGV allein gestützter Rechtsakt wegen Kompetenzüberschreitung aufgehoben worden (zu Problemfeldern der Mißachtung der Subsidiarität von Art. 235 gegenüber Einzelermächtigungen vgl. Grabitz, Eberhard, in: ders. [Hg.]: Kommentar zum EWG-Vertrag, 1989, Art. $235 \mathrm{Rdn} .45$ ). 
Die mit der EG verbundene Zweckverflechtung und Überlagerung zwischen europäischer und nationaler Entscheidungsgewalt erstreckt sich auf alle maßgeblichen Staatszwecke, einschließlich in jüngster Zeit die Kultur ${ }^{98}$.

Das in der Präambel (neben dem Wiedervereinigungsgebot) verankerte Ziel der Bundesrepublik, als gleichberechtigtes Glied in einem vereinten Europa dem Frieden der Welt zu dienen, ist auch in Anknüpfung an Art. 24 Abs. 1 GG verfassungsgebunden; die Verfassung ist ihrerseits aber europaoffen ${ }^{99}$. Daraus ergeben sich Schlußfolgerungen: Erstens: Nicht nur ein Nebeneinander zweier Rechtsordnungen ${ }^{100}$, sondern eine Verschränkung und Einbeziehung des europäischen Gemeinwohls in die Auslegung und Anwendung der Grundrechte, also eine spezifische europarechtliche Grundrechtsinterpreta$\operatorname{tion}^{101}$. Zweitens: Die Mitgliedschaft der Bundesrepublik Deutschland in den Europäischen Gemeinschaften hat das Ziel eines vereinten Europas, das nicht auf Westeuropa beschränkt ist, nicht konsumiert ${ }^{102}$. Die Vereinigung Europas darf verfassungsrechtlich in Phasen verwirklicht werden, auch wenn die Fortentwicklung, Ausdehnung und Veränderung zu einem vereinten Europa vom Vertragsänderungs- und Ergänzungswillen aller Mitgliedstaaten abhängig gemacht wird. Verfassungsrechtlich besteht keine Herstellungs- oder Auswei-

\footnotetext{
${ }_{98}$ Vgl. Ipsen, Hans Peter: Der „Kulturbereich“ im Zugriff der Europäischen Gemeinschaft, in: Verfassungsrecht und Völkerrecht. Gedächtnisschrift für Wilhelm Karl Geck, 1989, S. 339 ff.

${ }_{99}$ Zur Entscheidung für eine offene Staatlichkeit vgl. Vogel, Klaus: Die Verfassungsentscheidung des Grundgesetzes für eine internationale Zusammenarbeit, 1964. (454).

100 Kirchbof, Paul: Gegenwartsfragen an das Grundgesetz, JZ 1989, S. $453 \mathrm{ff}$.

101 BVerfGE 73, 339 (386): „Auch die vom Grundgesetz verbürgten Grundrechte stehen im Gefüge der Verfassung als einer normativen Sinneinheit und sind demgemäß im Einklang und in Abstimmung mit anderen von der Verfassung normierten und von ihr anerkannten Rechtsgütern auszulegen und anzuwenden. Dazu gehört auch das Bekenntnis in der Präambel des Grundgesetzes zu einem vereinten Europa und zu den über Art. 24 Abs. 1 GG ermöglichten besonderen Formen supranationaler Zusammenarbeit." Vgl. dazu Streinz, Rudolf: Bundesverfassungsgerichtlicher Grundrechtsschutz und Europäisches Gemeinschaftsrecht, 1989, S. $260 \mathrm{ff}$

102 Vgl. z. B. Ress, Georg, a. a. O. (Anm.6), Rdn. 109; Schweisfurth, Theodor: Europabekenntnis und Wiedervereinigungsgebot des Grundgesetzes, in: Völkerrecht als Rechtsordnung - Internationale Gerichtsbarkeit - Menschenrechte. Festschrift für Hermann Mosler, 1983, S. 857 ff. (860ff.); a. A. Doebring, Karl, a. a. O. (Anm.16), S.634.
} 
tungspflicht. Die gegenteilige Ansicht hätte zur Folge, daß die Bundesrepublik schon aus Verfassungsgründen gehalten wäre, Aufnahmeanträge neuer Staaten in die Europäischen Gemeinschaften zu unterstützen oder ihnen zuzustimmen ${ }^{103}$. Drittens: Die Wahrung der Verfassungsidentität nach Art. 79 Abs. 3 reserviert auch die Staatlichkeit der Bundesrepublik (einschließlich des Staatsvolkes) ${ }^{104}$ im Sinne von Art. 20 Abs. 1 GG. Art. 24 Abs. 1 gestattet demnach nicht die Eingliederung in einen Bundesstaat, der nicht mehr als zwischenstaatliche Einrichtung begriffen werden könnte, wohl aber die Eingliederung in eine Europäische Union (short of a federal state) ${ }^{105}$.

Die Entwicklung der europäischen Integration hat zwar zur Zurücknahme der Kontrollnorm durch das BVerfG geführt ${ }^{106}$, nicht jedoch eine rechtliche Minderung der Funktionsnorm (der Verfassungsidentität) bewirkt. Die Gerichte der Bundesrepublik haben Auslegungsspielräume des Gemeinschaftsrechts zu nutzen, um eine Verletzung des verfassungsrechtlichen Kernbestands zu vermeiden. Dieser These liegt die kollisionsrechtliche Sicht zugrunde, daß die Pflicht zur gegenseitigen Rücksichtnahme gebietet, sich um eine Konkordanz von nationaler und Gemeinschaftsrechtsordnung $\mathrm{zu}$ bemühen ${ }^{107}$. Sofern das Gemeinschaftsrecht Entscheidungsspielräume über Art. 100 a Abs. 4 EWGV eröfnet, sind diese nicht nur zur Wahrung der Verfassungsidentität, sondern zur Wahrung der Normalverfas-

${ }^{103}$ Die in der Präambel verankerte Integrationsbereitschaft stellt lediglich eines von mehreren Momenten dar, die das politische Ermessen der zuständigen Behörden bei ihrer Prüfung von Beitrittsanträgen lenken (vgl. z.B. AK-GG-Zuleeg, 2. Aufl. 1989, Art. 21 Abs. 1 Rdn.4); im übrigen ist nicht ersichtlich, daß die verfassungsrechtliche Verpflichtung weiter gehen soll als diejenige im Rahmen des jeweiligen Integrationsverbands.

104 Vgl. Quaritsch, Helmut: Einbürgerungspolitik als Ausländerpolitik?, Der Staat 27 (1988), S. $481 \mathrm{ff}$ (496); a. A. Gramlich, Ludwig: Wahlrecht für nichtdeutsche Inländer, ZAR 1989, S. $51 \mathrm{ff}$.

$105 \mathrm{Vgl}$. Maunz, in Maunz/Dürig/Herzog/Scholz, Komm. z. GG, Art. 24 Rdn. 20; Ress, Georg: Souveränitätsverständnis in den Europäischen Gemeinschaften als Rechtsproblem, in: ders. (Hg.): Souveränitätsverständnis in den Europäischen Gemeinschaften, 1980, S. 11 ff. (16 ff.); ders.: Über die Notwendigkeit der parlamentarischen Legitimierung der Rechtsetzung der Europäischen Gemeinschaften, in: Verfassungsrecht und Völkerrecht. Gedächtnisschrift für Wilhelm Karl Geck, 1989, S. 625 ff. (668).

106 BVerfGE 73, 339 (378 ff.).

$107 \mathrm{Vgl}$. Streinz, a. a. O. (Anm. 101), S. $329 \mathrm{ff}$; Ress, Georg: Wechselwirkungen zwischen Völkerrecht und Verfassung bei der Auslegung völkerrechtlicher Verträge, in: Berichte der Deutschen Gesellschaft für Völkerrecht, Heft 23, 1982, S. 7 ff. (18f.). 
sung zu nutzen. Im übrigen läßt sich die Auswirkung dieser Zweckverlagerung bei den einzelnen Staatszwecken und -zielen nur für jedes einzelne Sachgebiet gesondert feststellen ${ }^{108}$.

\section{Der Staatszweck „Sicherheit “}

14. Nach 40 Jahren Grundgesetz besteht angesichts einer Reihe von Vorgängen Anlaß, sich der Bedeutung der Sicherheit als historisch primärem Staatszweck ${ }^{109}$ zu erinnern. Ein Beispiel wie die Hamburger Hafenstraße schafft ein paktiertes Ausnahmerecht; der Besuch von Amtsträgern bei Straßenblockaden untergräbt ebenso wie zahlreiche Phänomene der von der Verwaltung geduldeten Nichtbefolgung von Gesetzen - nicht generell, aber punktuell - den Rechtsgehorsam des Bürgers; Rechtsgehorsam wird moralisch desavouiert. Das Grundgesetz setzt die Gewährleistung der inneren Sicherheit als selbstverständliches Element des Rechtsstaats voraus. Streitigkeiten und Konflikte zwischen den einzelnen oder Gruppen innerhalb des Staates müssen friedlich, d.h. ohne Anwendung physischer Gewalt und in geordneten rechtlichen Verfahren ausgetragen werden. Dem modernen Staat steht als Element der inneren Souveränität das rechtsstaatlich gebundene Gewaltmonopol der demokratisch legitimierten Staatsgewalt $\mathrm{zu}^{110}$. Das parallele Verbot der Anwendung physischer Gewalt im Verhältnis zwischen den seiner Personal- und Territorialhoheit unterworfenen Personen kommt im Strafrecht, namentlich im Nötigungstatbestand, und im Vollstreckungsrecht zum Ausdruck. Friedenseinheit des Staates ohne Gewaltmonopol ist nicht denkbar; günstigstenfalls Friedenspluralismus, schlechtestenfalls und wahrscheinlicher: Anarchie. Der Monismus staatlicher Gewalt beruht als

\footnotetext{
108 Deutlicher noch, da vordergründiger, tritt diese Verlagerung bei bestimmten Staatsaufgaben hervor (vgl. z. B. für die Ausländerpolizei: Randelzhofer, Albrecht: Der Einfluß des Völker- und Europarechts auf das deutsche Ausländerrecht, 1980, S. $19 \mathrm{ff}$; für den Umweltschutz: Klöpfer, Michael: Umweltrecht, 1989, S. $289 \mathrm{ff}$.; zur Einordnung des Umweltschutzes vgl. z. B. Klöpfer, Michael: Umweltschutz und Verfassungsrecht, DVBI. 1988, 305; Murswiek, Dietrich: Umweltschutz Staatszielbestimmung oder Grundsatznorm?, ZRP 1988, 14).

${ }_{109}$ Vgl. Herzog, Roman: Staaten der Frühzeit, 1988, S. 75 f.; Isensee, Josef, a. a. O. (Anm. 28), S.3.

110 Vgl. z. B. Merten, Detlef: Rechtsstaat und Gewaltmonopol, 1975, S.62; Böckenförde, Ernst Wolfgang, a.a.O. (Anm. 34), S. 14; Kriele, Martin: Freiheit und Gleichheit, in: Benda, Ernst et al. (Hg.): Handbuch des Verfassungsrechts, 1983, S. $129 \mathrm{ff} .(136 \mathrm{f}$.).
} 
Teil des Rechtsstaats auf der Vorherrschaft des Rechts. Verfassungsrechtlich hat er seinen Ort in Art. 20 Abs. 1, 28 Abs. 1 S.1 GG, in der Rechtsweggarantie des Art. 19 Abs. 4 S.1 GG (mit der analogen Erstreckung auf die Zivilgerichtsbarkeit) und in Art. 93 Abs. 1 Nr. 4 a $\mathrm{GG}^{111}$.

15. Auch das - durch den Einbruch der Arbeitnehmerfreizügigkeit in die nationalen „öffentlichen" Verwaltungen nach Art. 48 Abs. 4 EWGV reduzierte ${ }^{112}$ - Beamtenprivileg des Art. 33 Abs. 4 GG läßt sich als indizierender Beleg für das grundgesetzlich vorausgesetzte Gewaltmonopol anführen. Die partielle Öfnung des Bereichs der öffentlichen Verwaltung für EG-Ausländer kann nicht durch eine rein nationale Interpretation dieses europarechtlichen Begriffs abgewehrt werden. Der Beamtenstatus ist entweder in Zukunft teilweise für EGAusländer zu öffnen oder auf bestimmte staatliche Funktionen (außerhalb des Leistungsbereichs) zu reduzieren ${ }^{113}$.

Dem staatlichen Gewaltmonopol korrespondiert die Pflicht des Bürgers zur friedlichen Rechtausübung; ihm ist Privatgewalt grundsätzlich untersagt: Selbsthilfe, Notwehr und Nothilfe stehen ihm nur bei Ausbleiben staatlichen Eingreifens zur Verfügung. Die in Art. 8 Abs. 1 GG beim Versammlungsrecht erwähnte Friedlichkeit ist für die Ausübung aller Grundrechte maßgebend ${ }^{114}$. Zwar darf die Interpretation der verfassungsrechtlich gebotenen Friedlichkeit den Gesetzes-

111 Vgl. Merten, Detlef: Konstruktionsprinzipien staatlicher Gewalt im Verfassungsstaat der Bundesrepublik, in: Randelzhofer, Albrecht/Süß, Werner ( $\mathrm{Hg}$.): Konsens und Konflikt, 1986, S. 324 ff. (325); Herzog, Roman, a.a. O. (Anm. 72), Rdn. 39 ff.

112 Deutlich wird diese Reduktion durch die neuere Rechtsprechung des EuGH in den Urteilen in der Rs.66/85, Lawrie-Blum/Land Baden-Württemberg, Slg. 1986, 2121 (2146f.) sowie der Rs.225/85, Kommission/Italien, Slg. 1987, 2625 (2638f.).

113 Vgl. zur Reduktionsmöglichkeit Lecheler, Helmut: Der öffentliche Dienst, in: Isensee, Josef / Kirchhof, Paul (Hg.): Handbuch des Staatsrechts, Bd. III, 1988, $\$ 72, \mathrm{Rdn} .34 \mathrm{ff}$. Der Ausweg des rein innerstaatlichen Verständnisses der „öffentlichen Verwaltung" besteht nicht. So aber Lecheler, Helmut: Öffentliche Verwaltung in den Mitgliedstaaten nach Maßgabe der "Dynamik der Europäischen Integration", Der Staat 22 (1989), S. $137 \mathrm{ff}$.

114 Vgl. Bethge, Herbert: Gewissensfreiheit, in: Isensee, Josef/Kirchhof, Paul (Hg.): Handbuch des Staatsrechts, Bd. VI, 1989, $\$ 137$ Rdn. 39; Isensee, Josef: Die Friedenspflicht der Bürger und das Gewaltmonopol des Staates, in: Staatsorganisationen und Staatsfunktionen im Wandel. Festschrift für Kurt Eichenberger, 1982, S. $23 \mathrm{ff}$. ( $26 \mathrm{ff}$.). 
vorbehalt des Art. 8 Abs. 2 GG nicht funktionslos machen ${ }^{115}$, jedoch geht Friedlichkeit dem Wortverständnis nach über die Abwesenheit physischer Gewalt hinaus (und kann auch Fälle passiver Resistenz erfassen $)^{116}$.

Der Einsatz des eigenen Körpers zu Blockadezwecken ist immer ein physisches Ereignis. Von einer „Vergeistigung des Gewaltbegriffs“ kann jedenfalls bei derartigen Handfestigkeiten keine Rede sein ${ }^{117}$. Um noch einmal im Bild von Hobbes und der klassischen Gesellschaftsvertragslehre zu bleiben: Der Gewaltverzicht des einzelnen zugunsten des Gewaltmonopols des Staates setzt voraus, daß der Staat auch garantiert, daß der für den demokratischen Meinungsbildungsprozeß unerläßliche Diskurs auch wirklich herrschaftsfrei, d.h. frei von Gewalt Dritter, sich vollzieht. Konsequenterweise wird unfriedlichen Versammlungsteilnehmern die Berufung auf Art. 2 Abs. 1 GG versagt, weil es eine Art "Naturrecht" zum unfriedlichen Versammeln ebensowenig gibt wie zum Morden oder Stehlen (selbst wenn derartige Strafbestimmungen gestrichen wären $)^{118}$.

Die nationale Rechtslage erfährt durch Art. 11 EMRK Bestätigung. Unfriedlich sind Blockadeversammlungen, bei denen durch den Einsatz der Versammelten der Verkehr blockiert und bestimmte Gebäude abgeriegelt werden. Es genügt aber nicht, daß Extremisten die Versammlung unterlaufen könnten, um sie dem Schutzbereich des Art. 11 EMRK zu entziehen ${ }^{119}$.

Auch der Staat darf den Bürger nicht - auch nicht augenzwinkernd - vom Rechtsgehorsam als - einziger - Grundpflicht freistellen ${ }^{120}$.

$115 \mathrm{Vgl}$. Herzog, Roman, in: Maunz/Dürig/Herzog/Scholz: Grundgesetz. Kommentar, 1989, Art. 8, Rdn. 71.

116 A. A. Frank, Götz: Das Gewaltmonopol des Staates und das Versammlungsrecht, in: Festschrift für Helmut Ridder, 1989, S. 37 ff. (47), der z. B. „Lächerlichmachungen durch das Werfen von Farbbeuteln oder faulen Früchten“ noch nicht als unfriedlich ansehen möchte.

117 Zutreffend die Beurteilung bei Christian Starck, Anmerkung zu BVerfG Urt. v. 11.11.1986 (E 73, 206), JZ 1987, S. 145 ff. (146).

$118 \mathrm{Vgl}$. Götz, Volkmar: Versammlungsfreiheit und Versammlungsrecht im Brokdorf-Beschluß des Bundesverfassungsgerichts, DVBl. 1985, 1347 (1352); Kröger, Klaus: Forum: Die vernachlässigte Friedenspflicht, JuS 1984, 172; Murswiek, Dietrich, a. a. O. (Anm. 24), S. 104.

119 Vgl. EKMR Beschwerde Nr. 8440/78 (Christians against Racism and Fascism gegen Vereinigtes Königreich) - Entscheidung v. 16.7.1980, EuGRZ 1981, 216 (217).

120 Vgl. zu dieser Grundpflicht Diskussionsbeitrag Doebring in der Aussprache zu "Grundpflichten als verfassungsrechtliche Dimension“, VVDStRL 41 (1983), S. 100; ders.: Das Staatsrecht der Bundesrepublik Deutschland, 3. Aufl. 1984, 
Das privilegienfeindliche demokratische Gesetz verkörpert als das Allgemeine auch die demokratische Gleichheit. Als Machteinheit muß der Staat sicherstellen, daß geltende Normen und getroffene Entscheidungen befolgt werden. Der gedankliche Zusammenhang zum klassischen Gesellschaftsvertrag wird hier besonders deutlich ${ }^{121}$. Dem einzelnen steht zwar kein allgemeiner Gesetzesvollziehungsanspruch $\mathrm{zu}^{122}$, wohl aber darf er als Kehrseite der Unterwerfung unter die staatliche Herrschaftsgewalt erwarten, daß Gleichheit und Allgemeinheit des Gesetzes beachtet werden. Die insgesamt desintegrierende Wirkung für den Staat als Friedenseinheit bei der Bildung von angeblich außerstaatlichen herrschaftsfreien Räumen, die realiter alles andere als herrschaftsfrei sind, vielmehr Ausprägungen eines Gewaltenpluralismus darstellen, ist evident. Der in der Rechtsordnung kraft des Gewaltmonopols gezähmte Leviathan tritt bei Gewaltenpluralismus diffus und ungezügelt seinen verheerenden Gang an ${ }^{123}$.

16. Die Gewissensfreiheit vermag im demokratischen Rechtsstaat zwar nach Art. 4 Abs. 1 und 3 GG und Art. 9 EMRK im Fall einer ernsthaften existentiellen Entscheidung für den einzelnen vom Rechtsgehorsam zu entbinden. Grenzen der Gewissensfreiheit sind indessen nicht nur der Bestand des Staates und die Möglichkeiten seiner Sicherung nach außen, sondern gerade auch der innerstaatliche Friedenszustand und der Schutz von Leben und Freiheit der Person. Das Grundrecht der Gewissensfreiheit stellt kein Privileg dar, das den Grundrechtsträger außerhalb des demokratischen Rechtsstaats stellt ${ }^{124}$.

17. Die im letzten Jahrzehnt erneut aufgebrochene Gegenüberstellung von Legalität und Legitimität des Rechts mit der daraus gezoge-

S. 278; vgl. ferner: Stern, Klaus: Idee und Herkunft des Grundpflichtdenkens, in: Staat und Völkerrechtsordnung. Festschrift für Karl Doehring, 1989, S. 969 ff.

$121 \mathrm{Vgl}$. Böckenförde, Ernst-Wolfgang, a. a. O. (Anm. 34), S. $14 \mathrm{f}$.

122 Vgl. Ress, Georg: Das subjektive öffentliche Recht, in: Ermacora, Felix et al. (Hg.): Allgemeines Verwaltungsrecht, 1979, S. 105 ff. (109).

${ }_{123}$ Vgl. zu einzelnen Problemfeldern derartiger Entwicklungen Sendler, Horst: Der Rechtsstaat im Bewußtsein seiner Bürger, NJW 1989, 1761.

${ }_{124} \mathrm{Vgl}$. Böckenförde, Ernst-Wolfgang: Das Grundrecht auf Gewissensfreiheit, VVDStRL 28 (1970), S. 33 ff. $(60,61$ Fn. 84); Herdegen, Matthias: Gewissensfreiheit und Normativität des positiven Rechts, 1989, S. $198 \mathrm{ff}$.; Klein, Hans H.: Gewissensfreiheit und Rechtsgehorsam, in: Staat und Völkerrechtsordnung. Festschrift für Karl Doehring, 1989, S. 479 ff. (497); weitergehend Franke, Dietrich: Gewissensfreiheit und Demokratie. Aktuelle Probleme der Gewissensfreiheit, AöR 114 (1989), S. 7 ff. (40 ff.). 
nen Konsequenz der rechtlichen Zulässigkeit sog. „begrenzter Regelverletzung" vermag in einem demokratischen Rechtsstaat Gehorsamsverweigerung des Bürgers nicht zu rechtfertigen. Die von Habermas und einer Reihe anderer Autoren aufgestellte These, daß auch im demokratischen Rechtsstaat legale Regelungen illegitim sein können, ist durchaus nicht sensationell. Wenn freilich daran die Konsequenz geknüpft wird, daß eine derartige Illegitimität gemessen an den „für alle einsichtigen moralischen Prinzipien " ${ }^{25}$ zur Gehorsamsverweigerung berechtige, dann geht diese Einsicht an dem natürlichen Spannungsverhältnis zwischen privaten Moralvorstellungen und staatlicher Rechtsordnung gerade in einer normalen Situation vorbei. Der Lösungsversuch, der die staatliche Rechtsordnung zu einem akzidentiellen Faktor der Moralordnung macht, kann nicht gelingen. Die Konfliktsituation zwischen moralischen Normen, die für verpflichtend angesehen werden, und staatlicher Rechtsordnung ist ein klassisches Paradigma - auch jenseits des Unrechtsstaats - und eine Situation, in die jeder geraten kann. Aber keine positive Rechtsordnung, so liberal und freiheitsverbunden sie sein mag, ist je in der Lage, solche Konfliktsfälle auszuschließen. Sie lassen sich von seiten der Rechtsordnung auch nicht dadurch lösen, daß die moralisch legitimierte Verweisung oder der Widerstand vorweg durch eine Art Legitimationsklausel in das normative Konzept hineingedacht werden. Auch wenn Habermas nur demjenigen, der die demokratischen Grundsätze anerkennt, das Recht auf zivilen Ungehorsam zuspricht, so läßt sich gerade im demokratischen Rechtsstaat die Autorität des Rechts und der Verfassung nicht allein auf die Gewalt des besseren Arguments zurückführen ${ }^{126}$. Die Bindung demokratischer Herrschaftsakte an die jeweilige konkrete Akzeptanz der Regierten ist keine Regelung des geltenden Rechts; die generelle Akzeptanz ist eine außerrechtliche Bedingung der tatsächlichen Rechtsgeltung ${ }^{127}$; sie steht aber gerade in der Normallage nicht in Frage. Die parlamentari-

125 Habermas, Jürgen: Ziviler Ungehorsam - Testfall für den demokratischen Rechtsstaat. Wider den autoritären Legalismus in der Bundesrepublik Deutschland, in: Glotz, Peter (Hg.): Ziviler Ungehorsam im Rechtsstaat, 1983, S. 29 ff. (39); vgl. dazu Starck, Christian: Der Frieden im Dreieck der Staatsziele, FAZ Nr. 64 v. 15.3.1984, S. 11.

126 Siehe dazu Ress, Georg: Die Autorität des Verfassungsrechts, in: Stein, Torsten $(\mathrm{Hg}$.): Die Autorität des Rechts. Verfassungsrecht, Völkerrecht, Europarecht, 1985, S. 5 ff. (13).

$127 \mathrm{Vgl}$. Doehring, Karl: Der Autoritätsverlust des Rechts, in: Festschrift für Ernst Forsthoff, 1972, S. 103 ff. (106). 
sche Demokratie verweist derartige Anliegen auf das Verfahren der Gesetzesänderung.

18. Sicherheit als Staatszweck umfaßt auch den Selbstschutz des Staates, da ohne ihn die innere und äußere Sicherheit nicht gewährleistet werden können. Nicht nur Vorkehrungen zum Schutz der freiheitlich-demokratischen Grundordnung, wie dies in den Bestimmungen der Art. 9 Abs. 2, 18, 21 Abs. 2 und 91 GG umschrieben ist, gehören dazu, sondern auch der Bestand und die Funktionsfähigkeit des Staates und seiner Einrichtung schlechthin ${ }^{128}$. Die Funktionsfähigkeit staatlicher Organe trat als Grundrechtsschranke erst spät, aber als ein dem Grundgesetz selbstverständlich ${ }^{129}$ zugrundeliegendes Schutzgut hervor. Die Funktionsfähigkeit in ihrer rechtlichen Bedeutung wird erst als Kehrseite des vom Bürger im Rahmen des Grundverhältnisses geleisteten Gewaltverzichts als Garant des inneren Friedens verständlich ${ }^{130}$.

Der Schutz staatlicher Funktionen als Teil des Schutzes der Rechtsordnung gehört im Rahmen der EMRK zu den in einer demokratischen Gesellschaft notwendigen Maßnahmen, wobei die zu schützende Staatsfunktion ihrerseits daraufhin überprüft werden muß, ob sie den Konventionszielen genügt ${ }^{131}$. Insofern bilden sich europäische Standards heraus, die auch für die Auslegung des nationalen Rechts (in der Bundesrepublik über das Rechtsstaatsprinzip, in Österreich über die Verfassung selbst) mittelbare Relevanz haben. Wird Funktionenschutz (wie der Schutz der Funktionsfähigkeit der Gerichte anhand der contempt of court-Regel, die das Ansehen und die Unparteilichkeit der Rechtsprechung gewährleisten soll) wie im Sunday-TimesFall ${ }^{132}$ des Straßburger Gerichtshofs als in einer demokratischen Gesellschaft (im Einzelfall) nicht notwendig angesehen, weil es an einem konkreten sozialen Bedürfnis fehle, die Freiheit der Gerichts-

${ }^{128}$ Zur Funktionsfähigkeit vgl. BVerfGE 32, 40 (46); 49, 24 (56f.); BVerwGE 43, 353 (355f.); 73, 237 (242 ff.); Isensee, Josef, a. a. O. (Anm. 56), Rdn. 118; Götz, Volkmar, a. a. O. (Anm. 21), Rdn. 22 (m.w. N.)

${ }^{129}$ BVerfGE 38, 105 (115f.); 38, 312 (321); kritisch insoweit Denninger, Erhard: Verfassungsrechtliche Schlüsselbegriffe, in: Festschrift für Rudolf Wassermann, 1985, S. 279 ff. (292).

130 Dies wird besonders bei der Frage der Funktionstüchtigkeit der Strafrechtspflege deutlich (vgl. Götz, Volkmar, a. a. O. [Anm.21], Rdn. 22).

$131 \mathrm{Vgl}$. Weidmann, Klaus W., a. a. O. (Anm. 88), S. $269 \mathrm{ff}$.

132 EGMR, Urt. v. 26. 4. 1979 - Times Newspaper Ltd. u. a. gegen Vereinigtes Königreich, EuGRZ 1979, 386 (389). 
berichterstattung einzuschränken, so verliert bei einer Berücksichtigung konkreter sozialer Bedürfnisse die tieferliegende Dimension der staatlichen Ordnungsfunktion gerade zum Schutz der Individualrechte und des inneren Friedens an Gewicht ${ }^{133}$.

Der moderne Staat ist vom Sicherheitsbewahrungs- zum Risikovorsorgestaat geworden ${ }^{134}$, wobei die Risikovorsorge im Begriff steht, sich bei einem sehr weiten Verständnis zu einem neuen Staatszweck der Zukunftsvorsorge auszudehnen ${ }^{135}$. Es sind nicht nur Gefahren abzuwehren, sondern es ist bestimmten, nicht zumutbaren Risiken vorzubeugen. Die Zumutbarkeit ist vom technisch-zivilisatorischen Entwicklungsstand abhängig, von der Art und dem Ausmaß des Schadens und der Wahrscheinlichkeit des Schadenseintritts ${ }^{136}$. Absolute Sicherheit kann es nicht geben. Jede Risikovorsorge muß deshalb mit dem Mangel an individueller Beherrschbarkeit, mit der Erheblichkeit der Gefahr und dem wahrscheinlichen Schadenseintritt gerechtfertigt werden. Hier gibt es eine Bandbreite vertretbarer Entscheidungen, die dem Gesetzgeber obliegen ${ }^{137}$. Ein sensibler Bereich, weil die Selbstverantwortung berührt wird, ist z.B. die Anschnallpflicht, durch die ein wohlfahrtsstaatlicher $Z$ wang zum Selbstschutz ausgeübt wird $^{138}$.

${ }_{133}$ Zur Kritik am Sunday-Times-Urteil vgl. z. B. Frowein, Jochen Abr., in: ders./Peukert, Wolfgang: EMRK-Kommentar, 1985, Art.10 Rdn. 16; Faweett, J.E.S., a. a. O. (Anm. 85), S. $270 \mathrm{ff.}$

${ }^{134}$ Vgl. Brewer, Rüdiger: Gefahrenabwehr und Risikovorsorge im Atomrecht, DVBl. 1978, S. 829 ff.; Bender, Bernd: Gefahrenabwehr und Risikovorsorge als Gegenstand nukleartechnischen Sicherheitsrechts, NJW 1979, S. 1425 ff.; Murswiek, Dietrich, a.a.O. (Anm.24), S. $127 \mathrm{ff}$; kritisch zu dieser Entwicklung wie ihrer rechtswissenschaftlichen Durchdringung Denninger, Erhard: Der Präventions-Staat, Kritische Justiz 1988, S. $1 \mathrm{ff}$.

135 Vgl. Henseler, Paul: Verfassungsrechtliche Aspekte zukunftsbelastender Parlamentsentscheidungen, AöR 108 (1983), S. 489 ff. (539ff.; 547 ff.); Hofmann, Hasso: Nachweltschutz als Verfassungsfrage, ZRP 1986, S.87ff.; Saladin, Peter: Verantwortung als Staatsprinzip, 1984, S. 118 ff.; ders. / Zenger, Christoph Andreas: Rechte künftiger Generationen, 1988, S. 15 ff.; von Hippel, Eike: Der Schutz des Schwächeren, 1982, S. $140 \mathrm{ff}$.

$136 \mathrm{Vgl}$. zur Frage der Zumutbarkeit z. B. BVerwG DÖV 1970, 713 (715); OVG Lüneburg DÖV 1978, 294 (296).

137 Vgl. Murswiek, Dietrich, a. a. O. (Anm. 24), S. 145.

138 Vgl. zur Anschnallpflicht BVerfG NJW 1977, 301; NJW 1987, 180; OLG Hamm, NJW 1985, 1790 sowie zur Schutzhelmpflicht BVerfGE 59, 275; vgl. dazu von Münch, Ingo: Grundrechtsschutz gegen sich selbst?, in: Hamburg - Deutschland - Europa. Festschrift für Hans Peter Ipsen, 1977, S. $113 \mathrm{ff}$. 
19. Der Staatszweck Sicherheit verbürgt zwar keine Freiheit vor Furcht und Angst, wohl aber Schutzpflichten des Staates für Leben, Gesundheit und andere grundrechtliche Schutzgüter. Die Schutzpflicht als Gewährleistungspflicht folgt aus dem Zweck des Staates oder verfassungsrechtlich gewendet: aus dem Grundverhältnis in Verbindung mit der objektivrechtlichen Seite der Grundrechte ${ }^{139}$. Die Gewährleistungspflicht besteht auch gegenüber dem werdenden Leben und hängt nicht davon $a b$, ob wenigstens theoretisch die Möglichkeit besteht, bei Versagen staatlichen Schutzes Selbsthilfe zu üben ${ }^{140}$. Der Schutzzweck konkretisiert sich in einzelnen Grundrechten. Der staatstheoretischen Ableitung entspricht die verfassungsrechtliche Einordnung. Sie entlastet die Grundrechte in ihrer Begründungsfunktion ${ }^{141}$. Die zweckbedingten objektiven Schutzpflichten des Staates, für die die Grundrechte Maßstab sind, umfassen die Pflicht, effektiven und dem Rechtsgut angemessenen Schutz zu gewährleisten. Der strafrechtliche Schutz stellt ein Höchstmaß dar; der Gegenschluß, daß ein Verhalten, welches nicht unter Strafe gestellt ist, als rechtmä-

${ }^{139}$ Das BVerfG (E 77, 170 [214] m.w. N.) rekurriert nur auf die Grundrechte. Theoretisch richtiger ist der Ansatz bei Eckart Klein (ders.: Grundrechtliche Schutzpflichten des Staates, NJW 1989, S. 1633 ff.).

${ }_{140}$ Klein, Eckart, a. a. O. (Anm. 139), S. 1635 f.; Robbers, Gerhard: Sicherheit als Menschenrecht, 1987, S. 127.

141 Die Anknüpfung an die objektiv-rechtliche Funktion der Grundrechte (insbesondere Art. 2 Abs. 2 GG) als wertentscheidende Grundsatznorm wird dadurch nicht überflüssig oder sinnlos. Die Aussage des BVerfG, daß das "Gesetz (man muß hinzufügen: insbesondere die Grundrechte) bleibender Ausdruck sozialethischer - und ihr folgend - rechtlicher Bewertung menschlicher Handlungen ist" (BVerfGE 39, 1 [59]), bleibt gültig. Staatszweck und Wertbetrachtung könnten in der Rechtsordnung der Bundesrepublik als austauschbar oder völlig komplementär begriffen werden, was mit der Konstruktion des Art. 2 Abs. 1 GG als allgemeine Handlungsfreiheit zusammenhängt, womit ein geschlossener Grundrechtsschutz (und parallel: ein geschlossenes Wertesystem) ermöglicht wird. Im europäischen Kontext verfügen viele Verfassungen nicht über ein derartig lückenloses Grundrechtssystem. Der Zweck des Staates, gegenüber Dritten zu schützen, ist von der Existenz cines solchen Systems auch nicht abhängig. Es mag bezeichnend sein, daß sich gerade in Großbritannien (nicht erst seit Dicey's Auslegung der rule of law als Bindung an das Recht, als Gleichbehandlung unter dem Recht und als Schutz [vgl. Dicey, A.V.: Introduction to the Study of the Law of the Constitution, 10. Aufl. 1960, S. $188 \mathrm{ff}$.$] ) als Element der rule of law die "principles of private law" als$ "rights of individuals" als der Verfassung vorausgehende Rechtsgrundlagen entwickelt haben (the law of the constitution is not the source but the consequence of the right of the individuals [vgl. a. a. O., S. 203]) und daß der Staat durch common law remedies diese Rechte zu schützen hat. 
Big und erlaubt zu gelten habe, verbietet sich schon deshalb, weil der strafrechtliche Schutz nur in Ausnahmefällen erforderlich ist. Der Rechtsgüterschutz kann zusätzlich in einer zivil- oder verwaltungsrechtlichen Norm Ausdruck finden und muß dies, wenn sich herausstellt, daß der strafrechtliche Schutz unzureichend ist - ein Problem, das sich z. B. bei der Frage der Zulässigkeit von Sozialversicherungsleistungen für nichtstrafbare Abtreibungen deutlich zeigt ${ }^{142}$. Als Grundregulativ, aber auch nur als solches, genügt eine allgemeine Schadensersatzgeneralklausel, die jedoch für einen differenzierteren, dem Gewicht des einzelnen Rechtsguts angemessenen Schutz nicht ausreicht ${ }^{143}$.

Aus diesen Erwägungen ergeben sich für die Regelung des sog. gezielten (oder finalen) Todes- oder Rettungsschusses Anhaltspunkte. Der Staat hat den Schutz des Lebens von Geiseln durch klare gesetzliche Regelungen sicherzustellen und darf den eigenen Vollzugsbeamten nicht auf die für Bürger geltenden strafrechtlichen Rechtfertigungsgründe verweisen. Die Einsicht, daß es sich um die Pflicht des Staates zur Abwehr der Höchstform von Privatgewalt, nämlich der rechtswidrigen Bedrohung des Lebens, handelt, ist in der öffentlichen Diskussion zugunsten einer Äquivalenzbetrachtung mit der direkten Lebensbedrohung des Täters zurückgetreten. Eine solche Betrachtung verkennt die dem Staatszweck Sicherheit innewohnende Verpflichtung zum Lebensschutz vor rechtswidriger Gewaltanwendung. Eine Regelung über die Zulässigkeit des gezielten Todesschusses ist mit Art. 2 Abs. 2 a EMRK vereinbar, der - zum Teil enger als die privaten strafrechtlichen Rechtfertigungsgründe - auch sicherstellt, daß eine polizeirechtliche Regelung den Rahmen des ordre public européen nicht verläßt ${ }^{144}$.

Die Ableitung der Pflicht des Staates zum ausreichenden Rechtsgüterschutz aus den Grundrechten ist im Begriff, zum Bestandteil der

${ }^{1+2} \mathrm{Vgl}$. hierzu Isensee, Josef: Abtreibung als Leistungstatbestand der Sozialversicherung und der grundrechtliche Schutz des ungeborenen Lebens, NJW 1986, 1645 (1646 ff.); Geiger, Willi: Abtreibung und Rechtsordnung, JURA 1987, 60 (65).

${ }_{143}$ Denn dieses Grundregulativ wird schon dem präventiv gestellten Schutzauftrag nicht gerecht (vgl. Robbers, Gerhard, a. a. O. [Anm. 140], S. 127).

${ }_{14}$ Vgl. Doebring, Karl: Zum „Recht auf Leben“ aus nationaler und internationaler Sicht, in: Völkerrecht als Rechtsordnung -- Internationale Gerichtsbarkeit Menschenrechte. Festschrift für Hermann Mosler, 1983, S. 145 ff.; Frowein, Jochen Abr.: in: ders. / Peukert, Wolfgang: EMRK-Kommentar, 1985, Art. 2, Rdn. 10 f.; Merten, Detlef: Zum Streit um den Todesschuß, in: Staat und Völkerrechtsordnung. Festschrift für Karl Doehring, 1989, S. 579 ff. (584, 595 f.) 
gemeineuropäischen Rechtskultur zu werden ${ }^{145}$. Der französische Conseil Constitutionnel hat aus den objectifs de valeur constitutionnels Regelungspflichten des Gesetzgebers zur Wahrung der Pluralität im Rundfunk-, Fernsehen- und Pressebereich, einschließlich deren finanzieller Transparenz hergeleitet ${ }^{146}$. Ebenso hat der Straßburger Gerichtshof aus Art. 8 EMRK die Verpflichtung des Staates zum positiven Schutz des Privatlebens durch Gesetzgebung hergeleitet und den Staat zum Erlaß von Strafrechtsnormen für verpflichtet angesehen $^{147}$.

20. Aus dem Staatszweck „Sicherheit“ allein ergibt sich noch kein Grundrecht ${ }^{148}$ oder Menschenrecht auf Sicherheit ${ }^{149}$. Ein Menschenrecht ließe sich allenfalls bei einer extensiven Interpretation aus Art. 5 Abs. 1 EMRK entnehmen, auch wenn es von den Konventionsorganen bisher nicht i.S. einer positiven Handlungspflicht des Staates gedeutet wurde ${ }^{150}$. Es liegt nahe, ein solches Recht aus dem Grundverhältnis in Verbindung mit der objektiv-rechtlichen Seite der Grundrechte herzuleiten. Die Grundrechte geben dem allgemeinen Schutzanspruch des Bürgers auf diese Weise inhaltliche Konturen und dogmatische Fundierung ${ }^{151}$.

21. Der Staat muß zur Friedensgewährleistung angemessene und effektive Verwaltungs- und Gerichtsverfahren zur Verfügung stellen. Ein Justizgewährungsanspruch folgt aus den Grundrechten und dem Rechtsstaatsprinzip, deutlicher noch aus Art. 6 EMRK, der insgesamt

145 Vgl. Classen, Claus Dieter: Die Ableitung von Schutzpflichten des Gesetzgebers aus Freiheitsrechten - ein Vergleich von deutschem und französischem Verfassungsrecht sowie der Europäischen Menschenrechtskonvention, JöR 36 (1987), S. $29 \mathrm{ff}$.

${ }_{146}$ Vgl. Conseil Constitutionnel, Urt. Nr. 86-210 DC v. 29. 7. 1986, J. O. 1986, S. 9393 (9393); Nr. 84-181 DC v. 10. u. 11.10.1984, J.O. S. 3200 (3201); Genevois, Bruno: La jurisprudence du Conseil Constitutionnel, 1988, S. $204 \mathrm{ff}$.

147 Vgl. EGMR, Urt. v. 9. 10.1979, Airey gegen Irland, EuGRZ 1979, 626 (629); Urt. Nr. 16/1983/72/110 v. 26.3.1985 - X und Y gegen Niederlande, EuGRZ 1985, 297 (299), sowie Frowein, in: Frowein/Peukert, a. a. O. (Anm. 144), Art.8, Rdn. $8 \mathrm{f}$.

148 So aber Isensee, a. a. O. (Anm. 20), S. 33 f.

149 So aber Robbers, a. a. O. (Anm. 140), S. $13 \mathrm{ff}$.

${ }^{150}$ Nachweise bei Peukert, in: Frowein/Peukert, a.a. O. (Anm.133), Art. 5 Rdn. 4 ff. Robbers (a.a.O. [Anm. 140], S.23) lehnt eine solche Interpretation ebenfalls ab. Der Wortlaut spricht aber dafür.

151 In diesem Sinne deutlich Murswiek, Dietrich, a.a.O. (Anm. 24), S. $102 \mathrm{ff}$. und andeutungsweise auch Klein, Eckart, a. a. O. (Anm.139), S, 1636. 
als Bestandteil des Rechtsstaatsprinzips anzusehen ist. Art. 19 Abs. 4 GG, der umfassenden und effektiven Rechtsschutz gegen die Exekutive gewährt, bildet nur einen Teilaspekt des Justizgewährungsanspruchs. Ebenso wie Art. 19 Abs. 4 verbürgt Art. 13 EMRK keinen Rechtsschutz gegen die Legislative ${ }^{152}$. Die überlange Verfahrensdauer, die schon mehrfach zu Verurteilungen durch den Straßburger Gerichtshof geführt hat, kann sich zur Rechtsstaatsverweigerung auswachsen, wenn die friedensstiftende Funktion der letztinstanzlichen Entscheidung über Jahre, ja bis ein Jahrzehnt, hinausgezögert wird ${ }^{153}$. Der verfassungsrechtlich zumindest prinzipiell gebotene Suspensiveffekt von Rechtsbehelfen und Anfechtungsklagen nach Art. 80 VwGO zeigt das Gegenbild zu Frankreich, wo ein solcher Effekt jeweils erst gerichtlich ausgesprochen werden muß - was relativ selten geschieht. Dieser bescheiden anmutende Unterschied zeigt mehr an fundamentaler Grundkonzeption des Staat-Bürger-Verhältnisses, als es durch feierliche Erklärungen möglich ist ${ }^{154}$.

22. Die Europäisierung der Entscheidungen über Sicherheitsstandards führt zu einem Auseinanderfallen von Rechtssetzungsbefugnis und Durchsetzungsbefugnis ${ }^{155}$. Da sich die Befugnis zur Definition und Festlegung von Sicherheitsstandards - insbesondere im Bereich

152 Vgl. EGMR, Beschwerden Nr. 7106/76, I. Mc. L. Young u. N. H. James gg. Vereinigtes Königreich u. 7806/77, R. R. Webster gg. Vereinigtes Königreich, EuGRZ 1980, 450 (454).

153 Vgl. EGMR, Urt. v. 28.6. 1978, Fall König, EuGRZ 1978, 406 (415 ff.); Urt. v. 15.7.1982, Hans und Marianne Eckle gegen die Bundesrepublik Deutschland, EuGRZ 1983, 371 (379 ff.) sowie Peukert, a. a. O. (Anm. 144), Art. 6 Rdn. 104 ff.; Ulsamer, Gerhard: Europäische Menschenrechtskonvention und deutsche Strafverfolgungspraxis, in: Festschrift für Wolfgang Zeidler, Bd.2, 1987, S. $1799 \mathrm{ff}$. (1804f., $1807 \mathrm{f}$.)

${ }_{154}$ Nachweise bei Ress, Georg (Hg.): Grenzüberschreitende Verfahrensbeteiligung im Umweltrecht der Mitgliedstaaten der Europäischen Gemeinschaften, 1985, S. 15, 152; vgl. auch Bullinger, Martin: Der Gerichtsschutz gegenüber der vollziehenden Gewalt in rechtsvergleichender Sicht, in: Gerichtsschutz gegen die Exekutive, Bd. 3, 1971, S. 199 ff. (209); Debbasch, Charles/Ricci, Jean-Claude: Contentieux administratif, 1985, Rdn. $462 \mathrm{ff}$.; Woehrling, Jean-Marie: Verwaltungsgerichtlicher Rechtsschutz in Frankreich auf dem Gebiet des Umweltrechts - unter Einschluß der Probleme grenzüberschreitender Verfahrensbeteiligung - (Vorträge, Reden und Berichte aus dem Europa-Institut der Universität des Saarlandes, Nr. 70), 1986, S. 15 f.

155 Letztere fehlt den Gemeinschaften, vgl. Stein, Torsten: Die Autorität des Europäischen Gemeinschaftsrechts, in: ders. (Hg.): Die Autorität des Rechts. Verfassungsrecht, Völkerrecht, Europarecht, 1985, S. 53 ff. (54). 
der Produktsicherheit - in einem erheblichen Umfang auf die Organe der EG verlagert hat ${ }^{156}$ - die EG hat erst kürzlich einen Vorschlag für eine allgemeine Produktsicherheitsrichtlinie vorgelegt ${ }^{157}-$, verbleibt den Mitgliedstaaten lediglich die - angesichts der unmittelbaren Wirkung zahlreicher Richtlinienbestimmungen häufig auf automatischen Nachvollzug beschränkte - Rechtsdurchsetzung. Die Entwicklung tendiert zur Zulassung der Sicherheitsstandards nach dem jeweiligen Herkunftsland ${ }^{158}$, was nicht nur die nationalen Gerichte mit der Anwendung ausländischen Verwaltungsrechts als Vorfragen ${ }^{159}$ in ungeahntem Ausmaß konfrontieren, sondern auch für den Bürger einen schwer durchschaubaren Sicherheitspluralismus zur Folge haben wird ${ }^{160}$. Als Etappe auf dem Weg zu einer Rechtsharmonisierung ist eine derartige Zwischenlösung wohl unvermeidlich ${ }^{161}$.

\section{Insbesondere: äußere Sicherheit}

23. Das ius defensionis - die Wahrung der äußeren Sicherheit wird zu den klassischen Staatszwecken gerechnet. Der Staat muß

${ }_{156} \mathrm{Vgl}$. Langeheine, Bernd, in: Grabitz, Eberhard (Hg.): Kommentar zum EWG-Vertrag, 1989, Art. 100, Rdn. 63 ff. Begünstigt wird diese Verlagerung durch die mit der EEA erfolgte Einführung des Art. 100 a EWGV als Rechtsangleichungsregelung.

157 ABI EG C 193 v. 31.7.1989, S.1.

${ }^{158} \mathrm{Zu}$ dem zugrundeliegenden Äquivalenzgrundsatz vgl. z. B. Müller-Graff, Peter-Christian: Die Rechtsangleichung zur Verwirklichung des Binnenmarktes, EuR 1989, S. 107 ff. (111); Bruba, Thomas: Rechtsangleichung in der Europäischen Gemeinschaft. Deregulierung durch „Neue Strategie“?, ZaöRV 1986, 1 (6ff.).

${ }_{159}$ Über die Art und die Grenzen der Anwendbarkeit ausländischen öffentlichen Rechts herrscht in den Mitgliedstaaten der EG alles andere als Einigkeit. Vgl. dazu den Bericht von P. B. Carter: Transnational Recognition and Enforcement of Foreign Public Laws, in: International Law Association, 63rd Conference Warsaw 1988, S. $719 \mathrm{ff}$.

${ }_{160}$ Diese Entwicklung erschwert den nationalen Verbraucherschutz. Die Bedenken sind im Anschluß an die Entscheidungen des EuGH zum Reinheitsgebot für Bier (EuGH, Rs. 178/84, Kommission/Deutschland, Slg. 1987, 1227 ff.) und zu Zusatzstoffen in der "Deutschen Wurst“ (EuGH, Rs. 274/87, Kommission/ Deutschland, Urt. v. 2.2.1989, [1989] 2 Common Market Law Reports 733) erhoben worden (vgl. dazu Rabe, Hans-Jürgen: Freier Warenverkehr für Lebensmittel nach dem Bier-Urteil des EuGH, EuR 22 (1987), 253 (259); van Rijn, Thomas: A Review of the Case Law of the Court of Justice on Articles 30 to 36 EEC in 1986 and 1987, Common Market Law Review 25 (1988), 593 (609 ff.).

$161 \mathrm{Vgl}$. Langeheine, Bernd: Rechtsangleichung unter Art. 100 a EWGV Harmonisierung vs. nationale Schutzinteressen -, EuR 1988, 235 (255 f.); MüllerGraff, Peter Christian, a. a. O. (Anm. 158), S. 151. 
Sicherheit nicht nur im Inneren, sondern auch gegenüber dem äußeren Feind gewährleisten ${ }^{162}$. Dieser Staatszweck ist davon unabhängig, ob eine völkerrechtliche Verpflichtung zur Unterhaltung von Streitkräften und zur Selbstverteidigung für den Staat besteht. Da sich aus dem Völkerrecht keine grundsätzliche Verpflichtung, sondern nur das Recht zur Aufstellung von Streitkräften und zur Selbstverteidigung herleiten läßt, stellt die Regelung in Art. 87 a Abs. 1 GG, wonach der Bund Streitkräfte zur Verteidigung aufstellt, einen originären Verfassungsauftrag dar, der den latent dahinter liegenden Staatszweck aufgreift $^{163}$. In der Bundesrepublik Deutschland besteht nach wie vor eine doppelte Wehrverfassung: die des Grundgesetzes in Verbindung mit dem NATO-Vertrag und dem NATO-Truppenstatut und daneben die von den Alliierten durch die Erklärung vom 5.Juni 1945 formalisierte, auf Deutschland als Ganzes und insbesondere auf Berlin bezogene Befugnis zur besatzungsrechtlichen Truppenstationierung. Mögen diese originären, d.h. bündnisunabhängigen Stationierungsrechte, wie sie in Art. 4 Abs. 2 S. 1 des Deutschland-Vertrages angesprochen und vom Bundesverfassungsgericht im Pershing-II-Urteil ${ }^{16+}$ erwähnt worden sind, bislang auch keine Rolle gespielt haben, weil die originär stationierten mit den NATO-assignierten Truppen identisch sind und dem NATO-Truppenstatut nebst Zusatzabkommen unterliegen, so träten diese originären Stationierungsrechte doch bei Kündigung des NATO-Vertrages und des NATO-Truppenstatuts unvermindert hervor ${ }^{165}$.

Die Einrichtung und Funktionsfähigkeit der Bundeswehr haben verfassungsrechtlichen Rang. Das grundgesetzliche Gebot der militärischen Funktionsfähigkeit erfordert einen Versorgungs- und Ausrüstungsstand, mit dem die ständige effektive Einsatzbereitschaft der

162 Vgl. Bluntschli, J. C.: Lehre vom modernen Staat, Erster Teil: Allgemeine Staatslehre, 6. Aufl. 1886, S. 362 ff.; Jellinek, Georg, a. a. O. (Anm. 26), S. 255 f.; von Humboldt, Wilhelm: Werke, 1.Bd. (1785-1795), 1903, S.97 ff. (134); Herzog, Roman, a.a. O. (Anm. 109), S. 75 f.

${ }_{163}$ Vgl. Kirchbof, Ferdinand, a. a. O. (Anm. 95) Rdn. 7 ff.; Hernekamp, KarlAndreas, in: v. Münch, Ingo: GG-Kommentar, Bd.3, 2. Aufl. 1983, Art.87a, Rdn. 7; eine völkerrechtliche Pflicht zur Aufstellung von Streitkräfren und zur Selbstverteidigung besteht nur für dauernd neutrale Staaten (vgl. Verdross/Simma, a. a. O. [Anm. 58], \$401).

16- BVerfGE 68, 1 (110).

${ }^{165}$ Vgl. hierzu z. B. Frowein, Jochen Abr.: Die Rechtslage Deutschlands und der Status Berlins, in: Benda, Ernst et al. (Hg.): Handbuch des Verfassungsrechts, 1983, S. 29 ff. (42 ff.); Ress, Georg, a. a. O. (Anm. 7), S. 38 f.; Schweisfurth, Theodor: Deutschland -- immer noch ein besetztes Land, in: Völkerrecht - Recht der 
Streitkräfte aufrechterhalten werden kann ${ }^{166}$. Die Würdigung des weiten Beurteilungsspielraums insbesondere des Haushaltsgesetzgebers, dessen Grenzen nur bei offensichtlicher Willkür überschritten werden, hat sich an dieser Funktionsfähigkeit zu orientieren ${ }^{167}$.

24. Darüber hinaus ist die äußere Friedenssicherung nicht nur über Art. $25 \mathrm{GG}$ an dem Völkerrecht, sondern durch Art. 26 GG positiv an der Verpflichtung ausgerichtet, das friedliche Zusammenleben der Völker nicht zu stören. In Verbindung mit dem Bekenntnis zu Menschenrechten als Grundlage des Friedens und der Gerechtigkeit in der Welt verpflichtet das Grundgesetz damit die Bundesrepublik Deutschland auf eine menschenrechtsbewußte Außenpolitik, verbietet demnach auf jeden Fall eine in dieser Hinsicht völlig indifferente Haltung ${ }^{168}$.

Gegen die These, daß die Kriegswaffenherstellung als solche schon ein potentieller Störungsfaktor des friedlichen Zusammenlebens ist, spricht Art. 26 Abs. 2, der von der prinzipiellen Zulässigkeit ausgeht. Der Staatszweck der äußeren Sicherheit wird unter den heutigen Bedingungen auch im Rahmen von kollektiven Sicherheitssystemen (Art. 24 Abs. 2 GG) wahrgenommen.

$\mathrm{Zu}$ einem für das ius defensionis maßgeblichen Diskussionspunkt ist der Einsatz der Streitkräfte der UN-Peace-Keeping-Forces geworden. Die Verfassung verbietet einen derartigen Einsatz nicht, regelt ihn aber auch nicht ausdrücklich. Die verfassungsrechtliche Schranke des Art. 87 a Abs. 2 bestimmt, daß die Streitkräfte „außer zur Verteidigung... nur eingesetzt werden (dürfen), soweit dieses Grundgesetz es

Internationalen Organisationen - Weltwirtschaftsrecht. Festschrift für Ignaz Seidl-Hohenveldern, 1988, S. 537 ff. (549ff., 566 ff.); Stein, Torsten: Landesverteidigung und Streitkräfte im 40. Jahr des Grundgesetzes, in: Staat und Völkerrechtsordnung. Festschrift für Karl Doehring, 1989, S. 935 ff. (938 Fn. 14).

166 Vgl. st. Rspr. des BVerfG (E 28, 36 [47]; 32, 40 [46]; 48, 127 [159]) und des BVerwG (E 55, 217 [219]; 63, 37 [38]; 63, 99 [101]) sowie Brunkow, Wolfgang: Rechtliche Probleme des Einsatzes der Bundeswehr auf dem Territorium der Bundesrepublik Deutschland nach Art.87 a GG, 1971, S.30; Dürig, in: Maunz/ Dürig/Herzog/Scholz: Grundgesetz. Kommentar, 1989, Art. 87 a, Rdn. 19; Kirchhof, Ferdinand: Bundeswehr, a. a.O. (Anm.95), Rdn. 9; a. A.: Lutz, DieterS./ Rittberger, Volker: Abrüstungspolitik und Grundgesetz, 1976, S. $42 \mathrm{f}$.

167 Letztere darf niemals isoliert, sondern stets nur in Zusammenhang mit einer in einem bestimmten Zeitpunkt gegebenen sicherheitspolitisch-strategischen Lage beurteilt werden. Es gibt kein absolutes, starres Niveau der Sicherheit, sondern nur eine Spannbreite, unterhalb derer von einer Verletzung des Verteidigungsauftrages gesprochen werden kann. Vgl. Stein, Torsten, a. a. O. (Anm. 165), S. 938.

${ }_{168} \mathrm{Vgl}$. auch Bleckmann, Albert: Grundgesetz und Völkerrecht, 1975, S. $238 \mathrm{f}$. 
ausdrücklich zuläßt“. Diese Schranke ist deshalb nicht berührt, weil es sich bei einer UN-Truppenbeteiligung um einen durch Art. 24 Abs. 2 im Rahmen des kollektiven Sicherheitssystems zugelassenen Einsatz handelt. Der Begriff Verteidigung schließt selbstverständlich den Einsatz im Rahmen normaler Bündnisverpflichtungen und auch in einem System kollektiver Sicherheit ein. Schutz des Friedens zwischen verfeindeten Staaten oder Sicherung des Unabhängigkeitsprozesses (in Namibia) ${ }^{169}$ lassen sich dem völkerrechtlichen Begriff der Verteidigung nicht einordnen, wohl aber dem der internationalen Sicherheit (Art. 11 UN-Charta) ${ }^{170}$.

Zum Staatszweck Sicherheit gehört auch der diplomatische Schutz Deutscher im Ausland, auf den der Bürger am Maßstab der Grundrechte Anspruch hat. Diesen Anspruch kann jeder Deutsche - einschließlich der Bewohner der DDR - in Anspruch nehmen ${ }^{171}$. Drittstaaten haben bei konkurrierenden Staatsangehörigkeiten (wie zwischen der deutschen Staatsangehörigkeit und der Staatsbürgerschaft der DDR) im Prinzip ein Auswahlermessen, welchem Heimatstaat des Betroffenen sie den Schutz gestatten wollen. Dabei ist nicht nur die nähere Bindung (genuine link) entscheidend, sondern aufgrund der Anerkennung der Menschenrechte dem Willen des Betroffenen der Vorrang einzuräumen ${ }^{172}$.

169 Vgl. Stein, Torsten, a. a. O. (Anm. 165), S. 938, $940 \mathrm{f.}$

170 So auch Coridaß, Alexander: Der Auslandseinsatz von Bundeswehr und Nationaler Volksarmee, 1985, S.87f.; Kersting, Klaus: Kollektive Sicherheit durch peace keeping operations. Insbesondere: Zur Beteiligung der Bundeswehr an UNAktionen, NZWehrr 1983, 64 (72); Mössner, Jörg Manfred: Bundeswehr in blauen Helmen, in: Staatsrecht - Völkerrecht - Europarecht. Festschrift für HansJürgen Schlochauer, 1981, S.97ff. (110f.); Speth, Wolfgang: Rechtsfragen des Einsatzes der Bundeswehr unter besonderer Berücksichtigung sekundärer Verwendungen, 1985, S. $162 \mathrm{ff}$; a.A. Klein, Eckart: Rechtsprobleme einer deutschen Beteiligung an der Aufstellung von Streitkräften der Vereinten Nationen, ZaöRV 34 (1974), 429 (442f.); Riedel, Norbert Karl: Der Einsatz deutscher Streitkräfte im Ausland, 1989, S. 195 f.; von Bülow, Christoph: Der Einsatz der Streitkräfte zur Verteidigung, 1984, S. $198 \mathrm{ff}$.

171 Vgl. Doehring, Karl: Die Pflicht des Staates zur Gewährung diplomatischen Schutzes, 1959, S. 14 ff., 89 ff.; Geck, Wilbelm Karl: Diplomatic Protection, in: R. Bernhardt (ed.), Encyclopedia of Public International Law, Instalment 10 (1987), S. 99 ff. (105); Klein, Eckart: Diplomatischer Schutz und grundrechtliche Schutzpflicht, DÖV 1977, 704 ff.; Ress, Georg: Diplomatischer Schutz, in: SeidlHohenveldern, Ignaz (Hg.): Lexikon des Rechts. Völkerrecht, 1985, S. 54 ff.

${ }_{172} \mathrm{Vgl}$. Hailbronner, Kay: Deutsche Staatsangehörigkeit und diplomatischer Schutz durch die Bundesrepublik Deutschland, JZ 1975, 596 (598f.); Ress, Georg, 


\section{Zum Staatszweck „Freiheit“}

25. Der Staatszweck Freiheit ist am Bild des zu freier Selbstbestimmung und selbstverantwortlicher Lebensführung berufenen Menschen ausgerichtet. Zum Staatszweck Freiheit gehören die im demokratischen Rechtsstaat zur Freiheitssicherung notwendigen Vorkehrungen, u. a. - neben der Zweckbindung des staatlichen Handelns am Gemeinwohl - die Gewaltenteilung, der Gesetzesvorbehalt, die Menschen- und Grundrechte, das demokratische Wahlverfahren, die Sicherung der Gründungsfreiheit und Artikulationsfähigkeit für die politischen Parteien, die Kontrolle der Exekutive, die Verantwortlichkeit der Regierung und schließlich die Kontrolle aller staatlichen Gewalten durch das BVerfG ${ }^{173}$.

26. Als Herzstück des modernen Verfassungsstaates gilt nicht nur die Gewährleistung vorstaatlicher Menschenrechte, sondern auch die Verbürgung verfassungsrechtlicher Grundfreiheiten, wie sie in Art. 1 Abs. 3 GG verankert ist und durch die Verfassungsbeschwerde ihre prozessuale Krönung erfahren hat. Für dieses „unaufgebbare Essentiale“ ${ }^{174}$, wie es im 1. Solange-Beschluß des BVerfG hieß, ist nach 40 Jahren Grundgesetz die Ergänzungs- und Verdrängungsfunktion der europäischen Rechtsordnung höchst bemerkenswert. In der Bundesrepublik Deutschland verfügt jeder über eine völkerrechtlich gesicherte (freilich von der Verlängerung der Unterwerfungserklärung abhängige) Beschwerdebefugnis vor der Menschenrechtskommission gegen den Staat. Der einzelne wird damit zum Träger völkerrechtlicher Rechtspositionen - die auch bestehen, wenn, wie in anderen Staaten häufig, die Europäische Menschenrechtskonvention nicht in innerstaatliches Recht umgesetzt worden ist $\mathrm{t}^{175}$. Darüber hinaus hat in der Bundesrepublik Deutschland jeder EG-Angehörige einen eigen-

a. a. O. (Anm. 171), S. 55; kritisch Kammann, Karin: Probleme mehrfacher Staatsangehörigkeit, 1984, S. $61 \mathrm{f}$.

${ }_{173} \mathrm{Da}$ der Freiheitszweck auch auf die persönliche Teilnahme des Bürgers am politischen Entscheidungsprozeß ausgerichtet ist, kann auch die Demokratie als die organisatorische Seite der persönlichen Freiheit als Staatszweck betrachtet werden (vgl. Bethge, a. a. O. [Anm. 1], S. 849).

174 BVerfGE 37, 271 (280).

175 Wozu die Vertragsstaaten m. E. aus Art. 13 EMRK aber verpflichtet sind. Vgl. Ress, Georg: Die Europäische Menschenrechtskonvention und die Vertragsstaaten: Die Wirkungen der Urteile des Europäischen Gerichtshofes für Menschenrechte im innerstaatlichen Recht und vor innerstaatlichen Gerichten, in: Maier, Irene (Hg.): Europäischer Menschenrechtsschutz, 1982, S. 227 ff. (244f.). 
ständigen europarechtlichen Rechtsstatus, den er im Klagewege vor den nationalen Gerichten und in beschränktem Umfang direkt vor dem EuGH geltend machen kann ${ }^{176}$.

Die Komplementarität zwischen Grundrechtsgewährleistung und effektivem verfahrensrechtlichem Schutz wird durch Art. 24 Abs. 1 dahin modifiziert, daß Grundrechtsschutz gegen Akte des sekundären Gemeinschaftsrechts in letztverbindlicher Auslegungskompetenz vom EuGH anhand des Standards allgemeiner Rechtsgrundsätze gewährt wird - von einem prinzipiellen Souveränitätsvorbehalt abgesehen ${ }^{177}$. Dem System der konzentrierten nationalen Verfassungsgerichtsbarkeit tritt parallel zu dieser Entwicklung ein System diffuser Kontrolle am Maßstab des EG-Rechts mit Verwerfungsbefugnis durch jeden deutschen Richter zur Seite. Eine Ergänzungsfunktion für den Grundrechtsschutz kommt auch der EMRK zu, deren Garantien in der Bundesrepublik - wie im Pakelli-Beschluß des Bundesverfassungsgerichts angedeutet - über das Rechtsstaatsprinzip in einem bisher noch nicht ermittelten Ausmaß materieller Bestandteil der Verfassungsordnung und damit verfassungsbeschwerdefähig geworden $\operatorname{sind}^{178}$.

Mit dieser Entwicklung tritt für die Bundesrepublik die schon aus Österreich und der Schweiz bekannte rechtliche Situation ein, daß nicht nur der gleiche Fall, sondern die identische Rechtsfrage vom nationalen Verfassungsgericht (bzw. Bundesgericht) und dem Straßburger Gerichtshof nacheinander überprüft werden können. Zugleich gewinnen damit die Urteile des Straßburger Gerichtshofs für die Auslegung des Grundgesetzes wenn auch keine Bindungswirkung, so doch eine Orientierungswirkung ${ }^{179}$.

176 Zum europarechtlichen Rechtsstatus vgl. Wenig, in: Grabitz, Eberhard (Hg.): Kommentar zum EWG-Vertrag, 1989, Art. 173 Rdn. 52 ff.

177 Vgl. Ress, Georg: Wichtige Vorlagen deutscher Verwaltungsgerichte an den Gerichtshof der Europäischen Gemeinschaften, Die Verwaltung 1987, S. $177 \mathrm{ff}$.; Steinberger, Helmut: Entwicklungslinien in der neueren Rechtsprechung des Bundesverfassungsgerichts zu völkerrechtlichen Fragen, ZaöRV 48 (1988), 1 (11); zur Verfahrenseffektivierung von Grundrechten im deutschen Recht vgl. Stern, Klaus, a. a. O. (Anm. 17), S. $970 \mathrm{ff}$.

${ }_{178}$ Vgl. BVerfG, Beschluß v. 11.10.1985, ZaöRV 46 (1986), S.289ff. mit Anmerkung von Jochen Abr. Frowein, ibidem, S. $286 \mathrm{ff}$.; BVerfGE 74, 358 (370). Vgl. ferner Ress, Georg: Verfassungsrechtliche Auswirkungen der Fortentwicklung völkerrechtlicher Verträge, in: Festschrift für Wolfgang Zeidler, Bd. 2, 1987, S. $1775 \mathrm{ff} .(1790 \mathrm{ff}$.$) .$

179 Deutlich in: BVerfGE 74, 358 (370); Hesse, Konrad: Grundzüge des Verfassungsrechts der Bundesrepublik Deutschland, 16. Aufl. 1988, Rdn.278. 
Die Rechtsstellung des einzelnen verändert sich durch die Verdrängung des Grundrechtsschutzes in der Substanz nicht. Zwar kann der einzelne den EuGH nur im Rahmen von Art. 173 Abs. 2 EWGV bei unmittelbarer und individueller Betroffenheit durch eine Verordnung anrufen. Ihm steht jedoch die Verfassungsbeschwerde gegen die letztinstanzliche Nichtvorlage wegen Verletzung des Rechts auf den gesetzlichen Richter zur Verfügung. Die Anerkennung des EuGH als gesetzlicher Richter erweist sich im Lichte der Forderung nach einem effektiven Verfahrensschutz der Grundrechte als verfassungsrechtlich konsequent, ja geboten. Daß nur eine Willkürprüfung stattfindet, verengt den Grundrechtsschutz nicht gegenüber dem vergleichbaren gegen innerstaatliche Gerichtsentscheidungen. Die Verfassungsbeschwerde nach Art. 93 Abs. 1 Nr. 4 a GG ist daher nicht nur die verfahrensrechtliche Ergänzung des Art. 1 Abs. 3 GG, sondern gewährleistet auch eine prozessuale Innen- oder Binnenabsicherung des über Art. 24 Abs. 1 außenverlagerten Grundrechtsschutzes. Der einzelne verfügt nicht nur über einen status negativus, activus und processualis im innerstaatlichen Rechtsbereich, sondern auch über einen status internationalis, der ihm die Anrufung der Straßburger Kommission, und einen status europaeus, der ihm den Weg an den EuGH nach Luxemburg vermittelt.

Nicht die Grundrechtstheorie des introvertierten Verfassungsstaates, sondern des extrovertierten, auf völker- und europarechtliche Verfassungsergänzung angelegten Staates ergibt das mit dem Staatszweck Freiheit verbundene Gesamtbild. Die im Marckx-Fall ${ }^{180}$ zutagegetretene evolutiv-dynamische Interpretation des Begriffs Familie unter Anknüpfung an die Staatenpraxis wäre als verfassungsrechtliche Interpretation methodisch verfehlt. Gleichwohl bindet sie die Bundesrepublik und könnte, sollte das BVerfG in Zukunft den Weg über Art. 2 Abs. 1 i. V. m. dem Rechtsstaatsprinzip gehen und die EMRK in den Prüfungsmaßstab einbeziehen, die Auslegung des Familienbegriffs in Art. 6 Abs. 1 mitbestimmen. Auch ein Kollisionsfall ist nicht auszuschließen. Die Grundrechtstheorie hat bisher diese verschiedenen Ebenen des in der Rechtsordnung der Bundesrepublik maßgeblichen Grundrechtsverständnisses nicht in einem Gesamtzusammenhang aufgearbeitet ${ }^{181}$. Auch die Rückwirkungen der nationalen

${ }^{180}$ EGMR, Urt. v. 13.6. 1979, NJW 1979, 2449 (2451); vgl. hierzu Weidmann, a. a. O. (Anm. 88), S. $65 \mathrm{ff}$.

${ }_{181}$ Bezeichnend - aber auch erstaunlich - ist das Fehlen derartig internationaler normativer Einbindungen in der "Grundrechtstheorie" von Robert Alexy (ders.: Theorie der Grundrechte, 1985). 
Grundrechtstheorie auf die europäische Ebene sind noch schwach ausgebildet ${ }^{182}$.

\section{Sozialstaatsziel}

27. Im Vergleich zu totalen wohlfahrtstaatlichen Zwecksetzungen (bei Wolff und Justi) ${ }^{183}$, für die der Endzweck des Staates die allgemeine Glückseligkeit der Menschen ist - eine Vorstellung, welche die marxistische Lehre mit dem Ideal, daß die Gesellschaft alle Bedürfnisse des einzelnen erfüllen und jedermann frei nach seinen Bedürfnissen soll leben können, aufgreift ${ }^{184}-$, hat das Grundgesetz nur einen limitierten Wohlfahrtszweck - als Modifikation und Ergänzung des Freiheits- und Autonomiegedankens des Liberalismus, aber nicht unter dessen Aufgabe - in die Verfassung aufgenommen. Damit

182 So entspricht z. B. der Schutzpflicht der EG-Organe für die Gemeinschaftsgüter eine Handlungspflicht zur Änderung des Gemeinschaftsrechts, falls dies im Interesse dieser Güter (ordre public) zwingend erforderlich ist (vgl. Ress, Georg: Luftreinhaltung als Problem des Verhältnisses zwischen europäischem Gemeinschaftsrecht und nationalem Recht, in: Festschrift 150 Jahre Landgericht Saarbrükken, 1985, S. 355 ff. [371 f.]). Die EuGH-Rechtsprechung hat leider nicht erkannt, daß der EG, sofern sie die Kompetenz zur sekundären Rechtsetzung in Anspruch nimmt (und damit die Mitgliedstaaten von der Regelungsbefugnis ausschließt), auch Schutzpflichten gegenüber den Mitgliedstaaten erwachsen, deren Inhalt sich an Art. 36 EWGV und der Cassis-de-Dijon-Rechtsprechung orientieren kann. Die Kompetenz zum nationalen Alleingang in Art. 100 a EWGV hat dieses Problem nicht gelöst (Hailbronner, Kay: Der "nationale Alleingang“ im Gemeinschaftsrecht am Beispiel der Abgasstandards für PKW, EuGRZ 1989, S. 101 ff.; Ress, Georg: Löst Art. 100 a EWGV die Probleme der Rechtsangleichung des einheitlichen Binnenmarktes?, in: ders. [Hg.]: Rechtsprobleme der Rechtsangleichung [Vorträge, Reden und Berichte des Europa-Instituts der Universität des Saarlandes, Nr. 137], 1988, S. $9 \mathrm{ff}$. [16ff.]).

${ }^{183}$ Vgl. Wolff, Christian: Vernünftige Gedanken vom gesellschaftlichen Leben des Menschen und insonderheit vom gemeinen Wesen, 4. Aufl. 1736; ders.: Vernünftige Gedanken von der Menschen Tun und Lassen, 1752; Justi, Jobann Heinrich Gottlieb: Grundsätze der Polizeiwissenschaft, 1756; vgl. ferner Hug, Hans, a. a.O. (Anm. 1), S. 82 ff.; Jellinek, a. a.O. (Anm. 28), S. 243 f.; Thomann, Marcel/Wolff, Christian, in: Staatsdenker im 17. und 18. Jahrhundert, 2. Aufl. 1987, S. $257 \mathrm{ff}$,

${ }^{184}$ Erinnert sei an die berühmte Formel von Karl Marx in seiner „Kritik des Gothaer Programms“ (1985) "Jeder nach seinen Fähigkeiten, jedem nach seinen Bedürfnissen“ (Marx/Engels: Werke, Bd. 19, S. 21); vgl. z. B. auch Fetscher, Iring: Von Marx zur Sowjetideologie, 20. Aufl. 1977, S. 22 ff. 
wurde "an das der historischen sozialen Bewegung Gemeinsame“ angeknüpft ${ }^{185}$.

Der moderne Staat, an den diese Regelung anknüpft, hatte die Lösung der sozialen Frage zu seiner eigenen gemacht. Die 1919 gegründete ILO sollte nicht nur einen arbeitsrechtlichen, sondern auch einen sozialrechtlichen Mindeststandard in den Mitgliedstaaten verwirklichen. Soziale Rechte griffen der Vertrag von Versailles, die UNO-Charta und die Menschenrechtserklärung von 1948 mit dem Recht auf soziale Sicherheit, Arbeit, angemessenen und gleichen Lohn, Koalitionsfreiheit, Erholung und Freizeit, eine Lebenshaltung, die Gesundheit und Wohlbefinden gewährleistet, Schutz der Mütter und Kinder, Bildung und kulturelle Teilhabe auf. Dies war das international vorformulierte sozialstaatliche Zielgut, welches das Grundgesetz vorfand ${ }^{186}$.

Eine soziale Ausrichtung und Vorsorge ist ein Wesenselement des modernen westeuropäischen Staates ${ }^{187}$. Für den modernen Industriestaat ist Daseinsvorsorge aus der sozialen Dimension mehr und mehr in die wirtschafts- und finanzpolitische hinübergewachsen. Schon Lorenz von Stein hatte gesehen, daß eine „Freiheit ... eine wirkliche erst in dem (ist), der die Bedingungen derselben, die materiellen und geistigen Güter, als die Voraussetzung der Selbstbestimmung besitzt“" ${ }^{188}$. Das Sozialstaatsziel soll dazu die Chance eröffnen. Es kann nicht in einer expansiven Freiheitsvorsorge i.S. der gleichen Güter- und Rechtszuteilung seinen Ausdruck finden, sondern nur in den unerläßlichen sozialen Voraussetzungen der Realisierung der Freiheit für alle - also im sozialen Ausgleich und sozialer Umverteilung zur Gewährleistung eines Mindeststandards an den Lebensgütern $^{189}$.

185 Zacher, Hans F.: Das soziale Staatsziel, in: Isensee, Josef/Kirchhof, Paul (Hg.): Handbuch des Staatsrechts, Bd. I, 1987, \25, Rdn. 21 .

186 Vgl. a.a.O., Rdn. $11 \mathrm{ff}$; Perrin, Guy: Die Ursprünge des internationalen Rechts der sozialen Sicherheit, 1983.

${ }^{187}$ Es verwundert nicht, daß soziale Ziele auch in der Wirtschafts- und Finanzpolitik selbst von solchen westeuropäischen Staaten verfolgt werden, in deren Verfassung sich keine - wie man rechtsvergleichend feststellen kann - Sozialstaatsbestimmung findet. Besonders auffällig ist dieser Sachverhalt in Schweden.

188 Von Stein, Lorenz: Geschichte der sozialen Bewegung in Frankreich von 1789 bis auf unsere Tage. Ausg. Salomon, 1921, Bd. 3, S. 104.

$189 \mathrm{Vgl}$. Grimm, Dieter: Grundrechte und soziale Wirklichkeit, in: Hassemer, Wilfried ( $\mathrm{Hg}$.): Grundrechte und soziale Wirklichkeit, 1982, S. 39 f. 
„Unerläßlich" meint das gleiche wie das, was nach der EMRK in einer demokratischen Gesellschaft notwendig ist. Die Eigentumsgewährleistung bestimmt - neben der nur verhältnismäßigen Einschränkung grundrechtlicher Freiheiten - Inhalt und Grenze derartigen staatlichen Handelns ${ }^{190}$. Diese charakteristische Verbindung findet sich in der europarechtlichen Nebenverfassung der Bundesrepublik wieder. Neben den vielfältigen Befugnissen der Wirtschaftspolitik steht der sozialpolitische Auftrag der EG mit der Abstimmung der Sozialordnungen ${ }^{191}$. Der in Art. 119 EWGV festgelegte Grundsatz des gleichen Entgelts für Mann und Frau hat sich seit den DefrenneEntscheidungen des $\mathrm{EuGH}^{192}$ in allen Mitgliedstaaten durch Richtlinie ${ }^{193}$ durchgesetzt. Die EEA hat mit Art.130 a EWGV eine EGPolitik zur Stärkung des sozialen Zusammenhalts neben dem wirtschaftlichen eingeführt. Unterschiede im sozialen Niveau, der Vollständigkeit der Sozialleistungen und des Interventionszeitpunktes bestehen fort. Sie allein lösen einen Teil der Wanderungsbewegung im Rahmen der Arbeitnehmerfreizügigkeit nach Art. 48 EWGV aus, der sich zu einem weitgefaßten Anspruchstitel auf Sozialleistungen und Bildung entfaltet hat. Die Gleichstellung in den Arbeitsbedingungen erfaßt mittlerweile den gesamten sozio-kulturellen Bereich einschließlich

190 Vgl. EGMR Urt. v. 23.9.1982 - Fall Sporrong und Lönneroth gegen das Königreich Schweden - EuGRZ 1983, 523 (526f.); zu den damit verbundenen Grenzen der Tätigkeit des Staates vgl. Bieback, Karl Jürgen: Sozialstaatsprinzip und Grundrechte, EuGRZ 1985, 657 (661 f.); Kirchbof, Paul: Die Finanzierung des Leistungsstaates, Jura 1983, 505; Leisner, Walter: Eigentum, in: Isensee, Josef / Kirchhof, Paul (Hg.): Handbuch des Staatsrechts, Bd. VI, 1989, \$149 Rdn. $133 \mathrm{ff}$. Das Sozialstaatsprinzip ist aber keine "normative Einbahnstraße“, sondern läßt innerhalb des eisernen Rahmens des Unerläßlichen andere politische Gewichtungen und damit sozialen "Rückschritt“ zu (so auch Badura, Peter, a. a. O. (Anm. 18), S. 496; Schlenker, Rolf Ulrich: Soziales Rückschrittsverbot und Grundgesetz, 1986, S. $130 \mathrm{ff})$.

191 Art. 117 Abs. 2 EWGV; vgl. dazu z. B. Lichtenberg, Hagen (Hg.): Sozialpolitik in der EG, 1986, S. 9 ff., 81 ff.; Däubler, Wolfgang: Sozialstaat EG? Die andere Dimension des Binnenmarktes, 1989, S. 35 ff., 175 ff. Eine problematische Entwicklung nimmt die Rechtsprechung des EuGH zur sozialpolitischen Dimension der Arbeitnehmer-Freizügigkeit (vgl. dazu Randelzbofer, in: Grabitz, Eberhard [Hg.]: Kommentar zum EWG-Vertrag, 1989, Art. 48 Rdn. 31).

$192 \mathrm{EuGH}$, Rs. 80/70, Defrenne/Sabena, Slg. 1971, S.445ff.; Rs.43/75, Defrenne/Sabena, Slg. 1976, S. $455 \mathrm{ff}$.

${ }_{193}$ Richtlinie des Rates vom 10. Februar 1975 zur Angleichung der Rechtsvorschriften der Mitgliedstaaten über die Anwendung des Grundsatzes des gleichen Entgelts für Männer und Frauen (75/117/EWG), ABl EG 1975 L 45/19). 
der Zulassung zum Studium ${ }^{194}$. Die wirtschaftliche Seite des Staatszwecks der allgemeinen Wohlfahrt kehrt als deutliche Zweckrichtung des gesamten EWG-Vertrages in der Präambel mit dem Ziel der Verbesserung der Lebens- und Beschäftigungsbedingungen und mit der Aufgabenbeschreibung in Art. 2 wieder. Sie stimmt mit den im Stabilitätsgesetz von 1967 vereinigten Zielvorstellungen nahezu wörtlich überein. Hier liegen Zweckausrichtungs- und Zielverfolgungsidentität vor ${ }^{195}$.

Die gegenseitige Bedingtheit von Freiheit und Sozialgestaltungsziel, ihre Spannung und ihr ständiger vom Gesetzgeber - und auch vom BVerfG - zu leistender Ausgleich sind ebenfalls Wesensmerkmale des modernen demokratischen Industriestaates. Dieser ist längst aus allgemeinen Ordnungsaufgaben herausgewachsen, um Aufgaben der allgemeinen Gestaltung der Wirtschafts- und Sozialpolitik zu übernehmen. Da es sich um einen limitierten und nicht totalen Staatszweck handelt, gilt das Primat der Selbstbestimmung und Selbstverantwortung ${ }^{196}$. Die staatliche Förderungspflicht ist wegen der im GG angelegten Eigenverantwortung des Bürgers zur freien Lebensgestaltung subsidiär. Die Entwicklung des Sozialstaatsziels im GG zeigt die Typik eines Staatszwecks: Keine Gewährung unmittelbar subjektivöffentlicher Rechte - von einer extremen existenzgefährdenden Situation abgesehen ${ }^{197}$ - wohl aber in einem Kernbereich positive Leistungsverpflichtungen des Staates zum sozialen Ausgleich (durch Leistungsgesetze). Konsequenterweise hat das BVerfG daher selbständige Rechtsansprüche aus dem Sozialstaatsprinzip als verfassungsrechtlicher Verankerung des Wohlfahrtszwecks in ständiger Rechtsprechung grundsätzlich abgelehnt ${ }^{198}$. Im Gegensatz zu totalen Wohl-

${ }^{194}$ Der Kreis ist seit dem Gravier-Urteil des EuGH (Rs. 293/83, Gravier/Stadt Lüttich, Slg. 1985, S. $593 \mathrm{ff}$.) auf alle rechtmäßig im Ausland wohnenden EGAngehörigen auszudehnen, wenngleich nur für die Zulassung zu und Ausbildungsförderung in einem berufsqualifizierenden Ausbildungsgang (vgl. hierzu Oppermann, Thomas: Von der Freizügigkeit zur gemeinsamen Ausbildungspolitik? Die "Gravier"-Doktrin des Gerichtshofs der Europäischen Gemeinschaften, 1988).

195 Vgl. Grabitz, Eberhard, in: ders. (Hg.): Kommentar zum EWG-Vertrag, 1988, Art. 2 Rdn. 2.

196 Vgl. Zacher, HansF., a.a.O. (Anm. 185), Rdn. 28 ff.; Schuppert, Gunnar Folke, a. a. O. (Anm. 82).

197 Stern, Klaus: Das Staatsrecht der Bundesrepublik Deutschland, Bd. I, 2. Aufl. 1984, S. 895.

198 Vgl. BVerfGE 65, 182 (193); 69, 272 (314f.) m.w. N. Die einzige, nicht überzeugende Abweichung von dieser Linie bildet das erste Numerus Clausus Urteil mit einem eigenständigen Leistungsanspruch auf staatliche Bildungsgüter aus Art. 12 GG i. V.m. dem Sozialstaatsprinzip (BVerfGE 33, 303 [331 f.]). Die liberal 
fahrtszwecken ist das Sozialstaatsziel an einer marktwirtschaftlichen Ordnung orientiert. Die Behauptung, daß das Verfassungsrecht keine bestimmte Wirtschaftsordnung festgelegt und gewährleistet habe, gehört ebenso zu den Standardaussagen wie die, daß die soziale Marktwirtschaft von der EG nicht übernommen wurde ${ }^{199}$. Die Grundrechte des Eigentums, der Berufsfreiheit, der Freizügigkeit und der allgemeinen Vertrags- und wirtschaftlichen Handlungsfreiheit mit dem Recht zur freien Vermögensdisposition und der unternehmerischen Wettbewerbsfreiheit fügen sich indessen zu einem deutlichen Ordnungsbild ${ }^{200}$, dem die planwirtschaftliche Wirtschaftsverfassung der DDR als Gegenbild kraß gegenübersteht.

konzipierten Grundrechte stehen einer Umdeutung in soziale Grundrechte nicht offen. Denn sie ließe die Dignität der individuellen, „negativen“ Freiheit fraglich werden und würde den Richter zur sozialgestalterisch tätigen politischen Verteilungsinstanz machen, womit die grundgesetzliche Kompetenzordnung verletzt würde (vgl. Haverkate, a. a. O. [Anm. 34], S.75f.; kritisch auch Lücke, Jörg: Soziale Grundrechte als Staatszielbestimmungen und Gesetzgebungsaufträge, AöR 107 [1982], 15).

199 Vgl. zur These von der wirtschaftspolitischen Neutralität des Grundgesetzes BVerfGE 4, 7 (17f.); 50, 290 (338); Krüger, Herbert: Staatsverfassung und Wirtschaftsverfassung, DVBl. 1951, $361 \mathrm{ff}$; Schlaich, Klaus: Neutralität als verfassungsrechtliches Prinzip, 1972, S. $105 \mathrm{ff}$; zur entsprechenden These für das Gemeinschaftsrecht vgl. VerLoren van Themaat, Pieter: Die Aufgabenverteilung zwischen dem Gesetzgeber und dem Europäischen Gerichtshof bei der Gestaltung der Wirtschaftsverfassung der Europäischen Gemeinschaften, in: Eine Ordnungspolitik für Europa, Festschrift für Hans von der Groeben, 1987, S. 425 ff. (429 f.); kritisch: Mestmäcker, Ernst-Joachim: Auf dem Weg zu einer Ordnungspolitik in Europa, ibidem, S. 9 ff. (13ff.); Götz, Volkmar: Verfassungsschranken interventionistischer Regulierung nach europäischem Gemeinschaftsrecht im Vergleich mit dem Grundgesetz, JZ 1989, 1021 (1023 f.).

${ }^{200}$ So z. B. auch Herzog, in: Maunz/Dürig/Herzog/Scholz, Komm. z. GG, Art. 20 VIII, Rdn.60f.; Karpen, Ulrich: Wirtschaftsverfassung und Grundgesetz, 4. Aufl. 1986, S. $41 \mathrm{ff}$. Auch wenn im Mitbestimmungsurteil des BVerfG (E 50, 290 [336]) ein "Ordnungs- und Schutzzusammenhang der Grundrechte“ und ein „institutioneller Zusammenhang der Wirtschaftsverfassung“ als Kontrollmaßstab verworfen wurde, muß schon anhand der Einzelgrundrechte mit ihrer primären Schutzrichtung von einer privatwirtschaftlichen Ordnung ausgegangen werden. Hier kann und muß der Gesetzgeber zur Sicherung des Sozialstaates Zielschranken setzen, insbesondere auch durch Aufrechterhaltung des Konkurrenzprinzips. Dieses ist ein grundrechtlich gesicherter Bestandteil der "Wirtschaftsverfassung" der Bundesrepublik (vgl. Lübbe-Wolff, Gertrude: Die Grundrechte als Eingriffsabwehrrechte, 1988, S. $293 \mathrm{ff}$.). Dort, wo auf der Grundlage konkurrierender Ausübung der wirtschaftsrelevanten Grundrechte der Art. 2 Abs. 1, 12 und 14 GG eine Wettbewerbsordnung konstituiert ist, wird die Integrität dieser Ordnung vom 
Je mehr wirtschafts- und damit verbunden sozialpolitische Regelungsbefugnisse von der EG aufgegriffen werden, um so wichtiger wird die zur nationalen Wirtschaftsverfassung parallel laufende Frage, an welchen Kontrollmaßstäben die Wirtschaftsverfassung der Gemeinschaft ${ }^{201}$ gemessen wird. Der EuGH rekurriert zur Prüfung der Zulässigkeit von Zulassungssystemen und Verwertungsbeschränkungen in Richtung auf jene Allgemeinbegriffe, die das BVerfG in seiner Prüfung zu vermeiden versucht hat, nämlich auf die „Grundsätze des freien Warenverkehrs und des freien Wettbewerbs sowie die grundrechtliche Handelsfreiheit“ als allgemeine Rechtsgrundsätze ${ }^{202}$. Wie selbstverständlich wird dabei der zu jener Zeit noch nicht im EWG-Vertrag verfaßte Umweltschutz als ein im Gemeininteresse liegendes Ziel zur Rechtfertigung von Einschränkungen herangezogen, d.h. als ein selbstverständlicher Bestandteil des Gemeinwohls, der keiner Erwähnung in der Präambel bedarf. Beide Rechtsordnungen, die der EWG und des Grundgesetzes, gehen vom Primat der Wirtschaftsfreiheit vor der staatlichen Intervention aus. Der EuGH hat allerdings die für den zwischenstaatlichen Verkehr strengen Maßstäbe, die er am Verbot für Maßnahmen mit gleicher Wirkung entwikkelt hat, nicht durchgängig auf die Prüfung gemeinschaftsrechtlicher Regulierungen selbst übertragen, d.h. der Gemeinschaftsgesetzgeber stellt sich interventionistisch selbst freier, als dies im zwischenstaat-

Schutzzweck der Grundrechte selbst umfaßt. Die soziale Komponente der Marktwirtschaft als ordnungspolitische Umsetzung der wirtschaftsverfassungsrechtlichen Rahmenbedingungen gebietet, daß der Staat Vorsorge für Entstehung und Bestand der Konkurrenz trifft.

201 Vgl. zur Gemeinschaftswirtschaftsverfassung Oppermann, Thomas: Europäische Wirtschaftsverfassung nach der Einheitlichen Europäischen Akte, in: Müller-Graff, Peter-Christian / Zuleeg, Manfred (Hg.): Staat und Wirtschaft in der EG, 1987, S. 53 ff.; Scherer, Josef: Die Wirtschaftsverfassung der EWG, 1970; Stober, Rolf: Handbuch des Wirtschaftsverwaltungs- und Umweltrechts, 1989, S. 151ff.; Zuleeg, Manfred: Demokratie und Wirtschaftsverfassung in der Rechtsprechung des Europäischen Gerichtshofes, EuR 1982, S. 21 ff. (26 ff.); ders.: Die Wirtschaftsverfassung der Europäischen Gemeinschaften, in: Arbeitskreis Europäische Integration ( $\mathrm{Hg}_{\text {.): }}$ Wirtschafts- und gesellschaftspolitische Ordnungsprobleme der Europäischen Gemeinschaften, Bd. 1, 1978, S. $73 \mathrm{ff}$.

${ }^{202}$ EuGH, Rs.240/83, Procureur de la République/ADBHU, Slg. 1985, 531 (548f.); vgl. dazu Götz, Volkmar: Verfassungsschranken interventionistischer Regulierung nach europäischem Gemeinschaftsrecht im Vergleich mit dem Grundgesetz, in: Ress, Georg (Hg.): Wissenschaftliches Kolloquium zum Völkerrecht, Europarecht und Verfassungsrecht anläßlich des 70 . Geburtstages von Günther Jaenicke (Europa-Institut, H. 166), 1989, S. 27 ff. (36 f.). 
lichen Handel gestattet ist ${ }^{203}$. Dafür gibt es zwar Gründe, weil der grenzüberschreitende Verkehr sich mit Zunahme des Binnenmarktes in seiner Regulatorik erschöpfen wird, während allgemeine gemeinschaftsrechtliche Marktregulierungen zunehmen werden. Dann ist es aber um so eher geboten, von einer Homogenität der Maßstäbe für zwischenstaatliche und für gesamtgemeinschaftliche Regelungen auszugehen. Nimmt man das genannte Urteil des EuGH mit der Anerkennung des freien Warenverkehrs, Wettbewerbs und der Handelsfreiheit ernst, dann dürfte die in der Literatur vertretene These von der Neutralität der Gemeinschaftsverfassung als Gleichwertigkeit von Wirtschaftsfreiheit und Intervention nicht zutreffen.

\section{Integrationszweck}

28. Es gehört zu den Eigentümlichkeiten, die Georg Jellinek am modernen Staat völlig zutreffend konstatierte, daß er die Voraussetzungen in geistig-sittlicher Hinsicht, auf denen er ruht, nicht selbst schaffen kann ${ }^{204}$. Wenn in der Präambel der Europäischen Menschenrechtskonvention von dem gemeinsamen Erbe an geistigen Gütern und von dem Geist, von dem die Regierungen der europäischen Staaten beseelt sind, ausgegangen wird, dann wird damit auch an die Verfassungswerte angeknüpft, die den Mitgliedstaaten gemeinsam sind. Für diese darf auch der moderne Staat sich werbend einsetzen ${ }^{205}$. Ihm kommt insofern auch eine geistige Selbsterhaltungsaufgabe zu, die - anders als die réligion civile Rousseaus - gegenüber dem Bürger nicht eine Ausrichtung an einer bestimmten gemeinsamen Gesinnung annehmen darf. Dem Frieden in der Welt, von dem Art. 1 und 26 des Grundgesetzes als Staatsziel ausgehen, vermag nur ein Staat zu dienen, der unter seinen Beamten und Bürgern auf eine entsprechende ethisch fundierte Hinwendung trifft ${ }^{206}$.

203 Vgl. EuGH, Rs. 46/76, Bauhuis/Niederlande, Slg. 1977, 5 (17f.); kritisch: Timmermans, Christian W. A.: Der freie Warenverkehr, in: Dreißig Jahre Gemeinschaftsrecht, 1983, S. 259 ff. (291); Ress, Georg: Wirtschaftslenkung in der Europäischen Gemeinschaft (erscheint 1990).

${ }^{204}$ Jellinek, Georg, a. a. O. (Anm. 28), S. 252.

${ }^{205}$ Zur Kontroverse um ein dynamisches oder ethisches, im gesellschaftlichen oder staatlichen Raum angesiedeltes Konsensverständnis vgl. Vorländer, Hans a. a. O. (Anm.65), S.136 ff.; vgl. auch Burmeister, Joachim, a.a.O. (Anm.51), S. $104 \mathrm{ff}$.

206 Vgl. Böckenförde, Ernst-Wolfgang, a.a.O. (Anm. 34), S. 26 ff.; Burmeister, a. a. O. (Anm. 51), S. 120 ff. Der Staat darf diese Hinwendung (z. B. durch entspre- 
Staatliches Werben zur Integration des Volkes auf der Grundlage der Verfassungswerte der Toleranz, des Pluralismus, der Ideenoffenheit sowie der europäischen Zielgebundenheit umfaßt auch die Pflege des Nationalbewußtseins. Der Staat darf um am Gemeinwohl orientierte ethische Grundhaltungen im Rahmen der zulässigen Selbstdarstellung einer Regierung ${ }^{207}$ und des Staates werben. Er darf kulturelle Gestaltungsmöglichkeiten eröffnen, aber nicht selbst vorschreiben. Aus dem Wiedervereinigungsgebot hat der Staat den Auftrag, auf den nationalen Zusammenhalt, die Wahrung der nationalen Einheit hinzuwirken. Die Zulässigkeit einer derartigen wertorientierten Informationspolitik findet in der Rechtsprechung des Straßburger Gerichtshofes ${ }^{208}$ zu den zur Erhaltung einer demokratischen Gesellschaft notwendigen Maßnahmen (z. B. im Erziehungswesen) ihre Stütze.

\section{Konkretisierung und Konkurrenz}

29. Die Staatszwecke wenden sich ebenso wie die zusätzlichen verfassungsrechtlichen Zielnormen an alle staatlichen Organe. Der Gesetzgeber ist in erster Linie zur Konkretisierung der Staatszwecke und -ziele berufen ${ }^{209}$.

Die Einschränkung grundrechtlich verbürgter Freiheiten durch Ziele und Zwecke bedarf der gesetzlichen Grundlage. Im Gesetzesvorbehalt liegt die Sicherung gegen den direkten Zugriff der Ziele und Zwecke auf den einzelnen, aber auch die Ermächtigung zu deren Konkretisierung im grundrechtlichen Freiheitsraum und ein Ansatzpunkt zur zweck- und zielbezogenen Auslegung.

chende Schulbuchempfehlungen) fördern. Der Bürger ist im Denken allemal und im Handeln im Rahmen der Gesetze frei. Daß von den Amtsträgern, die in einem Dienst- und Treueverhältnis stehen, die Erfüllung des Amtsethos, des uneigennützigen Dienstes und eine innere Loyalität - nicht nur eine Ergebnis- oder Verhaltensloyalität - verlangt werden darf, bildet gerade die Ausnahme zur normalen Bürgerstellung (in diesem Sinne Klein, Hans Hugo: Verfassungstreue und Schutz der Verfassung, VVDStRL 37 [1979], S. 53 ff. [80 ff.]).

207 Dieser Aspekt schwingt bei den Entscheidungen zur Zulässigkeit der Öffentlichkeitsarbeit der Regierung mit (BVerfGE 44, 125 [147 ff.]; 63, 230 [243 ff.]).

${ }^{208}$ Vgl. EGMR - Fall Kjelsen, Busk Madsen und Pedersen, Urt. v. 7.12.1976 -, EuGRZ 1976, 478 (485).

${ }^{209}$ Es ist aber eine verfehlte Sicht zu behaupten, daß die Staatszwecke nur über die Gesetze wirken: denn z. B. hat die Regierung ihren Gestaltungsspielraum zur Gesetzesinitiative zweckorientiert im Rahmen des politischen Ermessens zu nutzen, die Verwaltung bei der Anwendung und Auslegung der Gesetze die Zwecke und Ziele zu beachten. 
Den rechtsstaatlichen Gesetzesvorbehalt hat das BVerfG um den parlamentarischen Wesentlichkeitsvorbehalt erweitert ${ }^{210}$. Wesentliche Entscheidungen für die Verwirklichung und auch Abgrenzung kollidierender Grundrechte - und damit Abwägungen bei der Zweckverwirklichung - sind vom Gesetzgeber zu treffen. Die damit für die Bewältigung von Gefahren und Risiken im Sicherheitsbereich, von sozialer und wirtschaftlicher Planung und zum Schutz von Grundrechten zu treffenden gesetzgeberischen Entscheidungen sind deshalb wesentlich, weil sie in aller Regel der Grundrechtsabgrenzung dienen $^{211}$. Die Entscheidung, ob und wie der Staat öffentliche Interessen aufgreift, ist eine politische, wenn nicht ausnahmsweise eine Verpflichtung aus der Verfassung abzuleiten ist. Der Gesetzgeber darf die Entscheidung im Rahmen unbestimmter Rechtsbegriffe dann der Exekutive überlassen, sofern es sich nicht um die wesentliche Zielbestimmung überhaupt handelt ${ }^{212}$.

Staatszwecke sind pflichtenaktivierend, aber im Prinzip anspruchsresistent $^{213}$. Einen unmittelbaren Anspruch gewährt weder das Wiedervereinigungsziel noch das Europaziel oder das Sozialstaatsziel. Allein aus der Pflicht zur Gewährleistung des inneren Friedens und aus Art. 1 Abs. 1 S. 1 GG lassen sich Schutzansprüche (nach Maßgabe der Grundrechte) herleiten. Ein bestimmtes Handeln des Gesetzgebers kann nicht verlangt werden. Es ist an der Zeit, die im deutschen

210 Vgl. BVerfGE 33, 1 (10f.); 47, 46 (78 ff.); 49, 89 (126 ff.); 57, 295 (320f.); 58, 257 (268ff.); Böckenförde, Ernst-Wolfgang, a.a.O. (Anm. 38), S. 388 ff.; Hesse, Konrad, a. a. O. (Anm. 179), Rdn. 508 f. (m.w. N.); Kisker, Gunter: Neue Aspekte im Streit um den Vorbehalt des Gesetzes, NJW 1977, 1313; Umbach, Dieter C.: Das Wesentliche an der Wesentlichkeitstheorie, in: Festschrift für Hans Joachim Faller, 1984, S. $111 \mathrm{ff}$.

211 Vgl. Hesse, Konrad, a. a. O. (Anm. 179), Rdn. 509.

212 Vgl. BVerfGE 34, 165 (192); 40, 237 (249); 41, 251 (260); 57, 295 (320). Die seit dem Kalkar-Beschluß des BVerfG (E 49, 69 [144f.]) erörterte Abgrenzungsfrage zwischen legislativem Hausgut und Exekutiventscheidungsbefugnis ist durch die Theorie des Versagungsermessens (vgl. Murswiek, Dietrich, a. a. O. [Anm. 24], S.284f.) auf eine neue - freilich nicht unproblematische - Grundlage gestellt worden. Soweit der Gesetzgeber bestimmte Tätigkeiten - wie die Verursachung von Risiken - ohne Verstoß gegen Grundrechte ganz verbieten dürfte, darf er nach dieser Auffassung als Minus ein repressives Verbot mit Befreiungsvorbehalt erlassen, also der Genehmigungsbehörde ein pflichtgemäßes Versagungsermessen einräumen.

${ }_{213}$ Vgl. Bethge, a. a. O. (Anm. 1), S. 847; zur Ausnahme eines Anspruchs auf Gewährung des Existenzminimums vgl. z. B. Badura, Peter, a.a. O. (Anm.18), S. 494. 
Verfassungsrecht entwickelte Wesentlichkeitstheorie auf die europäische Ebene zu übertragen, weil bei fortschreitender Auslagerung von Sachmaterien eine entsprechende demokratische Legitimation der Entscheidungen zur Wahrung der Verfassungsidentität erforderlich wird $^{214}$.

Kennzeichnend bei den Staatszwecken ist die Zurücknahme der Kontrollnorm gegenüber der Funktionsnorm, wobei unter der Funktionsnorm die materielle Verfassungs- bzw. staatsrechtliche Norm, welche das staatliche Handeln bindet, zu verstehen ist, während die Kontrollnorm den Umfang der gerichtlichen Überprüfbarkeit des staatlichen Handelns angibt. Eine gerichtliche Feststellung einer Staatszweckverfehlung ist wegen dieser "Justitiabilitätsschwäche ${ }^{\text {“215, }}$, die auch im Europäischen Gemeinschaftsrecht wiederzufinden ist, nur im Fall eines schweren und evidenten Verstoßes gegen den Staatszweck möglich ${ }^{216}$. Bei der Frage nach der gerichtlichen Kontrolle der Einhaltung der Zwecke und Ziele zeigt sich im übrigen ein deutlicher Unterschied zwischen der Kontrolle der Verwaltung und der des Gesetzgebers. Angesichts des außerordentlich großen Gestaltungsspielraums des Gesetzgebers sind die Fälle, in denen er den Sicherheits- oder sozialstaatlichen Anforderungen nicht genügt, außerordentlich selten. Die Gerichte scheuen sich mit Recht, der Einschätzungsprärogative des Gesetzgebers Zügel anzulegen. Nur in Ausnahmefällen, wie der Entscheidung zu $\$ 218 \mathrm{StGB}^{217}$, wird eine gesetzliche Regelung (oder: Nicht-Regelung) von gerichtlicher Seite für nicht ausreichend erachtet. Diese Zurückhaltung entspricht einer gemeineuropäischen Tendenz, die bisher nur einmal vom Straßburger Gerichtshof $1985^{218}$ durchbrochen - oder besser: in einem Extremfall bestätigt - wurde.

30. Konflikte zwischen Staatszwecken und -zielen müssen durch eine Konkordanz behoben werden. Eine Rangfolge zwischen den

${ }^{214}$ Vgl. Ress, Georg: Über die Notwendigkeit der parlamentarischen Legitimierung der Rechtsetzung der Europäischen Gemeinschaften, in: Verfassungsrecht und Völkerrecht. Gedächtnisschrift für Wilhelm Karl Geck, 1989, S. $625 \mathrm{ff}$.

${ }_{215}$ Stern, Klaus, a.a. O. (Anm. 197), S. 912.

216 Vgl. Forsthoff, Ernst: Über Maßnahmegesetze, in: ders.: Rechtsstaat im Wandel, 2. Aufl. 1976, S. 105 ff. (117f.); Murswiek, Dietrich: Der Umfang der verfassungsgerichtlichen Kontrolle staatlicher Öffentlichkeitsarbeit, DÖV 1982, 529 (534 ff.); Ress, Georg, a. a. O. (Anm. 126), S. 29 f.

217 BVerfGE 39, 1 (42 ff.).

218 Vgl. EGMR, Urt. Nr. 16/1983/72/110 v. 26.3.1985, X und Y gegen Niederlande, EuGRZ 1985, 297 (298f.). 
Zwecken Sicherheit und Freiheit und Verfassungszielen wie Sozialstaatlichkeit, europäische Einigung und Wiedervereinigung besteht nicht. Insbesondere ist zu der in der Vergangenheit mit Vehemenz geführten Diskussion über die Vereinbarkeit der Wiedervereinigung und der europäischen Einigung zu sagen, daß beide sich ohne Schwierigkeiten kompatibel gestalten lassen ${ }^{219}$. Ziele dürfen nie absolut gesetzt werden, da zwischen allen eine Spannung besteht. Die Europäische Union kann ebenso wie schon 1957 die EWG mit einem Vorbehalt zugunsten der Veränderungsmöglichkeiten der Rechtslage Deutschlands verknüpft werden.

31. Für Georg Jellinek ${ }^{220}$ rechtfertigt sich der Staat als Zweckeinheit durch die zur Erfüllung dieser Zwecke erbrachten Leistungen gerade für die Schwachen - nicht anders als bei Platon ${ }^{221}$. Daran hat sich bis heute nichts geändert.

${ }_{219} \mathrm{Vgl}$. allgemein Brugger, Winfried, a. a. O. (Anm. 1), S. 2428; zum speziellen Verhältnis vgl. Bücking, Hans-Jörg: Wiedervereinigung Deutschlands und die Einigung Westeuropas - Ein Widerspruch?, in: Hacker, Jens/Mampel, Siegried: Europäische Integration und deutsche Frage, 1989, S. $65 \mathrm{ff}$; Fiedler, Wilfried: Europäische Integration und deutschlandpolitische Optionen - Eine Alternative?, in: a.a.O., S. $115 \mathrm{ff}$. (125 ff.); skeptisch z. B. Geiger, Wilhelm: Die Entstehung der Präambel des Grundgesetzes und deren Bindungswirkung, in: Haack, Dieter et al. (Hg.): Das Wiedervereinigungsgebot des Grundgesetzes, 1989, S. 255 ff. (265 f.).

$220 \mathrm{Vgl}$. Jellinek, Georg, a.a.O. (Anm.28), S.229; nach Jellinek hat der Staat neben dem Macht-, Sicherheits- und Rechtszweck vor allem die „Verwaltung der Solidarinteressen" zu besorgen, aber nur, "soweit die freie individuelle oder genossenschaftliche Tat unvermögend ist" (a.a. O., S. 259).

${ }^{221}$ "Wohlan, sprach ich, laß uns also in Gedanken eine Stadt von Anfang an gründen. Es gründet sie aber, wie sich zeigte, unser Bedürfnis. - Was wohl sonst! - Aber das erste und größte aller Bedürfnisse ist die Herbeischaffung der Nahrung des Bestehens und Lebens wegen. - Auf alle Weise. - Das zweite aber die Wohnung; das dritte Bekleidung und dergleichen. - So ist es. - " (Platon, Politeia, in: Sämtliche Werke, Bd.3, 1958, 369 c, d). Bei Platon steht der sittliche, auf die Vollendung der Gerechtigkeit gerichtete Staatszweck zwar deutlich im Vordergrund. Der Solidaraspekt tritt aber stets mittelbar hervor, so in der Rede des Glaukon (Politeia, Nr. 359 a): „Wenn demnach die Menschen einander Unrecht tun und voneinander Unrecht leiden und sie somit beides auskosten, so dünkt es diejenigen, die diesem nicht entgehen, aber auch nicht jenes wählen können, von Vorteil, sich miteinander dahin zu verständigen, daß sie weder Unrecht tun noch Unrecht leiden. Und daher habe man dann angefangen, Gesetze zu geben und miteinander Verträge zu schließen, und was das Gesetz bestimmt, habe man als gesetzlich und gerecht bezeichnet." 
Leitsätze des 2. Berichterstatters über:

\section{Staatszwecke im Verfassungsstaat - nach 40 Jahren Grundgesetz}

\section{Vorbemerkung: das Gründungsverständnis}

1. Der Staatszweck der Bundesrepublik Deutschland wird auch nach 40 Jabren maßgeblich durch ihr Gründungsverständnis bestimmt: eine freibeitliche, rechtsstaatliche und demokratische Ordnung "für eine Übergangszeit" zu errichten, in deren Mitte der Mensch mit seiner Würde und seinen Freibeitsrechten stebt. Gründungszweck und Zweck der fortbestehenden alliierten (Besatzungs-) Rechte und Verantwortlichkeiten sind durch Art. 7 des Deutschlandvertrages auf Ausübung des Selbstbestimmungsrechts der Deutschen, Wiedervereinigung und Abschluß eines Friedensvertrages gerichtet. Der dem Grundgesetz zugrundeliegende Staat (Deutscbland) weist durch den nicht abgeschlossenen Separierungsprozeß neben völkerrechtlichen auch noch staatsrechtliche Bindungen $z u$ den anderen Teilen Deutschlands auf.

\section{Staatsbegriffe und Staatszwecke}

2. Staatszwecke gebören zum Staat. Sie sind keine Gesellschaftszwecke und - jedenfalls in sprachlicher Sonderung - auch keine Verfassungszwecke. Das Thema zielt auf den Staat in - oder hinter der Verfassung. Staatszwecke, Staatsziele und Staatsaufgaben steben in Zusammenhang, sind aber zu unterscheiden. Der "Staatszweck" fragt nach der Finalität des Staates (sein "Um-Willen") und einzelner staatlicher Funktionen, aber auch nach dessen Umfang und damit nach seiner Begrenzung. Das "Staatsziel“ kann einen einzelnen Aspekt aus den Staatszwecken besonders hervorbeben oder eingrenzen oder eine der Verfassung eigentümliche Direktive hinzufügen (z.B. Wiedervereinigungsgebot). Die Staatsaufgabe kann in der jeweiligen konkreteren Umschreibung ein Mittel sein, um dem Staatszweck oder Staatsziel näherzukommen. 
3. Staatszwecke sind historisch gesehen Staatsrechtfertigungs-, Ermächtigungs- und Begrenzungsideen. Sie sind idealtypisch an einem bestimmten Menschen-und Staatsbild orientiert und haben im Laufe der Entwicklung des modernen Staates die vielfältigsten Ausprägungen erfabren. In ibrem vernunftrechtlichen Gebalt sollten sie für den Bürger vornehmlich Sicherheit (inneren und äußeren Frieden) und Freiheit verbürgen sowie Kultur und soziale Woblfahrt ermöglichen. Mit der Vorstellung des Staates als "Selbstzweck" im 19.Jb. tritt die "instrumentale" Staatsbetrachtung in den Hintergrund.

4. Auch zur Rechtfertigung des modernen demokratischen Verfassungsstaates bietet sich der Rückgriff auf die mit der Idee der Freibeit des Menschen verbundene freiwillige Unterwerfung unter die selbstgewäblte Herrschaft unter Verzicht auf Privatgewalt an. Der Staat schuldet dafür Sicherung des äußeren und inneren Friedens sowie Gewäbrleistung der Menschenwürde und der Grundfreibeiten. Zwischen dem Rechtsgehorsam und dem staatlichen Schutz besteht ein unauflöslicher Zusammenhang. Der Satz: „Subiectio trabit protectionem" gehört zum Grundbestand des modernen Staates (Grundverbältnis).

\section{Staatszwecke im Verfassungsstaat}

5. Der demokratische Verfassungsstaat stellt eine rationale Zweckschöpfung (keine zwangsläufige Erscheinung eines automatisch verlaufenden Entwicklungsprozesses) dar. I $\mathrm{bm}$ eignen alle notwendigen Elemente des modernen Staates. Der Schutz der Menschenwürde, des inneren und äußeren Friedens sowie der Selbstschutz des Staates sind notwendige, aber für den modernen Staat nicht mehr binreichende Staatszwecke. Für den Typus des modernen demokratischen Staates ist außerdem charakteristisch, daß er die Grund- und Menschenrechte sowie ein Mindestmaß an sozialer Sicherbeit und an geistig-sittlicher Integration seiner Bürger gewäbrleisten soll.

6. In der Regel hat der Verfassungsstaat diese Staatszwecke des modernen Staates in seinem positiven Verfassungsrecht verankert und normativ näber ausgestaltet. Im demokratischen Verfassungsstaat spricht die Vermutung dafür, daß die Verfassung das "Staatsbild" normativ abschließend fixiert hat. Eine Erweiterung der verfassungsrechtlichen Legalität ist daber nur durch Rückgriff auf zweifelsfreie Elemente moderner Staatlichkeit zulässig.

7. Das Völkerrecht ist für die Ermittlung von positiven Staatszwekken derzeit noch relativ unergiebig, jedoch ist die Beliebigkeit 
staatlicher Zwecksetzungen durch die Bindung an einen Mindeststandard der Fremden-und Menschenrechte begrenzt. Dazu gehört auch die Anerkennung der Personalität (Subjektstellung) jedes Menschen. Ansätze zu einer Ausrichtung des Staates an bestimmten Zwecken sind auch mit der Idee einer Verfassung der Völkerrechtsgemeinschaft (internationaler ordre public) verbunden (Friedenspflicht/peace loving). Gewalt- und Interventionsverbot können als negative "Staatszwecke" (Verbot des Macht-Expansionszwecks) gedentet werden.

8. Staatszwecke haben im Verfassungsstaat weitgehend den Rechtscharakter von Staatsbegrenzungen, Gewäbrleistungspflichten oder Staatszielen angenommen.

9. Die vom Volk ausgehende Staatsgewalt ist prinzipiell allumfassend. Ibre Ausübung ist am Staatszweck "Wabrung des Gemeinwohls" ausgerichtet. Das sachliche Substrat des Gemeinwobls ist - von Fällen negativer Evidenz abgesehen - nicht näher präzisierbar. Konkreter ist die Ausricbtung an der Würde und Freibeit des Menschen. Diese Ausrichtung fübrt zu einer nach der Gewichtigkeit gestuften Rechtfertigungslast für jedes öffentliche Interesse, das zur Einscbränkung individueller Freibeit herangezogen wird.

10. Für die funktionale Scheidung von Staat und Gesellschaft und eine daran anknüpfende Staatsaufgabenlebre geben die Staatszwecke nicht mehr Aufschluß, als sich obnedies aus den Handlungsermächtigungen des Grundgesetzes, insbesondere der objektiv-recbtlichen Seite der Grundrechte, ergibt.

11. Die Staatszweckbetrachtung findet beute weitgebend ihren Ort in der Interpretation der Grundrechte, namentlich bei der Legitimation von Grundrechtseinschränkungen. Vergleichbar werden die "Staatszwecke" in der Europäischen Menschenrechts-Konvention bei der Frage relevant, welche Einschränkungen zum Schutze bestimmter Rechtsgüter in einer demokratischen Gesellschaft "notwendig" sind.

12. Grundentscheidungen auf der Verfassungsebene (z. B. militärische Landesverteidigung) können durch die dabinterliegenden Zwecke (Sicherung des äußeren Friedens) verdeutlicht und interpretatorisch "aufgebellt" werden. Eine Staatszweck-optimierende "Umdeutung" von Verfassungsnormen ist jedoch nicht zulässig.

\section{$I V$. Internationalisierung und Europäisierung von Statszwecken}

13. Staatszwecke verändern durch die Auslagerung einzelner Sachbereiche zur Zweckverfolgung auf internationale Organisationen 
(Internationalisierung, Europäisierung) nicht nur ibre sachlich-räumliche Reichweite, sondern erfabren durch die Akte unter fremder Zweckverfolgung eine Ergänzung durch multilaterale Gemeinwohlvorstellungen. Der Staat als Einrichtung der Daseinsvorsorge und Schutzund Friedensordnung kann dadurch für den Bürger an identifikationsfäbigen Grundlagen verlieren. Der Staat muß gewährleisten, daß Schutz und Rechtsgehorsam sich entsprechen.

\section{Der Staatszweck „Sicherheit"}

14. Der (primäre) Staatszweck "Sicherheit" verpflichtet den Staat zum Verbot von Privatgewalt, den Bürger zur friedlichen Rechtsausübung. Die Auslegung des Nötigungstatbestandes (Gewaltbegriff) muß an diesem Elementartatbestand orientiert werden. Eine Lockerung des staatlichen Gewaltmonopols fübrt aller Erfabrung nach nicht zu herrschaftsfreien Räumen, sondern zur Anarchie der Privatgewalt.

15. Der Staatszweck "Sicherheit" wird u.a. durch den öfentlichen Dienst - insbesondere durch den Funktionsvorbebalt nach Art. 33 Abs. 5 GG - gewährleistet. Der Einbruch der Arbeitnebmerfreizügigkeit in die nationalen "öffentlichen Verwaltungen" (Art. 48 Abs. 4 $E W G V)$ kann nicht durch eine rein nationale Interpretation dieses europarechtlichen - Begriffs abgewebrt werden.

16. Die Gewissensfreibeit durchbricht den Rechtsgehorsam, stellt aber den Grundrechtsträger nicht außerbalb des Rechtsstaates.

17. Sog. "begrenzte Regelverletzungen " lassen sich im demokratischen Rechtsstaat nicht unter Berufung auf deren angebliche Legitimität als legal rechtfertigen. Derartige Privatgewalt schafft Privilegien. Die parlamentarische Demokratie verweist die damit verknüpften Anliegen auf das Verfabren der Gesetzesänderung.

18. Der moderne Staat ist vom Sicherbeitsbewabrungs- zum Risikovorsorgestaat geworden. Risikovorsorge muß mit der Art der Gefabr (Mangel derindividuellen Beherrschbarkeit), ibrem Ausmaß (erbeblich) und dem wabrscheinlichen Eintritt eines Schadens gerechtfertigt werden.

19. Als Garant des Bürgerfriedens schuldet der Staat seinen Bürgern Schutz nach Maßgabe der Rechtsgüterordnung der Grundrechte. In der Regel wird dieser Schutz durch straf-und zivilrechtliche Normen besorgt werden können. Als Grund-Regulativ genügt eine Generalklausel (neminem laedere). Die Ableitung der Pflicht des Staates zu effektivem Rechtsgüterschutz aus derobjektiv-rechtlichen Seite der Grundrechte ist im Begriff, Bestandteil der europäischen Rechtskultur zu werden. 
20. Ein Grundrecht auf Sicherbeit läßt sich nicht aus dem Staatszweck "Sicherheit", sondern nur aus dem Grundverbältnis i. V. mit der objektiv-rechtlichen Seite der Grundrechte ableiten.

21. Der Staat muß zur Friedensgewäbrleistung angemessene und effektive Verwaltungs- und Gerichtsverfahren zur Verfügung stellen. Ein Justizgewährungsanspruch folgt aus den Grundrechten und dem Rechtsstaatsprinzip (ebenso Art.6 EMRK; Art.19 Abs. 4 GG).

22. Die Europäisierung der Entscheidungen über Sicherbeitsstandards fübrt zu einem Auseinanderfallen von Rechtsetzungsbefugnis (potestas) und Durchsetzungsbefugnis (vis). Unterschiedliche Sicherbeitsstandards nach dem Herkunftslandsprinzip haben einen für den Bürger schwer durchschaubaren Sicherheitspluralismus zur Folge.

\section{Insbesondere: äußere Sicherbeit}

23. Die Wabrung der äußeren Sicherheit als hergebrachter Staatszweck des modernen Staates liegt der verfassungsrechtlichen Grundentscheidung für eine militärische Landesverteidigung voraus und zugrunde. In der Bundesrepublik Deutschland bestebt auch nach 40 Jahren GG eine doppelte Webrverfassung: die des Grundgesetzes in Verbindung mit dem Nato-Vertrag; daneben die von den drei Westmächten im Hinblick auf Deutschland als Ganzes, einschließlich Berlin, vorbehaltenen originären Truppen-Stationierungsrechte.

24. Art. 26 Abs. 1 i. V. mit Art. 1 Abs. 2 GG verpflichtet die Bundesrepublik Deutschland auf eine menschenrechtsbewußte Außenpolitik. Der Staatszweck der "äußeren Sicherbeit" wird unter den beutigen Bedingungen auch im Rabmen von kollektiven Sicherbeitssystemen (Art. 24 Abs. 2 GG) wabrgenommen. Die Befugnis zum Einsatz von deutschen Streitkräften in den UN-Peace keeping forces läßt sich unter Berücksichtigung der völkerrechtsfreundlichen Haltung des GG aus Art. 87 a Abs. 2 i. V. mit Art. 24 Abs. 2 und Art. 11 und 29 UN-Charta berleiten. Zum Staatszweck "Sicherbeit" gehört auch der diplomatische Schutz Deutscher im Ausland. Der Bürger bat aus dem Grundverbältnis einen Anspruch auf ermessensfeblerfreie Entscheidung über den Schutz der in den Grundrecbten enthaltenen Schutzgüter.

\section{Zum Staatszweck „Freibeit"}

25. Der Staatszweck Freibeit ist am Bild des zu freier Selbstbestimmung und selbstverantwortlicher Lebensfübrung berufenen Men- 
schen ausgerichtet. Zum Staatszweck Freiheit gebören die im demokratischen Rechtsstaat zur Freibeitssicherung notwendigen Vorkehrungen, u. a. neben der Zweckbindung des staatlichen Handelns am Gemeinwobl die Gewaltenteilung, der Gesetzesvorbebalt, die Menschen- und Grundrechte, das demokratische Wablverfabren, die Sicherung der Gründungsfreibeit und Artikulationsfähigkeit für die politischen Parteien, Kontrolle der Exekutive, Verantwortlichkeit der Regierung, schließlich Kontrolle aller staatlichen Gewalten durch das Bundesverfassungsgericht.

26. In der Bundesrepublik Deutschland verfügt jeder über einen status internationalis (Art. 25 EMRK) und jeder EG-Angehörige über einen status europaeus (Art.173 Abs. 2, 175 Abs. 2; Art.177 EWGV i. V. mit Art. 101 Abs. 1 Satz 2 und 93 Abs. 4 a GG). Der Grundrechtsschutz im Grundgesetz wird mit fortschreitender Rechtsharmonisierung in der EG durch einen parallelen, am Maßstab allgemeiner europarechtlicher Rechtsgrundsätze orientierten Schutz (unter Einschluß der EMRK) ergänzt und partiell ersetzt. Dem System der konzentrierten nationalen Verfassungsgerichtsbarkeit tritt parallel $z u$ dieser Entwicklung ein System diffuser Kontrolle am Maßstab des EGRechts mit Verwerfungsbefugnis durch jeden deutschen Richter zur Seite. Die Einbindung der (wesentlichen Teile der) EMRK in das Rechtsstaatsprinzip fübrt in der Bundesrepublik Deutschland zu einer der Rechtslage in der Schweiz und Österreich vergleichbaren Kontrolle der Gesetze am Maßstab der EMRK. Zugleich gewinnen damit die Urteile des EGMR für die Auslegung des Grundgesetzes, wenn auch keine Bindungswirkung, so doch eine Orientierungswirkung.

\section{Sozialstaatsziel}

27. Das Grundgesetz bat nur einen limitierten Wohlfahrtszweck als Sozialstaatsziel unter Wabrung des Primats der Selbstverantwortung des einzelnen aufgegriffen; aus dieser an den Gesetzgeber gerichteten Direktive können unmittelbare Ansprüche des einzelnen -- von einer extremen existenzgefäbrdenden Situation abgeseben - nicht abgeleitet werden. Die Berücksichtigung des sozialen Zwecks (Daseinsvorsorge) des modernen Staates wäre auch obne ausdrückliche Verankerung des sozialen Staatsziels im Grundgesetz zulässig gewesen. Die Pflicht erfaßt nur einen engen Kernbereich, demgegenüber die gegenwärtige expansive Praxis an die Grenzen der moralischen Belastbarkeit (Pbänomen der Schattenwirtschaft) stößt. Die "Wirtschaftsverfassung" des Grundgesetzes gebt ebenso wie die der EWG von dem Primat der Wirtschaftsfreibeit vor staatlicher Intervention aus. 
IX. Integrationszweck

28. Dem Staat kommt auch der Zweck $z u$, sich für "Integration“ der Bürger, ibren geistig-etbischen Zusammenhalt auf der Grundlage der Verfassungswerte, werbend einzusetzen. $Z$ u diesem gebören u.a. Toleranz, Ideenoffenbeit, freibeitlich-demokratische Grundordnung, Pluralismus im Erziehungswesen, aber auch europäische Zielgebundenheit und nationale Zusammengebörigkeit.

\section{$X$. Konkretisierung und Konkurrenz}

29. Die Staatszwecke binden alle Staatsfunktionen. Der Gesetzgeber ist in erster Linie zur Konkretisierung der Staatszwecke (-ziele) berufen. Staatszwecke (-ziele) sind pflichtenaktivierend, aber im Prinzip anspruchsresistent. Einen unmittelbaren Anspruch gewäbre weder das Wiedervereinigungsziel noch das Europa-Ziel noch das Sozialstaatsziel. Allein aus der Pflicht zur Gewäbrleistung des inneren Friedens und aus Art.1I1 GG lassen sich Schutzansprücbe (nach Maßgabe der Grundrechte) herleiten: Ein bestimmtes Handeln des Gesetzgebers kann nicht verlangt werden. Es ist an der Zeit, die im deutschen Verfassungsrecht entwickelte Wesentlichkeitstheorie auf die europäische Ebene zu übertragen. Kennzeichnend ist die Zurücknabme der Kontrollnorm gegenüber der Funktionsnorm.

30. Konflikte zwischen den Staatszwecken (-zielen) müssen durch eine Konkordanz bebohen werden. Eine Rangfolge zwischen den Zwecken: "Sicherbeit" und "Freibeit" und Verfassungszielen wie Sozialstaatlichkeit, Kultur, Europäische Einigung und Wiedervereinigung bestebt nicht. Insbesondere: Wiedervereinigung und Selbstbestimmung der Deutschen und Europäischen Einigung lassen sich kompatibel gestalten. 


\section{Aussprache und Schlußworte}

\section{Staatszwecke im Verfassungsstaat - nach 40 Jahren Grundgesetz}

Vorsitzender (Denninger): Meine sehr verehrten Damen und Herren! Ich begrüße Sie zur Aussprache und möchte zunächst einige technische Dinge ansagen. Es stehen Saalmikrofone zur Verfügung, die jeweils dem Redner gegeben werden. Sie mögen bitte an diesen Mikrofonen nichts verstellen, sondern möglichst nah in die Geräte hineinsprechen - sie bleiben angeschaltet. Nach Gebrauch bitte das Mikrofon in der Reihe wieder nach außen an die Damen und Herren, die Sie hier sehen, zurückgeben. Dann habe ich generell auch ein paar Dinge zur Sache zu bemerken. Sie sehen an der Tafel - ich möchte sagen - nicht den Versuch einer Gliederung, sondern nur einige Stichworte, die Sie anregen mögen. Sie können aber natürlich auch ganz andere Stichworte bringen; eine Öffnung dieser Gliederung finden Sie unter IV., da habe ich mit Absicht überall dazugeschrieben „z. B.“. Da kann also ganz anderes gesagt werden. Ich nehme noch Wortmeldungen dankbar entgegen. Für die Redezeit möchte ich jetzt noch keine Limitierung vorgeben, obwohl ich mir vorgestellt habe, daß wir so ungefähr mit 4-5 Minuten pro Redner auskommen müßten. Die Glocke, um die ich gebeten hatte, ist noch nicht da. Ich habe also noch keine Waffe, um Kollegen, die das Maß überziehen, abzubremsen, aber ich möchte hier, indem ich Herrn Link in diesem einen Punkt entgegentrete, sagen, daß hier und heute nachmittag jedenfalls nicht die Freiheit besteht, sich auch nicht gemeinwohlorientiert zu verhalten. So sehr mir das sonst aus dem Herzen gesprochen war, aber hier, heute nachmittag, gilt das nicht. Sie haben sich also bitte gemeinwohlorientiert und das heißt: redezeitdiszipliniert zu verhalten, nur das ist gemeint, nichts anderes. Ein zweites noch: Ich möchte ausdrücklich die zahlreichen jüngeren Kollegen ermuntern, sich auch hier zu Wort zu melden und vorzustellen. Man hört ja manchmal so ein Gemunkel, nicht wahr, in der Diskussion redeten immer dieselben alten Herren. Das ist nicht der Fall und ist auch keineswegs gewünscht - also bitte machen Sie von der Möglichkeit Gebrauch, hier frank und frei Ihren Beitrag beizusteuern. (Zwischenruf) Das war eine Bitte. 
Damit bin ich auch schon am Ende. Vielleicht sollte ich ganz kurz noch ein paar Bemerkungen zu den Stichworten an der Tafel anfügen: $\mathrm{Zu}$ III. wäre nur zu sagen: Gemeint ist das Problem: Inwieweit ist eigentlich die staatliche Ebene noch die geeignete Ebene für bestimmte Problembewältigungen? Das stellt sich sowohl in Richtung auf Internationalisierung, Europäisierung wie auch in bezug auf Privatisierung - also Stichwort „Subsidiaritätsprinzip“. Zu VI. hatte ich bereits gesagt, daß das nur beispielhaft gedacht ist. Man kann natürlich diese Stichworte auch angesichts der Masse des Stoffes, der uns heute morgen vorgetragen worden ist - verlängern und erweitern. Aber ich glaube, daß mit diesen Stichworten einige wichtige Punkte eingefangen worden sind. Dann darf ich gleich die beiden ersten Diskussionsredner bitten, das Wort zu ergreifen. Zuerst wird Herr Ralf Dreier, sodann Herr Alexy sprechen.

Ralf Dreier: Ich möchte mich zunächst bei beiden Referenten sehr herzlich für ihre hochinteressanten und spannenden Vorträge bedanken. Sie werfen so viele Probleme auf, daß sie in dieser Diskussion nicht annähernd ausgeschöpft werden können. Ich beschränke mich daher auf drei kurze Bemerkungen. Erstens: Eine normative Staatszwecklehre ist nach meiner Auffassung auf eine normative Gerechtigkeitstheorie verwiesen. Ich hätte mir gewünscht, daß beide Referenten diesen Bezug etwas deutlicher gemacht hätten, obwohl ich natürlich weiß, daß man in 45 Minuten nicht alle Aspekte des weit gespannten Themas ansprechen kann. Es wäre z. B. interessant, vor dem Hintergrund der Staatszwecklehre die Gerechtigkeitstheorie von John Rawls, als eine eher wohlfahrtsstaatliche, mit der von Robert Nozick, als eine entschieden liberale oder besser: libertäre, zu vergleichen. Das ist ein weites Feld, das aber in der weiteren Staatszweckdiskussion vielleicht nützlich zu erörtern wäre. Zweitens: Mir ist der Begriff des Staatszwecks noch immer nicht ganz deutlich geworden. Herr Link hat eine interessante Sequenz vorgeschlagen - nach dem Abstraktionsgrad, wenn ich recht verstanden habe. Er hat zwischen Staatszwecken, Staatszielen, Staatsaufgaben und Verfassungsaufträgen unterschieden. Vielleicht wäre es zweckmäßig, deutlicher zwischen der Staatszwecklehre der Allgemeinen Staatslehre (sei sie als philosophische, juristische oder soziologische betrieben) und der Staatszwecklehre der Staatsrechtsdogmatik zu unterscheiden. In der Allgemeinen Staatslehre könnte nach dem Abstraktionsgrad zwischen Staatszwecken und Staatsaufgaben differenziert werdne, während die Staatsrechtsdogmatik wohl mit den verfassungsrechtlichen Staatszielbestimmungen $\mathrm{zu}$ beginnen hätte, die dann zu Staatsaufgaben zu 
konkretisieren wären bzw. durch spezielle Verfassungsaufträge konkretisiert sind. Ein Thema für sich wäre sodann die Frage, welches Verhältnis zwischen den Zwecklehren beider Disziplinen besteht. Drittens: Ziviler Ungehorsam. Beide Referenten haben dieses Problem angesprochen. Sie haben sich dazu im Sinne der in dieser Vereinigung - vorbehaltlich einiger „Ketzer“ - weithin herrschenden Meinung geäußert. Ich möchte dem einige kritische Anmerkungen hinzufügen. Zunächst darf ich daran erinnern, daß Carlo Schmid, immerhin einer der "Väter" unseres Grundgesetzes, 1945 gesprächsweise geäußert hat: „Man muß die deutsche Jugend zum Ungehorsam erziehen." Das war natürlich in eine bestimmte politische Situation hineingesprochen. Aber die Erfahrungen dieser Situation sind doch, glaube ich, gewichtig genug, um jenes Wort auch heute noch auf seine Aktualität zu überprüfen. In diesem Zusammenhang erschiene es mir sinnvoll, zunächst einmal nach den Ursachen zu fragen, aus denen sich die gestiegene Bereitschaft zum Gesetzesungehorsam erklärt. Es könnte ja sein, daß eine wesentliche Ursache darin liegt, daß der Staat seine $Z$ wecke, Ziele und Aufgaben nicht zur Befriedigung der Bürger erfüllt. Auf der Basis einer solchen Ursachenprüfung wäre dann nicht in erster Linie zu fragen, ob und inwieweit sich ziviler Ungehorsam rechtlich rechtfertigen läßt - das kommt ohnehin nur ganz marginal in Betracht -, sondern ob und inwieweit er politisch-moralisch rechtfertigungsfähig ist. Die Erörterung dieser Frage macht nach meiner Erkenntnis $\mathbf{9 0 - 9 5 \% ~ d e r ~ D i s k u s s i o n ~ a u s . ~ J u ̈ r g e n ~ H a b e r m a s , ~}$ der in einem der Referate angesprochen wurde, betont ausdrücklich, $\mathrm{da}$ er eine rechtliche Rechtfertigung zivilen Ungehorsams nicht für sinnvoll hält, wohl aber eine politisch-moralische, zu der dann auch die Bereitschaft gehört, die Sanktionen, die auf dem Ungehorsam liegen, zu tragen. Und ich habe in vielen Diskussionen mit Betroffenen festgestellt, daß sie an einer rechtlichen Rechtfertigung viel weniger interessiert sind als an den politisch-moralischen Problemen dieser Form des provokativen Protestes. Vielleicht wäre es auch in dieser Vereinigung zweckmäßig, das Problem des zivilen Ungehorsams etwas differenzierter zu behandeln, als es in den Randbemerkungen der beiden Referenten hierzu nach meinem Eindruck der Fall war.

Vorsitzender: Vielen Dank, Herr Dreier. Ich darf dann Herrn Alexy das Wort geben.

Alexy: Meine Bemerkungen zielen auf zwei Punkre. Der erste betrifft die Struktur einer Staatszwecklehre, der zweite das Problem einer Rangordnung der Staatszwecke. Wenn ich von der Struktur einer Staatszwecklehre spreche, dann möchte ich mich nicht auf eine 
allgemeine Staatszwecklehre beziehen, sondern auf eine Staatszwecklehre des demokratischen Verfassungsstaates und näherhin der Bundesrepublik Deutschland. Des weiteren möchte ich unter Staatszwekken nur solche Zwecke verstehen, die in rechtlich bindenden Entscheidungen als Gründe oder Argumente verwendet werden können. Diese beiden Eingrenzungen sind notwendig, wenn die Diskussion über die Staatszwecklehre nicht in allgemeines Gerede ausufern soll. Das Problem besteht nun darin: Wie ist es möglich, im Bereich des Staatszwecklehre mehr zu erhalten als einen bloßen Topoikatalog, den man in der juristischen Argumentation und auch in der politischen Rhetorik zu allen Zwecken einsetzen kann?

Ein erster wesentlicher Schritt ist, daß der Zweckbegriff einer Analyse unterzogen wird. Es gibt einige Anhaltspunkte dafür, daß der im Rahmen der Staatszwecklehre zumeist unbefangen verwendete Begriff des Zwecks Probleme bereitet. Ein Beispiel bietet der Begriff des negativen Zwecks. Negative Zwecke sind Zwecke, die der Staat nicht verfolgen darf. Schaut man näher hin, so stellt man fest, daß negative Zwecke schlichte Verbote sind. Also haben wir es in der Staatszwecklehre u. a. mit Verboten zu tun. Auf der Seite der positiven $Z$ wecke stößt man schnell auf Gebote. Bereits dies zeigt, daß eine über den Begriff des Zwecks hinausgehende Konzeptualisierung erforderlich ist. An dieser Stelle möchte ich an das anknüpfen, was Herr Dreier gesagt hat. Er erwähnte neuere Theorien des Wohlfahrtsstaats und des liberalen Staates und nannte dabei Autoren wie Rawls und Nozick. Man könnte etwa Buchanan hinzufügen. Nun wäre es nicht gut, wenn die Staatsrechtslehrervereinigung anfangen würde, allgemeine politische Philosophie zu betreiben. Es ist aber eine Aufgabe der Staatsrechtslehre, das alte Projekt der Staatszwecklehre dadurch fortzuführen, daß sie versucht, auf der Basis der institutionellen Realität der Bundesrepublik Deutschland eine allgemeine normative Theorie dieses Staates zu entwickeln. Dabei können Schriften wie die von Rawls, Nozick und Buchanan sehr hilfreich sein. Es geht darum, sich von der simplen Frage nach Staatszwecken zu lösen und zu der Frage überzugehen: „Was ist die richtige allgemeine normative Theorie des Staates Bundesrepublik Deutschland?"

Zu meinem zweiten Punkt: Wenn die Antwort auf die eben formulierte Frage einen Sinn haben soll, wenn also mehr herauskommen soll als Topoikatalog, dessen man sich beliebig bedienen kann, dann muß es eine Rangordnung zwischen Staatszwecken geben. Herr Ress vertritt in seinem Leitsatz 30 die These, es gäbe keine Rangordnung. Es heißt dort: „Eine Rangfolge zwischen den Zwecken: Sicherheit' und ,Freiheit‘ und Verfassungszielen wie Sozialstaatlichkeit, Kultur, Euro- 
päische Einigung und Wiedervereinigung besteht nicht." Ich möchte behaupten, daß eine adäquate Theorie der Staatszwecke der Bundesrepublik Deutschland Rangordnungsverhältnisse enthalten muß. Dabei geht es nicht um strikte Vorränge, die alle Kollisionen vorab und in diesem Sinne abstrakt lösen, sondern um prima facie-Vorränge, die Vermutungen begründen, die im konkreten Fall widerlegt werden können. Ich will zwei Beispiele nennen. Das erste betrifft das Verhältnis der negativen gegenüber der positiven Freiheit. In der institutionellen Realität des Rechtssystems der Bundesrepublik Deutschland existiert ein prima facie-Vorrang der ersteren vor der letzteren. Das zweite Beispiel betrifft das Verhältnis von individuellen Rechten und kollektiven Gütern. Ich behaupte, daß eine kritische Rekonstruktion des Rechtssystems der Bundesrepublik Deutschland zu einem prima facie-Vorrang individueller Rechte gegenüber kollektiven Gütern führt. Nach derartigen Vorrangrelationen zu suchen, scheint mir eine wesentliche Aufgabe der Staatszwecklehre zu sein. Wenn überhaupt keine Vorrangrelationen feststellbar oder begründbar sein sollten, könnte man das Projekt einer Staatszwecklehre aufgeben, denn dann wäre nichts anderes als eine Rhapsodie möglich, eine Rhapsodie von schönen Wörtern, deren wir uns in allerlei Begründungen bedienen könnten.

Vorsitzender: Vielen Dank, Herr Alexy. Ich habe jetzt für die erste Rubrik „Begriffliches“ noch zwei Wortmeldungen. Zunächst Herr Stettner und dann Herr Mantl. Herr Stettner, bitte.

Stettner: Herr Vorsitzender, meine Damen und Herren! Die Frage nach Staatszwecken, meine ich, ist vorrangig eine begriffliche Frage nach dem Staat selbst. Das Problem, was in den Staatsbegriff hineinzulegen ist, ist identisch mit der Frage nach dem Zweck des Staates. Denn ich denke, wenn wir verschiedene Gemeinwesen der Vergangenheit und der Gegenwart gleichermaßen als Staaten bezeichnen wollen, müssen wir hier wie dort identische oder gleichartige Merkmale vorfinden, die uns erlauben, diese zwischenmenschlichen Organisationen wie Perlen an einer Schnur aufzufädeln. Was aber ist es, was diese als Staaten auszeichnet? Das kann m. E. nicht die Herrschaft sein. Die Herrschaft ist eine Erscheinung, die wir in anderen menschlichen Organisationsformen auch vorfinden, und ich denke etwa an die Familie, die durchaus auch von Herrschaft geprägt ist, auch wenn das Bürgerliche Gesetzbuch heute vom Recht der elterlichen Sorge spricht. Es ist $\mathrm{m}$. E. der Zweck, und zwar der obligatorische Zweck des Staates, der den Begriff des Staates ausfüllt; ich spreche nicht von fakultativen, auf der Verfassungs- oder Gesetzesebene normierten 
Zwecken. Nun, was mag dieser Zweck sein? Hobbes hat ihn als den Frieden definiert, aber es ist sicher nicht erst zu Zeiten Hobbes', daß wir Gemeinwesen mit diesem Friedenszweck vorfinden. Trotzdem naheliegende Anachronismen bei der Verwendung des Staatsbegriffes werden aber vermieden, wenn wir uns über die Zwecke, die obligatorischen Zwecke des Staates einig werden. Nun gibt es allerdings diese Lehre von der Selbstzweckhaftigkeit des Staates, wonach diese Gebilde in sich ruht und nicht unter irgendwelche $Z$ wecke gebeugt werden darf und soll. Und natürlich, wenn das richtig ist, dann versagt dieses Identifizierungsmerkmal "Staatszweck" = obligatorischer Staatszweck". Es sei denn, wir definierten alle die Gebilde, die sich zwecklos im Raume befinden, als Staaten. Nun, meine Damen und Herren, ist das nun eine Erscheinung, die, wie ich glaube, bei Großorganisationen durchaus häufig auftritt, daß sie ihre eigentlichen $Z$ wecke aus den Augen verlieren, daß diese gegenüber dem Bestandsinteresse in den Hintergrund treten - eine Erscheinung, die der Organisationssoziologie durchaus bekannt ist. Wir können etwa an die Parteien denken, auch bei den Kirchen fragen, ob sie nicht in gewissen Epochen ihrer Geschichte das Bestandsinteresse durchaus akzentuiert haben entgegen ihren eigentlichen Zwecksetzungen, oder an die Gewerkschaften denken, die sich etwa in der Rolle als Arbeitgeber doch von ihren eigentlichen Orientierungen hin und wieder etwas hinwegbewegen. Die Selbstzweckhaftigkeit ist also keineswegs eine Erscheinung, der wir beim Staat allein begegnen. Ich glaube, daß diese Lehre an sich verwechselt eine empirische Erkenntnis mit einer normativen Aussage, d. h. wir finden hier die Erscheinung der Normativität des Faktischen vor, daß nämlich Tatsachen, die wir in der Gegenwart wie auch in der Vergangenheit beobachten können, in den Rang eines Postulats erhoben werden und davon, würde ich meinen, sollte man Abstand nehmen. Vielen Dank.

Vorsitzender: Danke sehr, Herr Stettner. Ich muß mich etwas korrigieren. Ich hatte Sie, Herr Leisner, unter der Rubrik II. eingeordnet, sehe aber, daß Sie doch zu I. sprechen wollen. Dann bitte sehr. Zunächst aber Herr Mantl aus Graz, bitte, und dann Herr Leisner.

Mantl: Ich bin angesichts des heutigen Themas mit gewisser Sorge hierhergefahren und möchte den Referenten danken, daß sie ihre Aufgabe nicht in festrednerischer Vollmundigkeit abgehandelt haben, sondern bemüht waren, den Gegenstand detailreich zu analysieren. Meine Zweifel, daß es eine geschlossene, normative Staatszwecklehre geben könne, laufen dem entgegen, was Herr Kollege Robert Alexy gesagt hat. Anders als er bin ich der Ansicht, daß Ergebnis unserer 
Bemühungen um die Staatszwecke kein System, sondern "nur“ ein Katalog von Topoi der Argumentation sein wird. Dieser Topoikatalog hat jedoch seinen Wert, gerade für die politische Diskussion vor dem eigentlich juristischen Bereich, ist aber auch für ihn von Bedeutung.

Schwierigkeiten, die sich einer Staatszwecklehre entgegenstellen, bestehen vor allem darin, daß es dem heutigen Lebensgefühl große Probleme bereitet, überhaupt individuelle Zwecke zu begreifen. Die starke Individualisierung und Pluralisierung des Lebens denkt Zwecke fast nur mehr als Ziele und Präferenzen des Individuums (eine der Wurzeln für die Wichtigkeit der individuell gewährleisteten Grundund Freiheitsrechte für das zeitgenössische Bewußtsein). Die Verknüpfung individueller Ziele und Präferenzen zu Systemzwecken und Institutionen ist durchaus prekär. Das zeigt sich ja auch an der Infragestellung großer Institutionen wie Staat, Kirche, Großpartei und Großverband. Dieser Prozeß gewinnt freilich noch an Dramatik, wenn man sich vor Augen hält, daß es heute überdies sogar eine Infragestellung selbst des neuzeitlichen Subjekts gibt, das einer strukturalistischen und postmodernen Erosion unterworfen ist. Es droht also auch das verlorenzugehen, was in christlicher, aber auch kantianischer Tradition zumindest als kleinster gemeinsamer Nenner philosophischer, politischer und rechtlicher Reflexion gilt.

Wenn wir in Österreich auch dazu neigen, die Grenzen des juristischen Denkens enger zu ziehen als in der Bundesrepublik Deutschland, so meine ich dennoch, daß die heute angestellten Erwägungen überall dort auch von juristischer Bedeutung sind, wo es um das „Abwägen“ und die Suche nach "guten Gründen“ im Bereich des Ermessens oder um vor allem teleologische Interpretation im Bereich der Gebundenheit geht. Im politischen Diskurs impliziert z. B. die Privatisierung öffentlicher Tätigkeit einen Begriff dessen, was Zweck und Aufgabe des Staates ist, sein sollte. Oder wenn in Österreich oder der Schweiz die Positionierung dieser beiden Staaten in Europa (das Pro und das Contra eines EG-Beitritts, Mitteleuropadiskussion, Brückenfunktion etc.) erörtert wird, dann handelt es sich - neben allen rechtlichen Fragen (Neutralität, Gesamtänderung der Bundesverfassung mit obligatorischer Volksabstimmung) - doch wesentlich um eine politische Auseinandersetzung um den Zweck eines konkreten Staates.

Daß Staatszwecke zum Bildungskanon einer bistorisch-deskriptiven Staatslehre zählen, bereitet uns kaum Kopfzerbrechen. Der harte Kern aktueller Diskussion von Staatszwecken - auch in den Ausführungen der beiden Referenten - ist jedoch die Legitimitätsfrage, die Anerkennung und die Anerkennungswürdigkeit als Rechtfertigung des 
Staates überhaupt gegen anarchische Sehnsüchte oder eines bestimmten Staates. Diese Staatszweckdebatte als Legitimitätsdebatte schließt die Frage des staatlichen Gewaltmonopols, der Gehorsamspflicht der Bürger und der Schutzpflicht des Staates ein. Ich teile Ralf Dreiers Ruf nach Gerechtigkeitserwägungen und bin davon überzeugt, daß die Juristen wieder stärker an der allgemeinen Diskussion dieser Probleme teilnehmen sollten. Die Legitimitätsdiskussion etwa erreichte 1975 auf der Duisburger Jahrestagung der Deutschen Vereinigung für Politische Wissenschaft mit den Referaten von Jürgen Habermas und Wilhelm Hennis, der ja "gelernter" Jurist ist, einen Höhepunkt, dem wir nicht sub titulo „Staatszwecklehre“ eine marginale Reprise nachsetzen sollten, indem wir in diesen Fragen trotzig ein juristisches proprium in Anspruch nehmen. Ich fürchte eine Selbstisolierung und Abschottung des juristischen Räsonnements in einem hortus conclusus. Wir müssen uns vielmehr der allgemeinen philosophischen, sozialwissenschaftlichen und politischen Diskussion stellen und in ihr unseren wichtigen, ja unverzichtbaren Beitrag mit unseren juristischen Topoi leisten.

Vorsitzender: Recht vielen Dank, Herr Mantl. Jetzt wäre Herr Leisner auf der Liste, auch noch zum Thema des ersten Blockes, aber ich sehe schon, daß sich die Trennung von I und II hier sowieso nicht so streng durchhalten läßt. Die nächsten Redner wären zunächst Herr Häberle, vielleicht geben Sie ein kleines Handzeichen, und Herr Schuppert. Danke sehr. Dann darf ich Sie, Herr Leisner, bitten.

Leisner: „Der Zweck im Recht“ ist ein berühmter juristischer Titel gewesen. Ich nehme an, daß der Vorstand beabsichtigte, daß hier ein ebenso bedeutender neuer Titel entstehen soll: „Der Zweck in der Verfassung" oder "Der Zweck im Staatsrecht".

Ein Wort voraus: Selbstverständlich meine ich, daß wir alle, als Mitglieder der Vereinigung der Deutschen Staatsrechtslehrer, Staatsphilosophen sind. Wer anders als wir sollte denn Staatsphilosophie gekonnt betreiben? (Beifall)

Die Referenten hatten es heute nicht leicht. Mit dem Begriff des Staatszweckes waren sie in ein weites Feld hinausgeworfen, das auch begrifflich seine Tücken hat. $\mathrm{Da}$ hörten wir nun vieles von den Staatszwecken im eigentlichen Sinne des Wortes - einem Begriff insbesondere der Staatsrechtfertigungslehre, der allgemeinen Staatslehre, mit Bedeutung sicher auch für das Staatsrecht. Dann aber war auch die Rede von Staatsaufgaben; dies ist ein primär staatsrechtlicher Begriff. Wie bringen wir diese beiden Begriffe zusammen? Herr Link hat dazu schon Wesentliches gesagt, was wir aufgreifen können. Was 
die Staatsaufgaben anlangt, so können wir in unserem Verfassungsstaat nicht mehr sagen, daß alles zu Gold - oder eben doch zu Unfreiheit - wird, was der Staat berührt. Hier stößt er an freiheitssichernde Grenzen, wenn er neue Aufgaben anfassen will, und der Staat muß sich diesen Schranken gegenüber aus seinen Staatszwecken legitimieren; dies scheint mir das Verhältnis der beiden Begriffe zueinander zu sein.

Dann begegnen wir noch den "Staatszielen“ - wiederum ein Begriff sowohl der allgemeinen Staatslehre als auch des Staatsrechts, der mir besonders am Herzen läge, weil wir ihn ja in unserer Dogmatik immer wieder antreffen. Bezeichnet er das zu Erreichende und doch nie ganz Verwirklichbare, von dem die Rede war? Meint er das Optimale, bei dem es genügt, daß man ihm näher kommt, auch wenn man es nicht ganz erreichen kann? Gibt es einen besonderen dogmatischen, normativen Gehalt eines solchen Staatszieles, etwa im Sinne der Wiedervereinigung oder auch der Sozialstaatlichkeit?

Und eine zweite grundsätzliche Bemerkung: Unser Thema wirft das Grundproblem auf, das dem eingangs erwähnten Buch seine Berühmtheit gebracht hat: Was bedeutet die Teleologie im Recht, im Staatsrecht? Was verleiht sie dem Staat, der Verwaltung an Befugnissen, können wir allein aus der Aufgabe, aus dem Ziel auch schon Kompetenzen, Befugnisse ableiten - was den Spezialisten des Polizeirechts unter uns eine Gotteslästerung bedeuten würde? Dürfen wir das, was dort nicht möglich ist, nun im Staat ganz allgemein praktizieren; und eine weitere Frage: Freiheit - ein "Zweck“ oder ein "normativer Inhalt"? Wenn wir schon Freiheitsbeschaffung und -bewahrung als einen Staatszweck fassen - kommt da nicht die ganz große Gefahr auf uns zu, daß im Namen dieser Freiheitsherstellung die Freiheit geschlagen wird?

Eine letzte Bemerkung zum Rechtsstaat: Wird nicht gerade hier diese Staatszwecklehre zur großen Gefahr, wenn sie nicht von uns und deswegen sind wir wohl zusammengekommen - domestiziert wird? Befugnisse aus Zwecken, der Zweck, der die Mittel rechtfertigen könnte? Da sei Gott vor und das Grundgesetz und die Vereinigung der Deutschen Staatsrechtslehrer!

Vorsitzender: Vielen Dank, Herr Leisner. Ich glaube, sagen zu dürfen, daß Sie wahrlich als Staatsphilosoph gesprochen haben. Das haben Sie auch für diese Vereinigung als Profession reklamiert, in der Weise, daß Sie lauter Fragen gestellt haben.

Damit haben wir Block I gewissermaßen abgearbeitet, und ich darf jetzt zum zweiten Themenbereich „Staatszwecke“, „Verfassungs- 
zwecke" die Herren bitten - Damen haben sich noch nicht gemeldet - zunächst Herrn Häberle, dann Herrn Schuppert, dann Herrn Steiger und als vierten Herrn Grimm.

Häberle: Herr Vorsitzender, verehrte Kolleginnen und Kollegen! Erlauben Sie mir eine Vorbemerkung und drei Grundsatzfragen zunächst zu II. der Diskussionsgliederung: 1) zum Zusammenhang von auf den Menschen bezogenen Staatszwecken und Grundrechten, Stichwort instrumentales Staatsverständnis, zu Ende zu gehen mit Art. 1 Verfassungsentwurf Herrenchiemsee und Art. 2 der Menschenrechtserklärung von 1789 sowie neueren Verfassungstexten. 2) Große Unterstützung der Referenten in bezug auf ihr prozessuales, pluralistisches Gemeinwohlverständnis, wobei ich Herrn Links Rekonstruktion des Begriffs "Gemeinwohl" besonders begrüße. 3) Ein den beiden Vorrednern folgender Vorgriff auf Punkt IV. der Diskussionsgliederung in Gestalt eines Wortes zu Rawls' Gerechtigkeitslehre bzw. der "civil disobedience“, Stichwort „Robin Wood" und "Green Peace“, begrenzte Regelverletzung. - Zunächst zur Vorbemerkung: Ohne unserem designierten Vorsitzenden, Herm Vogel, und seinem gestrigen Reformvorhaben nahetreten $\mathrm{zu}$ wollen: Heute hat sich wieder einmal bestätigt, daß diese Vereinigung alle Referenten im Plenum hören muß, daß sie hier mit ihnen diskutieren sollte. Auch heute haben sich beide Referate fast ideal ergänzt, auch bei gewissen Gegensätzlichkeiten. Die große geistes- und verfassungshistorische Klassikerperspektive von Ihnen, Herr Link, und die aufregenden europarechtlichen und internationalen Fragen von Ihnen, Herr Ress, etwa in LS13, müssen wir doch gleichzeitig im Plenum behandeln, nicht in Arbeitsgruppen. -

Jetzt zu Punkt 1: Stichwort „instrumentales Staatsverständnis“. Es besteht ein enger Zusammenhang zwischen Staats- und Grundrechtsverständnis sowie den Staatsaufgaben. Ihn haben zwei verfassungsstaatliche Klassikertexte am besten auf den Begriff gebracht, nämlich Art. 2 der Erklärung von 1789, der schlicht lapidar sagt: „Der Endzweck jeder politischen Vereinigung ist die Erhaltung der natürlichen und unveräußerlichen Menschenrechte. Diese Rechte sind Freiheit, Sicherheit, Eigentum" und - ich bin nicht ganz sicher - sogar "Widerstand gegen die Staatsgewalt". Herr Denninger, unser großer Vorsitzender, möge mich bitte korrigieren. Diese instrumentale Sicht, kein Eigenwert des Staates, steht hinter allen Staatsaufgaben, zugespitzt, letztlich sind es immer Grundrechtsaspekte, differenzierte Grundrechtsaufgaben im Grundrechtsstaat. Art. 1 Verfassungsentwurf Herrenchiemsee spricht ebenfalls für sich und uns: „Der Staat ist 
um des Menschen willen da, nicht der Mensch um des Staates willen." Diese anthropologische Prämisse des Verfassungsstaates müssen wir bis in die Staatsaufgabendogmatik hinein entwickeln, beide Referenten haben hier Vorarbeit geleistet, wobei ich einen kleinen Widerspruch wage zum Europarechtler Ress (Leitsatz 2): „Das Thema zielt auf den Staat in und hinter der Verfassung." Dazu ein Fragezeichen. Ich glaube nicht, daß wir im Rahmen einer verfassungsstaatlichen Aufgabenlehre so den "Staat" hinter dem Kompendium von europäisch-atlantischen Prinzipien des Verfassungsstaates stehen lassen dürfen. Wir sollten hier Rudolf Smend folgen: „Es gibt nur so viel Staat, wie die Verfassung konstituiert", oder dem großen Adolf Arndt: „Es gibt in der Demokratie keine ,Staatsräson', es gibt nur, Verfassungsräson“". - Der zweite Punkt: verfassungsstaatliches Gemeinwohlverständnis vom Verfahren her. Gewiß, wir finden in den historisch und kontemporär miteinander verglichenen Verfassungstexten auch wichtige inhaltliche Direktiven in Sachen Gemeinwohl, etwa die Menschenwürde und Grundrechte, aber vieles muß ins Offene gehalten werden, Stichwort „Offenheit des Verfassungsstaates" und seines ex post zu ermittelnden Gemeinwohls, dieses als Verfahrens- und Kompetenzproblem verstanden. Hier nur eine winzige Fußnotenkritik an beiden Referenten, die mit Recht von beiden Vorrednern schon über die Maßen - nein, mit richtigen Maßen - gelobt worden sind. Herr Oppermann fehlt heute leider, obwohl er es ist, der diese Rolle in unserer Vereinigung eingangs zu spielen pflegt. Wir sollten die modernen Texte der neuen Verfassungen von Griechenland 1975 über die Schweizer Kantonsverfassungen bis Guatemala 1985 vergleichend durchgehen, denn hier finden wir höchst aufschlußreiche Textstufen allgemeiner und sehr spezieller Staatsaufgabenkataloge. Wir finden eine Expandierung, Differenzierung der Staatsaufgaben und eine Verschränkung von Grundrechts- und Staatsaufgaben zu „Grundrechtsaufgaben". Eines Tages müssen wir im Blick auf die Einheit Europas die verfassungspolitische Frage stellen, wo und wie wir die nationalstaatlich bleibenden Staatsaufgabenkataloge in den Verfassungen systematisch plazieren, etwa sehr grundsätzliche schon in den Präambeln, im Grundrechtsteil oder erst im Kompetenzteil? Die neuen Verfassungen bieten eine anregende Fülle möglicher Problemlösungen, wobei ich mich entschieden gegen das "Modell Portugal“ wende, es hat in seiner Verfassung von 1976/82 die Staatsaufgabenkataloge sehr dynamisch über alle Maßen überladen und damit tendenziell entwertet. Man muß hier wohl einen dritten Weg der Mitte gehen. -

Letzter Punkt: Schon jetzt springe ich im Anschluß an die Herren Dreier und Alexy auf Ziff. IV. der Vorgabe des Vorsitzenden: „Ziviler 
Ungehorsam". Große Namen, auch der von Razels, sind schon gefallen. Beide Referenten haben uns mit vollem Recht das staatliche Gewaltmonopol in seiner Bedeutung für den Frieden vorgeführt. Aber darum müssen wir uns mit aller Konsequenz der Herausforderung der Lehre von der "civil disobedience" von Thoreau, früher einem Außenseiter und Einzelgänger, heute einem Klassiker mit Wirkung bis zu Rawls stellen. Ich kann hier nicht die strengen Voraussetzungen dieser Lehre im einzelnen schildern - Sie kennen sie -, die Rawls in seinem Gerechtigkeits-Buch verlangt, etwa Verhältnismäßigkeit, Einstehung für die Folgen etc. Uns fordert das Problem des zivilen Ungehorsams als moralische, als philosophische Frage. Hier gleich ein praktisches Beispiel: Selbst der Typus des demokratischen Verfassungsstaates, der in unseren offenen Gesellschaften in der Prämisse der Menschenwürde und ihrer organisatorischen Konsequenz, der freiheitlichen Demokratie, relativ optimal ausgebildet ist, hat offenbar nicht für alle aktuellen Gerechtigkeitsund Gemeinwohlprobleme immer genügend sensible „Frühwarnsysteme". Ich jedenfalls brauchte die begrenzten Regelverletzungen und Aktionen von Greenpeace und Robin Wood, um „wach" zu werden. Ich brauchte sie, um die dahinter stehenden Fragen des Umweltschutzes etwa in ihrem vollen Ausmaß zu erkennen. Dies bedeutet kein Plädoyer für "civil disobedience“ als juristischen Rechtfertigungsgrund, es ist ein Votum dafür, daß auch die Staatsrechtslehre bzw. der Typus Verfassungsstaat philosophischen Fragen gegenüber im Vorfeld ihrer Probleme genügend sensibel zu bleiben haben. Vielen Dank.

Vorsitzender: Vielen Dank, Herr Häberle. Der Vorstand freut sich, daß dieses Thema Sie in Ihren verfassungsrechtsvergleichenden Untersuchungen, die wir ja alle sehr schätzen, bestärkt und ermuntert, und wir hoffen, da noch mehr von Ihnen zu hören und zu lesen. Im übrigen haben Sie, glaube ich, den Art. 2 der Menschen- und Bürgerrechtserklärung vollkommen korrekt wiedergegeben. Es heißt dort nur am Ende: „et la résistance à l'oppression“ und das ist das Widerstandsrecht. Es wäre natürlich hier an der Tafel auch noch das Wort "Widerstandsrecht" angebracht, was ja nicht dasselbe ist wie Ziviler Ungehorsam. Das nur als Anregung, auch für die Diskussion. Vielen Dank nochmals, Herr Häberle, und jetzt darf ich dann Herrn Schuppert bitten.

Schuppert: Herr Vorsitzender, meine Damen und Herren! Nach diesen beiden, weit ausladenden staatsphilosophischen und verfassungsphilosophischen Beiträgen zögere ich etwas, überhaupt das Wort zu ergreifen, denn ich habe nur zwei winzige Punkte anzuspre- 
chen. Einmal das Verhältnis von Staatszwecken und Staatsaufgaben; zum andern möchte ich kurz auf den Untertitel des heutigen Themas eingehen. Die Erwähnung von „40 Jahre Grundgesetz" scheint mir doch darauf hinzudeuten, daß in der Diskussion über Staatszwecke auch eine dynamische Komponente zu berücksichtigen gewesen wäre.

Zu dem ersten Punkt: Nach meinem Geschmack - und dies bitte ich nicht als Kritik, sondern als Anregung zu verstehen - ist in beiden Referaten die Wechselbezüglichkeit von Staatszwecken und Staatsaufgaben zu kurz gekommen. Denn beides hängt doch sehr eng miteinander zusammen, zumindest - und dies hat Herr Ress uns ja sehr schön vorgeführt - bei einer Betrachtungsweise von oben nach unten. So hat Herr Ress ausgeführt, bestimmte Staatszwecke führten zu bestimmten - fakultativen oder sogar notwendigen Staatsaufgaben und bestimmte Staatszwecke bedingten eine bestimmte Art ihrer Erledigung, der Staatszweck der Sicherheit z. B. führe zum Verbot privater Sicherheitskräfte und privater Gewalt, die Wahrnehmung von Hoheitsaufgaben zur Konsequenz eines Berufsbeamtentums als Institution. Nun meine ich, daß diese Denkweise vielleicht ein wenig zu einlinig ist und daß man auch in die andere Richtung denken müßte, nämlich zu fragen, ob nicht aus einer beobachtbaren Veränderung von Staatsaufgaben eine Redefinition oder Revergewisserung der Staatszwecke notwendig werden könnte. Wenn wir also eine Veränderung von Staatsaufgaben beoabchten, etwa im Zuge der ökologischen Herausforderung des Staates, dann führt das - um nur ein Beispiel zu nennen - zu einer notwendig stärkeren Betonung des Staatszweckes der Zukunftsvorsorge, eines Staatszweckes, der ja normalerweise in der Quadriga oder der Troika der klassischen Staatszwecke so nicht vorkommt. Auf einen anderen Punkt hat Herr Dreier soeben hingewiesen: wenn etwas schief läuft bei der Erledigung von Staatszwekken, wenn z. B. der Ungehorsam der Bürger zunimmt, muß man dies möglicherweise zum Anlaß nehmen, darüber nachzudenken, ob das Verhältnis der Staatszwecke zueinander immer richtig gewichtet ist. Ich sehe ferner einen engen Zusammenhang - und dazu wird vielleicht Herr Grimm noch etwas sagen - zwischen dem ersten Tagungsthema und dem des zweiten Tages. Herr Grimm hat diesen Zusammenhang auf einer Bielefelder Tagung der Forschungsgruppe "Staatsaufgaben" thematisiert, und zwar unter dem Titel „Wachsende Staatsaufgaben - abnehmende Steuerungsfähigkeit des Rechts" also zum Nachdenken darüber aufgefordert, ob nicht ein Zusammenhang besteht zwischen der Überfülle von Staatsaufgaben und der zunehmenden Unfähigkeit des Staates, ihrer steuernd Herr zu werden. So käme man möglicherweise zu dem Befund eines "overload“ von 
Staatsaufgaben mit der Folge, daß man über eine veränderte Arbeitsteilung zwischen Staat und Gesellschaft, zwischen staatlichen und nichtstaatlichen Entscheidungsträgern nachdenken müßte. Lassen Sie mich dies - was sich zum Abschluß eines Gedankens immer hübsch macht - als Paradox formulieren: Staatsentlastung als ein zentraler Staatszweck.

Jetzt komme ich zu dem zweiten Punkt, zu 40 Jahren Grundgesetz. Ich vermisse in den Referaten die in diesem Untertitel angelegte dynamische Komponente. Wir haben Staatszwecke vorgeführt bekommen, die seit der Gründung des neuzeitlichen Staates unverändert sind: Freiheit, Sicherheit, Wohlfahrt und dergleichen. Daß hier jedes Moment von Bewegung und Fortentwicklung fehlt, liegt wahrscheinlich daran, daß die Staatszwecke von den Referenten auf einer so hohen Abstraktionsebene angesiedelt worden sind, daß man den Prozeß des Wandels in der Wahrnehmung von Staatsaufgaben nicht in den Blick bekommt. Deswegen mein Plädoyer, doch von dieser hohen Abstraktionsebene herabzusteigen und die Frage zu stellen, ob es nicht Entwicklungen gibt, die man unter dem Stichwort „Aufgabenwandel" zusammenfassen könnte: gibt es - so könnte man fragen neue, hinzugekommene Aufgaben und gibt es abgestorbene oder im Absterben begriffene Aufgaben und wodurch könnten solche Wandlungsprozesse bewirkt worden sein. Meine These dazu lautet, daß es gar nicht so sehr viel an dramatischen Veränderungen in dem Bestand der Aufgaben gibt, sondern was wir konstatieren können, ist eher eine Veränderung in den Instrumenten und Organisationsformen der Aufgabenerledigung, so daß - dies wäre meine Schlußfolgerung - wir über die Befindlichkeit des modernen Staates mehr erfahren, wenn wir nicht auf hohem Abstraktionsniveau über Staatszwecke sprechen, sondern vielmehr über den Zusammenhang von Staatszwecken, Staatsaufgaben, Staatsinstrumenten und Organisationsformen ihrer Erledigung. Vielen Dank.

Vorsitzender: Vielen Dank, Herr Schuppert, Sie haben eine Anzahl von wichtigen Stichworten hier in Erinnerung gerufen, und ich bin Ihnen auch dankbar, daß Sie den sogenannten "Untertitel“ dieses Tagungsthemas zum Anlaß genommen haben, darüber zu reflektieren. Die Reihenfolge ist: Zunächst Herr Steiger und dann Herr Grimm und dann wollte ich Herrn Isensee fragen, ob er in diesem Zusammenhang sprechen möchte. Ja? Gut, dann können wir so verfahren. Bitte, Herr Steiger.

Steiger: Herr Vorsitzender, meine Damen und Herren! Die Frage, die ich mir im Hinblick auf das Referat von Herrn Ress gestellt habe, 
in dem das besonders deutlich geworden ist, aber auch bei Ihnen, Herr Link, ist das angeklungen: Ist das, von dem wir heute geredet haben, eigentlich Staatszwecke, d.h. Zwecke, die spezifisch noch dem Staat als politischer Organisation zugeordnet sind? Sind das nicht in Wirklichkeit Zwecke, jedenfalls die allgemeinen wie Zukunftsvorsorge, Gemeinwohlsicherung, Sicherheit nach innen und außen und auch gerade Freiheitssicherung, Freiheitsgewährleistung, sind das nicht inzwischen längst Zwecke, die nicht mehr spezifisch dem Staat, sondern generell politischen Organisationen, auch auf über den Staat hinausgehende Ebenen, nämlich der europäischen und der internationalen Ebene zugehören. Ich kann bei diesen $Z$ wecken keinen spezifischen Unterschied entdecken, warum sie nur staatlich sein sollen und nicht etwa europäisch oder global. Denn wir können all diese Zwecke ohne das Zusammenwirken der Staaten kaum noch bewältigen; und es gibt einige, bei denen dieses notwendige Bedingung ihrer Lösung ist, etwa die ökologischen Fragen. So frage ich mich, ob nicht der Begriff "Staat“ in Wirklichkeit nur noch ein Kürzel für politische Organisationen ist und nicht mehr etwas Spezifisches. „Europäisierung“, die als Staatszweck der Bundesrepublik von Ihnen genannt worden ist, ist sogar gerade ein solcher, der die Staatlichkeit der Zwecke aufhebt, sie bewußt und gezielt auf die Ebene des Europäischen hebt. In dieser Richtung könnte man den Art. 24 evtl. interpretieren. Was bliebe noch für den Staat als Staat: allenfalls der Kulturstaat und etwas, was natürlich im Augenblick bei uns in der Bundesrepublik sehr aktuell ist, die „Wiedervereinigung". Wenn man es auf der allgemeinen Ebene diskutiert, ist es die Wahrung der nationalen Identität, das heißt also das, was den alten Nationalstaat ausmacht. Ist es nicht im Grunde nur noch dieses, was auch heute noch spezifisch staatlich sein könnte? Das mag zu Mißverständnissen, auch in der Bundesrepublik, Anlaß geben. Aber dieser Zweck bzw. seine Verwirklichung ist mit allen Konsequenzen in Beziehung zu setzen mit den anderen Zwecken. Das bedeutet u.a., daß nicht mehr staatliche Ausschließlichkeit, nicht mehr Souveränität staatlicher Existenz besteht, sondern die Notwendigkeit, auch gerade dieses nationale Ziel einzubetten in die Verwirklichung der Zwecke auf den anderen genannten Ebenen. Was wir dann aber tun müßten, wäre ja wohl den Versuch zu unternehmen, die Zuordnung der Zwecke zu den verschiedenen Ebenen politischer Organisation weiter voranzutreiben. Da scheint mir noch ein gewaltiges Defizit zu bestehen, - nicht in den Referaten bitte, damit das kein Mißverständnis gibt -, sondern generell in unseren Überlegungen. Ich glaube nicht, daß wir das vom $Z$ weckbegriff her machen können, weil es eben die Zwecke aller drei Ebenen sind, sondern man kann es 
nur über Aufgabenzuweisung und Kompetenzzuweisung machen. Herr Häberle hat das ja eben auch schon angesprochen. Die Frage kommt dann natürlich auf: Wie ist es mit der Subsidiarität? Herr Link, da würde ich Ihnen etwas zu widersprechen wagen. Ich glaube, wir müssen diesen Versuch doch noch einmal wiederaufnehmen, wenn er auch vielfach gescheitert zu sein scheint, um die Subsidiarität auch als Rechtsprinzip etwas deutlicher zu machen. Wenn ich etwa an den Art. 130 r Abs. 4 des EWG-Vertrages denke, wie er durch die Einheitliche Europäische Akte eingefügt worden ist, wo es heißt, daß die EWG tätig wird im Bereich des Umweltschutzes, wenn es besser ist, das auf gemeinschaftlicher Ebene zu tun, dann ist das sehr wenig, gerade aber im Hinblick auf die Verteilung der Aufgaben, der Zuständigkeiten und auch der $Z$ wecke $m$. E. unbedingt konkretisierungsbedürftig, und zwar auch theoretisch. Ein Wort bitte ich noch zu genehmigen, im Hinblick auf Neutralität. Die Frage ist für mich - ich stimme Ihnen, Herr Link, in all diesem, was Sie gesagt haben, zu, das werden Sie nicht anders erwarten - aber die Frage ist: Können wir diesen Begriff von Neutralität, wie wir ihn in der Bundesrepublik entwickelt haben, wie Herr Schlaich ihn dargelegt hat, wie Sie ihn heute dargelegt haben, noch so aufrecht erhalten, im Angesicht von Bewegungen religiöser Überzeugungen, die auf einem anderen Boden stehen als die bei uns bisher vorhandenen, - ich nenne den "Islam“ als Stichwort mit seinen fundamentalistischen Ansprüchen.

Vorsitzender: Ja, vielen Dank. Ich sehe, Herr Steiger, daß Sie, das hatten Sie auch angekündigt, zu II. und praktisch zu III. schon gesprochen haben; das geht etwas ineinander über. Ich darf aber trotzdem vielleicht in der Reihenfolge fortfahren und jetzt Herrn Grimm das Wort geben.

Grimm: Meine Damen und Herren, ich will nicht wie Herr Alexy einen Angriff gegen die Fragestellung richten. Ich fand die Fragestellung fruchtbar. Ich will aber einen Einwand gegen die Behandlung des Themas formulieren und glaube, daß ich mich dabei auf den Spuren von Herrn Schuppert und Herrn Steiger bewege. Der Einwand ist der eines gewissen Modernitätsdefizits der Referate, was nicht dasselbe wie Aktualitätsdefizit bedeutet - auf die DDR-Flüchtlinge ist oft genug angespielt worden. Der Einwand könnte etwa folgendermaßen lauten: Beide Referenten sind bei der Frage nach den Staatszwecken vom Staat ausgegangen, haben ihn als gegebene Größe unterstellt und dann das Gewaltmonopol sozusagen als harten Kern der Staatlichkeit ausgemacht, das dem Staat seine Identität verleiht und ihn von der Gesellschaft unterscheidet. Herr Ress sagt ausdrücklich: „Staats- 
zwecke sind nicht Gesellschaftszwecke." Vom Staat ausgehend, haben sie dann die Staatszwecke zu bestimmen versucht und sind dabei zu klassischen Triaden oder Quadrigen gelangt. Ich möchte demgegenüber behaupten: Staatszwecke lassen sich nur von den Bedürfnissen der Gesellschaft her definieren, und veränderte Bedürfnisse der Gesellschaft wandeln die Staatszwecke, und gewandelte Staatszwecke verändern ihrerseits wiederum den Staat. Wenn man auf diesen Prozeß nun mit der Knappheit, die hier geboten ist, eingeht, dann kann man sicherlich, wie es in beiden Referaten der Fall war, beim Sicherheitszweck des Staates Kontinuität feststellen und auch sagen, daß er ohne Gewaltmonopol nicht erfüllbar ist. Aber nachdem der Liberalismus die Staatszwecke vorübergehend auf den Sicherheitszweck reduziert hatte, können wir seit dem letzten Viertel des 19. Jahrhunderts eine fortgesetzte Ausweitung der Staatsaufgaben beobachten, die durchweg beim Staatszweck Wohlfahrt zu Buche schlägt. Dabei handelt es sich um eine beispiellose und bis heute nicht gebremste Ausweitung, die sich zunächst als sozialstaatliche Bearbeitung der Folgekosten von Liberalisierung und Industrialisierung und heute vor allem als wohlfahrtsstaatliche Bearbeitung der Folgekosten des wissenschaftlich-technischen Fortschritts mit dem Ziel der Zukunftssicherung beschreiben läßt. Das hat nun aber Weiterungen. Zunächst geht das, was beide Referenten als Funktion des Staatszwecks herausgestellt haben, nämlich seine begrenzende Wirkung für die Staatstätigkeit, verloren. Die gesellschaftliche Wohlfahrt trägt in sich keinerlei Grenze und kann sich daher auch auf den Staat nicht begrenzend auswirken. Das gilt zumindest für die Aufgabenebene. Es gibt heute keinen Bereich privaten oder öffentlichen Lebens mehr, der frei von staatlicher Intervention wäre. Es bleibt allerdings eine gewisse Begrenzung auf der Mittelebene erhalten. Die Grundrechte sichern dem Einzelnen trotz gewachsener Staatsverantwortung weiterhin Freiheit und garantieren den verschiedenen gesellschaftlichen Subsystemen relative Autonomie. Das führt aber in ein neues Dilemma. Es zwingt den Staat nämlich dazu, seine umfassenden Zwecke in den ausgegrenzten Bereichen ohne Einsatz des Gewaltmonopols zu erfüllen. Er tritt dann den gesellschaftlichen Kräften freilich auf der gleichen Ebene entgegen. Das hat in wachsendem Umfang Aushandlungssysteme zur Folge, in denen öffentliche und private Akteure staatliche Entscheidungen im Vereinbarungswege festlegen. Die Staatszwecke werden auf diese Weise zunehmend von verhandlungsmächtigen gesellschaftlichen Gruppen ausgefüllt, und der Staat gerät in Gefahr, von ihnen instrumentalisiert zu werden. Angesichts dieser Entwicklung stellt sich die Frage: Ist das noch der Staat, von dem wir als 
Juristen gewohnt sind zu sprechen, und kann man diesen mit klassischen Staatszwecklehren und traditionellem Verfassungsrecht noch in den Griff bekommen? Das sind einige der modernen Probleme, von denen mir in den Referaten zu wenig die Rede war.

Vorsitzender: Vielen Dank, Herr Grimm. Sie haben es auf Ihre vornehme Art, darf ich sagen, fertiggebracht, hier nun doch das kritische Moment $\mathrm{zu}$ betonen und eine allzugroße und allzufrühe Harmonie im Saal zu zerstören. Ich freue mich darüber. Ich darf dann Herrn Isensee das Wort geben.

Isensee: Das Thema des heutigen Tages hat schon Erfolg gezeitigt. Es hat das ausgelöst, was man im heutigen Kulturjargon einen Paradigmenwechsel nennt. Das neue Paradigma heißt „Staat“. In den vielen Tagungen der Vereinigung Deutscher Staatsrechtslehrer, an denen ich bisher teilgenommen habe, ist durchwegs nur die Rede gewesen von „Verfassung“. Heute aber ist der "Staat" in den Mittelpunkt gerückt. Kein Diskussionsteilnehmer, der nicht wesentlich und zuvörderst, wenngleich nicht immer in gleich affirmativer Sicht, das Thema "Staat" aufgenommen hat. In der Tat, das Thema zwingt dazu, über den Horizont der Verfassung hinauszublicken auf den Staat. Er ist nun einmal das Subjekt der Staatszwecke und der Staatsziele. (Dabei kann ich die möglichen Unterschiede zwischen "Zwecken“ und „Zielen" hier vernachlässigen.)

Eine begriffliche Zwischenbemerkung: Im Gespräch über "Staat“ und über "Verfassung" zeigt sich ein mehrfacher Dissens, weil jedes der beiden Wörter seine Bedeutung wechselt und (mindestens) je zwei Staats- und zwei Verfassungsbegriffen kursieren. "Staat" ist einmal im engeren Sinne - die Staatsorganisation, die „öffentliche Gewalt", wie das Grundgesetz sie versteht; „Staat“ also als das Gegenüber der Grundrechtsträger, der Gegenbegriff zur „Gesellschaft". Daneben aber steht der weitere Begriff: „Staat“ als das Gemeinwesen, die Nation, die res publica, das Ganze von "Staat“ (im engeren Sinn) und "Gesellschaft" (ebenfalls im engeren Verständnis der Staatstheorie). Im ersten Verständnis ist „Staat" der Adressat der Grundrechte, im zweiten bildet er das Umfassende der grundrechtsberechtigten Bürger und der grundrechtsverpflichteten Organisation. „Staat" im umfassenden Sinne von Gemeinwesen ist der Grund der Staatszwecke und -ziele. "Staat" im Sinne der Organisation ist das Instrument zu ihrer Verwirklichung. Auch die Bedeutung von „Verfassung“ wechselt: hier die formelle, dort die materielle Verfassung; hier das Grundgesetz, dort die rechtliche Grundordnung des Staates. 
Es mag heute schockieren, an einen Satz zu erinnern, den Reichspräsident Friedrich Ebert gesagt haben soll: Vor die Notwendigkeit gestellt, zwischen Deutschland zu wählen und der Verfassung, werde er sich für Deutschland entscheiden. Die Wahl, die in der Not nach 1945 von allen verfassungsstaats-tragenden Kräften getätigt wurde, war, sich für die Verfassung zu entscheiden, den Staat zu vergessen und zu verdrängen: das schwierige, das geteilte, das sich halb nationalstaatlich formierende, sich halb europäisch integrierende Deutschland. Aufschlußreich sind die schlichten Antithesen, die sich auch im verfassungsrechtlichen Schrifttum zuweilen finden, die Antithesen von Verfassungsraison statt Staatsraison, von Verfassungspatriotismus statt Patriotismus. „Verfassungspatriotismus", die erfolgreiche Wortgeburt Dolf Sternbergers, symbolisiert einen Dissens. Entweder geht es um die Zuwendung zum Gemeinwesen in seiner verfassungsstaatlichen Form, also um Einheit von Staat und Verfassung, oder aber es geht um den Ersatz des Patriotismus, um Zuwendung zu einer Verfassung, die nicht im Boden des deutschen Volkes gründet, sondern im Reich kosmopolitischer Ideale schwebt, im „Reich der Luft", jenem Reich, das schon früh Jean Paul den Deutschen als ihre politische Bestimmung zugewiesen hat, weil Land und Meer an die anderen Nationen vergeben seien.

Die juristische Bedeutung des Staatsverständnisses für die Verfassungsinterpretation zeigt das Beispiel der vorbehaltlosen Grundrechte. Sie sollen, so meint das Bundesverfassungsgericht, ihre Grenzen nur in der Verfassung selber finden, und zwar in der geschriebenen, „formellen“ Verfassung. Doch das Grundgesetz ist nicht als Kanon der Ziele, Zwecke, Aufgaben des Staates entworfen. Wenn das Bundesverfassungsgericht dennoch Grenzen aufdeckt, wo sie die praktische Vernunft vermutet, bemüht es sich jeweils um Anknüpfung im Text des Grundgesetzes und kommt nicht um gequälte, gekünstelte, weit hergeholte Deduktionen herum, wie die Topoi der Funktionstüchtigkeit der Bundeswehr oder der Funktionstüchtigkeit der Rechtspflege bezeugen. Die Prozedur ergibt nur Sinn, wenn man sie nicht lediglich auf die formelle Verfassung bezieht, sondern auch und wesentlich auf die materielle und das sich in ihr verkörpernde Staatsverständnis. Auf dieser Ebene hat das Thema "Staatszwecke“ seinen Platz. Hier haben beide Referenten es auch behandelt.

Ein Stichwort der Klassischen Staatszwecklehre ist heute noch nicht gefallen, nämlich "Selbstbehauptung“ des Staates. Dieser Zweck bezieht sich nicht auf den Staat im engeren Sinn. Die Staatsorganisation ist Mittel, nicht Zweck; sie wird nicht um ihrer selbst willen erhalten. Das aber ist der Fall für das Gemeinwesen, den Staat im 
weiteren Sinne. Seine Selbstbehauptung ist gemeint, wenn die Präambel davon spricht, die "nationale und staatliche Einheit zu wahren“. Die nationale und staatliche Einheit - in anderer Terminologie: die politische Einheit - ist, solange der nationale und politische Wille zur Einheit lebendig ist, Fundament auch des Verfassungsstaates, zumal in seiner demokratischen Dimension, und als solches zu pflegen, zu schützen und gegebenenfalls (wieder-)herzustellen. Just mit diesem Ziel tun sich die Deutschen schwer. Sie leiden an ihrer historisch belasteten und staatlich geteilten Nation. Sie neigen dazu, aus ihr und damit aus sich selbst zu emigrieren. Sie haben Grund dazu, weil ihr Selbstbild so unsympathisch ist. Eine Ursache der Verdrängungen und Neurosen liegt darin, daß die Deutschen zur Annahme ihrer selbst nicht willens oder nicht fähig sind. Am Anfang einer praktischen Staatszwecklehre steht der Wille einer politischen Einheit, zu sich selbst zu finden und sich selbst zu erhalten.

Sicher zielen die Ideen der Menschenwürde und der Menschenrechte höher. Aber in ihrer grundrechtlichen Gestalt sind sie auf den Staat als ihren Garanten bezogen, insoweit bedingt und begrenzt. Der menschenrechtliche Impetus des Grundgesetzes hebt nicht $\mathrm{ab}$ zu reinem Kosmopolitismus. Wenn das Grundgesetz sich zu den Menschenrechten „als Grundlage jeder menschlichen Gemeinschaft, des Friedens und der Gerechtigkeit in der Welt" bekennt, so sichert es nicht den Menschen aus aller Welt zu, daß sie ihre Menschenrechte im Gebiet der Bundesrepublik verwirklichen können. Probleme, die mit der Staatsverdrängung zusammenhängen, treten auf im Ausländerrecht, ebenso im Feld der militärischen Sicherheit oder dem der Bevölkerungspolitik; auf dem letzteren werden die Probleme heute nicht erörtert als Frage der Selbstbehauptung des deutschen Volkes, sondern als Frage der künftigen Funktionsfähigkeit der Sozialsicherung oder der Umweltvorsorge für künftige Generationen.

Ein letztes exemplarisches Problem: Wie löst der Verfassungsstaat das Dilemma zwischen der nationalen Einheit, die zu wahren bzw. deren volle Herstellung anzustreben ist, und dem Ziel der europäischen Einigung? Eines jedenfalls ist klar: Von der bundesrepublikanischen Verfassung bleibt nur soviel in Europa übrig, wie Europa an bundesrepublikanischer Staatlichkeit übrig läßt. Mit dem Aufgehen des Staates in den europäischen Staatenverein endet auch die Verfassung, die nicht weiter reichen kann als der Staat. - Wie soll das künftige Europa aussehen: ein integraler Schmelztiegel oder eine Föderation, in der die staatlichen Mitglieder ihre Besonderheit bewahren? Für die meisten Mitglieder der Europäischen Gemeinschaft ist das kein Problem, weil sich für sie nationale Selbstbehauptung und 
staatliche Selbstbestimmung von selbst verstehen. Wenn aber die Bundesrepublik als einziges Mitglied in vorauseilendem Integrationsgehorsam ihre staatliche Verbandsstrukturen offnet und sich um ihre politische Identität bringt - Stichwort: Ausländerwahlrecht -, bewährt sie weniger europäische Tugend, als daß sie europäische Inhomogenität schafft und europäische Irritation stiftet.

Vorsitzender: Vielen Dank, Herr Isensee. Ich könnte mir vorstellen, daß viele hier im Saal Ihrer Analyse sehr gerne folgen, daß aber über die conclusiones - ich darf auch mal ein Wörtchen Latein sprechen - hier doch erhebliche Differenzen bestehen. Ich habe in dieser zweiten Gruppe nun nur noch Herrn Burmeister und würde dann die beiden Herren Referenten zu einem $Z$ wischenwort einladen, denn ich glaube, es haben sich so viele Fragezeichen angesammelt, daß wir auf Antworten gespannt sein dürfen. Herr Burmeister, bitte.

Burmeister: Vielen Dank, Herr Vorsitzender. Es trifft sich gut, daß ich nach Herrn Grimm und nach Herrn Isensee Gelegenheit habe zu einer kurzen Bemerkung über Begriff und Wesen von Staatszwecken und -aufgaben. Wenn man den Staat ganz schlicht begreift als die Organisation bestmöglicher Verwirklichung des Gemeinwohles und weiterhin das Gemeinwohl - diesen rechtlich schwer faßbaren Begriff - begreift als den Auftrag zur Schaffung und Gewährleistung menschenwürdiger Lebensbedingungen, so ergeben sich daraus zwei fundamentale Einsichten für die Staatszwecklehre: Erstens, daß Staatszweck nur sein kann, was einen Bezug zum Individuum aufweist, ja der Individualbezug für jeden Staatszweck begriffs- und wesensprägend ist. Ich kann in aller Welt keine andere Sinnerfüllung des Gemeinwohlbegriffes erkennen als die Verpflichtung des Gemeinwesens, Bedingungen zu schaffen, die es dem Menschen ermöglichen, in Würde zu leben. Letztlich dient das Gemeinwohl nichts anderem als der Gewährleistung optimaler Bedingungen menschenwürdiger Existenz. Für den als Rechtsstaat verfaßten Hoheitsverband ist die Abwesenheit jeglichen staatlichen Selbstzwecks wesensprägend. Der Staat und seine verselbständigten organisatorischen Untergliederungen verfügen nicht über die Spur einer Befugnis, die diesen um ihrer selbst willen zustünde. Für staatliche Zwecke ist der Gemeinwohltatbestand, für die Wahrnehmung einer staatlichen Handlungsbefugnis die Gemeinwohlverwirklichung schlechthin konstituierend. Der Rechtsstaat ist die Institution zur Verwirklichung des Gemeinwohls, seine Aufgaben erschöpfen sich darin; das so verfaßte Gemeinwesen kennt keine Befugnis, die auf Durchsetzung eines nicht den Interessen der Allgemeinheit dienenden staatlichen Selbstzwecks ausgerichtet 
sein könnte. Nichts anderes besagt letztlich der Gemeinplatz: Der Staat ist um des Menschen willen da, nicht der Mensch um des Staates willen.

$\mathrm{Da}$ es mithin im Staat keinen Zweck geben kann, der um des Staates selbst willen bestehen könnte, wird - wie Herr Grimm zutreffend gesagt hat - die Rechtfertigung für die Wahrnehmung einer Aufgabe als Staatsaufgabe von den konkreten Bedürfnissen und Bedingungen definiert, damit der einzelne in Würde leben kann. So gibt es unter der Voraussetzung, daß in einer Gesellschaft ein Konsens über bestimmte moralische Verhaltensmaximen besteht, kein Bedürfnis für eine Staatsaufgabe zur Sicherung der inneren Ordnung, denn die Ordnung wird ohne den Staat gewährleistet. Desgleichen braucht ein Staat, der keine militärische Bedrohung von außen kennt, keine Vorkehrungen zur Sicherheit gegenüber militärischer Aggression zu treffen. Da die legitimen Zwecke und Aufgaben eines Staates aus konkreten Bedingungen und Bedürfnissen entstehen, gibt es auch keinen Katalog vorgegebener, apriorischer jedem Staat zukommender Zwecke; es gibt keinen Katalog wesensmäßiger Staatszwecke und - daraus folgend notwendiger Staatsaufgaben. Staatszwecke lassen sich nicht - und dies gilt es als zweite wichtige Einsicht festzuhalten - als vorgegebene Attribute des Hoheitsverbandes begreifen, sondern nur als sich ständig wandelnde Verwirklichungsaufträge. Nur auf der Grundlage dieses Wesensverständnisses wird im übrigen erklärlich, daß neue Ziele und Zwecke, wie beispielsweise die des Umweltschutzes, die gestern nicht als staatliche Verwirklichungsaufträge existent und erkannt waren, heute oder morgen zu dominanten Staatsaufgaben werden, wie umgekehrt ein Staatszweck von heute morgen seine Relevanz verlieren und damit die Legitimation des Staates, sich der zur Verwirklichung dieses Zwecks notwendigen Aufgaben anzunehmen, entfallen kann. Kurz gesagt: Die Staatszwecke unterliegen einer ständigen Wandlung, und ich meine, daß Richtung und Impulse dieses Wandlungsprozesses letztlich von nichts anderem als dem Auftrag zur Gewährleistung der Würde des Menschen bzw. menschenwürdiger Lebensbedingungen bestimmt werden. Darin ist alles eingeschlossen, was legitimer Staatszweck sein kann, umgekehrt aber auch alles ausgeschlossen, was nicht Staatszweck und konkreter Verwirklichungsauftrag des Staates sein kann. Vielen Dank.

Vorsitzender: Danke sehr, Herr Burmeister. Herr Ress, bitte sehr.

Ress: Schönen Dank, Herr Vorsitzender. Ich möchte in aller Kürze einige Bemerkungen zu den ersten Diskussionsbeiträgen machen, in denen die mehr theoretische Frage, ob man nicht besser statt der 
Staatszwecktheorie eine Gerechtigkeitstheorie entwickelt oder ausgebreitet hätte, aufgeworfen wurde. Ich habe mir diese Frage zwar gestellt, habe sie aber verworfen. Angesichts der staatsrechtlichen Problemstellung sah ich es nicht als meine Aufgabe an, eine philosophische Theorie zu kritisieren oder zu entwickeln, sondern im wesentlichen anhand der Verfassung zu versuchen -, allerdings orientiert an einem bestimmten Typus des modernen Staates, insbesondere des westeuropäischen Staates -, Zwecke zu erkennen und darzustellen. Aus den Thesen dürfte klar geworden sein, daß es hierbei um die Erkenntnis vielfältiger normativer Orientierungswirkungen dieser Zwecke in der konkreten Verfassung geht. Es geht nicht darum, aus einer abstrakten philosophischen Sicht des Staates irgendwelche Konklusionen für die Verfassung zu ziehen, sondern es geht darum, an einem sehr deutlichen konkreten Staatsbild - ermittelt durch Rechtsvergleichung, z. B. anhand jener Staaten, die unter der Europäischen Menschenrechtskonvention verfaßt sind und die sich auch einem gemeinsamen Regelungsschema unterworfen haben - zu erkennen, welche $Z$ weckausrichtung für diese Staaten faßbar und welche Zwecke folglich für ihre eigene Verfassungsordnung maßgeblich sind.

Der Begriff „negative Zwecke" ist in der Tat ein Unikum, ich habe ihn deshalb in den Thesen auch in Anführungszeichen gesetzt, wie Sie gesehen haben. Natürlich handelt es sich dabei um Verbote. Positive Zwecke können direkt als Gebote, also auch in anderer sprachlicher Form, normativ gewendet, ausgedrückt werden. Das eine schließt meiner Ansicht nach aber das andere nicht aus. Der Zweck etwa der Machterweiterung, der Expansion, wird gerade durch die Entwicklung der völkerrechtlichen Verbote begrenzt, und insofern ist dies durchaus ein Teil der Staatszwecklehre.

Die Frage nach der Rangordnung von Staatszwecken ist in der Tat schwierig. Man könnte etwa sagen: „Es gibt keine Freiheit ohne ein gewisses Maß an Sicherheit", oder: "Es gibt keine wirkliche Freiheit ohne ein gewisses Minimum an sozialer Wohlfahrt", oder: „Es gibt keine Sicherheit ohne die anderen beiden Komponenten der Freiheit und Wohlfahrt", um nur die drei zu nennen. Sie stehen also alle in einem unmittelbaren Zusammenhang, und es läßt sich schwerlich, obwohl es in der Literatur eine Fülle von Versuchen zur Hierarchisierung gibt, sagen, ein bestimmter Wert wie z. B. das Leben sei ein Höchstwert und müsse deshalb als Höchstwert allen anderen Werten vorrangig sein. Solche Versuche hat das Bundesverfassungsgericht vielfach unternommen. Wenn Sie die Judikatur durchsehen, werden Sie bei einer Reihe von Entscheidungen die Aussage finden, dieser oder jener Grundrechtswert sei fundamental, grundlegend. Es findet 
sich aber kein erkennbarer Rangfolgekatalog. Ich halte es auch für schwierig, wenn nicht gar unmöglich, sofern wir uns nicht auf Setzung, sondern Erkenntnis als Grundlage einigen, eine solche Reihenfolge aus einer „Werte-Erkenntnis“ abzuleiten. Ich glaube, daß man über die Aussage des optimalen Ausgleichs der größtmöglichen Verwirklichung nicht hinauskommt.

Die Steuerungsfähigkeit des Staates, ein Problem, das Herr Schuppert angeschnitten hat, also die Frage, in welchem Umfang und welcher Form die Staatsaufgaben oder die Staatszweckverfolgung heute von Staatswesen wirklich noch geleistet werden können, bedarf anderer Antworten als vor $50 \mathrm{Jahren}$. Ich habe, weil man nicht alles bringen konnte, dieses Kapitel weggelassen. Es ist notwendig, bei der Staatszweckverfolgung oder Aufgabenwahrnehmung die mittlere Ebene viel stärker zur Entfaltung zu bringen. Der Staat ist heute ohne Rückgriff auf Verbände, Selbsthilfeorganisationen und die verschiedensten vereinsmäßigen Engagements der Bürger überhaupt nicht mehr in der Lage, vielfältige Aufgaben wahrzunehmen. Das führt mich zu der Frage, die Herr Grimm aufgeworfen hat, ob nicht die Staatszwecke in Wirklichkeit in einer ununterbrochenen Wechselbeziehung zu den Gesellschaftszwekken stehen und von dort aus ihre Bereicherung bekommen. Das ist sicher eine zutreffende Beobachtung. Man muß nur um des Staates willen und auch um der Freiheit in der Gesellschaft willen zwischen diesen beiden Zweckverfolgungen unterscheiden. Sie haben gesagt, die den Staat begrenzende Wirkung geht verloren. Ich meine, daß gerade die begrenzende Wirkung durch die Freiheitsrechte - insofern haben Sie es auch ausgedrückt - , nicht verloren geht. Es gibt die Staatszweckbetrachtung in ihrer Legitimationsfunktion heute im wesentlichen in den Grundrechten. Bei jeder Grundrechtseinschränkung ist zu fragen: Darf der Staat dies? Hat er ein entsprechendes Interesse? Ist dieses Interesse entsprechend wichtig genug, um eine Grundrechtseinschränkung zu rechtfertigen? Und bei der ganzen Abfolge dieser im Grunde legitimatorischen Fragen tauchen nicht in erster Linie Gesellschaftszwecke auf, sondern es sind die Zwecke der staatlichen Organsation mit der Frage, ob sie diese Zwecke wahrnehmen darf. Insofern besteht hier nach wie vor eine deutliche Trennung. Ich teile Ihre Auffassung, die ich im Referat und in der These (Nr. 10) zur Aufgabenwahrnehmung unterstrichen habe, daß der Staat aus dem gesellschaftlichen Bereich eben Anregungen über die Parteien, die Verbände, die Kirchen usw. darüber bekommt, welche Aufgaben er aufgreifen und wahrnehmen soll, freilich immer vor dem Hintergrund, daß es einer entsprechenden Legitimation durch ein öffentliches Interesse bedarf. Es herrscht nicht, jedenfalls vor dem Hintergrund der Grundrechte, Beliebigkeit. 
Herr Steiger hat die Frage aufgeworfen, ob es wirklich nur Zwecke des "Staates" sind und ob es eigentlich noch sinnvoll sei, zwischen Staat und internationalen Organisationen zu unterscheiden. Ich glaube, wir müssen uns davor hüten, die Steuerungsfähigkeit internationaler Organisationen, selbst wenn sie so verfaßt sind wie die Europäischen Gemeinschaften, derjenigen der Staaten gleichzusetzen. Der wirkliche Schutz kann nach wie vor nur durch den Staat gewährleistet werden. Keine internationale Organisation ist wirklich in der Lage, den Bürgern diese unmittelbare Verbindung zwischen Schutz und Gehorsam sicherzustellen. Zwar hat sich ein Teil der Herrschaftsfunktionen verlagert, aber gerade die Durchsetzungsfunktion, das bedeutet: dort, wo das Gewaltmonopol und der Gewaltverzicht des Bürgers maßgeblich wird, liegt nach wie vor beim Staat. Die diplomatische Protektion wird - auch in Angelegenheiten der EG, selbst in ihrem Kompetenzbereich in den Drittstaaten, - nicht etwa von der EG, sondern von dem Heimatstaat des Betreffenden wahrgenommen. Hier ist der Staat nach wie vor noch die „Heimstatt“ des Bürgers, und die internationalen Organisatonen haben noch nicht - und es wird erhebliche Zeit dauern, bis sie, wenn überhaupt, dazu fähig sind jenen Grad an Schutzfähigkeit erlangt, der es erlauben würde, Staat und internationale Organisation gleichzusetzen.

Vorsitzender: Vielen Dank, Herr Ress, für dieses Zwischenwort. Ich darf jetzt das Mikrofon Herrn Link geben.

Link: Auch ich habe für viele Anregungen und auch für Kritik zu danken. Daß sie kommen würde, war mir klar - und Herrn Ress wahrscheinlich auch. Das uns gestellte Thema reizt, aber zwingt auch mehr zu persönlichen Bekenntnissen, als dies bei anderen hier verhandelten Gegenständen der Fall ist. Ich würde also sagen, wenn ich mich zunächst an Herrn Dreier und Herrn Alexy wenden darf, daß ein gewisser Bekenntnischarakter in der methodischen Entscheidung liegt, sich dem Thema nicht von einer normativen Gerechtigkeitstheorie her zu nähern, sondern von der Geschichte des Staatsdenkens her - dies nicht im Sinne eines bloßen Historismus, sondern im Sinne einer erlebten Staatserfahrung durch mehrere Jahrhunderte. Ich möchte trotz Ihres Einspruchs daran festhalten. - Ich gebe Ihnen völlig recht, daß das Problem des zivilen Ungehorsams von mir verkürzt behandelt worden ist. Dies ist zum einen der Fluch der einen Stunde, an die wir gebunden sind. Mir ging es zum anderen nicht um das moralische Problem, sondern um die rechtlichen Konsequenzen. Es ging m.a.W. um die Frage der Sanktionierung solchen zivilen Ungehorsams - und damit auch um die Bereitschft, derartige Sank- 
tionen in Kauf zu nehmen. Mit Herrn Häberle habe auch ich manchen "Aha-Effekt" bei solchen Aktionen gehabt, die auf Probleme hinwiesen, die mir so nicht deutlich oder jedenfalls nicht in ihrer Schärfe bewußt waren. Das Eindrucksvolle solcher Aktionen liegt dann aber gerade im Hinnehmen der Sanktion, und ich meine, daß eben dies in einem sehr viel größeren Umfang Gegenstand der Diskussion ist, als die von Ihnen genannten $5 \%$ - ich denke etwa an den Streit um die Mutlangen-Prozesse. Zu Herrn Alexy: Es war weder unsere Aufgabe noch stand es in unserer Möglichkeit, hier eine neue normative Theorie der Bundesrepublik zu entwickeln. Sie haben diese Frage auch an den Vorstand gestellt, an dessen Themenwahl wir gebunden waren. Daß eine solche neue normative Theorie Konsequenzen für die Staatszweckproblematik hätte, gestehe ich Ihnen gern zu. Ich zweifle aber trotzdem daran, daß ohne eine derartige Theorie die Staatszweckfrage nur einen Topoikatalog zur beliebigen Verwendung, eine „Rhapsodie von schönen Worten“ zu bieten hat. Darauf komme ich noch zurück. - Zu Herrn Stettner: Ich stimme Ihnen voll zu - und dies hat ja auch Herr Isensee sehr nachdrücklich und sehr eindrucksvoll hervorgehoben -, daß die Staatszwecke die Frage nach dem Staat selbst stellen, nicht nur nach der Verfassung; und auch darin, daß wenn man den Staat nicht primär durch die Herrschaft, sondern durch seine Zwecke konstituiert sieht - die Gefahr der Zweckverfehlung um der Selbsterhaltung willen besteht. Dies ist nicht nur eine dogmatische Konsequenz, sondern auch erlittene historische Erfahrung. Ich glaube aber, daß gerade hier eine Staatszwecklehre gefordert ist, die den Staat nicht als Selbstzweck mißversteht. Zu Herrn Mantl möchte ich sagen, daß natürlich auch die Großorganisationszwecke von Bedeutung sind und nicht einfach den Individualzwecken nachgeordnet werden können. Ich weiß nicht, ob Sie es so gemeint haben. Jede einfache Rangordnung zwischen Individual- und Organisationszwekken würde ich mit einem großen Fragezeichen versehen. - Zu Herrn Leisners Beitrag brauche ich nicht eigens zu betonen, daß ich mir mit ihm darin einig bin, daß eine Staatszwecklehre nicht eine Freiheitsgewährleistung, ja die Freiheit selbst beschränken darf. Ich habe versucht, in meinen Referat hervorzuheben, daß die Gewährleistung des Staatszweckes „Freiheit“ einen legitimen Standpunkt außerhalb des Leviathan voraussetzt, daß also der Staatszweck „Freiheitsgewährleistung" nicht selbst zum Hebel einer Freiheitsbeschränkung werden darf, daß Staatszwecke nur mit verfassungsmäßigen Mitteln verfolgt werden dürfen und daß aus solchen Zwecken keine konkreten Eingriffsermächtigungen folgen. Ebensowenig wie das Polizeirecht läßt auch eine Staatszwecklehre einen Schluß von der Aufgabe auf die 
Befugnis zu. Ich meine, daß sowohl Herr Ress wie ich hinreichend deutlich gemacht haben, daß es uns nicht darum ging, in den Staatszwecken sozusagen eine neue Normenschicht über der Verfassung zu entwickeln, sondern daß den Staatszwecken ein normativer Charakter nur im Rahmen der verfassungsrechrlichen Positivierung zukommt ebenso wie die polizeiliche Aufgabe sich eben erst in der polizeilichen Befugnis konkretisiert. - $\mathrm{Zu}$ Herrn Häberle: Ich glaube nicht, daß zwischen uns im prozessualen Gemeinwohlverständnis eine wirkliche Differenz besteht. Ich habe das hervorgehoben, möchte aber doch auf die nichtprozessualen Voraussetzungen nachdrücklich Gewicht legen. Nicht alles ist im Prozeß offen, sondern es gibt Konstanten des Gemeinwohlverständnisses, die typusprägend für den freiheitlichen Verfassungsstaat sind. Aber ich vermute, daß wir uns darin einig sind. Der Hinweis auf die Staatsaufgabenkataloge anderer Verfassungen ist der notwendigen Kürzung des Referats zum Opfer gefallen; einige erscheinen in den Fußnoten. - Die Antwort auf Herrn Schuppert und Herrn Grimm möchte ich zusammenziehen: Wenn ich beide recht verstanden habe, hielten sie es für sinnlos, abstrakte Staatszwecklehren zu entwerfen, da der Staat als Funktion der Gesellschaft alle gesellschaftlichen Bedürfnisse auch in Staatszwecke verwandele. Ich würde dem so nicht zustimmen - oder doch nur mit der Maßgabe, daß jedenfalls bestimmte Zwecksetzungen den Typus derjenigen Staatsform verändern, über die wir zu referieren hatten, nämlich den des demokratischen Verfassungsstaats. Sicherlich kann es konkrete gesellschaftliche Trends geben, die den Staat von diesem Typus wegdriften lassen und damit auch seine typusprägenden Zwecke in Frage stellen. Verzeihen Sie, wenn ich wieder auf die Geschichte zurückkomme, sie hat vieles vorgedacht und damit eine Argumentationsreserve angelegt: es ist die alte Frage, ob das Volk so frei ist, sich auch in die Knechtschaft zu begeben, sich einem imperium herile zu unterwerfen, das ganz andere Zwecke verfolgt. Natürlich kann es das, so sagt die ältere Staatsrechtslehre, aber es verändert eben den Staatstypus von Grund auf. Heute entspricht dem der Weg der Verfassungsrevision; es bedürfte einer neuen Verfassung, wie sie Art. 146 GG vorsieht. Ob sie kommt und wie sie aussieht - wir wissen es nicht. Wir aber hatten über den demokratischen Verfassungsstaat zu referieren, der von Konstanten seines Selbstverständnisses und seiner Zwecke geprägt ist, die nicht beliebig variierbar sind, sich aber natürlich in der Verfassung konkretisieren. Sie haben das als Modernitätsdefizit bezeichnet mit der Bemerkung, daß wir den Staat als eine vorgegebene Größe mit klassischen Staatszwecken und dem Gewaltmonopol als Kernstück betrachteten. Unsere Fragestellung - und ich 
glaube, ich kann hier auch für Herrn Ress sprechen - war dagegen eine andere, nämlich die, ob einerseits die zunehmende Steuerung gesellschaftlicher Prozesse durch den Staat, andererseits die Erosion von Kernfunktionen an Grenzen stößt, die dem modernen Verfassungsstaat seinem Wesen nach gezogen sind. Und noch eines: Sie haben uns ein Modernitätsdefizit wegen des Hinweises auf die uns in diesen Tagen bedrängende Flüchtlingsfrage, aber nicht ein Aktualitätsdefizit bescheinigt. Hier möchte ich doch mit einem gewissen Nachdruck betonen, daß dies für mich nicht nur eine Aktualitätsfrage, sondern eine Modernitätsfrage ist. Der Flüchtlingsstrom aus der DDR steht am Ende der Entwicklung einer Staatsvorstellung, die von der demokratisch-verfassungsstaatlichen grundverschieden ist, und er zeigt uns mit erschreckender Deutlichkeit, wohin solche andere Konzeptionen führen. Hier geht es um das Staatsverständnis selbst und ich meine, daß dieses jeweils mit Zwecksetzungen verbunden ist, die nicht so einfach dem jeweiligen Meinungswechsel unterliegen. Das zu zeigen war unser Anliegen. Ich verstehe Ihre Auffassung sehr gut, möchte aber deutlich machen, daß unsere Vorstellungen vom Staat hier möglicherweise grundlegend voneinander abweichen. - In diesem Zusammenhang gleich zu Herrn Isensee: Hier bitte ich mein Schweigen als Zustimmung zu werten. Lediglich zum Problem der Selbsterhaltung des Staates: Der ursprüngliche Abschnitt über die wehrhafte Demokratie in meinem Manuskript ist der Streichung zum Opfer gefallen. Hier haben Sie zu Recht auf ein Desiderat hingewiesen. Zuletzt noch zu Herrn Burmeister: Ich bin mit Ihnen ganz einig darin, daß der Staat als Organisation der bestmöglichen Verwirklichung des Gemeinwohls, der Schaffung menschenwürdiger Lebensbedingungen $\mathrm{zu}$ dienen hat und daß dies in Ausrichtung auf die Menschenwürde zu geschehen hat. Nur bleibt eben die Frage, welcher Mensch hier gemeint ist, wie die Menschenwürde zu definieren ist. Definieren wir sie im Sinne eines optimistischen Menschenbildes, dessen Gefahren ich aufzuzeigen versucht habe, oder im Sinne jenes gemäßigt pessimistischen, das für mich allein mit einer freiheitlichen Ordnung kompatibel ist? Insofern ist uns mit Recht gelegentlich vorgehalten worden, unsere Staatszwecklehre sei zu allgemein. In der Tat sind die Folgerungen, die sich aus einem solchen Menschenbild ergeben, noch konkreter zu bestimmen. Dies konnte im Rahmen eines solchen Referates nicht geleistet werden - aber gerade hier muß eine Staatszwecklehre konkret werden. Vielen Dank.

Vorsitzender: Vielen Dank, Herr Link. Meine sehr verehrten Damen und Herren, wir sind relativ günstig in der Zeit. Ich halte 
einen Moment inne, um dem Gelegenheit zu geben, den Saal möglichst geräuschlos zu verlassen, der das wünscht. Wir haben für die Blöcke III, IV, V und VI bis jetzt insgesamt nur sechs Wortmeldungen vorliegen, und ich habe den Eindruck, und das wird bestätigt durch zwei Wortmeldungen soeben, daß wir bei dieser Diskussion eben an einem ganz zentralen Punkt des Themas angelangt waren und deswegen möchte ich mir erlauben, von dem üblichen Usus der Diskussion hier ein bißchen abzuweichen, indem ich zwei Zwischenwortmeldungen zulassen möchte, die direkt zu diesem jetzigen Thema II sprechen möchten. Und ich möchte auch die Frage stellen, ob sonst noch zu diesem Thema, das in der Kontroverse zwischen Grimm, Schuppert und Isensee doch sehr prägnant herausgekommen ist, noch weiter das Wort gewünscht wird. (Ja, Herr Rauschning). Ich würde also dann bitten, daß der Reihenfolge nach Herr Brobm, dann Herr Lecheler und dann Herr Rauschning zu dem Komplex noch sprechen. Bitte, Herr Brobm, zunächst.

Brohm: Eine kurze Frage zur Kontroverse zwischen Herrn Isensee und Hern Grimm. Ich würde die Ansicht von Herrn Link teilen, daß man eine Kontinuität in den Staatszwecken „Sicherheit“ und „Wohlfahrt" feststellen kann, wenn man diese Begriffe auf einer sehr hohen Abstraktionsebene ansiedelt - mit einer entsprechend geringen Aussagekraft. Fragt man aber nach den konkreten Funktionen, die wir mit diesen Begriffen erfassen, dann hat sich, um auf das Beispiel von Herrn Grimm zurückzugreifen, der Wohlfahrtszweck inhaltlich wesentlich gewandelt. Neben der individuellen Fürsorge etwa, die geblieben ist, aber vielleicht an Bedeutung zurückgeht, haben wir heute ganz andere Wohlfahrtsbelange ins Auge zu fassen, etwa die Zukunftsdimension für die Allgemeinheit, und nicht nur für die Gesamtheit einer Nation, sondern darüber weit hinausgehend. Ähnliche Veränderungen können sich auch im Hinblick auf die Sicherheitsfunktion ergeben. Daher frage ich mich: Kann man mit der Annahme einer Kontinuität der Staatszwecke arbeiten, wenn sich diese Begriffe inhaltlich völlig wandeln?

Vorsitzender: Danke schön, Herr Brohm. Dann als nächster bitte, Herr Lecheler.

Lecheler: Meine Damen und Herren, ich wollte mich eigentlich in dieser Debatte zurückhalten und sie Berufeneren überlassen, aber die Frage des "Modernisten“ oder des „Nichtmodernisten" veranlaßt mich doch, einen Satz zu sagen, auch wenn ich nicht mit Herrn Isensee glaube, daß die Moderne durch die Postmoderne bereits 
überholt sei. Herr Grimm, Ihre verdienstvolle Wortmeldung hat mir in der Tat klar gemacht, welchen unverzichtbaren Wert für wissenschaftliche Betätigung die Fußnote hat. Denn, ob und inwieweit Herr Kollege Link "modern" oder "nichtmodern" war, das werden wir erst natürlich urkundlich nachprüfen können, wenn er seinen Fußnotenapparat vor uns ausgebreitet hat. Aber, Herr Kollege Link, erlauben Sie mir, daß ich das so deutlich sage, ich habe nicht ganz verstanden, warum Sie sich gegen den Vorwurf so gewehrt haben. Mich hätte er nicht getroffen. Die Frage der Begründung, ob "modern" oder nicht, hätte mich nicht so furchtbar interessiert. Das Problem ist ja alt. Und Herr Grimm, Ihre Antwort - die Begründungen haben Sie uns ja fußnotenmäßig auch nicht vorgelegt - Ihre Zentralthese ist auch nicht gerade modern. Was für mich nicht heißt, daß sie falsch sein muß, darüber kann man sich ja bekanntlich streiten und darüber ist ja auch gestritten worden und darüber soll auch ruhig weitergestritten werden. Sie haben das Verdienst durchaus, glaube ich, hier einen wichtigen Punkt markiert zu haben. Was für mich interessant war, das wäre es gar nicht so sehr gewesen, wenn Sie das in Ihrer Funktion in Bielefeld gesagt hätten. Ich kaute daran, als Sie es gesagt habe, weil Sie zumindest auch Vertreter eines Staatsorgans sind und da ist für mich die Frage: Haben Sie da in der Tat in dieser Funktion auch dieses Verständnis von Staatszweck und -umsetzung in der Staatspraxis? Das treibt mich jetzt, in der Tat, noch etwas um. Vielen Dank.

Vorsitzender: Danke sehr, Herr Lecheler. Weitere Wortmeldungen sind eingegangen. Ich gehe jetzt in der Reihenfolge vor.

Rauschning: Als Zwischenruf: Es wird die Frage diskutiert, ob es sich nur um staatliche $Z$ wecke handelt oder ob wir diese $Z$ wecke nicht anderen Akteuren wie internationalen Organisationen oder Gemeinschaften, gesellschaftlichen Kräften und der Wirtschaft oder im Grunde genommen uns allen zuordnen. Natürlich ist die innere Sicherheit und der innere Frieden eine zunächst uns einzeln gesetzte Aufgabe, die durch persönliches Verhalten zum Teil zu erfüllen ist; so ist auch die Versorgungssicherheit in der konkreten Gestalt, ob die Familie hungert, wenn am Montag die Geschäfte nicht öffnen, zunächst eine Aufgabe für den Privathaushalt selbst. Dennoch sollten wir nicht, Herr Steiger, schon von der Relativierung des Staates sprechen. Der Staat ist die Institution, die die Erfüllung dieser Zwecke garantiert. Wenn in unserer Gemeinde ein katholischer und ein evangelischer Kindergarten und noch ein kommunaler bestehen, dann ist eine Versorgung gegeben. Es muß aber für die Allgemeinheit diese Versorgung garantiert werden, und der Staat als der Sachwalter des 
Allgemeinen im Sinne Herbert Krügers garantiert die Versorgung derart, daß der einzelne sich nicht mit einer Gruppe identifizieren muß, um an dieser Versorgung teilzuhaben. Ich glaube nicht - und ich schließe mich insoweit der Stellungnahme von Herrn Ress an -, daß wir bei einer Relativierung des Staatszwecks zur Garantie dieser Aufgabenerfüllung angekommen sind: Ohne den Staat und ohne die staatliche Garantie als die Garantie durch die Allgemeinheit kommen wir nicht aus.

Vorsitzender: Vielen Dank, Herr Rauschning. Herr Grimm direkt dazu? Gern. Ich habe jetzt in dieser Runde noch eine Reihe von Wortmeldungen, allmählich kommen die Herren aus dem Versteck, sozusagen: Herr Bothe, Herr Wielinger, Herr Subr, Herr Meyer und das wäre dann wohl der Abschluß in dieser Runde. Dann können wir in dieser Weise verfahren, also Herr Bothe, bitte.

Bothe: Ich glaube, Herr Vorsitzender, auch nach dem, was Herr Link eben gesagt hat, wird er nicht leugnen wollen, daß der Staat ein "historisches Tier" ist, daß er das Produkt einer historischen Entwicklung ist und $\mathrm{da} ß$ er weiterhin einem historischen Wandel unterliegt. Das darf nicht daran hindern, Momentaufnahmen zu machen und zu sehen, wie der Staat nun in dieser Situation verfaßt ist, was auch dauerhafte Elemente dieser Verfassung, und dazu gehören auch seine Aufgaben, sind. Wenn wir das historisch sehen, so ist schon mehrfach das Absterben des Staates prognostiziert worden, jedesmal zu Unrecht. Marx hat es prognostiziert, und was wurde daraus? Daraus wurde der Staatsmonopolkapitalismus. Am Ende des Zweiten Weltkrieges haben viele Utopisten den Staat absterben sehen. Was bekamen wir statt dessen? Wir bekamen in der Dritten Welt eine Renaissance des staatlichen Souveränitätsdenkens.

Das führt uns dazu, daß wir fragen, was in dieser historischen Entwicklung eigentlich das Besondere dieses "Tieres Staat" ist, was unterscheidet ihn in seinen Aufgaben und Funktionen von anderen Organisationsformen. Wir müssen ihn abgrenzen - das hat die Diskussion deutlich gemacht - einmal gegenüber gesellschaftlichen Organisationsformen (Verbänden, Unternehmen und dergleichen) und gegenüber anderen politischen Organisationsformen. Beide, oder alle drei, haben bestimmte Funktionen zur Lösung gesellschaftlicher Probleme - das ist unbestreitbar. Mir liegt daran, zunächst einmal zu zeigen, daß diese gesellschaftlichen Probleme über den staatlichen Rahmen hinausgreifen, über den Rahmen des nationalen Staates hinausgreifen, das ist hier schon mehrfach gesagt worden. Man sollte deutlich machen, daß sie dies in einer doppelten Weise tun: Einmal 
gibt es eine ganze Fülle von Problemen, die zweifelsohne als Aufgaben des Staates gesehen werden, die der einzelne Staat nicht mehr alleine lösen kann. Das Problem der äußeren Sicherheit bedarf der Kooperation. Der überzeugteste Abschreckungstheoretiker wird das nicht leugnen. Das Problem der Sorge für die Umwelt ist in weiten Bereichen sinnvoll nicht von einem Staat zu lösen, auch wenn es um die eigene Umwelt geht. Ähnliches gilt für die sozialen Bereiche. Angesichts der ungeheuren Migrationsvorgänge, die wir haben, ist auch soziale Sicherheit und Wohlfahrt im eigenen Land nicht ohne internationale Kooperation zu lösen. Darüber hinaus, und das ist die andere Komponente, gibt es viele Probleme, die sich eigentlich in anderen Teilen der Welt stellen, hinsichtlich derer aber auch unser eigener Staat gefordert ist. Ich nenne das Problem der Armut in der Dritten Welt. Der Sozialstaatsgedanke fordert unter anderem eine Umverteilung, auch einen Ausgleich zwischen unseren reichen und den armen Ländern auf weltweiter Ebene.

Dies ist ein komplexes Gewebe von Aufgaben, die zu bewältigen sind, von welchen Akteuren? Hier sehen wir, glaube ich, ganz deutlich, daß in der gegenwärtigen historischen Phase der Staat als Akteur zur Bewältigung dieser weltweiten Aufgaben unverzichtbar ist, daß er nach wie vor eine zentrale Rolle spielt. Das gilt auch und gerade in bezug auf internationale Organisationen, weil diese Organisationen eben zum großen Teil kein eigentliches Eigenleben haben, sondern eine Form der Kooperation von Staaten sind. Das gilt sogar, wenn auch geringer, für die EG, wo wir doch auch sehr weitgehend einen Prozeß der Problemlösung durch Konsens haben und damit eben in diesem Kooperationsmodell bleiben. Der heutige Staat ist, im Hinblick auf die Lösung weltweiter und eigener Aufgaben, der Staat der internationalen Kooperation. Das ist eine wesentliche Funktion, die er hier heute hat.

Daneben darf man ihn aber auch nicht überbewerten. Es gibt eine ganze Reihe weiterer Akteure, auch auf der internationalen Ebene, die wir im Blick behalten müssen: Das sind Verbände, „nongovernmental organisations" wie amnesty international, das sind multinationale Unternehmen, das sind aber auch andere Untergruppierungen wie Minoritäten, von mir aus bis hin zu den Befreiungsbewegungen. Darf ich mir eine zweite Wortmeldung zu einem weiteren Themenbereich vorbehalten?

Wielinger: Erlauben Sie mir eine Frage, die vielleicht auch der Begriffsklärung dienen könnte, an die beiden Herren Referenten. Eine Frage im Zusammenhang mit einem historischen Rückblick auf ein 
vielleicht singuläres Phänomen: Es gab in diesem Jahrhundert einen Staat, der bei seiner Gründung erklärt hat, es sei sein höchstes Ziel, daß er nicht existieren wollte und der damit auch nicht hinter dem Berg gehalten hat. Das war die erste Republik Österreich. In der Geburtsstunde dieses Staates wurde die Erklärung abgegeben, daß man nicht als Staat existieren wollte. Würden die Herren Referenten eine solche Erklärung als die Fixierung eines Staatszweckes dieses konkreten historischen Staates ansehen? Ich möchte jetzt keineswegs die Begriffsdiskussion neu beleben, aber dennoch bitten, diese Frage $\mathrm{zu}$ beantworten. Erlauben Sie mir noch eine weitere Bemerkung, die in diesem Zusammenhang vielleicht nicht uninteressant ist. Wir können das verfassungshistorische Phänomen beobachten, daß sich ein Staat eine Verfassung in der erklärten Absicht gegeben hat, eine staatliche Ordnung nur für eine Übergangszeit zu schaffen, nämlich für die Zeit bis zur Erreichung des erklärten Zieles der Selbstauflösung dieses Staates durch den Anschluß. Der historische Nachfolger dieses Staates hat nun aber die im wesentlichen gleiche Verfassung, eine in ihren Grundzügen identische Verfassung und dies, obwohl dieser Staat nicht nur wegen völkerrechtlicher Verpflichtungen, sondern weil dies nunmehr seinem Selbstverständnis entspricht, keineswegs daran denkt, jemals seine Identität aufzugeben. Ich danke Ihnen.

Vorsitzender: Vielen Dank, Herr Wielinger, für diese wirklich schwierige Frage, die Sie den Referenten gestellt haben. Sie werden sie beantworten, aber vielleicht im Schlußwort, mit Ihrem Einverständnis. Dann bitte, Herr Subr, jetzt.

Suhr: Meine kurze Bemerkung. Ich glaube, es hätte die Diskussion geklärt, wenn insgesamt schärfer unterschieden worden wäre zwischen dem, was man sich unter "Staat" vorstellt. Ich möchte nur zwei Pole herausstellen, nicht herausarbeiten: zum einen Staat als „politisches System": Das wäre ein modernes Verständnis als Organisation zur Produktion von Entscheidungen, womöglich mit Gewaltmonopol, also eine nüchterne „Maschinerie“ ohne Identifizierungswert. Da hat man kein erhabenes Gefühl oder dergleichen, sondern das ist eben das nüchterne moderne Gebilde. Zum anderen Staat als „Heimstatt“. Das ist, was viel mitschwingt und mitklingt, wenn hier von "Staat" die Rede ist, wobei dann noch zwei Nuancen zu unterscheiden sind: einmal "Staat" als seelische Heimstatt, die politische Nischen der Psyche besetzt oder, frei gesagt, wo man sich mit seiner politischen Psyche einnisten kann, die sich von der Religion vielleicht inzwischen nicht mehr ganz befriedigt findet, "Staat" als Heimstatt der Seele, wo man sich wohlfühlen kann in einem Gemeinschaftsgebilde. Zum 
anderen "Staat" als Heimstatt des materiellen Wohlstandes, wo man mit anderen zusammenlebt und ein verfaßtes Gemeinwesen darstellt, in dem man miteinander lebt. Dieses Gemeinwesen als verfaßtes Gemeinwesen existiert als Staat und gibt sich eine politische Maschinerie zur Produktion von politischen Entscheidungen.

Wenn man diese verschiedenen Figuren ein bißchen auseinanderhält, dann kann man den Klang, der bei einigen Diskussionsbeiträgen vorherrschte, einsortieren: Das gehört mehr in den seelischen Bereich; das betrifft mehr die Wohlfahrt; der hat es mit der politischen Maschinerie zu tun. Dann erklärt sich einiges.

Vorsitzender: Vielen Dank, Herr Subr. In dieser Runde habe ich jetzt noch die Wortmeldung von Herrn Meyer und dann wollte Herr Grimm zum Schluß noch mal kurz erwidern und dann darf ich gleich ankündigen, ist in der Runde III. Herr Doebring angemeldet. Herr Meyer, bitte.

Meyer: Ich habe einiges nicht verstanden. In einem Punkt hätte ich aber gerne eine Aufklärung - bei den anderen bin ich sicher, daß es sich nicht lohnt, mich aufzuklären. Herr Link, Sie haben Herrn Isensee stillschweigend zugestimmt. Das verstehe ich nicht. Wenn ich Herrn Isensee richtig verstanden habe, hat er versucht, das Thema zu transzendieren. Er hat sich bemüht, von Staatszwecken oberhalb der Verfassung zu sprechen, von Zwecken des Staats jenseits der Verfassung, während Sie ja doch Wert darauf gelegt haben, sich an das Thema zu halten und von den Staatszwecken des Verfassungsstaates zu sprechen. Sie können ihm also eigentlich gar nicht zustimmen. Er hat so beifällig das große Wort von Ebert gebraucht, und ich hätte ihn - schade, daß er nicht da ist - gerne gefragt, ob er, da ihm ja der Nationalstaat unser eigentlicher Staatszweck ist, der Meinung ist, daß wirklich die Einheit der Freiheit vorgeht, was ja in unserem Kreise erstaunlich wäre zu hören. Das wäre aber immerhin die Konsequenz, wenn man diesen Staatszweck so betont. Das ist meine Aufklärungsfrage. Ob hier nicht „qui tacet, clamat" die richtige Haltung gewesen wäre?

Die zweite Bemerkung: Ich verstehe nicht, daß wir uns so große Sorgen mit den Staatszwecken machen. Dem Staat ist alles erlaubt, als Zweck zu setzen, was nicht verboten ist, und ich will Ihnen ein ganz einfaches Beispiel sagen, so läppisch es scheinen mag: Der Staat bemüht sich - ich glaube seit 1953 - um die sehr simple Aufgabe, für die Bundesrepublik Deutschland möglichst viele Goldmedaillen bei der Olympiade herauszuholen. Man hat dafür viel Geld ausgegeben. Früher hieß das der Goldene Plan, und es gab souverän ignorierte Kompetenzprobleme mit den Ländern. Wer wollte denn behaupten, 
daß dieser Staatszweck vom Staat nicht frei gesetzt oder auch gelassen werden kann. Und aus dieser Beliebigkeit der Staatszwecke ergibt sich das, worauf Herr Schuppert hingewiesen hat, daß viele andere dieselben $Z$ wecke genauso verfolgen könnten. Jeder von uns verfolgt den Zweck seiner eigenen Wohlfahrt und der seiner Familie. Der eine schafft es besser und der andere weniger gut, und der Staat macht mehr oder weniger dasselbe.

Es gibt also über die Staatszwecke, wenn wir sie so fassen, wie sie hier gefaßt sind, keine sehr signifikanten Aussagen, weder für den Staat noch für die Verfassung.

Vorsitzender: Vielen Dank, Herr Meyer. Herr Grimm, Entschuldigung, Herr Bartlsperger hatte um einen Zwischenruf gebeten.

Bartlsperger: Ich möchte die Wortmeldung nutzen, um etwas aufzugreifen, was vorher Herr Meyer angesprochen hat. Bei beiden Referenten hat mir sehr eingeleuchtet, daß diese eine Staatszwecklehre aus den Grundrechten konstituiert haben, nämlich aus dem Grundrechtsstatus, aus den grundrechtlichen Schrankenregeln und, besonders wohl im Falle von Herrn Ress, aus der objektiven Wertordnung des Grundrechtskatalogs. Entgegen Herrn Alexy bin ich der Auffassung, daß die Referenten hinsichtlich der Staatszwecke nicht nur einen Topoi-Katalog aufgestellt, sondern daß sie eine sehr geschlossene Theorie von den Staatszwecken ausgehend von den Grundrechten entwickelt haben. In Anknüpfung an die vorhergegangene Frage von Herrn Meyer kann ich deshalb nicht verstehen, warum Herr Link bereit war, der Ansicht von Herrn Isensee zuzustimmen, die dieser ebenso literarisch vertritt, wonach der Staat auch hinsichtlich der Festlegung von Staatszwecken „vor der Verfassung“ liege. Dies paßt mit einer Begründung der Staatszwecke aus den Grundrechten der Verfassung nicht mehr zusammen. Ich muß also feststellen, daß die Konstituierung einer geschlossenen Staatszwecktheorie aus den Grundrechten sehr einleuchtend ist, daß hiermit aber die Auffassung unvereinbar erscheint, die Staatszwecke seien vor der Verfassung vorhanden. Insofern wäre ich für eine Aufklärung dankbar. In dem Zusammenhang möchte ich, da ich nun einmal das Wort habe, auch noch eine Bemerkung machen zu Äußerungen, die am Anfang der Aussprache bei allgemeinen Fragen gefallen sind. Für mich ist es auch eine nichtjuristische moralische Frage, ob ein Bürger einer freiheitlich repräsentativen Demokratie sich an repräsentativ zustandegekommene Staatsentscheidungen hält und keinen Widerstnd leistet, vor allem, wenn die Entscheidungen in der Form von Mehrheitsbeschlüssen zustandegekommen sind. Dies will ich bei dieser Gelegenheit 
deshalb nochmals sagen, weil Herr Link in seiner Erwiderung auf Herrn Dreier insofern nach meiner Ansicht zu zurückhaltend war.

Vorsitzender: Vielen Dank, Herr Bartlsperger. Herr Link wird sicherlich Gelegenheit nehmen, im Schlußwort darauf einzugehen. Dann Herr Grimm bitte.

Grimm: Ich wollte eigentlich nicht replizieren, aber Herr Lecheler hat es nun doch nötig gemacht. Herr Lecheler, ich repräsentiere vor der Staatsrechtslehrervereinigung für mich und keine Institution. Wir haben es also gar nicht mit Repräsentation, sondern mit Identität zu tun. Jetzt aber ein Wort zur Sache, das sich auch an die Referenten und ihre Erwiderung richtet. Was ich in meinem ersten Beitrag beabsichtigt habe, war eine empirische Aussage über den gegenwärtigen Zustand des demokratischen Verfassungsstaates, nicht irgendeines Staates, und was ich beklagt habe, war, daß den Referenten ein Staatsverständnis zugrundelag, das nach meiner Auffassung dem gegenwärtigen Zustand des Verfassungsstaates nicht gerecht wird. Es waren substanzhafte Vorstellungen vom Staat, und diesem substanzhaft vorgestellten Staat wurden dann relativ konstante Zwecke zugeordnet. In Wirklichkeit ist der Staat überhaupt kein Realphänomen, sondern "Staat" ist eine ganz bestimmte, historisch entstandene Weise, System und Ordnung politischer Herrschaft zu begreifen, die ihrerseits freilich real ist und reale Folgen hat. Daß der Staat selber jedoch kein Realphänomen ist, kann man sehr gut daran ablesen, daß in den angelsächsischen Ländern und denen, die in ihrer Tradition stehen, der Begriff „Staat" nicht verbreitet ist. Das kann nur bedeuten, daß sich dort ein anderes Verständnis politischer Ordnungen und politischer Systeme ausgebildet hat als unser staatliches. Die Eigenart, das politische System als Staat zu verstehen, ist auf dem Kontinent unter den Bedingungen des modernen souveränen Staates entstanden, wie er sich im Gefolge der Glaubensspaltung ausgebildet und im Nationalstaat des 19. Jahrhunderts seinen Höhepunkt gefunden hat, und ich habe nur gesagt, daß diese dem Staatsbegriff zugrundeliegenden Realitäten sich so gründlich geändert haben, daß man ohne Rücksicht auf die Veränderungen keine kompetente Aussage über Staatszwecke machen kann.

Vorsitzender: Damit können wir, glaube ich, diese Runde II, die doch einen sehr grundsätzlichen Charakter gewonnen hat, abschlieBen, womit ich nicht gesagt haben will, daß das, was jetzt kommt, nebensächlich ist. In der Runde III liegt bis jetzt nur eine Wortmeldung von Herrn Doebring vor und dann habe ich in der Reihenfolge 
zum Problem "Gemeinwohl“ - Komplex IV - Herrn Schachtschneider und Herrn Bartlsperger, und zur Runde VI dann Herrn Mußgnug, Herrn Roellecke und Hern Bothe. Dann darf ich jetzt zunächst Herrn Doebring bitten.

Doehring: Vielen Dank, Herr Vorsitzender. Ich habe zwei ganz konkrete Fragen an meinen Freund und Kollegen Ress, möchte aber vorher noch sagen, daß ich den Staat durchaus als eine Realität begreife. Jetzt möchte ich deshalb konkreter werden, weil ich das Gefühl habe, man verliert sich hier zu sehr in allgemeinen Erwägungen. Die erste Frage betrifft das Folgende: Wir hatten schon in der Staatsrechtslehrertagung 1979 die Deutschlandfrage behandelt, und Herr Bernhardt hatte dort vorgetragen. Damals hatte ich gesagt und vorher schon geschrieben -, es sei durchaus ein Problem, was nun Vorrang habe, die europäische Integration oder die Wiedervereinigung Deutschlands, denn eine in Europa majorisierte Regierung der Bundesrepublik kann dann allein nicht mehr die Verantwortung übernehmen für die Vereinigung der beiden deutschen Staaten. Hans Peter Ipsen hatte damals gesagt, diese Frage solle man gar nicht stellen, da sie nicht "tunlich“ sei, und zwar aus politischen Gründen. Aber heute ist die Frage aktuell und wird immer härter gestellt werden. Jetzt zeigt sich das Problem der Rangordnung dieser beiden Staatszwecke. Die Wiedervereinigung ist bestimmt ein Staatszweck; ob die Integration Europas ein solcher ist, darüber kann man vielleicht streiten. Herr Ress hat gesagt: Beides müsse kein Gegensatz sein, wenn man, wie seinerzeit Herr Hallstein im Jahre 1957 bei Abschluß des EWG-Vertrages, einen entsprechenden Vorbehalt bei weiterer Integration mache. Nun zeigt aber die Notwendigkeit eines Vorbehalts allein schon den Vorrang der Wiedervereinigung, denn man bedürfte dessen nicht, wenn diese Wiedervereinigung nicht Vorrang hätte. Was aber soll geschehen, wenn die anderen Vertragspartner den Vorrang nicht akzeptieren? Dann müssen wir uns entscheiden, und schon deshalb ist unser Staat eine Realität, weil wir der Entscheidung nicht ausweichen können. Nun kommt die zweite Frage, die auch Europa betrifft. Wir übertragen Hoheitsrechte auf Europa. Das ist nicht unproblematisch hinsichtlich eines generellen Staatszwecks. Dieser liegt wesentlich vor der Verfassung, wie wohl auch Herr Isensee meinte. Man schwört nicht Treue zur Verfassung, sondern zum Staat. Der Staat ist zum Schutz der Bürger verpflichtet und der Bürger zur Staatstreue. Protectio und subjectio entsprechen sich. Wenn das richtig ist, dann hat der Staat die primäre Verpflichtung, auch sekundäre Staatszwecke zu schützen; diese kann man - mit 
Herrn Meyer - sich aussuchen, aber danach müssen sie geschützt werden. Wenn aber der Staat die Staatszwecke schützen muß, dann kann er sie nicht abgeben, abtreten oder übertragen. D.h., wenn wir immer mehr Staatszwecke auf die EWG übertragen, selbst sie aber gar nicht mehr schützen können, kann der Staat auch nicht mehr die Totalverantwortung für die Staatsbürger tragen. Da bricht etwas auseinander, was die Staatszwecklehre zu beachten hätte. Um ein Beispiel zu geben: Europa hat keine Bundespolizei mit überregionalen Befugnissen wie die USA. Dabei wird die grenzüberschreitende Kriminalität in Europa eine große Rolle spielen. Was soll dann geschehen? Wir übertragen aus Staatszwecken entstehende Aufgaben an Europa, behalten aber dennoch die Totalverantwortung für die Staatsbürger. Europa soll die Aufgaben übernehmen, kann aber die Verantwortung nicht tragen und hat auch nicht diese Totalverantwortung. Nun die konkrete Frage: Können wir aufgrund des Art. 236 EWGV noch weitere Aufgaben duch Änderung der Verfassung der EWG übertragen? Können wir zustimmen, daß mit dem Mittel des Art. 235 EWGV weitere Aufgaben an Europa übertragen werden? Wir stehen vor der Tatsache, daß der Gerichtshof in Luxemburg progressiv entscheidet; er erklärte Richtlinien für im einzelnen verbindlich, obwohl sie nach dem EWGV hätten in das nationale Recht umgesetzt werden müssen. So müssen wir uns fragen, ob wir dann unter diesen Umständen die totale Verantwortung für den Schutz unserer Staatszwecke noch tragen können. Danke schön.

Vorsitzender: Vielen Dank, Herr Doebring. Darf ich fragen, ob es in dieser Runde noch Beiträge gibt spontaner Art, Herr Meyer?

Meyer: Ich sage Herrn Doehring, daß der Eid der Verfassungsorgane dem deutschen Volk geleistet wird, nicht dem Staat. Das kann man in Art. 56 GG nachlesen.

Vorsitzender: Vielen Dank, Herr Meyer. Wir kommen dann zur Runde "Gemeinwohl, Gemeinwohlproblematik“. Ich habe die Wortmeldung von Herrn Schachtschneider und dann die von Herrn Bartlsperger, noch einmal. Herr Schachtschneider, bitte. Herr Schachtschneider scheint im Moment nicht anwesend zu sein, dann darf ich Sie, Herr Bartlsperger, gleich bitten.

Bartlsperger: Beiden Referenten möchte ich noch Fragen zum Gemeinwohlbegriff und zur Konkretisierung dieses Begriffes stellen, allerdings nicht in dem Sinnzusammenhang der drei Begriffe „Gemeinwohl - Neutralität - Amt“, wie er für die Aussprache vorgeschlagen wurde, sondern hinsichtlich der Frage einer „Konkreti- 
sierung des Gemeinwohls durch den Gesetzgeber". Das ist aus der Sicht des Verwaltungsrechts, wo die Problematik der Staatszwecke sich schließlich abspielt und zum Schwur kommt, eine sehr wichtige Frage. Es ist selbstverständlich davon auszugehen, daß der Gesetzgeber die Kompetenz haben muß, das Gemeinwohl zu konkretisieren. Aber wie sind die Fälle zu beurteilen, in denen der Gesetzgeber die Gemeinwohlklausel einfach weitergibt, d.h. wie stellt sich aus der Sicht der Referenten die Rechtslage dar, wenn teils vorkonstitutionelle, teils nachkonstitutionelle Gesetze den Gemeinwohlbegriff verwenden, sei es bei allgemeinen Zulassungsregelungen für Vorhaben oder bei Zulassungsregelungen, nach denen die Inanspruchnahme der öffentlichen Infrastruktur einschließlich der Umwelt "bewirtschaftet“ wird. Die Referenten haben auf der anderen Seite, wie schon erwähnt, sehr stark den Grundrechtsaspekt der Staatszwecke hervorgehoben, insbesondere die grundrechtlichen Schrankenregeln. Unter diesem Gesichtspunkt stellt sich natürlich, ohne das weiter ausführen zu müssen, die Frage, ob es in unserem Verfassungsstaat noch verfassungsrechtlich zulässig ist, in den Verwaltungsgesetzen ganz einfach Gemeinwohlklauseln zu verwenden und anzuwenden oder, soweit es sich um älteres, insbesondere vorkonstitutionelles Recht handelt, solche einfachen Gemeinwohlklauseln heute verfassungskonform zu interpretieren. Das scheint mir eine ganz wichtige Frage zu sein; denn es geht bei dem Thema nicht nur um die Staatszwecke, sondern um die Staatszwecke im Verfassungsstaat, und zwar im Verfassungsstaat des Grundgesetzes. Als problematisches Beispiel ist die Gemeinwohlklausel in $\$ 4$ Abs. 2 S. 2 Energiewirtschaftsgesetz anzuführen, der eine sehr weitgehende Eingriffsermächtigung zur Investitionskontrolle bei Energieanlagen festlegt. Vielleicht ist auch eine Differenzierung dahin vorzunehmen, $\mathrm{da}$ ß bei den schon angesprochenen „Bewirtschaftungsvorschriften“, etwa für die Gewässerbenutzung, eine besondere Lösung für die legislative Verwendung und für den Verwaltungsvollzug des Gemeinwohlbegriffs gefunden wird. In diesen Fällen läßt sich eine Planifizierung der Zulassungsvorschriften annehmen, so daß es geboten und auch verfahrensrechtlich Vorsorge dafür getroffen ist, alle einschlägigen öffentlichen und privaten Belange bei der Konkretisierung der betreffenden gesetzlichen Gemeinwohlklauseln im Einzelfall zu berücksichtigen. Auch eine zweite Frage ist anzufügen, die sehr zukunftsträchtig zu sein scheint. Kann der Gesetzgeber, unter Umständen auch auf der Ebene der Verfassung, aber vor allem der einfache Gesetzgeber bei der Konkretisierung der Gemeinwohlklauseln auch Ranghierarchien aufstellen? Ist zum Beispiel die Festlegung eines Landesdenkmalschutzes möglich, daß Vorhaben nur dann unter 
Zurücksetzung der Denkmalbelange zulässig sein sollen, wenn die Vorhabenbelange und andere öffentliche Belange zugunsten des Vorhabens von ganz besonderem Gewicht sind? Es ist in dem Zusammenhang auch noch kurz darauf hinzuweisen, daß in der rechtspolitischen Diskussion zum Umweltrecht gesetzliche Klauseln über Rechtfertigungslasten erörtert werden, wonach umweltbelastende Vorhaben nur noch bei entsprechender Rechtfertigung nach Maßgabe des betreffenden Verfahrensrechts zugelassen werden können. Darin scheinen zukunftsträchtige Fragen hinsichtlich der Staatszwecke in unserem Verfassungsstaat zu liegen. Vor allem glaube ich, daß sich vielleicht auch die vorhin erörterte Grundsatzfrage einer „alten“ und „modernen" Bestimmung der Staatszwecke in diesem Verwaltungsrechtsbereich einigermaßen lösen wird, wenn der Gesetzgeber bei der Konkretisierung des Gemeinwohlbegriffs die Anforderungen der grundrechtlichen Schrankenregeln und des rechtsstaatlichen Bestimmtheitsgebots einhält.

Vorsitzender: Vielen Dank, Herr Bartlsperger, für diesen wichtigen Hinweis auf den Zusammenhang zwischen Staatszwecklehre und verwaltungsrechtlicher Gesetzgebungspolitik, wenn ich so sagen darf. Dann käme jetzt, nachdem Herr Schachtscbneider den Saal wieder betreten hat, Herr Schachtschneider ans Mikrofon.

Schachtschneider: Ich bitte um Entschuldigung, Herr Vorsitzender, daß ich gerade draußen war. Mir macht die Isenseesche Unterscheidung zwischen Staat und Verfassung auch Schwierigkeiten. Wenn man einen Staatsbegriff sucht, bietet sich unter dem Grundgesetz der kantianische an, nämlich, daß der Staat die Vereinigung einer Menge von Menschen unter Rechtsgesetzen sei. Danach wäre die verfaßte Bürgerschaft der Staat, Verfaßtheit und Staatlichkeit wären zu identifizieren. Im Rahmen der Verfassung würde näherhin das Staatliche durch Gesetze verwirklicht. Staatlichkeit wäre Gesetzlichkeit. Ein solcher Staatsbegriff wäre die Logik dessen, daß der Staat, wie beide Referenten betont haben, ausschließlich auf der Freiheit gründet; denn Freiheit läßt sich nur durch Gesetze verwirklichen, jedenfalls, wenn man Freiheit als Autonomie versteht. Dieser Ansatzpunkt führt zu einer anderen Sprache, die einige Vokabeln vermeiden kann, die mir jedenfalls Schwierigkeiten machen, etwa die Vokabeln "Schutz" und "Gehorsam", insbesondere aber die Vokabel "Herrschaft", die immer wieder angesprochen worden ist. Ich meine, daß ein freiheitliches Gemeinwesen kein Herrschaftssystem ist. Daraus folgt, daß Staat und Gesellschaft nicht getrennt werden können, wenn man bürgerlich oder freiheitlich denkt. Im Begriff der Gesetzlichkeit 
wäre, weil das Gesetz zu vollziehen, zu verwirklichen ist, der Aspekt „Schutz“, aber auch der Aspekt "Gehorsam" enthalten. Beide Worte weisen in andere Zeiten. Das Wort Herrschaft ist auch nicht definiert. Die Geschichte zeigt, daß die Herrschaftsformen sehr unterschiedlich sein können. Herrschaft kann Sklaverei sein, kann Leibeigenschaft sein und was auch immer. Mir erscheint auch der Begriff der Herrschaft des Gesetzes sehr problematisch. Der Begriff der Gesetzlichkeit genügt. Die Freiheitlichkeit des gemeinsamen Lebens legt es nahe, den Staatszweck formal, nicht offen, zu definieren, durchaus im Sinne der angesprochenen Quadriga der Staatszwecke, nämlich als das gemeinsame gute Leben aller in Freiheit. Diese Freiheit läßt sich nur durch Gesetzlichkeit verwirklichen. Also ist unsere Frage m. E. die nach den Zwecken des Gesetzes. Gibt es eine Möglichkeit, den Gesetzgeber durch einen Zweck des Staates zu begrenzen? Ich meine nein. Das liegt an der Formalität des Staatszwecks, den ich anzusprechen versucht habe. Wie die Menschen miteinander leben, wie sie, wenn man so will, glücklich sind, jeder einzelne, aber auch alle zusammen, ist die Frage, die alle angeht, also eine Frage des Gesetzes. Das führt zu einem für mich wesentlichen Punkt: Herr Link hat sich für das Mehrheitsprinzip ausgesprochen. Von seiner Begrifflichkeit her ist das richtig, von meiner eher fragwürdig. Es gibt eine Mehrheitsregel. In jedem Gremium entscheidet die Mehrheit, wenn nichts anderes geregelt ist. Das ist kein Mehrheitsprinzip, welches eine Mehrheitsherrschaft widerspiegelt. Verbindlich ist nicht die Regelung, welche die Mehrheit hinter sich hat. Herr Link hat die Rousseausche Irrtumslehre angegriffen, weil diese zu einem Totalitarismus führen könne. Das wäre überzeugend, wenn es eine materiale Richtigkeit gäbe. Ich vertrete keine materiale, sondern eine formale Richtigkeitslehre, die aber dennoch reklamiert, daß das Richtige in einem, wenn man so will, repräsentativ-konsensualen Verfahren zu erkennen ist. Dabei kann man sich irren, wie Rousseau lehrt. Das führt aber in keiner Weise dazu, daß nun diejenigen, die meinen, das Richtige erkennen zu können, die anderen totalitär beherrschen dürften. Ein Mehrheitsprinzip kann nur eine ideologische Wirkung entfalten; denn niemals hat die Mehrheit eines Volkes entschieden. Wir haben eine Amtsverfassung. Zu dieser gehört die Mehrheitsregel. Wir haben keine plebiszitären Entscheidungsverfahren. Selbst wenn wir sie hätten, würde realiter nicht die Mehrheit entscheiden. Das Mehrheitsprinzip ist ein Topos, der legitimieren soll, aber nicht legitimiert. Weitere Folgerungen aus diesen Ansätzen stelle ich zurück. Danke. 
Vorsitzender: Vielen Dank, Herr Schachtschneider. Zu Punkt V. „Sicherheit" liegt hier keine besondere Wortmeldung vor. Das überrascht nicht, weil wesentliche Teilprobleme bereits zu Punkt I. und II. durch Herrn Dreier und andere Herren angesprochen worden sind. Herr Suhr, wollten Sie dazu noch kurz etwas sagen, dann darf ich Sie dazwischenschieben. Bitte sehr, Herr Subr.

Suhr: In der Diskussion wurde der Zusammenhang zwischen Schutz und Gehorsam betont. Dann wurde auch darauf hingewiesen, daß man, wenn Bürger ihrem Staat den Gehorsam zu verweigern beginnen, sich nicht nur kritisch äußern, sondern auch über die Ursachen nachdenken solle. Und da meine ich, sollte man den Bogen zurückschlagen zu „Schutz und Gehorsam“. Wenn nämlich irgendwelche Bürger meinen, sie seien nicht mehr genügend geschützt in diesem Staat, sei es vor Immissionen, sei es vor atomaren Risiken oder vor was auch immer, dann nagt in diesen Bürgern auch irgendetwas an ihrer Bereitschaft zum Gehorsam. Das wiederum müßte unseren Blick zurücklenken auf die Staatszwecke, die so verfolgt werden, daß Bürger sich als schutzlos empfinden. Bitte sehen Sie das nicht als eine Legitimierung von zivilem Ungehorsam, sondern als ein weiteres Nachbohren in der Richtung, die die Diskussion schon angezeigt hat. Nachzudenken wäre darüber: Genügt der Staat in seinen Zwecken, insbesondere bei Erfüllung seiner „Schutzpflichten“, noch so sehr den Bedürfnissen seiner Bürger, die von Lärm und Dreck und ich weiß nicht was geplagt werden, daß diese Bürger bereit sind, den selbstverständlichen Gehorsam weiterhin zu geben?

Vorsitzender: Vielen Dank, Herr Subr. Wir kennen ja aus Ihren früheren Werken die Aufforderung, als Staatslehrer auch Sozialpsychologie zu treiben. Ich komme zu Komplex VI. und habe hier zunächst zwei Wortmeldungen von Herrn Mußgnug und von Herrn Roellecke. Und dann hatten sich Herr Bothe und Herr Meyer noch einmal dazu gemeldet. Darf ich also zunächst Herr Mußgnug bitten.

Mußgnug: Wird in der Diskussion auf Staatszwecke hingewiesen, die in den beiden Referaten nicht angesprochen worden sind, so kann das leicht als Kritik mißverstanden werden. Deshalb bitte ich, es nicht als Beckmesserei aufzufassen, wenn ich zwei Punkte nenne, die m. E. im Zusammenhang mit unserem Thema ebenfalls Beachtung verdienen:

Als Erstes möchte ich auf die Sicherung des Geld- und Währungswesens aufmerksam machen, deren Gewicht als Staatszweck durch ihre Selbstverständlichkeit verschleiert, aber durch einen Rückblick in die Verfassungsgeschichte ins rechte Licht gerückt wird. Daß die 
Einheit der Währung zentrale, ja sogar staatskonstituierende Bedeutung besitzt, macht das Schicksal des alten Deutschen Reichs klar. Seine Ohnmacht hat sich auch darin gezeigt, daß es ihm nicht gelungen ist, seine Geldordnung zentral zu steuern und für eine in allen seinen Territorien in gleicher Weise gültige „kurrente Münze“ zu sorgen. Darum hat sich das Reich zwar bis zu seinem Ende redlich bemüht. Aber es war ihm in seiner Endphase kein rechter Erfolg mehr beschieden. Es gibt kaum einen drastischeren Beweis dafür, daß dem alten Reich die Qualität eines modernen Staates abging. Die ausschlaggebende Wichtigkeit der Geldordnung unterstreicht auch die Währungsreform von 1948. Mit ihr wurde sichtbar, daß Deutschland seine staatliche Einheit eingebüßt hat; will es sie wieder gewinnen, so wird es allem voran zu einer für den Osten und den Westen gemeinsamen Währung zurückfinden müssen. Das deckt wohl zur Genüge auf, daß die Vorsorge für ein funktionsfähiges Währungssystem bei der Auflistung der Staatszwecke nicht fehlen sollte.

Der zweite Punkt, für dessen Beachtung ich werben möchte, betrifft das Bildungs- und Erziehungswesen. Es ist bereits angedeutet worden, daß die Selbsterhaltung einer der vornehmsten $Z$ wecke des Staates ist. Aber es liegt auf der Hand, daß der Staat seinen Fortbestand nicht nur mit den Methoden des Polizeirechts und mit dem Einsatz seiner Machtmittel garantieren kann. Auf Dauer kann der Staat nur bestehen, wenn er seine Bürger für sich gewinnt und sich bei ihnen durch eine staatsbürgerliche Erziehung in Erinnerung hält. Das verleiht den Schulen einen festen Platz im Katalog der Staatszwecke. Sie gehören in diesen Katalog nicht nur, weil sie Allgemeinbildung zu vermitteln haben, sondern auch deshalb, weil ihnen die Erziehung der nachwachsenden Generationen zu Staatsbürgern obliegt. Herr Dreier hat vom staatsbürgerlichen Ungehorsam gesprochen und ihm einen hohen Stellenwert beigemessen. Aber der staatsbürgerliche Ungehorsam spielt für mein Empfinden im Lehrprogramm unserer Schulen eine allzu dominante Rolle. Der nicht minder wichtige staatsbürgerliche Gehorsam kommt darüber zu kurz. Gewiß, er kennt Grenzen, und es gehört zur staatsbürgerlichen Bildung zu erfahren, wo diese Grenzen verlaufen. Aber darüber sollte nicht vernachlässigt werden, daß der Staat allein vom Ungehorsam seiner Bürger nicht leben kann. Deshalb zählt für mich zur raison d'être des Staates auch sein Auftrag, sich, seinen Institutionen und seiner Rechtsordnung Gehorsam nicht nur zu erzwingen, sondern zu diesem Gehorsam zu erziehen, also der Indifferenz nachhaltiger entgegenzutreten, die gegenwärtig insbe- 
sondere die junge Generation ihm gegenüber - angeleitet von der in den Medien, in der Jugendkultur und auch im Schulunterricht gepflegten Attitüde der Staatsverdrossenheit - an den Tag legt.

Vorsitzender: Danke sehr, Herr Mußgnug. Herr Link hatte Ihren zweiten Punkt angesprochen, wenn ich mich recht erinnere. Der erste Punkt veranlaßt mich zur scherzhaften Frage, ob wir im gesunden Geldsystem vielleicht den einzigen notwendig vorgegebenen vorverfassungsmäßigen Staatszweck haben, nervus rerum, oder nicht? Nun Herr Roellecke bitte.

Roellecke: Der erste Punkt: Ob der Staat Substanz, Realität oder Idee ist, ist eine Frage der Erkenntnistheorie. Die Antwort hängt davon ab, welchen Standpunkt man als Beobachter einnimmt. Wenn man dogmatisch argumentiert, meine ich, ist es richtig, den Staat ähnlich wie eine Substanz zu verstehen. Aber darüber müßte man erkenntnistheoretisch diskutieren.

Der zweite Punkt gehört eigentlich zu I. Ich habe mich nicht zu I. gemeldet, weil ich hoffte, der zweite Punkt würde sich im Laufe der Diskussion erledigen. Er hat sich aber nur zum Teil erledigt. - Es ist mehrfach darauf hingewiesen worden, daß eine Staatszwecklehre Legitimations- und Rechtfertigungsfragen des Staates betrifft. Man könnte sogar sagen: Wenn die beiden Referate unter der Überschrift "Legitimation des Verfassungsstaates“ gehalten worden wären, hätte man sie nur unwesentlich zu ändern brauchen. Wenn das richtig ist, dann taucht die Frage auf: Warum ausgerechnet "Staatszweck" und nicht einfach "Legitimation" oder "Rechtfertigung“? Ich kann dazu nur Vermutungen äußern: Wenn wir nach der Rechtfertigung, nach dem Sinn des Staates fragten, müßten wir eine normative Antwort geben - deshalb hat Herr Alexy eine normative Theorie gefordert und dann gerieten wir in die üblichen Begründungsschwierigkeiten. Wer die Diskussion über die Begründung von Normen in den letzten Jahren verfolgt hat, weiß, daß sie noch lange nicht zu Ende ist. Dieser Schwierigkeiten entschlägt man sich, wenn man von Staatszwecken spricht. Freilich hat die Rede von den Staatszwecken dann wohl auch die Funktion, die Schwierigkeiten mit der Begründung von Normen zu verdecken. Insofern ist sie ideologieverdächtig. Jedenfalls muß man fragen: Was heißt eigentlich „Zweck"? Offengestanden, die Antworten der Referenten haben mich nicht befriedigt.

Eher schon die Anregung von Herrn Leisner, der an Iherings „Zweck im Recht" erinnert hat. Bei Ihering weiß man, was mit Zweck gemeint ist. Ihm ging es um die Frage, ob die rechtsetzenden Staatsorgane an irgendetwas gebunden seien. Er antwortete: Ja, an die 
Zwecke der Individuen und ihrer Gruppierungen. Mit „Zwecke“ meinte Ihering also die Interessen in der Gesellschaft. Da er den Zweck als gesellschaftliche Realität betrachtete, hat Ihering noch in der Tradition des Naturrechtes argumentiert. Die Kritik, die in den 20er Jahren an der Theorie der Staatszwecke geübt wurde, richtete sich wohl auch gegen diese quasinaturrechtliche Konzeption des Zweckes, also: Zweck als Interesse, Zweck als Bedürfnis. Wenn jene Kritik berechtigt war - ich meine, sie war es -, dann ist zu fragen: Wie setzen wir heute an? Mir scheint, die Antwort müßte in einer Theorie liegen. Bloße Empirie genügt nicht, wie uns die Soziologen mit Recht sagen. Der erste Satz dieser Theorie müßte sein, daß man zwischen Staat und Gesellschaft differenziert und fragt: Welche der Bedürfnisse der Gesellschaft sind für den Staat überhaupt relevant? Wie selegiere ich die Bedürfnisse, die ich ja nicht alle gleichzeitig befriedigen kann? Außerdem scheinen die meisten Bedürfnisse gar keine echten Bedürfnisse zu sein, sondern nur öffentliche Themen oder öffentliche Meinungen. Auch zwischen Politik und gesellschaftlichen Bedürfnissen muß man unterscheiden. Dafür benötigt man ein unterscheidungskräftiges Konzept, das sowohl normativen wie kognitiven Ansprüchen genügt. Ich weiß allerdings nicht, ob das überhaupt $\mathrm{zu}$ leisten ist.

Vorsitzender: Vielen Dank, Herr Roellecke, für diesen eher doch grundsätzlichen Beitrag der Runden I. und II. Aber es war vielleicht doch gut, daß wir noch mal auf diese Thematik zurückgeführt wurden. Ich darf jetzt, da wir allmählich zum Ende kommen, Herrn Bothe und anschließend Herrn Meyer noch einmal bitten und dann, wenn sonst keine dringenden Wortmeldungen mehr sind, die beiden Referenten zum Schlußwort einladen. Herr Bothe, bitte.

Bothe: Noch ein Wort zum Wiedervereinigungsgebot, an dem man, glaube ich, sehr schön die rechtliche Problematik von Staatszwecken und Staatszielen zeigen kann. Herr Ress hat gesagt, und dem möchte ich voll zustimmen, daß es wohl nicht angemessen wäre, die Rechtsprechung des Bundesverfassungsgerichts zum Wiedervereinigungsgebor etwa auf die Europazielsetzung des Grundgesetzes zu übertragen. Ich würde vielleicht umgekehrt noch weiter gehen wollen und mir wünschen, daß die Nichtrechtsprechung des Bundesverfassungsgerichts zu bestimmten Staatszielen, wie z. B. zu dem Friedensgebot, vielleicht auf das Wiedervereinigungsgebot in einer zukünftigen Rechtsprechung übertragen werden sollte. Denn die Frage ist immer, in welcher Weise man denn eigentlich eine Staatszielbestimmung operationalisiert. Welche juristische Tragweite kann sie wirk- 
lich haben, wenn man die Dinge genauer nimmt. Herr Häberle hat hier zu Recht Rechtsvergleichung eingefordert. Es ist leider durchaus üblich bei uns, viele moderne Verfassungen, die Staatsziele, Staatsaufgaben sehr umfangreich, ja liebevoll zu formulieren, etwas als juristische Lyrik abzutun. Das verkennt m.E. die soziale Wirklichkeit in Staaten wie Portugal, wie Brasilien, wo das in extenso erfolgt ist, nämlich, daß dort diese oder jene Staatszielbestimmung in einer sehr konkreten politischen Auseinandersetzung als ein Instrument der Gestaltung der Gesellschaft gewollt ist; als ein Instrument, das vielleicht nicht so wirkt, daß man damit zum Kadi gehen kann und sagen: das ist die Lösung; aber immerhin als ein Instrument der politischen Gestaltung. Zugleich sieht man an diesem Beispiel auch die Grenzen der Leistungsfähigkeit von Staatszielbestimmungen.

Jetzt komme ich zurück zum Wiedervereinigungsgebot, nämlich, zu den Grenzen der Leistungsfähigkeit solcher Verfassungsvorgaben, gerade im internationalen Bereich. Die Tatsache, daß wir ein Staatsziel "Wiedervereinigung" im Grundgesetz haben, kann an der faktischen Lage, auch an der völkerrechtlichen Lage Deutschlands nicht rütteln. $\mathrm{Ob}$ die DDR ein Staat ist, ob sie ein vom deutschen Reich erfolgreich sezedierter, separierter Staat ist, entscheidet nicht das Grundgesetz, sondern das Völkerrecht. Das Grundgesetz kann allenfalls deutschen Staatsorganen aufgeben, so zu tun, als sei die Separierung nicht erfolgt. Dann stellt sich eine rechtspolitische Frage oder auch eine solche vernünftiger Auslegung: Sollte das Grundgesetz die Staatsorgane der Bundesrepublik wirklich dazu zwingen, von Entwicklungen in der völkerrechtlichen Lage abzusehen und sie nicht zur Kenntnis zu nehmen?

Das führt mich zu einem letzten Punkt: Mit dem Wiedervereinigungsgebot (auch ein allgemeiner Punkt, der von Herrn Ress zu Recht angeschnitten wurde) stellt sich die Frage des Verhältnisses verschiedener Staatszielbestimmungen zueinander. Es gibt immer, wenn wir konfligierende Zielvorgaben in der Verfassung haben, die schöne Formel von der praktischen Konkordanz, die es wohl auch hier zu üben gilt. Allerdings ist es mit der Operationalisierung besonders schwierig. Versuchen wir die praktische Konkordanz zwischen den Staatszielbestimmungen "Wiedervereinigung“, "Frieden" und „Europa“, so muß dies, jedenfalls in den voraussehbaren historischen Konstellationen, dazu führen, die Wiedervereinigungspolitik, die rechtlich vorgeschrieben sein soll, sehr vorsichtig zu führen. Dies schließt nicht nur das Streben nach Wiedervereinigung mit Gewalt aus, darüber sind sich ja alle einig, sondern es schließt auch aus ein Streben nach Wiedervereinigung in einer Konstellation, in der ein 
wiedervereinigtes Deutschland eine Destabilisierung in Europa zur Folge haben könnte, also in gewisser Weise friedensgefährdend wäre. Wir bewegen uns dabei allerdings in einem Bereich historischer Spekulation. Wenn man es mit der juristischen Operationalisierung der gesamten Staatszielbestimmungen ernst meint, dann muß man sich diese Schwierigkeiten, die man sich dann einhandelt, wirklich klar machen. Soll das dann noch justitiabel sein?

Vorsitzender: Vielen Dank, Herr Botbe. Als vorletzter Diskussionsredner Herr Meyer. Bitte um Kürze, da die Zeit voranschreitet und die Schlußworte noch zu sprechen sind.

Meyer: Unsere Rezeption der Präambel ist eine geschönte Rezeption. Sie entspricht weder dem, was der Parlamentarische Rat gewollt noch dem, was er niedergeschrieben hat. Daß die Wiedervereinigung ein an die Verfassungsorgane der Bundesrepublik gerichtetes verfassungsrechtliches Gebot ist, ist eine Erfindung des Bundesverfassungsgerichts und keine gute. Ich will das begründen: Erstens widerspricht es der deutschen Tradition, Sätze der Präambel wie normale Rechtssätze der Verfassung aufzufassen und auch der Parlamentarische Rat hat nicht im Traume daran gedacht, daß die Präambel Rechtssätze in diesem Sinne enthalten soll. Die Präambel ist vielmehr Ausdruck zum Teil seines außerordentlich schlechten Gewissens und zum Teil der Hoffnung, die er gehegt hat. Sie brauchen nur die Kommentierung von v. Mangoldt in der ersten Auflage seines Grundgesetzkommentars und die Starcksche Kommentierung in der 3. Auflage zu lesen, dann sehen Sie, wie die Schönung in diesem Punkte vorangeschritten ist. V. Mangoldt wußte Bescheid. Er war nämlich der Vorsitzende des Ausschusses, der die Präambel bis auf die letzte Fassung gemacht hat. Die letzte Fassung ist zwar weit über das hinausgegangen, was debattiert worden ist, aber in dem uns interessierenden Punkte nicht. Und v. Mangoldt hat natürlich nicht im Traume daran gedacht, daß der letzte Satz der Präambel ein Verfassungsrechtssatz im geläufigen Sinne ist.

Ich kann Ihnen auch nachweisen, daß es weder sein kann noch daß wir uns daran halten. Wenn es sich nämlich bei dem letzten Satz der Präambel um ein Verfassungsgebot handelte, wäre es auch ein Verfassungsgebot an die Verfassungsorgane, die Freiheit Deutschlands zu vollenden. Wenn ich meine Kollegen oder Studenten frage: Was heißt denn in diesem Kontext "Freiheit"? sagen alle: „Das meint unsere grundrechtliche oder demokratische Freiheit." Das ist keineswegs der Fall. Freiheit in diesem Text heißt Souveränität. In diesem letzten Satz der Präambel ist nichts anderes ausgesprochen als die Hoffnung des 
Parlamentarischen Rates, das, was er nicht schaffen konnte, nämlich die Souveränität, würden die folgenden Generationen schaffen und das, was er vertiefen mußte, die Spaltung, würden diese aufheben. Wo ist aber der Verfassungsrechtler, der sagte, daß unsere Verfassungsorgane nach der Präambel immer schon die Verfassungspflicht traf, gefälligst dafür zu sorgen, daß wenigstens die mit uns verbündeten Alliierten uns unsere Souveränität, soweit das möglich ist, übertragen. Mit gutem Grund sind wir da vorsichtig.

Im übrigen wird der Text der Präambel offensichtlich nicht gelesen. Dort steht nämlich nicht: „Die Verfassungsorgane sind verpflichtet“, vielmehr steht dort lediglich eine Erinnerung an eine quasi historische Pflicht, die also nicht vom Parlamentarischen Rat stammt, sondern als eine Pflicht der Deutschen offensichtlich schon immer bestanden haben soll. An diese Pflicht wird lediglich erinnert und nicht etwa eine solche Pflicht durch den Parlamentarischen Rat statuiert. Im übrigen wäre die Rechtslage, wenn wir weiterhin die These des Bundesverfassungsgerichts vertreten, viel schlimmer, als Herr Doebring sie dargestellt hat. Denn auch der erste Satz der Präambel wird falsch gelesen. Im Parlamentarischen Rat war man sich völlig einig: Man will zuerst die Einheit, dann die Souveränität - möglichst beides zusammen und dann gibt man alles in die europäische Einigung ein, und zwar in die europäische Einigung im vollen Sinne des Wortes, nicht etwa nur in eine westeuropäische. Was wir jetzt tun in Westeuropa einschließlich möglicher Sicherheitspakte, wäre natürlich ein eklatanter Verfassungsverstoß, wenn wir diese Verfassungsrechtsprechung ernsthaft akzeptieren würden. Wir tun gut daran, das angebliche Verfassungsgebot als einen nicht nur zulässigen, sondern auch vernünftigen und historisch naheliegenden Staatszweck der Bundesrepublik Deutschland zu begreifen und möglichst zu vertreten. Aber wir tun nicht gut daran, etwas zu einer verfassungsrechtlichen Pflicht zu machen, das der Parlamentarische Rat nur als eine historische Aufgabe angesehen hat.

Vorsitzender: Vielen Dank, Herr Meyer. Ich sehe drei Meldungen. $\mathrm{Ja}$, meine sehr verehrten Herrn, wir kommen in erhebliche zeitliche Bedrängnis. Zunächst hatte sich Herr Rauschning gemeldet, dann Herr Häberle und dann Herr Isensee. Also, ich bitte um Kürze.

Rauschning: Ich wende mich dagegen, von "der sogenannten Erfindung des Bundesverfassungsgerichts vom Wiedervereinigungsgebot" zu sprechen! Die Erkenntnis des Bundesverfassungsgerichts, $\mathrm{da} ß$ das Wiedervereinigungsgebot im Grundgesetz enthalten ist, nimmt ihren Ausgang in dem Rechtsgespräch zwischen Konrad Zwei- 
gert als Bundesverfassungsrichter und Herbert Kröger von der Akademie für Rechtswissenschaft Potsdam-Babelsberg als Vertreter der KPD; ich habe das in der Festschrift für Karl Doebring nachgezeichnet. Das Bundesverfassungsgericht hat seine richterliche Erkenntnis, daß diesem Gebot aktuelle Rechtssatzqualität zukommt, in vielen Entscheidungen beständig ausgesprochen und näher begründet. Wir bejahen auch sonst die Entwicklung unserer lebenden Verfassung und sind eigentlich nicht gewohnt, Inhaltskonkretisierungen, wie sie das Bundesverfassungsgericht etwa zu den Problemen einzelner Grundrechte entwickelt hat, mit dem Argument abzulehnen, eine solche Konkretisierung stehe diesem Verfassungsorgan nicht zu. Wir akzeptieren die Maßgeblichkeit von Entscheidungen des Bundesverfassungsgerichts und sollten auch zu dieser unserer Haltung stehen.

Ich meine auch nicht, daß der Rechtssatz wegen der begrenzten Justiziabilität in Frage zu stellen ist. Herr Meyer kritisiert Widersprüche im Wiedervereinigungsgebot. Nun, er sieht sie eben, und das ist eine Frage der Auslegung der Entscheidungen des Bundesverfassungsgerichts durch ihn. Eine weitere Bemerkung in diesem Zusammenhang: Ein Destabilisierungsverbot steht gewiß nicht im Grundgesetz. Und ich bezweifele, daß wir das, was wir gegenwärtig an Destabilem in Europa sehen, dadurch stabilisieren könnten, daß wir der Wiedervereinigung abschwören.

Vorsitzender: Danke, Herr Rauschning. Herr Häberle, bitte.

Häberle: Lieber Herr Meyer, ich gehöre zu denen, die sich, wie von Ihnen gewünscht, provoziert fühlen. Erlauben Sie, eine Gegenposition zur normativen Kraft der Präambel des Grundgesetzes in Sachen deutsche Einheit aufzubauen, aktuell wegen der Massenflucht aus der DDR: 1) Ich habe Zweifel, ob Ihre Interpretation allein von der Entstehungsgeschichte her und nicht auch geltungszeitlich einem solchen Schatzhaus, wie es die Verfassungspräambel sprachlich (Feiertagssprache) und juristisch (Grundsatzgehalte) ist, gerecht wird. 2) Die Rechtsvergleichung belehrt uns, daß auch in anderen Verfassungsstaaten aus den Präambeln Großes herausgeholt wird. Der französische Conseil Constitutionnel holt seit einigen Jahren aus der Präambel von 1958 die klassischen Menschenrechte heraus und nimmt sie normativ ernst. 3) Man muß in ganzheitlicher Interpretation zur Präambel den Art. 146 Grundgesetz hinzunehmen. 4) Ein Allerletztes: Die Väter und Mütter des Grundgesetzes sprechen in großer Klugheit für ihr Selbstverständnis nicht von "Wiedervereinigung“, was oft unterstellt wird, sondern sie rufen auf, "die Einheit und Freiheit Deutschlands zu vollenden“. Über das "Wie“ ist nichts 
gesagt. Der Begriff „Einheit Deutschlands“ läßt viele unterschiedliche Modellstrukturen und andere als bisher bekannte Formen einer Einheitsbildung $\mathrm{zu}$, zumal wir, was bislang übersehen wurde, Art. 24 Grundgesetz beim Begriff „Einheit“ im Sinne der Präambel von vornherein hinzunehmen sollten. Das Präambelelement „vereintes Europa" baut schon die Brücke zu Art. 24. Dieser - wohl neue Versuch, den dynamischen, den Nationalstaat relativierenden Art. 24 von vorneherein in die für Gesamtdeutschland zu entwerfenden offeneren Modelle hineinwirken zu lassen, erschließt der schöpferischen Phantasie unserer Staatsrechtslehrervereinigung ungeahnte Betätigungsfelder.

Vorsitzender: Vielen Dank, Herr Häberle. Sie machen uns Mut für die weitere Arbeit. Herr Isensee.

Isensee: Herr Meyer, Sie haben eben das Muster eines Staatsrechts ohne Staat geliefert und den Text der Verfassung interpretiert ohne Blick auf den konkreten Staat, aus dem sie hervorgeht und für den sie Geltung beansprucht: eben die Bundesrepublik Deutschland als Teilstaat der Deutschen. Diese Staatsperspektive wird im Verfassungstext selbst formuliert mit der Präambel. Die Präambel (hier möchte ich Herrn Häberle zustimmen) macht den Sinnhorizont deutlich, in dem die positiv-rechtlichen Normen des Grundgesetzes stehen. Die Präambel enthält die Selbstreflexion des Verfassunggebers über sein Werk, über die konkrete politische Situation, in der die Verfassung entworfen, und die Ziele, auf die hin sie konzipiert wurde. Sie ist nicht als Aussage über historische Fakten erheblich, wohl aber als geschichtliches Dokument der Verfassungsentstehung und damit als Orientierung historischer wie teleologischer Interpretation. In ihr verkörpert sich ein normatives Zukunftsprogramm, am deutlichsten im Schlußsatz: „Das gesamte deutsche Volk bleibt aufgefordert, seine Einheit zu vollenden.“

Diese Schlußsentenz enthält das Staats- und Verfassungsziel der Wiedervereinigung. Die rhetorische Formel, daß das Volk aufgefordert „bleibt“, bedeutet natürlich nicht, daß das deutsche Volk immer auf dem Wege bleiben oder, faustisch verstanden, sich ewig strebend bemühen müsse, um am Ende Erlösung zu finden. Die Verfassung verheißt nicht Erlösung. Auch in seinen rhetorischen Passagen kann das Grundgesetz nur nach Maßgabe des politisch Möglichen interpretiert werden. Die Präambel markiert das Ziel, daß das deutsche Volk die staatliche Einheit, die es im Jahre 1949 nur zu einem Teil erlangt, als Ganzes wiederfindet. Die Verfassung schreibt keinen Weg vor. Sie gebietet aber, mögliche Wege offenzuhalten und tunlichst gangbare Wege zu bahnen und zu beschreiten. 
Die Schlußbestimmung des Grundgesetzes (Art. 146) macht deutlich, wie die gesamtdeutsche Verfassung auszusehen hat, mit der das Grundgesetz selbst seine Geltung für beendet erklärt: Die künftige Verfassung muß vom deutschen Volke in freier Entscheidung beschlossen werden, also der Selbstbestimmung des deutschen Volkes entspringen, der gesamtdeutschen Demokratie. Es läge nahe, einen Widerspruch zu konstruieren zwischen dem Staatsziel der deutschen Einheit und der rechtsstaatlich-demokratischen Verfassungssubstanz des Grundgesetzes, die gerade die Besonderheit der Bundesrepublik darstellt und den Unterschied ihres Systems zu dem der DDR begründet. Man könnte fragen, ob denn etwa um der deutschen Einheit willen die verfassungsrechtliche Besonderheit des Grundgesetzes geopfert werden darf, ob Grundrechte und Demokratie, all das, was man unter dem Kürzel freiheitliche demokratische Grundordnung versteht oder als westlichen Verfassungsstaat bezeichnet, zur Disposition steht und Verhandlungsmasse ist im Wiedervereinigungsprozeß. Die Frage ist zu verneinen. Der Widerspruch, der sich scheinbar aus dem Grundgesetz ergibt, wird eindeutig gelöst im Deutschlandvertrag, den die Bundesrepublik, als sie in relative Selbstverantwortung und in relative Souveränität eintreten sollte, mit den drei Westmächten schloß. Auch der Deutschlandvertrag richtet das Wiedervereinigungsziel auf, bindet es aber ein in die verfassungsstaatliche Ordnung und in die europäische Integration. Die vier Vertragspartner wollen zusammenwirken, „um mit friedlichen Mitteln ihr gemeinsames Ziel zu verwirklichen: Ein wiedervereinigtes Deutschland, das eine freiheitlich-demokratische Verfassung, ähnlich wie die Bundesrepublik, besitzt und das in die europäische Gemeinschaft integriert ist" (Art. 7 Abs. 2).

Die Harmonie der Verfassungsziele und Verfassungsstrukturen ist bereits in der Präambel angelegt. Diese werden hier aufgewiesen in ihrer staatlichen Verortung, wenn das Verfassungsmotiv genannt wird, die nationale und staatliche Einheit zu wahren. Freilich vorerst nur für einen Teilbereich. Das Grundgesetz ist konzipiert für ein individuelles Staatswesen. Eine Verfassungsinterpretation, die diese Spezifizierung und Zurechnung der Verfassungsnormen nicht begreift, verflüchtigt sich in das Reich der Luft. Sie ist auch keine korrekte positiv-rechtliche Interpretation, weil sie die positiv-rechtlichen Vorgaben der Präambel ignoriert.

Vorsitzender: Vielen Dank, Herr Isensee. Die Realien zwingen uns leider, diese hochinteressanten Diskussionen hier abzubrechen. Ich darf die beiden Berichterstatter bitten, ihr Schlußwort zu sprechen. Zunächst Herr Ress, bitte. 
Ress (Schlußwort): Es ist eine Fülle von Anregungen gekommen, für die ich mich bei Ihnen allen bedanken möchte. Sie werden verstehen, daß ich nicht auf alle in der Diskussion aufgeworfenen Probleme antworten kann und auch nicht auf alle eine Antwort habe.

Ich möchte mit dem Problem beginnen, das zuletzt diskutiert wurde. Für den Völkerrechtler ist es eine selbstverständliche Vorstellung, daß es Staat und Verfassung zu trennen gilt. Die Verfassungen werden dem Staat gegeben, aber der Staat als solcher, von den sehr seltenen Fällen des Staatsuntergangs abgesehen, bleibt als Völkerrechtssubjekt - und somit als Staat - bestehen. Es ist eine nur verfassungsrechtsintrovertiert zu verstehende Fragestellung, daß Staat und Verfassung immer das gleiche rechtliche Schicksal haben müßten. Großbritannien besteht - ohne jetzt ein historisches Datum zu nennen - ohne formale Verfassung, aber mit seiner Rechtsordnung. Der deutsche Staat besteht seit 1867 im Gewand vieler Verfassungen. Diese Trennung steht für die völkerrechtliche Betrachtung außer Frage. Nur die Anerkennung einer bestimmten Regierung oder einer durch eine bestimmte Verfassungsordnung legitimierten Regierung spielt dann eine Rolle und wirft Probleme auf, aber doch nicht die Frage der Staatlichkeit.

In der Situation Deutschlands kann man sich mit guten Gründen über die völkerrechtliche Lage streiten. Ich will hier nicht das ganze Pandaimonion der völkerrechtlichen Situation Deutschlands ausbreiten. Hinzuweisen ist jedoch darauf, daß wir nach wie vor einen fortbestehenden Vier-Mächte-Status mit Rechten und Verantwortlichkeiten für ganz Deutschland haben und daß diese Verantwortlichkeiten und Rechte auch ausgeübt werden und funktionieren. Die vier Mächte haben einen Vorbehalt anläßlich der Mitgliedschaft beider deutschen Staaten in den Vereinten Nationen eingelegt, einen Vorbehalt zugunsten der Ausübung dieser Vier-Mächte-Rechte und -Verantwortlichkeiten, der im Ergebnis dazu führt, daß die DDR und die Bundesrepublik Deutschland in einer Art „Sonderstatus“ Mitglied in den Vereinten Nationen sind. Wir können alles dies, was sich an völkerrechtlichen Besonderheiten in bezug auf den Staat „Deutschland" nach 1945 entwickelt hat, doch nicht ohne weiteres abstreifen. Dies wird ein rechtlich - und politisch - schwieriger Vorgang.

In Berlin ist die Ausübung alliierter Befugnisse tägliche Realität, aber nicht nur dort. Daraus ergeben sich Konsequenzen, nämlich die Existenz eines Staatsrechts, das über den Staat Bundesrepublik Deutschland hinausreicht. Ich habe deshalb ausdrücklich gesagt: „Es gibt noch staatsrechtliche Verbindungen." Diese Elemente der Rechtslage müssen in den Griff genommen werden, um zu sehen, daß 
es nicht nur um „Verfassung“ und „Staat“ als eine Identität geht, sondern daß es hier auch einen Staat gibt, der in der Verfassung aufgegriffen und teilverfaßt wird, der aber eine ganz andere völkerrechtliche Qualität hat. Zu den einzelnen Punkten möchte ich nicht noch einmal ausführlich antworten, aber ich glaube, ich habe damit meine Haltung zu dieser Frage deutlich gemacht.

Die Frage, ob sich aus dem Grundgesetz ein Wiedervereinigungsgebot, das in der Tat so nicht im Grundgesetz steht, ergibt, ist eine Frage der Verfassungsinterpretation. Sie kann der Frage des Fortbestehens oder Nichtfortbestehens des Staates „Deutschland“ als völkerrechtlicher Frage nichts hinzufügen, aber auch nichts nehmen. Ob der Staat fortbesteht, beantwortet sicher nicht die Präambel. Aber sie kann als Pflicht, als Direktive an die deutschen Staatsorgane natürlich eine gewisse Funktion ausüben zur Aufrechterhaltung nach wie vor wichtiger gesamtdeutscher staatlicher Funktionen. Daß wir aus diesem Grunde eine nach wie vor gesamtdeutsche Staatsangehörigkeit haben und aufrechterhalten müssen, ist nicht nur ein Verfassungsgebot, sondern ist auch auch in der politischen Sphäre eine heilsame Entscheidung gewesen.

Ich darf jetzt doch noch auf einzelne Punkte eingehen: Herr Suhr hat zwei Staatsbegriffe gegenübergestellt. Natürlich kann man beide Staatsbegriffe so sehen. Es bestehen meines Erachtens aber erhebliche Probleme, den Staat im Sinne einer Organisationstheorie nur als "Produktion von Entscheidungen“ zu verstehen. Was ist damit an Erkenntnis über den Staat wirklich ausgesagt oder gewonnen? Sie haben diese beiden Begriffe auch nur modellartig gegenübergestellt. Der Staat läßt sich zwar - und das ist eine Erkenntnisfrage - mit den Mitteln der Organisationstheorie beschreiben. Erfassen läßt er sich damit nur in bestimmten Perspektiven. Er bleibt eben immer nur der Staat der Organisationstheorie, also eines ganz bestimmten Erkenntniszuganges, und es ist nicht der gesamte normative Staat, etwa des Völkerrechts oder des Staatsrechts, und es ist auch nicht der Staat als Phänomen der allgemeinen Staatslehre.

$\mathrm{Zu}$ der Grundfrage, die Herr Meyer aufgegriffen hat, und in der er sich von Herrn Isensee abgesetzt hat, möchte ich doch sagen, daß es ein Bild des modernen Staates und des Verfassungsstaates gibt, wie es uns hinter oder mitverfaßt in der Europäischen Menschenrechtskonvention, um nur ein Beispiel zu nennen, sichtbar wird. Sie werden vielleicht sagen, dieses Bild sei etwas Vorverfassungsrechtliches. Dies wäre eine höchst verkürzende Sichtweise, gerade auch vom normativen Standpunkt aus. Denn durch das Aufgreifen einer Art internationaler Verfassung, wenn wir die Menschenrechtskonvention einmal so 
benennen, kann ein Staatsbild greifbar gemacht werden, welches auch Rückschlüsse auf die eigene Staatlichkeit bzw. Verfaßtheit erlaubt. Der Typus des modernen westeuropäischen Verfassungsstaates ist durch bestimmte qualitative, materiale Wertvorstellungen gekennzeichnet. Damit soll nicht einer totalen Werthomogenität das Wort geredet werden, etwa in dem Sinne, daß es beliebig sei, aus Spanien oder Großbritannien etwas zu übernehmen oder auszutauschen. Aber es gibt eine Ebene der wertbezogenen Gemeinsamkeiten, die in dieser Ordnung vorausgesetzt worden ist, und diese kann ich deutlich machen, gerade auch im Rahmen der Grundrechtstheorie in ihrer Zweckhaftigkeit.

Herr Doebring hat mit Recht auf das Problem - auch eine alte Streitfrage - hingewiesen, ob denn nicht doch eine Rangfolge zwischen europäischer Integration und Wiedervereinigung besteht und ob wir nicht im Extremfall vor die Alternative gestellt werden zu wählen, was uns denn nun lieber sei bzw. was uns verfassungsrechtlich aufgegeben sei. Es werden in der Literatur natürlich die eine und die andere Alternative und Wahlpräferenz vertreten. Wenn man sich der Frage nüchtern zuwendet und sich fragt: , Was sagt denn die Verfassung selbst dazu?', dann stößt man auf die Frage: ,Ist die Wiedervereinigung nicht vielleicht der Sonder-Gründungszweck der Bundesrepublik und nicht nur irgendein untergeordnetes Ziel? Das greift dieselbe Frage auf, die unser österreichischer Kollege Wielinger im Grunde für die österreichische Verfassung des Jahres 1918 gestellt hat (die Republik Österreich sollte „Bestandteil“ der Deutschen Republik sein, d. h. werden). Ist das Wiedervereinigungsgebot demnach eine Grundlage dieser Staatlichkeit, dieser Verfaßtheit überhaupt und steht damit auf einer ganz anderen Ebene als das Europaziel und andere Ziele, die in der Verfassung aufgegriffen sind? Ich sehe nicht, daß man die Zielvorstellung der Wahrung und der Wiederherstellung der Einheit als vorrangigen Gründungszweck so fundamental sehen kann. Die Vereinigung der beiden deutschen Staaten soll sich in einer Ordnung vollziehen, in welcher Deutschland als gleichberechtigtes Glied in einem vereinten Europa "dem Frieden der Welt" dienen kann.

Diese Zielsetzungen lassen sich nicht isolieren. Alle haben ihre spezifische verfassungsrechtliche Verankerung und Verästelung. Art. 79 Abs. 3 GG schreibt z. B. einen auf den Gesamtstaat „Deutschland" bezogenen Volksbegriff fest, was auch verfassungsrechtlich das Wiedervereinigungsgebot widerspiegelt und für die Staatsangehörigkeit eine ausreichende Grundlage bietet. Das „Europa“-Ziel findet in Art. 24 Abs. 1 GG seine verfassungsrechtliche Absicherung (mit weitgehender verfassungsdurchbrechender Wirkung). Das Wiedervereini- 
gungsziel steht deshalb nach meiner Auffassung auf der gleichen Ebene wie etwa das Europaziel, und nichts anderes ist im übrigen auch in dem schon zitierten Art. 7 des Deutschland-Vertrages bestätigt worden. Das bedeutet: Es gibt ein Optimierungsgebot. Es gibt nicht das Gebot, Extrempositionen zu verfolgen, sondern den Ausgleich anzustreben. Wir müssen also sichern, daß wir die „Wiedervereinigung" oder welche Form der Annäherung sich immer bietet, im Einklang mit den anderen verfassungsrechtlich verfolgen.

Den Gedanken von Herrn Häberle, auf Art. 24 GG auch bei der institutionellen Verständigung $z$ wischen den beiden deutschen Staaten zurückzugreifen, halte ich für richtig; es gibt viele Formen der zwischenstaatlichen Verständigung und der übergreifenden Organisationen, die man sich vorstellen kann, insbesondere, wenn man sich das Reservoir im Rahmen des Art. 24 an gewissen Zurücknahmen von Verfassungsgeboten vorstellt, die wir in Zukunft nutzen könnten. Wenn man die Verfassungslage so sieht, muß man zu dem Ergebnis kommen, daß beides (Wiedervereinigung und Europäische Integration) gleichermaßen verfolgt werden muß. Es kann nicht eine Lösung in dem Sinne geben, daß nur die Wiedervereinigung ohne die europäische Einigung verfolgt werden darf (oder umgekehrt), sondern beide Ziele sind zu optimieren.

Herr Doehring hat noch die Frage aufgeworfen, ob eine fortschreitende Integration überhaupt zulässig sei, weil die Bundesrepublik in eine Situation kommen könne, in der sie nicht mehr die staatliche Totalverantwortung innehabe oder ausüben könne, weil bestimmte Sachbereiche vollständig verlagert worden seien. Diese Gefahr besteht in der Tat, auch wenn bisher noch das Schema, subjectio trabit protectionem" einigermaßen funktioniert. Wir sind uns darüber im klaren, daß der Art. 173 Abs. 2 und 175 Abs. 3 EWGV dem einzelnen nur einen beschränkten Zugang zum EuGH gibt. Wir sind uns auch darüber im klaren, daß der Art. 177 EWGV dem einzelnen kein prozessuales Recht auf Aufgreifen der europarechtlichen Fragestellung durch das nationale Gericht gibt. Es wird Rechtsgehorsam verlangt, aber Schutz nur in einer geminderten Form gewährt. Das ist deshalb noch erträglich, weil das BVerfG den EuGH als gesetzlichen Richter „eingesetzt" hat - mit der Folge, daß subjectio und protectio hier noch weitgehend übereinstimmen. Es kann aber sein - und das ist eine These, die nicht eingeführt habe, aber die ich gleichwohl vertrete - daß beim Fortschreiten der europäischen Integration eine solche Fülle von Materien auf die EG übertragen werden, daß wir in den Zustand einer Exekutivgesetzgebung durch den Ministerrat geraten, in dem bei uns die parlamentarische Gesetzgebung funktionslos 
wird, d.h. eine Entparlamentarisierung - von der Entföderalisierung ganz abgesehen - eintritt, die nicht mehr mit den Grundanforderungen des Art. 79 Abs. 3 GG übereinstimmt. Es ist theoretisch denkbar und möglich, daß ein völkerrechtlicher Vertrag (wie der EWGV) im Zuge seiner "Fortentwicklung" durch Praxis und Konsens der Mitgliedstaaten und Organe auch verfassungswidrig werden kann.

Ich komme zum Schluß. Bei meinen Vorarbeiten habe ich eine Fülle von Staatszwecken katalogartig anhand verschiedener Verfassungstexte aufgeschrieben und - ähnlich wie Herr Häberle - im Wege der Rechtsvergleichung die wunderschönsten Staatszwecke feststellen können. Im wesentlichen reduzieren sie sich aber auf die drei des klassischen Reservoirs. Es geht immer um die Sicherheit, die Freiheit und die Wohlfahrt mit all ihren Ausprägungen. Es ist zugegeben, daß der Wohlfahrtsbegriff eine Leerformel wird, wenn man alle möglichen Ausfächerungen darunter aufnehmen will. Aber es ist diese Trias, um deren Verhältnis es letztlich geht. Und um noch einmal auf Ihre Frage zurückzukommen. Herr Grimm: Es ist wegen der Grundrechte gerade doch die Scheidung zwischen Staat und Gesellschaft und damit verbunden die Sicherung dieses Freiheitsbereiches, die die Beliebigkeit des Aufgreifens und des Tätigwerdens des Staates begrenzt. Darin liegt eine wesentliche Funktion der Staatszwecke. Auf diesem Wege werden sie erkennbar und spielen in der Grundrechtsdiskussion nach wie vor ihre - auf einer höheren Ebene angesiedelte und interpretatorisch hilfreiche - begrenzende Rolle.

Vorsitzender: Vielen Dank, Herr Ress. Ich übergebe an Herrn Link.

Link: Vielen Dank. Im Grunde lassen sich die erhobenen Einwände auf zwei Problemkreise konzentrieren. Der eine ist die Frage der inhaltlichen Unbestimmtheit einer Staatszwecklehre (Herr Brohm, Herr Bothe, Herr Meyer). Es ist der Einwand, daß Staatsziele variabel sind, daß sich auch Staatszwecke wandeln und daß sie heute anders als in der Vergangenheit verfolgt werden müssen. Ich bestreite das nicht. Beide Referate haben aufzuzeigen versucht, welche Probleme sich heute auch in der Wahrnehmung der klassischen Staatszwecke stellen und $\mathrm{daß}$ dafür historische Lösungsmodelle keine überzeitlichen Rezepte liefern, daß sich etwa im Wohlfahrtszweck die Frage der Zukunftsdimension in ganz anderer Weise stellt, als etwa noch den Vätern des Grundgesetzes bewußt war. Natürlich kann sich auch der Staat andere Zwecke wählen, und er hat dies in der Vergangenheit oft genug getan (Machtzweck). Er kann - Herr Meyer - auch den Sport oder sonst etwas fördern: Nach der von mir verwendeten Terminolo- 
gie handelt es sich dabei überhaupt nicht um Staatszwecke, sondern allenfalls - wenn überhaupt - um Staatsziele. Keiner von uns hat einen numerus clausus der Staatsziele behauptet. Die Frage ist nur, ob sich diese unbestimmte Vielzahl möglicher Staatsziele im demokratischen Verfassungsstaat jedenfalls dort reduziert, wo damit dasjenige beschränkt und gefährdet wird, was wir als elementare Staatszwecke bezeichnet haben. Nur das ist die Frage, nicht ob der Staat den Sport fördern kann oder soll. In diesem Zusammenhang zu Herrn $M u \beta$ gnug: Den Kulturstaatszweck würde ich unter den Wohlfahrtszweck subsumieren und habe es im Referat auch getan; die Sorge um Geldund Währungswesen scheint mir ein zentraler Bestandteil des staatlichen Schutzzwecks zu sein. Gerade die Älteren unter uns haben noch sehr deutliche Erinnerungen an die damit verbundene existentielle Bedrohung. Die Frage - und damit schlage ich die Brücke zu Herrn Grimms Votum - ist nicht die, ob die Modalitäten der Staatszweckwahrnehmung gleich bleiben - natürlich nicht! - , keiner von uns wollte dies behaupten. Die Frage ist vielmehr, ob hinter solchen Wahrnehmungsmodalitäten relativ konstante Zwecke stehen, die den Typus "Staat" und „demokratischer Verfassungsstaat" prägen. Ehe ich darauf eingehe, noch zu Herrn Bartlsperger: Die Konsequenzen einer Staatszwecklehre für das Verwaltungsrecht liegen nicht darin, die Kompetenz des demokratischen Gesetzgebers zur Gewichtung von Staatszielen und Staatsaufgaben, und um die geht es ja bei Denkmalschutz usw., zu beschränken. Mit Staatszwecken war hier etwas anderes gemeint, das vor solchen Konkretionen liegt. Gerade die Gemeinwahlkonkretisierungskompetenz ist eben im demokratischen Prozeß offen. Ich habe das so gesagt und Herr Häberle wird mir darin wohl zustimmen. Ich zweifle deshalb daran, daß eine Staatszwecklehre dieses Problem lösen kann.

Die Frage, die dahinter steht - und damit komme ich zum zweiten Problemkreis -, scheint mir die eigentliche und wirkliche Kontroverse zu sein, die Frage nämlich: Gibt es überhaupt einen Staat, der sich Zwecke setzen kann, oder ist es nur die Verfassung, die Staatsziele festlegt? Existiert „der Staat“ als solcher oder gewinnt er Realität erst mit der und durch die Verfassung. In der Konsequenz dieser Auffassung läge es, Zwecke und Ziele allein der jeweiligen Verfassung zu entnehmen. Hier ist mir meine Zustimmung zu Herrn Isensee mehrfach vorgeworfen oder als Widerspruch zu meinem Referat angekreidet worden. Ich möchte mich trotzdem dazu bekennen. Ich meine, daß sich Staatszwecke aus dem Begriff des Staates und eines bestimmten Staatstypus ergeben, der nicht mit der Verfassung identisch ist. Herr Ress hat dafür eben - für mich sehr eindrucksvoll - das Völkerrecht als Beleg 
herangezogen. Ich würde dasselbe aus der Geschichte ableiten. Ich habe zwischen Staat und Verfassung unterschieden - ohne damit zu leugnen, daß das konkrete Erscheinungsbild des Staates durch die Verfassung konstituiert wird. In der Tat ist es so - Herr Subr -, daß der Staatsbegriff vielschichtig ist. Ich würde allerdings die von Ihnen genannten Merkmale nicht als Alternativen oder gar als unterschiedliche Staatsdefinitionen ansehen wollen. Ein Staat, der etwas auf sich hält, muß allen diesen Anforderungen genügen. Dies mag, und diesen Vorwurf muß ich auf mir sitzen lassen, eine substanzhafte Vorstellung vom Staat sein. Ich sehe in der Tat den Staat als Realphänomen. Deshalb bin ich auch der Meinung - und insofern bin ich von Herrn Bartlsperger mißverstanden worden, daß sich die Staatszwecke nicht nur aus den Grundrechten erschließen. Der Staatszweck „Freiheitsgewährleistung" ist ein Essential des demokratischen Verfassungsstaats. Grundrechte sind Konkretisierungen dieses Freiheitsgewährleistungszwecks und daraus folgt, wie ich glaube, ihre primäre Abwehrfunktion. Aber ich vermag aus den verfassungsrechtlich positivierten Grundrechten nicht eine Staatszwecklehre abzuleiten. Die Staatszwecke - und hier hat Herr Doebring das gesagt, was ich meine liegen vor der Verfassung, sie werden aber durch die Verfassung konkretisiert und ausgeformt. Normative Verbindlichkeit bekommen sie nur durch die Verfassung. Anderenfalls wäre in der Tat - Herr Roellecke - der Ideologieverdacht kaum auszuräumen.

Insgesamt geht es hier wohl darum, wie wir das Staatsschiff ansehen. Sehen wir es als ein auf den Wellen treibendes, von den Winden beliebig bewegtes Gefährt ohne feste Kursbestimmung? Ich würde eher dazu neigen, das Staatsschiff als ein (in diesem Sinn) Linienschiff zu sehen, das ein konkretes Ziel ansteuert. Seine Funktion ist es, die Bürger zum Ziel eines bestmöglich realisierten Gemeinwohls zu befördern, das sich letztlich in den anderen Staatszwecken verwirklicht. Das Staatsschiff kann von diesem Kurs abkommen und kann sich in beliebige andere Richtungen bewegen - dann hört es aber auf, ein solches Linienschiff zu sein. Vielen Dank.

(Beifall)

Vorsitzender: Meine sehr verehrten Damen und Herren, wir sind am Ende des ersten Arbeitstages angelagt. Ich darf den Herren Berichterstattern sehr herzlich danken. Ich darf Ihnen allen für diese lebhafte Diskussion danken, die m. E. gezeigt hat, daß es sinnvoll ist, $\mathrm{da} ß$ in der Vereinigung Völkerrechtler mit Europarechtlern und Staatsrechtlern und Verfassungsrechtlern und sogar Verwaltungsrechtlern an einem Ort zusammen diskutieren. 